Board of Governors of the Federal Reserve System

International Finance Discussion Papers

Number 377

March 1990

\title{
EVALUATING THE PREDICTIVE PERFORMANCE OF TRADE-ACCOUNT MODELS
}

\author{
Jaime Marquez and Neil R. Ericsson
}

NOTE: International Finance Discussion Papers are preliminary materials circulated to stimulate discussion and critical comment. References in publications to International Finance Discussion Papers (other than an acknowledgment that the writer has had access to unpublished material) should be cleared with the author or authors. 


\begin{abstract}
This paper evaluates the distributional properties of forecasts from six econometric models of the U.S. trade account. Using stochastic (Monte Carlo) simulation, we derive confidence intervals and forecast-based test statistics which account for uncertainty from future disturbances and from coefficient estimation. Empirically, the confidence intervals of the trade-account forecasts are very wide, and are generally (but not necessarily) increasing with the forecast horizon. Even with such a large degree of uncertainty, some models exhibit "predictive failure" when tested. To evaluate forecasts across models, we generalize Chong and Hendry's (1986) forecast-encompassing test statistic to allow for model nonlinearity and to account for uncertainty arising from estimation. All models are rejected by this test, i.e., the data are highly informative. Although both the calculated forecast uncertainty and the test failures temper the role of these models in formulating policy, the failures imply the potential for improved model specification with narrower confidence bands.
\end{abstract}


Evaluating the Predictive Performance of Trade-account Models

Jaime Marquez and Neil R. Ericsson ${ }^{1}$

\section{Introduction}

Accepting these [forecast] errors and suitable frequencies, it would be healthier if economic forecasts were provided in probabilistic intervals. On several occasions, relevant errors have been estimated and tabulated, but prevailing practice is to provide only point estimates, with a number of decimal places. That exceeds the limits of our precision.

Lawrence Klein (1981, p. 56)

A statistical prediction means simply a (probability) statement about the location of a sample point not yet observed. [Parentheses in original.]

Trygve Haavelmo (1944, p. 105)

Model-based forecasts of the U.S. trade account are commonplace. Yet, in spite of the rocky track-record of forecasts from econometric models, most existing analyses treat predictions from stochastic trade models as though they were outcomes of deterministic processes, taking their statistical accuracy for granted. ${ }^{2}$ The statistical accuracy of forecasts can be measured easily, and its calculation has numerous uses. For example, statistical accuracy (or the lack thereof) is central to evaluating the likely consequences of policy actions. Depending upon the actual uncertainty, (e.g.) fine tuning may be straightforward or completely unrealistic. A measure of statistical accuracy is also helpful when using forecasts to evaluate competing models. Statistical assessments of forecasts include the standard errors and confidence intervals of the forecasts, the means (and so the biases) of the forecasts, and ex post performance relative to forecast uncertainty. This paper provides such measures for four structural econometric models of the U.S. trade account, each differing in size, dynamic specification, estimation method, and level of

\footnotetext{
${ }^{1}$ The authors are staff economists in the Division of International Finance. The views expressed in this paper are solely the responsibility of the authors and should not be interpretcd as reflecting those of the Board of Governors of the Federal Reserve System or other members of its staff. This paper was presented at the Brookings conference "Empirical Evaluation of Alternative Policy Regimes", March 8-9, 1990. We are grateful to William Helkie for encouraging this project and providing the data for the Helkie-Hooper model, to Ralph Tryon for the use of his program DOCMOD which prepared the model documentation in Appendix E, and to Ned Prescott and Lucia Foster for excellent research assistance. We also wish to thank Julia Campos, Hali Edison, Ray Fair, William Helkie, Peter Hooper, Fred Joutz, Andy Rose, Charlie Thomas, and Ralph Tryon for valuable comments and suggestions. All numerical results in this paper were obtained using TROLL Version 13; cf. Intex Solutions (1989).

${ }^{2}$ See, for example, Feldstein (1986), Eichengreen (1989), Krugman and Baldwin (1987), Marris (1987), Bryant and Holtham (1988), Krugman (1988), Cline (1989a, 1989b), Hooper (1988, 1989), Helliwell (1989), Howard (1989a, 1989b), Meade (1988), United States Library of Congress (1988), and United States Congressional Budget Office (1989).
} 
country and commodity disaggregation. For comparison, we include two time-series models of the trade account.

The analysis begins in Section 2 by describing these trade models and estimating their parameters. Estimated income elasticities for the structural models are positive and statistically significant, and, for some models, are in line with the asymmetries in income elasticities noted by Houthakker and Magee (1969). The estimated price elasticities are negative and significant, and satisfy the Marshall-Lerner (stability) condition; and the pass-through of exchange rates to import prices is positive and significant. As a benchmark for later results, Section 2 generates deterministic forecasts of the trade account from each model. Although widely used, deterministic forecasts may be biased by model nonlinearities such as those common to these trade models, even if the coefficient estimates are unbiased. Also, deterministic forecasts often are presented without any measure of forecast uncertainty, thereby undermining their usefulness when studying the determinants of international trade, predicting the likely response of international trade to economic policies, and addressing other practical questions in which uncertainty plays a role.

To address these limitations, Section 3 calculates the distribution of trade account forecasts for these models. Two complications arise in doing so: multiple sources of uncertainty, and the lack of an analytical solution.

Forecast uncertainty arises from many sources, including the inherently stochastic nature of the process generating the data (i.e., from as yet unknown future shocks) and the imprecision of coefficient estimates in the model producing the forecasts. As an example of the latter, the trade elasticities estimated in Section 2 create a source of uncertainty in the forecasts of the trade account because the elasticities are estimated rather than known. Although exact formulae for forecast distributions accounting for these two sources of uncertainty exist only for static models and the simplest of dynamic models, reasonable analytical approximations are available for general linear dynamic models. 
Unfortunately, the nonlinearities typical to empirical trade and price equations preclude applying these analytical formulae, so we rely upon stochastic simulation. Simulation begins with random draws of both model coefficients and disturbances from specified distributions to produce a simulated forecast. Many such forecasts are generated, and, from the resulting "sample" of forecasts, we obtain estimates of the mean forecast, the mean forecast error, the standard deviation of the sample of forecasts (which is the estimated forecast standard error), and the $95 \%$ confidence interval. In effect, taking functions of these Monte Carlo replications (such as averaging) mirrors evaluating the integrals which would be required for an analytical solution.

Empirically, the associated forecast errors are large relative to the magnitude of the tradeaccount forecasts and relative to the deviations between forecasts from the different models. Often, the errors are systematic and increase in magnitude as the forecast horizon lengthens. The forecast standard errors tend to be large as well, ranging from approximately $\$ 13$ to $\$ 30$ billion for one-step ahead forecasts from the structural models, and up to $\$ 36$ billion for comparable s-step ahead forecasts. This evidence leads naturally to an appraisal of ex post forecast performance, in which the realized outcomes of the trade account are compared with the confidence regions around the forecasts to see whether or not the forecasts deviate (statistically) significantly from the outcomes. On the whole, confidence bands are so large that they embrace the path of actual realizations. This result, however, stems from the sizeable uncertainty of the forecast and is not necessarily indicative of predictive accuracy or of model reliability.

Forecasts and outcomes can help evaluate trade models in another fashion. Different models may capture different aspects of the trade balance's behavior, in which case forecasts from one model are informative in explaining the forecast errors from another. Conversely, forecast encompassing, or the lack of additional information in another model's forecasts, is evidence in favor of one's own model. Chong and Hendry (1986) propose this concept, and Section 4 generalizes it for multi-step forecasts from nonlinear models and calculates the corresponding test statistics. They reveal mis-specification in all models. Alternatively viewed, the forecast performance of each model indicates room for improved model specification, and the 
statistics may suggest ways in which that re-specification could occur. For instance, the structural models fail against the time-series models, suggestive of dynamic misspecification in the former. Failure of the time-series models against the structural models points to behavioral misspecification of the time-series models.

Section 5 evaluates the contribution of model nonlinearities to forecast biases, using the Monte Carlo technique of "antithetic variates" in order to increase the numerical precision of the estimates of bias. Our analysis relaxes an assumption maintained in previous applications of antithetic variates to forecasts from econometric models, namely, that the coefficient estimates are known with certainty. The results indicate that biases from model nonlinearity are statistically significant for all the structural trade models, but economically significant only for the model explaining trade on a bilateral basis. From the evidence in earlier sections, Section 6 draws implications for econometric practice, trade modeling, and policy analysis.

\section{Econometric Models of the U.S. Trade Account}

This section summarizes the form of the four structural and two time-series models (Section 2.1), reports estimates of certain elasticities from the structural models (Section 2.2), describes the forecasting process (Section 2.3), and calculates deterministic forecasts for all models (Section 2.4). The first structural model is that developed in Helkie and Hooper (1988); the remaining three structural models are treated as variations on it. $^{3}$ The two time-series models are a univariate autoregression of the trade account and a four-equation VAR. Although the choice of models is not exhaustive, the Helkie-Hooper model is widely used in the literature, and VARs and univariate time-series models are often taken as "non-structural" alternatives. ${ }^{4}$ Detailed descriptions of the models appear in Appendix E.

\footnotetext{
${ }^{3}$ In fact, the first model deviates from that in Helkie and Hooper (1988). Following advice from William Helkie, we re-estimated the Helkie-Hooper model with a slightly different specification and dataset. Even so, the coefficient estimates and other model properties remained virtually unchanged from the original model. See Helkie and Hooper (1987) for additional details on the Helkic-Hooper model.

${ }^{4}$ For example, Krugman and Baldwin (1987), Bryant and Holtham (1988), Cline (1989a, 1989b), Helliwell (1989), and Howard (1989b) use forecasts from the "Helkie-Hooper" model and variants thereon to evaluate the policy
implications of the U.S. external deficit.
} 


\subsection{Model Structure}

The form of the four structural models is summarized in (1)-(5) below.

(1) $\ln \left(\mathrm{P}_{\mathrm{xt}}\right)=P_{x}\left(\mathrm{P}_{\mathrm{t}}, \mathrm{E}_{\mathrm{t}}, \mathrm{P}_{\mathrm{t}}^{*}\right)+\mathrm{upx}_{\mathrm{t}}$

(2) $\ln \left(\mathrm{X}_{\mathrm{t}}\right)=X\left(\mathrm{P}_{\mathrm{xt}} /\left(\mathrm{E}_{\mathrm{t}} \cdot \mathrm{P}_{\mathrm{t}}^{*}\right), \mathrm{Y}_{\mathrm{t}}^{*}\right)+\mathrm{ux}_{\mathrm{t}}$

(3) $\ln \left(\mathrm{P}_{\mathrm{mt}}\right)=P_{m}\left(\mathrm{E}_{\mathrm{t}}, \mathrm{P}_{\mathrm{t}}^{*}, \mathrm{P}_{\mathrm{xt}}\right)+\mathrm{upm}_{\mathrm{t}}$

(4) $\ln \left(\mathrm{M}_{\mathrm{t}}\right)=M\left(\mathrm{P}_{\mathrm{mt}} / \mathrm{P}_{\mathrm{t}}, \mathrm{Y}_{\mathrm{t}}\right)+\mathrm{um}_{\mathrm{t}}$

(5) $\mathrm{NX}_{\mathrm{t}}=\mathrm{P}_{\mathrm{xt}} \cdot \mathrm{X}_{\mathrm{t}}-\mathrm{P}_{\mathrm{mt}} \cdot \mathrm{M}_{\mathrm{t}}$

The variables $\mathrm{P}_{\mathrm{m}}, \mathrm{P}_{\mathrm{x}}$, and $\mathrm{P}$ are the prices of imports and exports and the general price level; $\mathrm{E}$ is the nominal exchange rate (domestic/foreign); $\mathrm{M}, \mathrm{X}, \mathrm{NX}$, and $\mathrm{Y}$ are the volume of imports, the volume of exports, the (nominal) trade account, and real income, respectively; and the absence or presence of an asterisk * denotes a variable measured for the domestic (i.e., U.S.) or foreign country. Each model assumes that the errors $\left(u p x_{t}, u x_{t}, u p m_{t}, u m_{t}\right)^{\prime}$, denoted $u_{t}$, are normally and independently distributed:

(6) $\mathrm{u}_{\mathrm{t}} \sim \mathrm{NI}(0, \Omega)$,

conditional upon a given dynamic structure for (1)-(4). To distinguish the econometric models based upon (1)-(5) from the two time-series models, we will refer to the former as "structural": (1)-(5) rely upon an underlying economic theory to explain both trade flows and prices whereas the time-series models do not.

Empirical implementation of (1)-(5) requires specification of exogeneity, dynamics, estimation technique, and level of trade disaggregation. The econometric model of U.S. trade in Helkie and Hooper (1988) makes the following assumptions.

A1-- Real incomes, the general domestic and foreign price levels, and the nominal exchange rates are super exogenous with respect to trade elasticities.

A2-- International markets operate recursively: prices affect trade, but trade does not affect prices (neither contemporaneously nor at a lag).

A3-- Trade prices follow the markup-pricing model; cf. Hooper and Mann (1989). 
A4-- Internationally traded goods are imperfect substitutes for domestic products; cf. Goldstein and Khan (1985).

A5-- Trade elasticities are sensitive to the commodity composition of trade. Thus, exports are disaggregated into agricultural and non-agricultural exports, and imports are disaggregated into oil and non-oil imports.

A6-- Trade elasticities are equal across trading partners and cross-price elasticities are zero.

A7-- Trade flows are subject to non-price rationing.

A8-- In a given equation, dynamic responses obey Almon polynomials for non-normalized (RHS) variables and exclude lags on the normalized ("own" dependent) variable. However, several equations are estimated with autoregressive disturbances, and so implicitly include the lagged dependent variable, albeit with the common factor restriction imposed.

A9-- The covariance matrix of contemporaneous structural disturbances, $\Omega$, is diagonal.

Assumptions A1-A4 are standard in existing trade models and, to keep the analysis manageable, the practical implications of modifying them will not be addressed in this paper. ${ }^{5}$ The specific issues of concern to Helkie and Hooper (1988) bore directly on the choice of the level of commodity disaggregation (Assumption A5). ${ }^{6} \quad$ The equality of parameters across trading partners (Assumption A6) permits modeling trade on a multilateral basis. The use of a non-price rationing variable (Assumption A7) seeks to avoid inadequacies in the construction of price indexes for international trade. Helkie and Hooper (1988) measure the rationing variable as the ratio of U.S. to foreign capital stocks, an ad hoc procedure, and one that they recognize as such. By excluding lags on the normalized endogenous variable from each equation's specification (Assumption A8), this model rules out certain forms of persistence. Finally, recursive

\footnotetext{
${ }^{5}$ On Assumption A1, see Engle, Hendry, and Richard (1983) on four distinct concepts of exogeneity, some of which are used in this paper. Briefly, weak, strong, super, and strict exogeneity correspond to different notions of being "determined outside the model under consideration" according to the purposes of the inferences being conducted, i.e., conditional inference (estimation and hypothesis testing), prediction, policy analysis, and forecasting, respectively. It is not valid to make variables exogenous simply by not modeling them, but testing for the validity of the various exogeneity assumptions in the models examined is beyond the scope of this paper. Although estimation of Helkie and Hooper's model requires only weak exogeneity, Al states super exogencity because of the model's design for and use in policy analysis. The analysis of s-step ahead forecasts assumes
strong exogeneity.

Baldwin (1988) and Krugman (1989) scrutinize Assumption A3.

${ }^{6}$ Oil trade relies on the perfect substitute model (cf. Goldstcin and Khan, 1985), with domestic oil production taken as strongly exogenous and oil consumption modeled as a function of real income and relative prices. Note (4).
} 
international markets and diagonal $\Omega$ (Assumptions A4 and A9) may simplify parameter estimation.

This paper examines the sensitivity of results from the Helkie-Hooper model to certain changes in Assumptions A5-A9 via three additional structural models. Table 1 shows the form of these models, and Table 2 contains the associated parametric restrictions. Labeling the HelkieHooper model as M1, model M2 relaxes Assumption A9 to allow for a (possibly) non-diagonal covariance matrix $\Omega$, and so uses Full Information Maximum Likelihood (FIML) to estimate the coefficients. ${ }^{7}$ Model M3 modifies Assumptions A7, A8, and A9, as follows.

A7'-- Non-price rationing variables are not included.

A8'-- Dynamic adjustment is modeled as partial adjustment, generalized to include some lagged non-normalized endogenous variables.

A9'-- The covariance matrix $\Omega$ may be non-diagonal, so the coefficients are estimated by FIML.

Model M4 is from Marquez (1989) and alters Assumptions A5-A9.

A5"-- Trade elasticities across commodities are equal. Thus, trade flows are aggregated across commodities.

A6"-- Trade elasticities are not assumed equal across countries and cross-price elasticities are not imposed to be zero. Thus, the model explains U.S. exports and imports on a bilateral basis with respect to Canada, Germany, Japan, the United Kingdom, the rest of the OECD countries (ROECD), non-OPEC developing countries (LDCs), and OPEC. Trade with centrally planned economies is assumed known.

A7"-- Non-price rationing variables are not included.

A8"-- Dynamics appear via lagged endogenous variables and Almon polynomials on (some) other variables.

A9"-- The covariance matrix $\Omega$ may be non-diagonal, so the coefficients are estimated by FIML.

Note that the behavioral equations in all of the structural models are logarithmic in form, implying that trade volumes and prices are nonlinear functions of the coefficient estimates and

\footnotetext{
${ }^{7}$ The FIML procedure in TROLL does not handle autoregressive disturbances per se but docs accept nonlinear equation specifications. Thus, those equations in Ml which have autoregressive errors were coded as nonlinear equations with white-noise errors. Then all the equations in M1 were estimated by nonlinear FIML. We also estimated each nonlinear equation by TROLL's Nonlinear Least. Squares (NLS) routine and obtained virtually identical parameter estimates to those obtained by Helkic and Hooper (1988) using the Cochrane-Orcutt procedure.
} 
Table 1

Alternative Econometric Models of the U.S. Trade Account

Schematic Specifications

Commodity-disaggregated Systems (M1, M2, M3)

$$
\begin{aligned}
& \left(1-\alpha_{0 i}{ }^{L}\right) \ln X_{i t}=\alpha_{1 i}+\alpha_{2 i} \ln Y_{t}^{*}+\alpha_{3 i}(L) \ln \left[P_{x i t} /\left(E_{t} P_{t}^{*}\right)\right]+\alpha_{4 i} N_{x i t}+\alpha_{5 i} T_{x i t}+u x_{i t} \\
& \left(1-\beta_{0 i} L^{L}\right) \operatorname{lnM}_{i t}=\beta_{1 i}+\beta_{2 i}(L) \ln Y_{t}+\beta_{3 i}(L) \ln \left[P_{m i t} / P_{t}\right]+\beta_{4 i} N_{m i t}+\beta_{5 i} T_{m i t}+u_{i t} \\
& \left(1-\gamma_{0 i} L^{L}\right) \ln P_{x i t}=\gamma_{1 i}+\gamma_{2 i} \operatorname{lnC} C_{t}+\gamma_{3 i} \ln \left[E_{t} P_{t}^{*}\right]+u p x_{i t} \\
& \left(1-\delta_{0 \mathrm{i}} \mathrm{L}\right) \ln \mathrm{P}_{\text {mit }}=\delta_{1 \mathrm{i}}+\delta_{2 \mathrm{i}}(\mathrm{L}) \ln \mathrm{E}_{\mathrm{t}}+\delta_{3 \mathrm{i}}(\mathrm{L}) \ln \mathrm{P}_{\mathrm{t}}^{*}+\mathrm{upm}_{\mathrm{it}} \\
& \mathrm{NX}_{\mathrm{t}}=\Sigma_{\mathrm{i}} \mathrm{P}_{\mathrm{xi} \mathrm{t}} \mathrm{X}_{\mathrm{it}}-\Sigma_{\mathrm{i}} \mathrm{P}_{\text {mi t }} \mathrm{M}_{\mathrm{it}}
\end{aligned}
$$

\section{Country-disaggregated System (M4)}

$$
\begin{aligned}
& \left(1-\alpha_{0 j}^{\prime} L\right) \ln X_{j t}=\alpha_{1 j}^{\prime}+\alpha_{2 j}^{\prime} \ln P_{j t}+\alpha_{3 j}^{\prime} \ln Y T_{j t}+\alpha_{4 j}^{\prime}(L) \ln \left[P_{x t} /\left(E_{j t} P_{j t}\right)\right]+\alpha_{5 j}^{\prime}(L)\left(\sum_{r \neq j} \omega_{r} \ln \left[\left(E_{r t} P_{x r t}\right) /\left(E_{j t} P_{j t}\right)\right]\right)+u_{j t} \\
& \left(1-\beta_{0 j} L\right) \ln M_{j t}=\beta_{1 j}+\beta_{2 j} \ln Y P_{t}+\beta_{3 j}^{\prime} \ln Y T_{t}+\beta_{4 j}^{\prime}(L) \ln \left[E_{j t} P_{x j t} / P_{t}\right]+\beta_{5 j}^{\prime}(L)\left(\sum_{t \neq j} \pi_{r} \ln \left[E_{r t} P_{x r t} / P_{t}\right]\right)+u m_{j t} \\
& \left(1-\gamma_{0}^{\prime} L\right) \ln P_{x t}=\gamma_{1}^{\prime}+\gamma_{2}^{\prime} \ln P_{t}+\gamma_{3}^{\prime}\left[\Sigma_{j} \omega_{j} \ln \left(E_{j t} P_{x j t}\right)\right]+u p x_{t} \\
& \left(1-\delta_{0 j}^{\prime}{ }^{L}\right) \ln P_{x j t}=\delta_{1 j}^{\prime}+\delta_{2 j}^{\prime} \ln \left(P_{x t} / E_{j j}\right)+\delta_{3 j}^{\prime} \cdot \ln P_{j t}+u p m_{j t} \\
& N X_{t}=\Sigma_{j} P_{x t} X_{j t}-\Sigma_{j} E_{j t} P_{x j t} M_{j t}
\end{aligned}
$$

\section{Vector Auotregressive System (M5)}

$$
\begin{aligned}
& \ln \mathrm{x}_{\mathrm{t}}=\xi_{11}+\xi_{12}(\mathrm{~L}) \ln \mathrm{X}_{\mathrm{t}-1}+\xi_{13}(\mathrm{~L}) \ln \mathrm{M}_{\mathrm{t}-1}+\xi_{14}(\mathrm{~L}) \ln \mathrm{P}_{\mathrm{x}, \mathrm{t}-1}+\xi_{15}(\mathrm{~L}) \ln \mathrm{P}_{\mathrm{m}, \mathrm{t}-1}+\mathrm{ux}_{\mathrm{t}} \\
& \ln _{\mathrm{t}}=\xi_{21}+\xi_{22}(\mathrm{~L}) \ln \mathrm{X}_{\mathrm{t}-1}+\xi_{23}(\mathrm{~L}) \ln \mathrm{M}_{\mathrm{t}-1}+\xi_{24}(\mathrm{~L}) \ln \mathrm{x}_{\mathrm{x}, \mathrm{t}-1}+\xi_{25}(\mathrm{~L}) \ln \mathrm{P}_{\mathrm{m}, \mathrm{t}-1}+\mathrm{um}_{\mathrm{t}} \\
& \operatorname{lnP}_{\mathrm{xt}}=\xi_{31}+\xi_{32}(\mathrm{~L}) \ln \mathrm{X}_{\mathrm{t}-1}+\xi_{33}(\mathrm{~L}) \ln \mathrm{M}_{\mathrm{t}-1}+\xi_{34}(\mathrm{~L}) \ln \mathrm{P}_{\mathrm{x}, \mathrm{t}-1}+\xi_{35}(\mathrm{~L}) \ln \mathrm{P}_{\mathrm{m}, \mathrm{t}-1}+\mathrm{upx}_{\mathrm{t}} \\
& \operatorname{lnP}_{\mathrm{mt}}=\xi_{41}+\xi_{42}(\mathrm{~L}) \ln \mathrm{X}_{\mathrm{t}-1}+\xi_{43}(\mathrm{~L}) \ln \mathrm{M}_{\mathrm{t}-1}+\xi_{44}(\mathrm{~L}) \ln \mathrm{x}_{\mathrm{x}, \mathrm{t}-1}+\xi_{45}(\mathrm{~L}) \ln \mathrm{P}_{\mathrm{m}, \mathrm{t}-1}+\mathrm{upm}_{\mathrm{t}} \\
& \mathrm{NX}_{\mathrm{t}}=\mathrm{P}_{\mathrm{xt}} \mathrm{X}_{\mathrm{t}}-\mathrm{P}_{\mathrm{mt}} \mathrm{M}_{\mathrm{t}}
\end{aligned}
$$

Time-series Equation (M6)

$$
\mathrm{NX}_{\mathrm{t}}=\lambda_{\mathrm{o}}+\lambda_{1} \mathrm{NX}_{\mathrm{t}-1}+\mathrm{v}_{\mathrm{t}}
$$

\section{Endogenous Variables}

M Real U.S. imports

NX Nominal trade account

$\mathrm{P}_{\mathrm{m}} \quad$ Import price index

$\mathrm{P}_{\mathrm{X}} \quad$ Export price index

$X \quad$ Real U.S. exports

\section{Disturbances}

um Import disturbance

ux Export disturbance

upm Import price disturbance

upx Export price disturbance

v Trade account disturbance

\section{Indexes and Definitions}

Subscript i denotes the ith commodity.

Subscript $j$ denotes the $\mathrm{jth}$ foreign country.

Subscript $t$ denotes time.

$\mathrm{An} *$ denotes foreign countries (aggregated).

A prime 'denotes a parameter from model M4.

The natural logarithm is denoted ln.

The lag operator is denoted $\mathrm{L}$.

\section{Exogenous Variables}

C Production costs

E Nominal exchange rate (US/foreign)

$\mathrm{NP}_{\mathrm{m}}$ Non-price rationing of imports

$\mathrm{NP}_{\mathrm{X}}$ Non-price rationing of exports

$T_{m} \quad$ Trend factors affecting imports
$\mathrm{T}_{\mathrm{x}} \quad$ Trend factors affecting exports

$P \quad$ GDP deflator

Y Real GDP

YP Estimated permanent income

YT Estimated transitory income 
Table 2

Alternative Econometric Models of the U.S. Trade Account Parametric Configurations

\begin{tabular}{|c|c|c|c|c|c|c|}
\hline \multirow{2}{*}{ Attributes } & \multicolumn{4}{|c|}{ Structural Models } & \multicolumn{2}{|c|}{ Time Series Models } \\
\hline & M1 & M2 & M3 & M4 & M5 & M6 \\
\hline Number of Coefficients ${ }^{\mathrm{a}}$ & 51 & 51 & 45 & 127 & 68 & 2 \\
\hline Number of Disturbances & 8 & 8 & 8 & 21 & 4 & 1 \\
\hline $\begin{array}{l}\text { Number of Autoregressive } \\
\text { Disturbances }\end{array}$ & 7 & 7 & 0 & 0 & 0 & 0 \\
\hline \multirow[t]{6}{*}{ Parameter Restrictions } & $\alpha_{0 \mathrm{i}}=0$ & $\alpha_{0 \mathrm{i}}=0$ & $\alpha_{3 i}(L)=\alpha_{3 i}$ & & & \\
\hline & $\beta_{0 \mathrm{i}}=0$ & $\beta_{0 \mathrm{i}}=0$ & $\beta_{3 i}(L)=\beta_{3 i}$ & & & \\
\hline & $\gamma_{0 \mathrm{i}}=0$ & $\gamma_{0 \mathrm{i}}=0$ & $\alpha_{4 i}=0$ & & & \\
\hline & $\delta_{0 \mathrm{i}}=0$ & $\delta_{0 \mathrm{i}}=0$ & $\alpha_{5 i}=0$ & & & \\
\hline & & & $\beta_{4 i}=0$ & & & \\
\hline & $\Omega$ diagonal & & $\beta_{5 i}=0$ & & & \\
\hline
\end{tabular}

Notes: $\quad$ Model M1: Helkie and Hooper (1988).

Model M2: Model M1 by FIML.

Model M3: Model M1 by FIML, with partial adjustment, without non-price rationing.

Model M4: Bilateral trade model by FIML.

Model M5: VAR(4) of import and export volumes and price indices.

Model M6: AR(1) of the nominal trade account. a. The number of coefficients excludes the number of variances and covariances for the model's vector of
disturbances. 
disturbances. These nonlinearities have important practical implications for the distribution of the forecasts from the trade account, as Sections 3-5 below show.

The time-series models M5 and M6 are included in our analysis as benchmarks for the dynamic specification and forecasting performance of models M1-M4. Model M5 is a fourthorder, four-variable vector autoregressive representation (VAR) for the logarithms of export and import volumes and price indices. From the logarithms, the trade account is constructed via the identity (5). Thus, the VAR will have qualitatively similar nonlinearities to the structural models.

Model M6 is one of the simplest possible time-series specifications, a first-order univariate autoregressive process (AR) of the level of the trade account:

$$
N X_{t}=\lambda_{0}+\lambda_{1} N X_{t-1}+v_{t}
$$

By construction, model M6 uses only past information on the trade account in forecasting the trade account. Similarly, model M5 uses only past information on export and import volumes and price indices.

In addition to differences in behavioral specification (or the lack thereof), these six models differ in size, whether measured by the number of equations or the number of parameters. For example, model M6 has one stochastic equation with two coefficients whereas model M4 has 21 stochastic equations with 127 coefficients (cf. Table 2). Taken as whole, the diversity in model specification offers an opportunity to evaluate the consequences of both model structure and estimation technique on forecast performance.

\subsection{Model Estimation}

This sub-section reports estimates of parameters associated with models M1-M6, using quarterly data ending in 1984Q4 (to match Helkie and Hooper (1988)). We focus on derived income, price, and pass-through elasticities. The data are described in Appendix A.

Table 3 reports the estimated elasticities for models M1-M4. Several features are of particular interest, including their economic and statistical properties, and their sensitivity to estimation method, model specification, and degree of disaggregation. 
Table 3

Alternative Structural Models of the U.S. Trade Account ${ }^{a}$ Long-run Elasticity Estimates

(standard errors in parentheses)

\begin{tabular}{|c|c|c|c|c|c|c|c|c|}
\hline \multirow{2}{*}{ Attributes } & \multicolumn{8}{|c|}{ Structural Models } \\
\hline & \multicolumn{2}{|r|}{ M1 } & \multicolumn{2}{|c|}{ M2 } & \multicolumn{2}{|c|}{ M3 } & \multicolumn{2}{|r|}{ M4 } \\
\hline $\begin{array}{c}\text { Estimation } \\
\text { Sample }^{b} \\
\text { Method }\end{array}$ & $\begin{array}{r}\text { 1969Q3 } \\
\text { NLS }\end{array}$ & $\begin{array}{l}-1984 Q 4 \\
\text {, OLS }\end{array}$ & $\begin{array}{r}\text { 1969Q3- } \\
\text { FI }\end{array}$ & $\begin{array}{l}-1984 Q 4 \\
\text { IML }\end{array}$ & $\begin{array}{r}\text { 1969Q3 } \\
\mathrm{F}\end{array}$ & $\begin{array}{l}1984 Q 4 \\
\text { ML }\end{array}$ & $\begin{array}{r}\text { 1973Q1- } \\
\text { FI }\end{array}$ & $\begin{array}{l}-1984 Q 4 \\
\text { IML }\end{array}$ \\
\hline $\begin{array}{l}\text { Import Volume } \\
\text { Income } \\
\text { Non-oil } \\
\text { Oil } \\
\text { Canada } \\
\text { Germany } \\
\text { Japan } \\
\text { United Kingdom } \\
\text { ROECD } \\
\text { LDCs } \\
\text { OPEC }\end{array}$ & $\begin{array}{l}2.08 \\
3.62\end{array}$ & $\begin{array}{l}(0.11) \\
(0.03)\end{array}$ & $\begin{array}{l}2.36 \\
3.55\end{array}$ & $\begin{array}{l}(0.68) \\
(0.55)\end{array}$ & $\begin{array}{l}2.75 \\
1.36\end{array}$ & $\begin{array}{l}(0.08) \\
(1.10)\end{array}$ & $\begin{array}{l}1.64 \\
2.92 \\
3.70 \\
2.43 \\
2.32 \\
3.12 \\
5.19\end{array}$ & $\begin{array}{l}(0.17) \\
(0.31) \\
(0.30) \\
(0.52) \\
(0.31) \\
(0.21) \\
(0.85)\end{array}$ \\
\hline Aggregate $^{c}$ & 2.34 & $(0.18)$ & 2.70 & $(0.49)$ & 2.29 & $(0.33)$ & 3.01 & $(0.16)$ \\
\hline $\begin{array}{l}\text { Price } \\
\text { Non-oil } \\
\text { Oil } \\
\text { Canada } \\
\text { Germany } \\
\text { Japan } \\
\text { United Kingdom } \\
\text { ROECD } \\
\text { L.DCs } \\
\text { OPEC }\end{array}$ & $\begin{array}{l}-1.12 \\
-2.58\end{array}$ & $\begin{array}{l}(0.11) \\
(0.91)\end{array}$ & $\begin{array}{l}-1.07 \\
-0.83\end{array}$ & $\begin{array}{l}(0.08) \\
(0.36)\end{array}$ & $\begin{array}{l}-0.97 \\
-0.61\end{array}$ & $(0.09) \mathrm{d}$ & $\begin{array}{l}-0.63 \\
-1.41 \\
-0.58 \\
-0.44 \\
-0.68 \\
-1.44 \\
-3.97\end{array}$ & $\begin{array}{l}(0.17) \\
(0.33) \\
(0.23) \\
(0.39) \\
(0.14) \\
(0.43) \\
(1.95)\end{array}$ \\
\hline Aggregate & -1.56 & $(0.29)$ & -0.99 & $(0.36)$ & -0.85 & $(0.14)$ & -1.36 & $(0.31)$ \\
\hline $\begin{array}{l}\text { Export Volume } \\
\text { Income } \\
\text { Agricultural } \\
\text { Non-agricultural } \\
\text { Canada } \\
\text { Germany } \\
\text { Japan } \\
\text { United Kingdom } \\
\text { ROECD } \\
\text { LDCs } \\
\text { OPEC }\end{array}$ & $\begin{array}{l}1.12 \\
2.24\end{array}$ & $\begin{array}{l}(0.34) \\
(0.10)\end{array}$ & $\begin{array}{l}1.11 \\
2.15\end{array}$ & $\begin{array}{l}(0.08) \\
(0.31)\end{array}$ & $\begin{array}{l}1.33 \\
1.27\end{array}$ & $\begin{array}{l}(0.10) \\
(0.11)\end{array}$ & $\begin{array}{l}1.70 \\
1.52 \\
0.75 \\
3.41 \\
1.79 \\
0.40 \\
1.29\end{array}$ & $\begin{array}{l}(0.21) \\
(0.17) \\
(0.17) \\
(0.70) \\
(0.29) \\
(0.16) \\
(0.47)\end{array}$ \\
\hline Aggregate & 2.06 & $(0.29)$ & 1.98 & $(0.26)$ & 1.28 & $(0.09)$ & 1.27 & $(0.01)$ \\
\hline
\end{tabular}


Table 3 (con't)

\begin{tabular}{lllll}
\hline & \multicolumn{4}{c}{ Structural Models } \\
\cline { 2 - 5 } Attributes & M1 & M2 & M3 & M4 \\
& & & & \\
\hline
\end{tabular}

Export Volume

Price

$\begin{array}{lccccccccc}\text { Agricultural } & -0.84 & (0.14) & -0.88 & (0.11) & -0.66 & (0.17) & & & \\ \text { Non-agricultural } & -0.98 & (0.11) & -0.92 & (0.12) & -1.04 & (0.26) & & & \\ \text { Canada } & & & & & & & & -0.44 & (0.34) \\ \text { Germany } & & & & & & & -0.99 & (0.17) \\ \text { Japan } & & & & & & -0.41 & (0.28) \\ \text { United Kingdom } & & & & & & & -0.87 & (0.36) \\ \text { ROECD } & & & & & & & -0.83 & (0.22) \\ \text { LDCs } & & & & & & & -1.62 & (0.62) \\ \text { OPEC } & & & & & & & -0.86 & (0.17) \\ \text { Aggregate } & -0.96 & (0.09) & -0.91 & (0.10) & -0.98 & (0.22) & -0.96 & (0.21)\end{array}$

Pass-through Coefficients

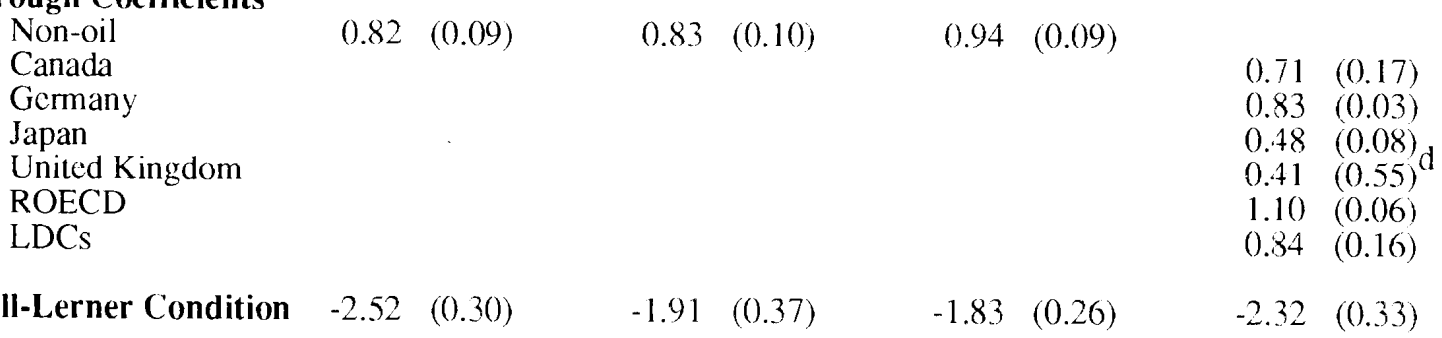

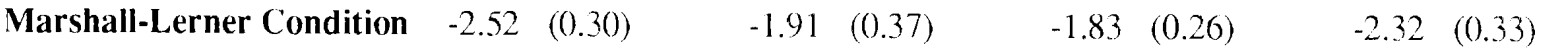

Houthakker-Magee Asymmetry

Canada

Germany

Japan

United Kingdom

ROECD

LDCS

OPEC

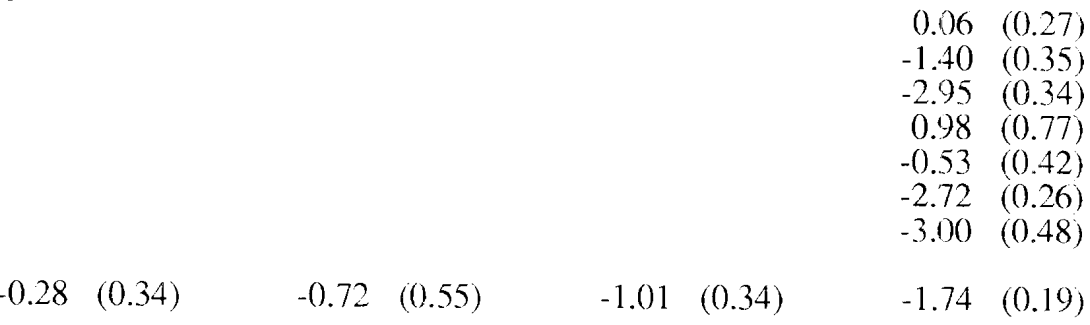
Aggregate
$-0.28 \quad(0.34)$
$-0.72(0.55)$
$-1.01-(0.34)$

Notes:

a. Model M1: Helkic and Hooper (1988).

Model M2: Model M1 by FIML.

Model M3: Model M1 by FIML, with partial adjustment, without non-price rationing.

Model M4: Bilateral trade model by FIML.

b. The starting observation for estimation varies across equations in model M1; see Appendix E. c. The elasticity estimates for aggregate trade are obtained as a weighted average of the disaggregated trade
elasticities.

d. For these two clasticities, the measure of dispersion is the scaled median absolute deviation. See Tables B. 1 and B. 2 for the estimated standard crror and for the $95 \%$ confidence interval. 
The estimated trade elasticities are consistent with standard theory. The income elasticities are positive, the price elasticities are negative, and the pass-through effect of exchange rates to import prices is positive. Also, the sum of the estimated price elasticities is more negative than minus unity, suggesting that these models satisfy the Marshall-Lerner condition. ${ }^{8}$ Most estimated elasticities are economically and statistically significant and have small standard errors. One notable exception is the elasticity of oil imports in model M3 which, in addition to being small $(-0.61)$, is not statistically significant. ${ }^{9}$

Several examples illustrate the sensitivity of the estimated elasticities to the choice of estimation method, the dynamic specification of the behavioral relations, and their level of disaggregation by country and commodity. First, estimation of the Helkie-Hooper model by FIML (M2) rather than NLS/OLS (M1) changes the corresponding price elasticity for oil imports from -2.58 to -0.83 . Second, income elasticities for aggregate exports and imports are not equal in models M3 and M4, but are in models M1 and M2. ${ }^{0}$ Thus, models M3 and M4 imply a deterioration of the U.S. trade account from equal increases in income throughout the world, ceteris paribus, whereas models M1 and M2 do not. Third, the price elasticity of imports for model M4 varies from -0.44 for the United Kingdom to -3.97 for OPEC, bringing into question the validity of Assumption A6 in models M1-M3. Similarly, the pass-through coefficients in M4 vary from 0.41 for U.S. imports from the United Kingdom to 1.10 for U.S. imports from the bloc of other OECD countries. Finally, aggregating the data reduces the range of elasticity estimates. For example, the income elasticity for aggregate imports varies from 2.3 for M3 to 3.0 for M4 whereas elasticities for the components of these aggregates are more disperse.

Before turning to the models' forecasts themselves, we note some basic time-series properties of the trade-account data. The first column of numbers in Table 4 lists characteristics

\footnotetext{
${ }^{8}$ The Marshall-Lerner condition states that the sum of the price elasticities for exports and imports should be less than minus one in order to avoid instability in market adjustments to changes in relative prices.

${ }^{9}$ Because the elasticities of models M3 and M4 are nonlincar functions of the estimated coefficients, both those elasticities and their standard errors must be derived. We do so by Monte Carlo simulation, as described in Appendix B.

${ }^{10} \mathrm{Cf}$. Houthakker and Magee (1969). The asymmetry in income clasticities is measured as the income elasticity for exports minus the income elasticity for imports. Note the large clasticity asymmetrics between the United States and Germany, Japan, and the LDCs.
} 
of the AR(1) model M6. For comparison, the second column gives estimates for an AR(4) model over the same sample. Both models are estimated by OLS, and standard errors are in parentheses. Based on these estimates, the trade account appears to be non-stationary, and possibly explosively so. That feature may stem from inclusion of the 1980-84 period in the estimation sample. ${ }^{1}$ Because forecasts from dynamic models need not have finite moments, an examination of the empirical properties of forecasts from models such as M5 and M6 may contribute to the literature on their analytical properties. ${ }^{12}$

Table 4: Summary Statistics for the Time-series Models

\begin{tabular}{lll} 
& \multicolumn{1}{c}{$\mathrm{M} 6(\mathrm{p}=1)$} & \\
$\hat{\lambda}_{0}$ & $-0.91(1.25)$ & $-0.87 \quad(1.25)$ \\
$\sum_{\mathrm{q}=1}^{\mathrm{p}} \hat{\lambda}_{\mathrm{q}}$ & $1.044(0.03)(\mathrm{p}=4)$ & $1.026(0.05)$ \\
$\hat{\sigma}$ & 7.805 & 7.64 \\
$\overline{\mathrm{R}}^{2}$ & 0.94 & 0.94 \\
Durbin's h & 0.30 & -0.115
\end{tabular}

The VAR (M5) is estimated by multivariate least squares, which is FIML here because the coefficients are estimated unrestrictedly. Estimated coefficients and standard errors appear in Appendix E.

\subsection{Forecasting}

Given the nonlinearities in the behavioral equations, forecasting the trade account $\mathrm{S}$ periods ahead (say) involves solving the whole trade model for import and export prices and volumes, period by period. For notational simplicity, the entire model is represented as:

(8) $f\left(\mathrm{y}_{\mathrm{t}}, \mathrm{y}_{\mathrm{t}-1}, \mathrm{z}_{\mathrm{t}}, \theta, \mathrm{u}_{\mathrm{t}}\right)=0$, $\mathrm{t}=1, \ldots, \mathrm{T}+\mathrm{S}$

\footnotetext{
${ }^{11}$ If the estimation sample ends in $1979 \mathrm{Q} 4$, then the $\Sigma \hat{\lambda}_{\mathrm{q}}$ are $0.96(0.06)$ and $0.94(0.07)$ for the $\operatorname{AR}(1)$ and
AR(4) models, respectively. ${ }^{12}$ See, for example, Orcutt and Winokur (1969), Sargan (1982), Hoque, Magnus, and Pesaran (1988), Ericsson and Marquez (1989), and Magnus and Pesaran (1989).
} 
where the first $\mathrm{T}$ observations are used in estimation (here, ending in 1984Q4), the remaining $\mathrm{S}$ are forecast, $f(\cdot)$ is an $\mathrm{n} \times 1$ vector of equations included in the model, $\mathrm{y}_{\mathrm{t}}$ is an $\mathrm{n} \times 1$ vector of endogenous variables in period $t, z_{t}$ is an $r \times 1$ vector of (assumedly) weakly exogenous variables, $\theta$ is a $c \times 1$ vector of parameters, and $u_{t}$ is an $m \times 1$ vector of corresponding disturbances. For describing forecast procedures, it is more convenient to write (8) solved for $y_{t}$ explicitly:

$$
\mathrm{y}_{\mathrm{T}+\mathrm{s}}=g\left(\mathrm{y}_{\mathrm{T}+\mathrm{s}-1}, \mathrm{z}_{\mathrm{T}+\mathrm{s}}, \theta, \mathrm{u}_{\mathrm{T}+\mathrm{s}}\right), \quad \mathrm{s}=1-\mathrm{T}, \ldots,-1,0,1, \ldots, \mathrm{S},
$$

where $g(\cdot)$ is a suitable redefinition of $f(\cdot)$ above, and the time subscript is changed such that forecasts are calculated for positive s.

By assumption, (9) is the process generating $y_{\mathrm{T}+\mathrm{s}}$, so (9) naturally serves for generating $\hat{y}_{\mathrm{T}+\mathrm{s}}$ (the forecast of $\mathrm{y}_{\mathrm{T}+\mathrm{s}}$ ), given some choice of assumptions about $\mathrm{y}_{\mathrm{T}+\mathrm{s}-1}, \theta$, and $\mathrm{u}_{\mathrm{T}+\mathrm{s}}$. The particular choice adopted determines the type of forecast. If the actual value of $\mathrm{y}_{\mathrm{T}+\mathrm{s}-1}$ is used, then the $\mathrm{S}$ forecasts $\left\{\hat{y}_{\mathrm{T}+\mathrm{s}} ; \mathrm{s}=1, \ldots, \mathrm{S}\right\}$ are one-period ahead, i.e., forecasts of the endogenous variables are conditional on the observed endogenous variables lagged one period. Alternatively, the previous forecast $\hat{y}_{\mathrm{T}+\mathrm{s}-1}$ could replace $\mathrm{y}_{\mathrm{T}+\mathrm{s}-1}$ in (9), but with observed $\mathrm{y}_{\mathrm{T}}$ starting the forecast process. This sequential solution for $\hat{y}_{T+s}$ in (9) generates a set of s-period ahead forecasts $(s=1, \ldots, S)$.

Given the class of forecasts (whether one-period or s-period ahead), the choice of $\theta$ and $\mathrm{u}_{\mathrm{T}}+\mathrm{s}$ in $g(\cdot)$ fully specifies the forecast procedure. Numerous choices of $\theta$ and $u_{T+s}$ exist, the most common being "deterministic simulation" $\left(\theta=\hat{\theta}\right.$ and $\left.\mathrm{u}_{\mathrm{T}+\mathrm{s}}=0\right)$ and "stochastic simulation" $(\theta$ and $\mathrm{T}+\mathrm{s}$ random). The remainder of this section considers the former; Section 3 calculates the latter by Monte Carlo methods and uses them for model evaluation via predictive failure tests; Section 4 uses the latter for model evaluation via forecast-encompassing tests; and Section 5 compares the numerical solutions for both. The analysis in the body of the paper is conducted with one-period and s-period ahead forecasts, in both cases drawing sets of random values for $\theta$ and $\mathrm{u}_{\mathrm{T}+\mathrm{s}}$; Appendix $\mathrm{C}$ presents the results for which only $\mathrm{u}_{\mathrm{T}+\mathrm{s}}$ is treated as random, cf. Section 3.1. For brevity, analytical derivations below often are given for s-step ahead forecasts only. However, the formal structure developed applies to both s-step and one-step forecasts, and both types of forecasts are examined empirically. 
Before proceeding, we note that the term simulation carries different meanings in the econometric and Monte Carlo literatures. To avoid confusion, we use the definition in Howrey and Kelejian (1969, p. 207): "A simulation experiment is the solution sequence generated by a dynamic model under certain specified conditions in which the exogenous variables are usually taken as given and the model is used to generate the endogenous variables sequentially."

\subsection{Deterministic Forecasts}

In deterministic simulation, (9) is solved numerically, setting $\theta$ equal to its in-sample estimated value $\hat{\theta}$ and $u_{\mathrm{T}+\mathrm{s}}$ equal to its expected value (usually zero). The associated one-step ahead forecasts are:

$$
\delta_{\mathrm{T}+\mathrm{s}}=g\left(\mathrm{y}_{\mathrm{T}+\mathrm{s}-1}, \mathrm{z}_{\mathrm{T}+\mathrm{s}}, \hat{\theta}, 0\right), \quad \mathrm{s}=1, \ldots, \mathrm{S} .
$$

The s-step ahead forecasts use the same formula, but with $\delta_{\mathrm{T}+\mathrm{s}-1}$ replacing $\mathrm{y}_{\mathrm{T}+\mathrm{s}-1}(\mathrm{~s}=2, \ldots, \mathrm{S})$. Equation (10) is computationally simple to implement for both one-step and s-step ahead forecasts, but, by ignoring $\hat{\theta}$ and $\mathrm{u}_{\mathrm{T}+\mathrm{s}}$ as sources of randomness, the extent of forecast uncertainty cannot be assessed. That precludes developing confidence intervals for the forecasts and evaluating the forecast performance of different models. ${ }^{13}$

To highlight these limitations, consider the deterministic one-step and s-step ahead tradeaccount forecasts from (10) for the period 1985Q1-1987Q4, plotted in Figure 1. ${ }^{4}$ Two features are notable: the forecasts differ substantially in numerical terms across models, and the dispersion of model forecasts increases strikingly as the forecast horizon lengthens. On the former, s-step ahead forecasts from models M1-M3 and M5 indicate a general improvement, whereas models M4 and M6 forecast continued deterioration. On the latter, the range of tradeaccount forecasts increases from $\$ 50$ billion (annual rates) at one quarter ahead to $\$ 140$ billion (annual rates), twelve quarters ahead. Hooper (1988) and Bryant and Holtham (1988) report

\footnotetext{
${ }^{13}$ Equation (10) also gives biased forecasts for most nonlinear functions $g(\cdot)$ because the expectation of a nonlinear function generally is not cqual to the function of the expectation. See Section 5 for a numerical analysis of such forecast biases.

${ }^{14}$ For the structural models M1-M4, the forecasts of $y$ are ex post in the sense that those forecasts are conditional upon the outcomes of the assumedly weakly exogenous variables $z$. However, the variables in y (import and export prices and volumes) are solved simultaneously at each period.
} 
Figure 1: Deterministic Forecasts of the Trade Account
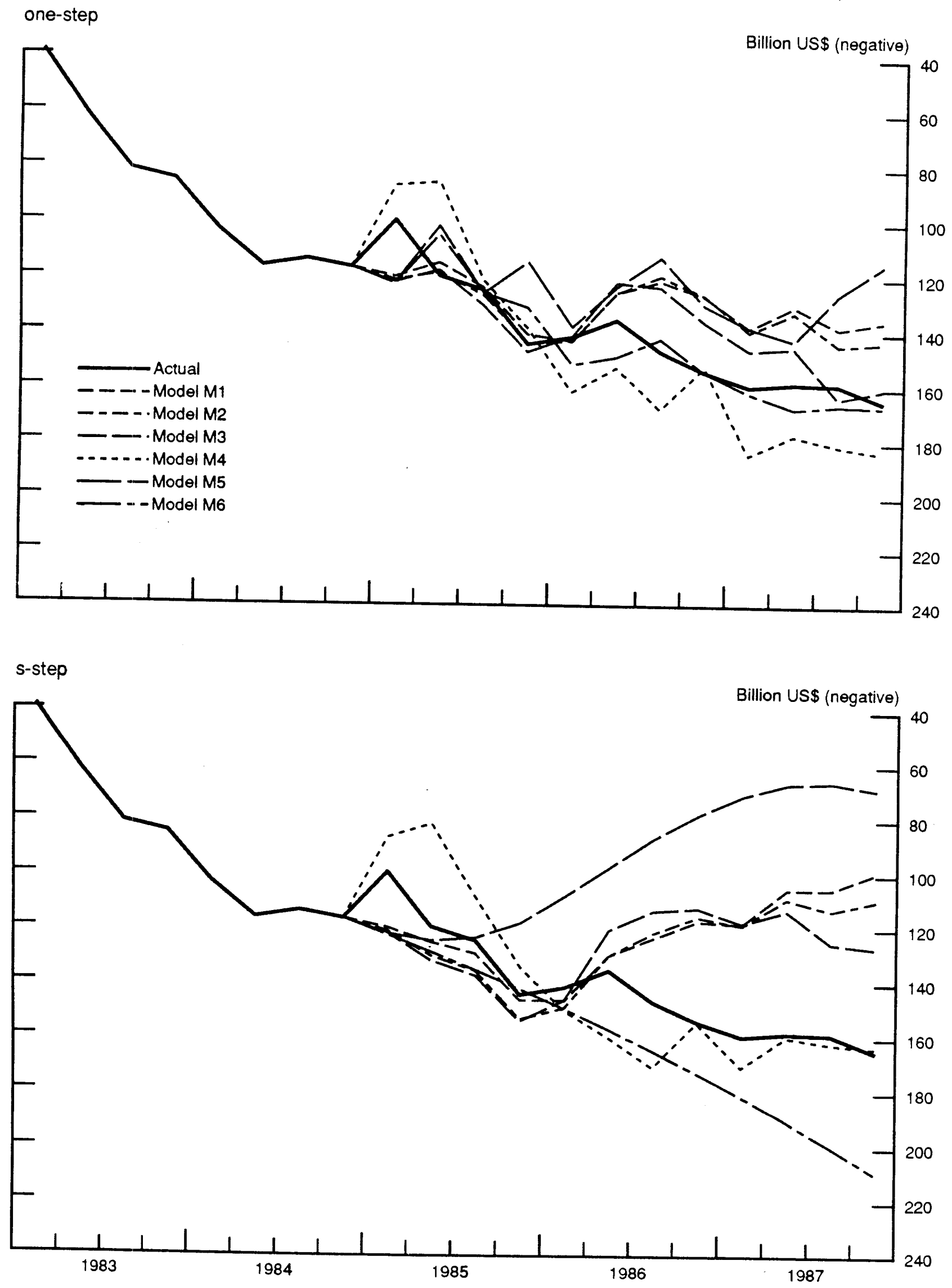
similar findings in comparing forecasts from different trade models and interpret the increase in forecast dispersion as indicative of forecast uncertainty. However, this interpretation unrealistically treats deterministic simulations from alternative models as though they were drawings from some (unspecified) distribution of outcomes.

Although forecast uncertainty may well increase with the forecast horizon, neither ex post nor ex ante measures of that uncertainty are related to the dispersion of deterministic simulations from alternative models, making the latter an unreliable estimate of forecast uncertainty. For instance, one model's forecasts might be always correct, yet the dispersion across different models' forecasts could be substantial due to misspecification in the other models. Conversely, all forecasts might be nearly identical (e.g., because of similar model design), yet all could have large uncertainty associated with them. Simply put, a set of forecasts from different models bears no relation to a sampling of possible outcomes of the variable forecast. For reasons discussed in Section 3.1 below, descriptive statistics of model performance such as mean absolute error (MAE) and root mean-square forecast error (RMSFE) are also unsatisfactory measures of forecast uncertainty.

Deterministic simulations are of potential interest, but often lack a measure of uncertainty. Numerically large differences between forecasts from alternative models (or between forecasts of a given model and actual outcomes) may or may not be statistically significant, and a measure of the forecasts' distributional properties is necessary to find that out. Lacking such a measure undermines the value of deterministic simulation for studying international trade and evaluating policies. Thus, Section 3 assesses the uncertainty of trade-account forecasts by means of stochastic simulation.

\section{Stochastic Properties of the Trade-account Forecasts}

In much the same way that coefficient estimates are estimates and hence are uncertain, so are forecasts. However, whereas the uncertainty of coefficient estimates in a well-specified model arises from only one source, namely, the disturbances over the estimation period, forecast uncertainty has two sources: "inherent" and "coefficient", i.e., that due to future disturbances and 
that arising from the estimation of model parameters. In light of (9), those sources are $\left\{\mathrm{u}_{\mathrm{T}+\mathrm{s}}, \mathrm{s}=1, \ldots, \mathrm{S}\right\}$ and the estimated coefficients $\hat{\theta}$, the latter being a function of the in-sample disturbances $\left\{\mathrm{u}_{\mathrm{t}}, \mathrm{t}=1, \ldots, \mathrm{T}\right\}$. Standard errors and confidence intervals can be constructed to reflect such uncertainty in forecasts, thereby permitting hypothesis testing. For linear dynamic systems, Schmidt (1974) and Baillie (1979) derive easily calculated analytical formulae which account for both sources of uncertainty; cf. Chong and Hendry (1986) for a summary and Monte Carlo analysis. However, (9) is nonlinear, so those formulae are not directly applicable. Instead, we solve a stochastic analogue to those analytical formulae, simulating by Monte Carlo the effects of inherent and coefficient uncertainty which are analytically derivable for linear models. Section 3.1 describes the design of that stochastic simulation; Section 3.2 analyzes the results.

\subsection{Experimental Design of the Stochastic Simulation}

From (9), the forecast $\hat{y}_{\mathrm{T}+\mathrm{s}}$ (relative to the outcome $\mathrm{y}_{\mathrm{T}+\mathrm{s}}$ ) depends upon the realizations of two random variables, $\hat{\theta}$ and $\left\{\mathrm{u}_{\mathrm{T}+\mathrm{i}}, \mathrm{i}=1, \ldots, \mathrm{s}\right\}$, so $\hat{\mathrm{y}}_{\mathrm{T}+\mathrm{s}}$ is also a random variable. If the distribution of the forecast $\hat{y}_{\mathrm{T}+\mathrm{s}}$ were derived analytically, assumptions would be made about the distributional properties of those disturbances and of the coefficient estimates. Similar assumptions are made when solving for the distributional properties of forecasts by stochastic simulation. Values of $\left\{\hat{\theta} ; \mathrm{u}_{\mathrm{T}+\mathrm{s}}, \mathrm{s}=1, \ldots, \mathrm{S}\right\}$ are randomly drawn according to those distributional assumptions, with each set of values generating a path of $S$ forecasts. From the sample of forecast paths, distributional properties of the forecasts can be estimated, e.g., the sample mean, the standard deviation (which gives the estimated forecast standard error), and the 95 percent confidence interval. The remainder of this sub-section describes the assumptions used, the procedure for generating the sample of forecasts, and some statistics derivable from that sample.

To generate random drawings for the errors $\mathrm{u}_{\mathrm{T}+\mathrm{s}}$, we assume normality and independence for all $u_{t}$ :

(11) $\mathrm{u}_{\mathrm{t}} \sim \mathrm{NI}(0, \Omega)$ $\mathrm{t}=1, \ldots, \mathrm{T}+\mathrm{S}$,

where $\Omega$ is an $m \times m$ covariance matrix independent of the time period $t$. Thus, the kth drawing of $\mathrm{u}_{\mathrm{T}+\mathrm{s}}\left(\right.$ denoted $\left.\mathrm{u}_{\mathrm{k}, \mathrm{T}+\mathrm{s}}\right)$ is: 


$$
\mathrm{u}_{\mathrm{k}, \mathrm{T}+\mathrm{s}}=\hat{\Lambda} \eta_{\mathrm{k}, \mathrm{s}}
$$

$$
\mathrm{k}=1, \ldots, \mathrm{K} ; \mathrm{s}=1, \ldots, \mathrm{S} \text {, }
$$

where $\Lambda$ is the (lower triangular) Cholesky decomposition of $\Omega$ (and so $\Lambda \Lambda^{\prime}=\Omega$ ), $\hat{\Lambda}$ is the (empirical) in-sample estimate of $\Lambda$ from $\hat{\Omega}$ (the in-sample estimate of $\Omega$ ), $\eta_{\mathrm{k}, \mathrm{s}}$ is an $\mathrm{m} \times 1$ vector of drawings from an independent standard normal distribution, and $\mathrm{K}$ is the number of replications (i.e., the number of times that the forecast is simulated). In this paper, $\mathrm{K}=1000$ and the forecast period is $1985 \mathrm{Q} 1$ to $1987 \mathrm{Q} 4(\mathrm{~S}=12)$.

To generate random drawings for all the coefficients in the model, we assume that the asymptotic properties of $\hat{\theta}$ hold in finite samples:

$$
\hat{\theta} \sim \mathrm{N}(\theta, \Sigma)
$$

where $\Sigma$ is the $\mathrm{c} \times \mathrm{c}$ asymptotic covariance matrix of $\hat{\theta}^{15}$ Thus, the kth drawing of $\hat{\theta}$, denoted $\theta_{\mathrm{k}}$, is:

$$
\theta_{\mathrm{k}}=\hat{\theta}+\hat{\Gamma} \zeta_{\mathrm{k}}, \quad \mathrm{k}=1, \ldots, \mathrm{K} ; \mathrm{s}=1, \ldots, \mathrm{S}
$$

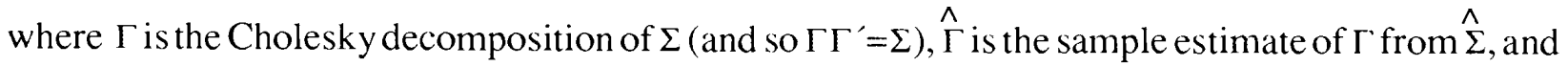
$\zeta_{\mathrm{k}}$ is a $\mathrm{c} \times 1$ vector of drawings from an independent standard normal distribution. ${ }^{16,17,18}$

At the $k$ th replication, $S$ forecasts are solved sequentially via (9) by combining $\theta_{k}$ from (14), $\left\{\mathrm{u}_{\mathrm{k}, \mathrm{T}+\mathrm{s}}, \mathrm{s}=1, \ldots, \mathrm{S}\right\}$ from (12), and the paths of the exogenous variables:

\footnotetext{
${ }^{15}$ Note that the estimation procedure may have implications for the assumed structure of $\Sigma$, e.g., block diagonality equation by equation for OLS and NLS.

${ }^{16}$ As an illustration of the magnitudes involved in (12) and (14), the dimensions of $\Omega$ and $\Sigma$ for model M4 are $21 \times 21$ and $127 \times 127$, respectively.

${ }^{17}$ Cf. Brown and Mariano (1984) and Fair (1984) on alternative procedures for drawing coefficients and/or residuals.

${ }^{18}$ At first blush, the assumption of normality in (11) and (13) may seem restrictive, and, to a certain extent, it is. However, analyses without forecast standard errors impose even more restrictive assumptions. E.g., they can be viewed as implicitly assuming normality and in addition setting $\Omega=0$ and $\Sigma=0$. Forecast standard errors from stochastic Monte Carlo simulation typically assume normality as well, with $\Omega$ equal to its estimated value (as above) but $\Sigma=0$. Thus, our procedure is more general than those commonly employed. Also, as the derivations in Schmidt (1974) and Baillic (1979) imply, finite sample deviations of the estimator's distribution from normality do not affect the distribution of the forecasts from linear models, to the order of approximation present (i.c., $\mathrm{o}(1 / \mathrm{T}))$.

Residual-based stochastic simulation sets $\Sigma=0$ and randomizes (permutes) the cstimated in-sample residuals to generate the simulated forecast errors, from which the estimated forecast standard errors are calculated. Although not quite a special case of our procedure, it omits coefficient uncertainty, and the randomized residuals need not approximate the underlying distribution of the errors any better than normality does. See Brown and Mariano (1989) for a comparative analysis of residual-based, deterministic, and Monte Carlo predictors.
} 
that arising from the estimation of model parameters. In light of (9), those sources are $\left\{\mathrm{u}_{\mathrm{T}+\mathrm{s}}, \mathrm{s}=1, \ldots, \mathrm{S}\right\}$ and the estimated coefficients $\hat{\theta}$, the latter being a function of the in-sample disturbances $\left\{\mathrm{u}_{\mathrm{t}}, \mathrm{t}=1, \ldots, \mathrm{T}\right\}$. Standard errors and confidence intervals can be constructed to reflect such uncertainty in forecasts, thereby permitting hypothesis testing. For linear dynamic systems, Schmidt (1974) and Baillie (1979) derive easily calculated analytical formulae which account for both sources of uncertainty; cf. Chong and Hendry (1986) for a summary and Monte Carlo analysis. However, (9) is nonlinear, so those formulae are not directly applicable. Instead, we solve a stochastic analogue to those analytical formulae, simulating by Monte Carlo the effects of inherent and coefficient uncertainty which are analytically derivable for linear models. Section 3.1 describes the design of that stochastic simulation; Section 3.2 analyzes the results.

\subsection{Experimental Design of the Stochastic Simulation}

From (9), the forecast $\hat{y}_{\mathrm{T}+\mathrm{s}}$ (relative to the outcome $\mathrm{y}_{\mathrm{T}+\mathrm{s}}$ ) depends upon the realizations of two random variables, $\hat{\theta}$ and $\left\{\mathrm{u}_{\mathrm{T}+\mathrm{i}}, \mathrm{i}=1, \ldots, \mathrm{s}\right\}, \hat{\mathrm{y}}_{\mathrm{T}+\mathrm{s}}$ is also a random variable. If the distribution of the forecast $\hat{y}_{T+s}$ were derived analytically, assumptions would be made about the distributional properties of those disturbances and of the coefficient estimates. Similar assumptions are made when solving for the distributional properties of forecasts by stochastic simulation. Values of $\left\{\hat{\theta} ; \mathrm{u}_{\mathrm{T}+\mathrm{s}}, \mathrm{s}=1, \ldots, \mathrm{S}\right\}$ are randomly drawn according to those distributional assumptions, with each set of values generating a path of $S$ forecasts. From the sample of forecast paths, distributional properties of the forecasts can be estimated, e.g., the sample mean, the standard deviation (which gives the estimated forecast standard error), and the 95 percent confidence interval. The remainder of this sub-section describes the assumptions used, the procedure for generating the sample of forecasts, and some statistics derivable from that sample.

To generate random drawings for the errors $\mathrm{u}_{\mathrm{T}+\mathrm{s}}$, we assume normality and independence for all $u_{t}$ :

(11) $u_{t} \sim \mathrm{NI}(0, \Omega)$

$$
\mathrm{t}=1, \ldots, \mathrm{T}+\mathrm{S}
$$

where $\Omega$ is an $m \times m$ covariance matrix independent of the time period $t$. Thus, the kth drawing of $\mathrm{u}_{\mathrm{T}+\mathrm{s}}\left(\right.$ denoted $\left.\mathrm{u}_{\mathrm{k}, \mathrm{T}+\mathrm{s}}\right)$ is: 


$$
\mathrm{u}_{\mathrm{k}, \mathrm{T}+\mathrm{s}}=\hat{\Lambda} \eta_{\mathrm{k}, \mathrm{s}}
$$

$$
\mathrm{k}=1, \ldots, \mathrm{K} ; \mathrm{s}:=1, \ldots, \mathrm{S}
$$

where $\Lambda$ is the (lower triangular) Cholesky decomposition of $\Omega$ (and so $\Lambda \Lambda^{\prime}=\Omega$ ), $\hat{\Lambda}$ is the (empirical) in-sample estimate of $\Lambda$ from $\hat{\Omega}$ (the in-sample estimate of $\Omega$ ), $\eta_{k, s}$ is an $m \times 1$ vector of drawings from an independent standard normal distribution, and $\mathrm{K}$ is the number of replications (i.e., the number of times that the forecast is simulated). In this paper, $\mathrm{K}=1000$ and the forecast period is $1985 \mathrm{Q} 1$ to $1987 \mathrm{Q} 4(\mathrm{~S}=12)$.

To generate random drawings for all the coefficients in the model, we assume that the asymptotic properties of $\hat{\theta}$ hold in finite samples:

(13) $\hat{\theta} \sim \mathrm{N}(\theta, \Sigma)$

where $\Sigma$ is the $\mathrm{c} \times \mathrm{c}$ asymptotic covariance matrix of $\hat{\theta} .^{15}$ Thus, the kth drawing of $\hat{\theta}$, denoted $\theta_{\mathrm{k}}$, is:

$$
\theta_{\mathrm{k}}=\hat{\theta}+\hat{\Gamma} \zeta_{\mathrm{k}}, \quad \mathrm{k}=1, \ldots, \mathrm{K} ; \mathrm{s}=1, \ldots, \mathrm{S}
$$

where $\Gamma$ is the Cholesky decomposition of $\Sigma$ (and so $\Gamma \Gamma^{\prime}=\Sigma$ ), $\hat{\Gamma}$ is the sample estimate of $\Gamma$ from $\hat{\Sigma}$, and $\zeta_{\mathrm{k}}$ is a $\mathrm{c} \times 1$ vector of drawings from an independent standard normal distribution. ${ }^{16,17,18}$

At the $k$ th replication, $S$ forecasts are solved sequentially via (9) by combining $\theta_{k}$ from (14), $\left\{\mathrm{u}_{\mathrm{k}, \mathrm{T}+\mathrm{s}}, \mathrm{s}=1, \ldots, \mathrm{S}\right\}$ from (12), and the paths of the exogenous variables:

\footnotetext{
${ }^{15}$ Note that the estimation procedure may have implications for the assumed structure of $\Sigma$, c.g., block diagonality equation by equation for OLS and NLS.

${ }^{16}$ As an illustration of the magnitudes involved in (12) and (14), the dimensions of $\Omega$ and $\Sigma$ for model M4 are $21 \times 21$ and $127 \times 127$, respectively.

${ }_{17}^{7} \mathrm{Cl}$. Brown and Mariano (1984) and Fair (1984) on alternative procedures for drawing coefficients and/or residuals.

${ }^{18}$ At first blush, the assumption of normality in (11) and (13) may seem restrictive, and, to a certain extent, it is. However, analyses without forecast standard crrors impose even more restrictive assumptions. E.g., they can be viewed as implicitly assuming normality and in addition setting $\Omega=0$ and $\Sigma=0$. Forecast standard errors from stochastic Monte Carlo simulation typically assume normality as well, with $\Omega$ equal to its estimated value (as above) but $\Sigma=0$. Thus, our procedure is more general than those commonly employed. Also, as the derivations in Schmidt (1974) and Baillie (1979) imply, finite sample deviations of the estimator's distribution from normality do not affect the distribution of the forecasts from linear models, to the order of approximation present (i.c.,
$\mathrm{o}(1 / \mathrm{T})$ ).

Residual-based stochastic simulation sets $\Sigma=0$ and randomizes (permutcs) the estimated in-sample residuals to generate the simulated forecast errors, from which the estimated forecast standard crrors are calculated. Although not quite a special case of our procedure, it omits coefficient uncertainty, and the randomized residuals need not approximate the underlying distribution of the errors any better than normality does. See Brown and Mariano (1989) for a comparative analysis of residual-based, deterministic, and Monte Carlo predictors.
} 
that arising from the estimation of model parameters. In light of (9), those sources are $\left\{\mathrm{u}_{\mathrm{T}+\mathrm{s}}, \mathrm{s}=1, \ldots, \mathrm{S}\right\}$ and the estimated coefficients $\hat{\theta}$, the latter being a function of the in-sample disturbances $\left\{u_{t}, t=1, \ldots, T\right\}$. Standard errors and confidence intervals can be constructed to reflect such uncertainty in forecasts, thereby permitting hypothesis testing. For linear dynamic systems, Schmidt (1974) and Baillie (1979) derive easily calculated analytical formulae which account for both sources of uncertainty; cf. Chong and Hendry (1986) for a summary and Monte Carlo analysis. However, (9) is nonlinear, so those formulae are not directly applicable. Instead, we solve a stochastic analogue to those analytical formulae, simulating by Monte Carlo the effects of inherent and coefficient uncertainty which are analytically derivable for linear models. Section 3.1 describes the design of that stochastic simulation; Section 3.2 analyzes the results.

\subsection{Experimental Design of the Stochastic Simulation}

From (9), the forecast $\hat{y}_{\mathrm{T}+\mathrm{s}}$ (relative to the outcome $\mathrm{y}_{\mathrm{T}+\mathrm{s}}$ ) depends upon the realizations of two random variables, $\hat{\theta}$ and $\left\{\mathrm{u}_{\mathrm{T}+\mathrm{i}}, \mathrm{i}=1, \ldots, \mathrm{S}\right\}$, so $\hat{\mathrm{y}}_{\mathrm{T}+\mathrm{S}}$ is also a random variable. If the distribution of the forecast $\hat{y}_{\mathrm{T}+\mathrm{S}}$ were derived analytically, assumptions would be made about the distributional properties of those disturbances and of the coefficient estimates. Similar assumptions are made when solving for the distributional properties of forecasts by stochastic simulation. Values of $\left\{\hat{\theta} ; \mathrm{u}_{\mathrm{T}+\mathrm{s}}, \mathrm{s}=1, \ldots, \mathrm{S}\right\}$ are randomly drawn according to those distributional assumptions, with each set of values generating a path of $S$ forecasts. From the sample of forecast paths, distributional properties of the forecasts can be estimated, e.g., the sample mean, the standard deviation (which gives the estimated forecast standard error), and the 95 percent confidence interval. The remainder of this sub-section describes the assumptions used, the procedure for generating the sample of forecasts, and some statistics derivable from that sample.

To generate random drawings for the errors $\mathrm{u}_{\mathrm{T}+\mathrm{s}}$, we assume normality and independence for all $u_{t}$ :

(11) $\mathrm{u}_{\mathrm{t}} \sim \mathrm{NI}(0, \Omega)$

$\mathrm{t}=1, \ldots, \mathrm{T}+\mathrm{S}$

where $\Omega$ is an $m \times m$ covariance matrix independent of the time period $t$. Thus, the kth drawing of $\mathrm{u}_{\mathrm{T}+\mathrm{s}}\left(\right.$ denoted $\left.\mathrm{u}_{\mathrm{k}, \mathrm{T}+\mathrm{s}}\right)$ is: 


$$
\mathrm{u}_{\mathrm{k}, \mathrm{T}+\mathrm{s}}=\hat{\Lambda} \eta_{\mathrm{k}, \mathrm{s}}
$$

$$
\mathrm{k}=1, \ldots, \mathrm{K} ; \mathrm{s}=1, \ldots, \mathrm{S}
$$

where $\Lambda$ is the (lower triangular) Cholesky decomposition of $\Omega$ (and so $\Lambda \Lambda^{\prime}=\Omega$ ), $\hat{\Lambda}$ is the (empirical) in-sample estimate of $\Lambda$ from $\hat{\Omega}$ (the in-sample estimate of $\Omega$ ), $\eta_{\mathrm{k}, \mathrm{s}}$ is an $\mathrm{m} \times 1$ vector of drawings from an independent standard normal distribution, and $\mathrm{K}$ is the number of replications (i.e., the number of times that the forecast is simulated). In this paper, $\mathrm{K}=1000$ and the forecast period is $1985 \mathrm{Q} 1$ to $1987 \mathrm{Q} 4(\mathrm{~S}=12)$.

To generate random drawings for all the coefficients in the model, we assume that the asymptotic properties of $\hat{\theta}$ hold in finite samples:

(13) $\hat{\theta} \sim \mathrm{N}(\theta, \Sigma)$,

where $\Sigma$ is the $c \times c$ asymptotic covariance matrix of $\hat{\theta}^{15}$ Thus, the kth drawing of $\hat{\theta}$, denoted $\theta_{k}$, is:

$$
\theta_{\mathrm{k}}=\hat{\theta}+\hat{\Gamma} \zeta_{\mathrm{k}}, \quad \mathrm{k}=1, \ldots, \mathrm{K} ; \mathrm{s}=1, \ldots, \mathrm{S},
$$

where $\Gamma$ is the Cholesky decomposition of $\Sigma\left(\right.$ and so $\left.\Gamma \Gamma^{\prime}=\Sigma\right), \hat{\Gamma}$ is the sample estimate of $\Gamma$ from $\hat{\Sigma}$, and $\zeta_{\mathrm{k}}$ is a $\mathrm{c} \times 1$ vector of drawings from an independent standard normal distribution. ${ }^{16,17,18}$

At the $k$ th replication, $S$ forecasts are solved sequentially via (9) by combining $\theta_{k}$ from (14), $\left\{\mathrm{u}_{\mathrm{k}, \mathrm{T}+\mathrm{s}}, \mathrm{s}=1, \ldots, \mathrm{S}\right\}$ from (12), and the paths of the exogenous variables:

\footnotetext{
${ }^{15}$ Note that the estimation procedure may have implications for the assumed structure of $\Sigma$, c.g., block diagonality equation by equation for OLS and NLS.

${ }^{16}$ As an illustration of the magnitudes involved in (12) and (14), the dimensions of $\Omega$ and $\Sigma$ for model M4 are $21 \times 21$ and $127 \times 127$, respectively.

${ }^{17}$ Cf. Brown and Mariano (1984) and Fair (1984) on alternative procedures for drawing coefficients and/or residuals.

${ }^{18}$ At first blush, the assumption of normality in (11) and (13) may seem restrictive, and, to a certain extent, it is. However, analyses without forecast standard crrors impose even more restrictive assumptions. E.g., they can be viewed as implicitly assuming normality and in addition setting $\Omega=0$ and $\Sigma=0$. Forecast standard crrors from stochastic Monte Carlo simulation typically assume normality as well, with $\Omega$ equal to its estimated value (as above) but $\Sigma=0$. Thus, our procedure is more general than those commonly employed. Also, as the derivations in Schmidt (1974) and Baillic (1979) imply, finite sample deviations of the estimator's distribution from normality do not affect the distribution of the forecasts from linear models, to the order of approximation present (i.e., $\mathrm{o}(1 / \mathrm{T}))$.

Residual-based stochastic simulation sets $\Sigma=0$ and randomizes (permutes) the estimated in-sample residuals to generate the simulated forecast errors, from which the estimated forecast standard errors are calculated. Although not quite a special case of our procedure, it omits coefficient uncertainty, and the randomized residuals need not approximate the underlying distribution of the errors any better than normality does. See Brown and Mariano (1989) for a comparative analysis of residual-based, deterministic, and Monte Carlo predictors.
} 
(15)

$$
\begin{array}{rlr}
\mathrm{y}_{\mathrm{k}, \mathrm{T}+\mathrm{s}} & =g\left(\mathrm{y}_{\mathrm{k}, \mathrm{T}+\mathrm{s}-1}, \mathrm{z}_{\mathrm{T}+\mathrm{s}}, \hat{\theta}_{\mathrm{k}}, \mathrm{u}_{\mathrm{k}, \mathrm{T}+\mathrm{s}}\right) \\
& =g\left(\mathrm{y}_{\mathrm{k}, \mathrm{T}+\mathrm{s}-1}, \mathrm{z}_{\mathrm{T}+\mathrm{s}}, \hat{\theta}+\hat{\Gamma} \zeta_{\mathrm{k}}, \hat{\Lambda} \eta_{\mathrm{k}, \mathrm{s}}\right), & \mathrm{s}=1, \ldots, \mathrm{S},
\end{array}
$$

with the initial condition that $\mathrm{y}_{\mathrm{k}, \mathrm{T}} \equiv \mathrm{y}_{\mathrm{T}}$. One element of (15) is the (kth) simulated trade-account forecast $\mathrm{NX}_{\mathrm{k}, \mathrm{T}+\mathrm{s}}$.

The full stochastic simulation produces a random sample of $\mathrm{K}$ trade-account forecasts, from which the mean forecast $\left(\mu_{\mathrm{T}+\mathrm{s}}\right)$, mean forecast error $\left(v_{\mathrm{T}+\mathrm{s}}\right)$, and standard deviation of the simulated forecasts $\left(\sigma_{\mathrm{T}+\mathrm{s}}\right)$ are estimated by:

$$
\tilde{\mu}_{\mathrm{T}+\mathrm{s}}=\sum_{\mathrm{k}} \mathrm{NX} \mathrm{k}, \mathrm{T}+\mathrm{s}_{\mathrm{K}}
$$$$
\tilde{v}_{\mathrm{T}+\mathrm{s}}=\mathrm{NX}_{\mathrm{T}+\mathrm{s}}-\tilde{\mu}_{\mathrm{T}+\mathrm{s}}
$$

(18) $\tilde{\sigma}_{\mathrm{T}+\mathrm{s}}=\left[\Sigma_{\mathrm{k}}\left(\mathrm{NX} \mathrm{k}, \mathrm{T}+\mathrm{s}-\tilde{\mu}_{\mathrm{T}+\mathrm{s}}\right)^{2} / \mathrm{K}\right]^{1 / 2}$, $\mathrm{S}=1, \ldots, \mathrm{S}$,

where $\mathrm{NX}_{\mathrm{T}+\mathrm{S}}$ is the recorded value of the trade account, and these Monte Carlo estimators are denoted by a tilde superscript $\sim$ in order to distinguish them from empirical estimators such as $\hat{\theta} .{ }^{19}$ Thus, $\tilde{\sigma}_{\mathrm{T}+\mathrm{s}}^{2}$ is the estimated variance for a single s-period ahead forecast. Unlike the deterministic forecasts from (10), equations (16)-(18) recognize that both coefficient estimates and innovations are random variables that could take values other than their (estimated) means. That randomness affects the forecast's distribution and is the basis for statistical inferences about the forecasts. ${ }^{20}$ In fact, $\tilde{\sigma}_{\mathrm{T}+\mathrm{s}}^{2}$ (and its generalization $\widetilde{\boldsymbol{\Phi}}$ below) can be calculated accounting for the uncertainty either from future shocks and coefficient estimation or from future shocks alone. Parallelling analytical formulae for linear models, the two possible calculations are referred to as the "approximate" and "asymptotic" formulae respectively. The latter is asymptotic because it ignores uncertainty from estimation, which affects the variance $\sigma_{\mathrm{T}+\mathrm{s}}^{2}$ in finite (estimation) samples only. The former is

\footnotetext{
${ }^{19}$ To obtain an unbiased estimator of $\sigma^{2}$, the summation in (18) should be divided by K-1 rather than K. We use K instead because the numerical differences are negligible for large $\mathrm{K}$ (and our choice of $\mathrm{K}=1000 \mathrm{secms}$ large) and it is consistent with the matrix generalization, $\Phi$, below.

${ }^{20}$ Using stochastic simulation to estimate $\mu$ (rather than calculating it analytically) introduces a third source of uncertainty when forecasting from nonlinear models. Although estimates of the uncertainty contributed by simulation are feasible, we ignore this complication, assuming that $\mathrm{K}$ is large enough so that simulation uncertainty is negligible relative to inherent and coefficient uncertainty.
} 
"approximate" because the assumption of $\hat{\theta}$ being exactly normal need not hold, even if the $\left\{u_{t}\right\}$ are normal; but this approximation affects $\sigma_{\mathrm{T}+\mathrm{S}}^{2}$ to only order $\mathrm{o}(1 / \mathrm{T})$.

The matrix generalization of $\tilde{\sigma}_{\mathrm{T}+\mathrm{s}}^{2}$ follows immediately. Define $\phi_{\mathrm{k}}$ as the vector of deviations between the kth stochastic simulation of the $\mathrm{S}$ forecasts and the estimated mean forecasts, i.e.:

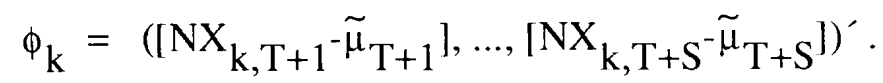

The standard Monte Carlo estimator for the variance of the vector of forecasts $\left(\tilde{\mu}_{\mathrm{T}+1}, \ldots, \tilde{\mu}_{\mathrm{T}+\mathrm{S}}\right)^{\prime}$ is:

$$
\widetilde{\Phi}=\sum_{\mathrm{k}} \phi_{\mathrm{k}} \phi_{\mathrm{k}}^{\prime} / \mathrm{K}
$$

Just as $\tilde{\sigma}_{\mathrm{T}+\mathrm{s}}^{2}$ provides a measure of the forecast uncertainty for the single forecast $\tilde{\mu}_{\Gamma+\mathrm{s}}$, so does $\widetilde{\Phi}$ for the vector of forecasts. Having constructed these measures of forecast uncertainty, forecastbased test statistics can be formulated.

A natural hypothesis to test is that the outcomes of the trade balance in the forecast period come from the same distribution as that assumed to generate the in-sample values, i.e., the distribution implied by the function $g(\cdot)$ in (9). One approach to testing this hypothesis is to compare the forecast errors with their variance-covariance matrix derived from $g(\cdot)$ and see whether the errors are substantially larger than anticipated. For a forecast at $\mathrm{T}+\mathrm{s}$, the corresponding test statistic is the forecast error t-ratio, i.e., the mean forecast error $\tilde{v}_{r} \Gamma+s$ divided by its estimated standard error $\tilde{\sigma}_{\mathrm{T}+\mathrm{s}}$. This statistic is approximately standard normal under the null hypothesis; its square is approximately $\chi^{2}(1)$. For the static linear model, this statistic simplifies to one based upon the one-step prediction interval; cf. Chow (1960, p. 593).

For the entire set of forecasts, the $\mathrm{S}$ forecast errors are compared with their measure of uncertainty. Denote the vector of mean forecast errors by:

$$
\text { (21) } \begin{aligned}
\tilde{v} & =\left(\tilde{v}_{\mathrm{T}+1}, \ldots, \tilde{v}_{\mathrm{T}+\mathrm{S}}\right)^{\prime} \\
& =\left(\left[\mathrm{NX}_{\mathrm{T}+1}-\tilde{\mu}_{\mathrm{T}+1}\right], \ldots,\left[\mathrm{NX} \mathrm{T}+\mathrm{S}^{\left.\left.-\tilde{\mu}_{\mathrm{T}+\mathrm{S}}\right]\right)^{\prime} .}\right.\right.
\end{aligned}
$$

Then the test statistic is:

(22) $\tau=\tilde{v}^{\prime}[\widetilde{\Phi}]^{-1} \tilde{v}$ 
Under the null hypothesis that the model is correctly specified over both the estimation and forecast samples, $\tau$ is approximately distributed as $\chi^{2}(S) .^{21}$ Large values of $\tau$ indicate misspecification of the model, such as from omitted variables bias with that bias varying as the correlation between included and omitted variables changes. While the power of $\tau$ is often high against such parameter non-constancy, $\tau$ may have little or no power against other forms of misspecification, e.g., the previous example but with no change in the inter-variable correlation. For linear models, the distribution of $\tau$ is invariant (approximately invariant) to the use of one-step or s-step ahead forecasts with the asymptotic formula (approximate formula); cf. Pagan (1989). The statistic $\tau$ is not invariant to the type of forecast from nonlinear models.

By allowing model nonlinearity, the statistic $\tau$ generalizes Chong and Hendry's (1986, p. 682, equation (31)) $\chi^{2}$ statistic for detecting predictive failure. ${ }^{2}$ However, in contrast to the linear framework, analytical solutions for the forecasts and their variance-covariance matrix $\Phi$ are not usually available, so both are estimated by stochastic simulation.

While $\tau$ may be a reasonable test statistic for detecting a wide class of deviations in forecast properties from those anticipated, more powerful tests exist for specific forms of deviation. For instance, forecast errors can be systematically off, so it may be of interest to test whether or not forecast errors have a fixed bias. One test statistic for this is:

(23) $\tau^{*}=(\sqrt{ } S) \cdot\left(\tilde{v}^{-}\left[\tilde{\Phi}^{-1 / 2}\right] \imath / S\right)$

where $\mathrm{l}$ is an $\mathrm{S} \times 1$ vector of ones. This statistic transforms the forecast errors into errors which (under the null hypothesis of correct model specification) are standardized and uncorrelated, averages those transformed errors, and rescales the average by $\sqrt{ } \mathrm{S}$. (By contrast, $\tau$ is the sum of squares of the transformed errors.) $\tau *$ is approximately distributed as Student's t-statistic $t(\mathrm{~S}-1)$ under the null of zero mean in the forecast error, and is designed to have power against the

\footnotetext{
${ }^{21}$ Note that the mean forecast errors $\widetilde{v}$ are the discrepancies between outcomes and the mean forccasts, whereas the elements of $\phi_{\mathrm{k}}$ are the discrepancies between the $\mathrm{kth}$ set of simulated forecasts and the mean forecasts, so being typical hypothesized forecast errors under the null of correct specification. The $\widetilde{v}$ indicate the actual forecast performance of the model, whercas the $\phi_{\mathbf{k}}$ (via $\widetilde{\Phi}$ ) are the basis for estimating how well the model ought to have
forecast if the model were well-specified.

22 Chong and Hendry's $\chi^{2}$ statistic in turn generalizes Hendry's (1979) $\chi^{2}$ statistic in two directions. The former accounts for coefficient uncertainty, making it similar to Chow's (1960, pp. 594-595) statistic; and it is applicable to s-step as well as one-step ahead forccasts.
} 
alternative of a non-zero mean, constant across forecasts. For linear models, Chow (1960, p. 594, equation (11)) and Hendry (1989, pp. 49-50) give equivalent analytical solutions for $\tau *$ including coefficient uncertainty. The invariance results for $\tau$ also apply to $\tau *$.

Criteria such as MAE and RMSFE often are used to measure the performance of alternative macroeconomic models. The usefulness of these statistics is questionable for dynamic and/or nonlinear models; and, even for static linear ones, their purposes contrast with those of $\tau$ and $\tau^{*}$. The issues are three-fold. First, in order to justify averaging a function of forecast errors over different forecast periods, these criteria assume that the moments of the forecast errors are constant across periods, but they are unlikely to be so in dynamic and/or nonlinear models. In general, the forecast error variance for a dynamic and/or nonlinear model depends upon the forecast period, i.e., the diagonal elements of $\Phi$ are not identical (nor need $\Phi$ be diagonal). That invalidates model comparison with such statistics. Thus, although MAE and RMSFE are reported below, little importance should be assigned to their values. (Note that the constant-variance assumption is made whether the forecasts are deterministic or stochastic.) Second, as Hendry and Richard (1982, pp. 26-31) and Fair (1984, pp. 264-265; 1986) note, such measures do not account for differences in conditioning sets across models, so models with greater reliance on exogenous variables may have an "unfair" advantage in ex post forecasting. To wit, Hendry and Richard show analytically that a misspecified model with invalidly assumed exogenous variables can have a smaller RMSFE (or MAE) than the correctly specified model. Third, a model which does well (or poorly) in terms of its MAE or RMSFE may still have its forecasts falling outside (or within) a suitable measure of forecast uncertainty. Such "conflicting" results may arise even when forecast variances are constant and the sample size is large (e.g., for static linear models with no coefficient uncertainty). The cause is that the two classes of statistics are being used to evaluate the models against different information sets: for $\tau$ and $\tau^{*}$, different subsamples within a given dataset, and, for MAE and RMSFE, different datasets over a given subsample. Cf. Ericsson (1989) for details. 


\subsection{Empirical Forecast Performance}

With the theoretical properties of the forecasts characterized and forecast-based test statistics formulated, the empirical forecasts generated by stochastic simulation may be interpreted. Table 5 lists the mean forecast error $\widetilde{v}_{\mathrm{T}+\mathrm{s}}$, its estimated (approximate) standard error $\tilde{\sigma}_{\mathrm{T}+\mathrm{s}}$, and their ratio across models and forecast periods for one-step ahead forecasts. Values of the MAE, RMSFE, and the test statistics $\tau$ and $\tau^{*}$ are also given for each model. Figure 2 presents the mean forecast $\tilde{\mu}_{\mathrm{T}+\mathrm{s}}$, an approximate $95 \%$ confidence interval given by $\tilde{\mu}_{\mathrm{T}+\mathrm{s}} \pm 2 \tilde{\sigma}_{\mathrm{T}+\mathrm{s}}$, and the realized trade balance $\mathrm{NX} \mathrm{X}_{\mathrm{T}+\mathrm{s}}$, one graph per set of one-step ahead forecasts for a given model. Table 6 and Figure 3 contain the corresponding information for s-step ahead forecasts. From these summaries of the stochastic simulation, we analyze the models' ex post forecast performarce, focusing on systematic biases in the forecasts, the economic and statistical magnitudes of forecast errors, the size of the forecast standard error, and statistical measures of forecast accuracy.

The one-step ahead forecast errors for models M1-M3 and M5 are systematic and highly autocorrelated, tending to be positive and decreasing over the first four or so periods and negative and increasing in magnitude over the remainder. Forecasts from $\mathrm{M} 4$ reflect this pattern, but with opposite sign. Model M6 has relatively small, unsystematic forecast errors. The s-step ahead forecast errors are (approximately) weighted cumulants of the one-step ahead forecast errors, with the patterns for M1-M5 being approximately the same or accentuated. The forecast errors for M6 are systematic and positive, although small relative to the confidence intervals.

Numerically, the forecast errors are often large relative to the size of the trade account. For example, model M1 underpredicts the trade deficit twelve periods ahead by $\$ 63$ billion in 1987Q4, i.e., by approximately one-third of the trade account. One explanation of such large errors lies in what is being forecast, namely, the difference of two large quantities, similar in magnitude, which themselves must be forecast." Even if imports and exports are determined independently and the forecast errors for imports and exports are small relative to their actual values, the forecast errors for their difference may well be of the same order as the difference 
Table 5

Forecast Performance: The U.S. Trade Account

One-step Ahead, Approximate Formula

\begin{tabular}{|c|c|c|c|c|c|c|c|c|c|c|c|c|c|c|c|c|}
\hline & \multicolumn{12}{|c|}{ Forecast Period } & \multicolumn{4}{|c|}{$\begin{array}{l}\text { Summary Measures of } \\
\text { Forecast Performance }\end{array}$} \\
\hline & \multicolumn{4}{|c|}{1985} & \multicolumn{4}{|c|}{1986} & \multicolumn{4}{|c|}{1987} & \multirow[b]{2}{*}{ MAE } & \multirow[b]{2}{*}{ RMSFE } & \multirow[b]{2}{*}{$\tau$} & \multirow[b]{2}{*}{$\tau^{*}$} \\
\hline & Q1 & Q2 & Q3 & Q4 & Q1 & Q2 & Q3 & Q4 & Q1 & Q2 & Q3 & Q4 & & & & \\
\hline \multicolumn{17}{|c|}{$\begin{array}{l}\text { Historical Trade Account } \\
\text { (billion LSS) }\end{array}$} \\
\hline & -99.5 & -119.8 & -124.8 & -144.5 & -141.7 & -135.4 & -146.9 & -154.1 & -159.5 & -158.2 & -158.7 & -164.8 & & & & \\
\hline \multicolumn{17}{|c|}{$\begin{array}{l}\text { Mean Forecast Error } \\
\text { (billion US\$) }\end{array}$} \\
\hline Model M1 & 21.4 & -4.1 & -0.3 & -3.0 & 2.4 & -9.2 & -25.0 & -25.9 & -19.7 & -25.4 & -17.9 & -27.1 & 15.1 & 18.2 & 10.7 & -1.6 \\
\hline Model M2 & 22.7 & -0.7 & 2.6 & 0.1 & 2.4 & -9.3 & -27.1 & -26.7 & -18.7 & -23.7 & -12.2 & -20.0 & 13.8 & 17.1 & 15.5 & -1.8 \\
\hline Model M3 & 23.4 & -1.5 & 6.2 & 2.9 & -0.1 & -13.6 & -23.8 & -17.8 & -12.9 & -12.0 & 5.5 & -5.0 & 10.4 & 13.0 & 10.7 & -0.9 \\
\hline Model M4 & -15.8 & -33.0 & -3.2 & 0.1 & 20.0 & 23.2 & 24.6 & -3.2 & 25.5 & 11.4 & 11.3 & 9.8 & 15.1 & 18.0 & 9.1 & 0.8 \\
\hline Model M5 & 23.6 & -17.6 & 1.8 & .30 .2 & -2.7 & -11.9 & -32.9 & -24.2 & -20.5 & -14.8 & -31.9 & -49.0 & 21.8 & 25.3 & 17.2 & -2.1 \\
\hline Model M6 & 23.0 & -15.3 & 0.9 & -12.9 & 10.1 & 13.0 & -4.4 & -0.1 & 2.5 & 8.9 & 7.5 & 1.7 & 8.4 & 10.7 & 19.7 & 0.3 \\
\hline \multicolumn{17}{|c|}{$\begin{array}{l}\text { Estimated Standard Error of the Mean Forecast Error } \\
\text { (billion LS\$) }\end{array}$} \\
\hline Model M1 & 13.2 & 13.0 & 13.7 & 14.3 & 14.5 & 14.3 & 15.2 & 16.1 & 17.3 & 18.8 & 20.1 & 21.5 & & & & \\
\hline Model M2 & 12.9 & 13.0 & 12.8 & 14.0 & 14.4 & 13.4 & 13.7 & 14.4 & 15.7 & 17.0 & 19.1 & 21.5 & & & & \\
\hline Model M3 & 14.0 & 13.5 & 13.5 & 13.8 & 14.1 & 13.7 & 14.4 & 14.5 & 15.6 & 16.1 & 17.2 & 17.8 & & & & \\
\hline Model M4 & 18.3 & 19.1 & 20.1 & 22.2 & 23.3 & 21.8 & 22.7 & 22.0 & 26.4 & 27.4 & 28.8 & 30.8 & & & & \\
\hline Model M5 & 14.8 & 14.8 & 15.2 & 15.0 & 16.7 & 16.1 & 16.0 & 19.3 & 21.3 & 20.7 & 21.4 & 22.4 & & & & \\
\hline Model M6 & 8.9 & 8.6 & 8.3 & 8.6 & 9.3 & 9.1 & 8.9 & 9.1 & 8.7 & 9.1 & 9.3 & 9.1 & & & & \\
\hline \multicolumn{17}{|c|}{ Forecast Error "t" ratio } \\
\hline Model M1 & 1.6 & -0.3 & -0.0 & -0.2 & 0.2 & -0.6 & -1.6 & -1.6 & -1.1 & -1.4 & -0.9 & -1.3 & & & & \\
\hline Model M2 & 1.8 & -0.1 & 0.2 & 0.0 & 0.2 & -0.7 & -2.0 & -1.9 & -1.2 & -1.4 & -0.6 & -0.9 & & & & \\
\hline Model M3 & 1.7 & -0.1 & 0.5 & 0.2 & -0.0 & -1.0 & -1.7 & -1.2 & -0.8 & -0.7 & 0.3 & -0.3 & & & & \\
\hline Model M4 & -0.9 & -1.7 & -0.2 & 0.0 & 0.9 & 1.1 & 1.1 & -0.1 & 1.0 & 0.4 & 0.4 & 0.3 & & & & \\
\hline Model M5 & 1.6 & -1.2 & 0.1 & -2.0 & -0.2 & -0.7 & -2.1 & -1.3 & -1.0 & -0.7 & -1.5 & -2.2 & & & & \\
\hline Model M6 & 2.6 & -1.8 & 0.1 & -1.5 & 1.1 & 1.4 & -0.5 & -0.0 & 0.3 & 1.0 & 0.8 & 0.2 & & & & \\
\hline
\end{tabular}

Notes: $\quad$ Model M1: Helkie and Hooper (1988).

Model M2: Model M1 by FIML.

Model M3: Model M1 by FIML, with partial adjustment, without non-price rationing.

Model M4: Bilateral trade model by FLML.

Model M5: VAR(4) of import and expor volumes and price indices.

Model M6: AR(1) of the nominal trade account.

MAE: $\quad$ Mean absolute error.

RMSFE: Root mean-square forecast error.

$\tau$ : $\quad$ The $\chi^{2}(12)$ statistic testing against predictive failure. Its $5 \%$ and $10 \%$ levels are 21.0 and 18.5 .

$\tau^{*}$ : The $t$-statistic testing against non-zero mean forecast error. 
Table 6

Forecast Performance: The U.S. Trade Account s-step Ahead, Approximate Formula

\begin{tabular}{|c|c|c|c|c|c|c|c|c|c|c|c|c|c|c|c|c|}
\hline & \multicolumn{12}{|c|}{ Forecast Period } & \multicolumn{4}{|c|}{$\begin{array}{l}\text { Summary Measures of } \\
\text { Forecast Performance }\end{array}$} \\
\hline & \multicolumn{4}{|c|}{1985} & \multicolumn{4}{|c|}{1986} & \multicolumn{4}{|c|}{1987} & \multirow[b]{2}{*}{ MAE } & \multirow[b]{2}{*}{ RMSFE } & \multirow[b]{2}{*}{$\tau$} & \multirow[b]{2}{*}{$\tau^{*}$} \\
\hline & Q1 & Q2 & Q3 & Q4 & Q1 & Q2 & Q3 & Q4 & Q1 & Q2 & Q3 & Q4 & & & & \\
\hline \multicolumn{17}{|c|}{$\begin{array}{l}\text { Historical Trade Account } \\
\text { (billion US\$) }\end{array}$} \\
\hline & -99.5 & -119.8 & -124.8 & -144.5 & -141.7 & -135.4 & -146.9 & -154.1 & -159.5 & -158.2 & -158.7 & -164.8 & & & & \\
\hline \multicolumn{17}{|c|}{$\begin{array}{l}\text { Mean Forecast Error } \\
\text { (billion USS) }\end{array}$} \\
\hline Model M1 & 21.4 & 6.5 & 5.6 & 2.7 & 5.8 & -4.6 & -22.8 & -36.0 & -40.0 & -50.3 & -50.5 & -63.1 & 25.8 & 33.0 & 11.0 & -1.7 \\
\hline Model M2 & 22.7 & 11.5 & 11.9 & 9.7 & 8.3 & -4.8 & -25.2 & -38.3 & -40.6 & -48.1 & -43.6 & -53.5 & 26.5 & 31.4 & 13.8 & -1.8 \\
\hline Model M3 & 23.4 & 13.7 & 14.1 & 10.9 & 5.8 & -13.8 & -32.8 & -40.7 & -40.4 & -42.9 & -31.0 & -36.3 & 25.5 & 28.5 & 11.4 & -1.4 \\
\hline Model M4 & -15.8 & -36.6 & -15.9 & -5.1 & 7.8 & 29.6 & 27.5 & -0.1 & 13.0 & -4.9 & -7.4 & -10.4 & 14.5 & 18.1 & 7.7 & -0.2 \\
\hline Model M5 & 23.6 & 6.8 & 0.5 & -25.6 & -32.2 & -36.5 & -56.9 & -73.4 & -85.2 & -87.7 & -87.6 & -90.3 & 50.5 & 59.9 & 7.9 & -1.0 \\
\hline Model M6 & 23.0 & 8.8 & 10.3 & -1.7 & 8.8 & 23.0 & 20.5 & 22.4 & 27.2 & 38.9 & 50.0 & 56.0 & 24.2 & 29.1 & 20.1 & 0.6 \\
\hline \multicolumn{17}{|c|}{$\begin{array}{l}\text { Estimated Standard Error of the Mean Forecast Error } \\
\text { (billion LSS) }\end{array}$} \\
\hline Model M1 & 13.2 & 15.7 & 17.3 & 19.2 & 19.7 & 19.5 & 20.7 & 22.7 & 25.6 & 28.5 & 31.1 & 33.9 & & & & \\
\hline Model M2 & 12.9 & 15.2 & 15.9 & 18.0 & 19.2 & 18.4 & 19.3 & 20.8 & 23.7 & 26.3 & 29.7 & 33.6 & & & & \\
\hline Model M3 & 14.0 & 16.9 & 18.6 & 20.8 & 21.4 & 20.7 & 21.8 & 22.7 & 26.0 & 26.8 & 28.9 & 30.3 & & & & \\
\hline Model M4 & 18.3 & 19.8 & 21.2 & 24.1 & 25.4 & 26.0 & 26.9 & 27.1 & 30.4 & 33.3 & 34.4 & 36.0 & & & & \\
\hline Model M5 & 14.8 & 23.8 & 28.9 & 33.6 & 40.4 & 50.2 & 58.6 & 67.0 & 72.4 & 77.5 & 82.9 & 88.4 & & & & \\
\hline Model M6 & 8.9 & 14.1 & 18.5 & 23.2 & 29.0 & 35.4 & 41.9 & 49.1 & 56.8 & 65.9 & 75.8 & 86.7 & & & & \\
\hline \multicolumn{17}{|c|}{ Forecast Error ' $t$ " ratio } \\
\hline Model M1 & 1.6 & 0.4 & 0.3 & 0.1 & 0.3 & -0.2 & -1.1 & -1.6 & -1.6 & -1.8 & -1.6 & -1.9 & & & & \\
\hline Model M2 & 1.8 & 0.8 & 0.7 & 0.5 & 0.4 & -0.3 & -1.3 & -1.8 & -1.7 & -1.8 & -1.5 & -1.6 & & & & \\
\hline Model M3 & 1.7 & 0.8 & 0.8 & 0.5 & 0.3 & -0.7 & -1.5 & -1.8 & -1.6 & -1.6 & -1.1 & -1.2 & & & & \\
\hline Model M4 & -0.9 & -1.8 & -0.7 & -0.2 & 0.3 & 1.1 & 1.0 & -0.0 & 0.4 & -0.1 & -0.2 & -0.3 & & & & \\
\hline Model M5 & 1.6 & 0.3 & -0.0 & -0.8 & -0.8 & -0.7 & -1.0 & -1.1 & -1.2 & -1.1 & -1.1 & -1.0 & & & & \\
\hline Model M6 & 2.6 & 0.6 & 0.6 & -0.1 & 0.3 & 0.6 & 0.5 & 0.5 & 0.5 & 0.6 & 0.7 & 0.6 & & & & \\
\hline
\end{tabular}

Notes: $\quad$ Model M1: Helkie and Hooper (1988).

Model M2: Model M1 by FIML.

Model M3: Model M1 by FIML, with partial adjustment, without non-price rationing.

Model M4: Bilateral trade model by FLML.

Model M5: VAR(4) of impor and expon volumes and price indices.

Model M6: AR(1) of the nominal trade account.

MAE: Mean absolute error.

RMSFE: Root mean-square forecast error.

$\tau: \quad$ The $\chi^{2}(12)$ statistic testing against predictive failure. Its $5 \%$ and $10 \%$ levels are 21.0 and 18.5 .

$\tau^{*}$ : The $t$-statistic testing against non-zero mean forecast error. 
Figure 2: $95 \%$ Confidence Intervals For Trade-account Forecasts

One-step ahead, Approximate formula

Figure 2a

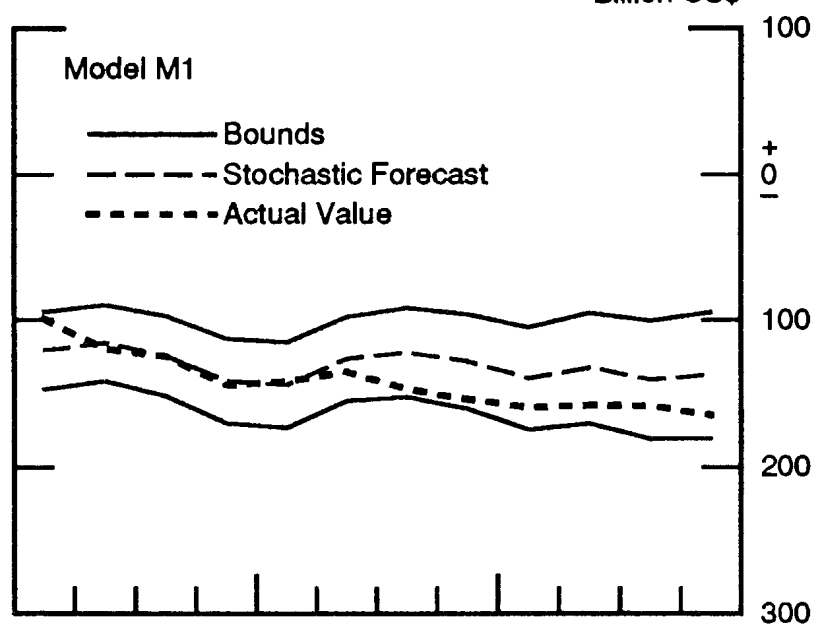

Figure 2c

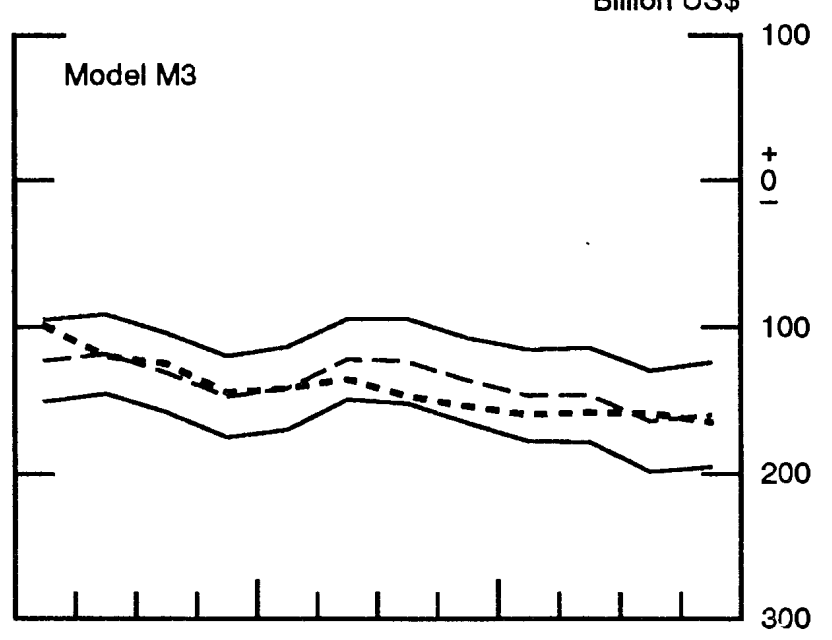

Figure $2 e$

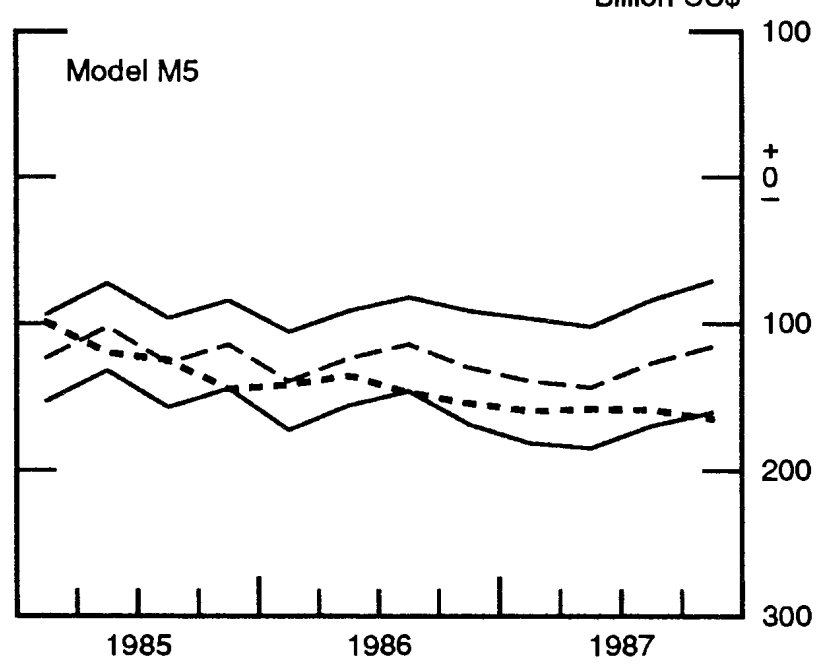

Figure $2 b$

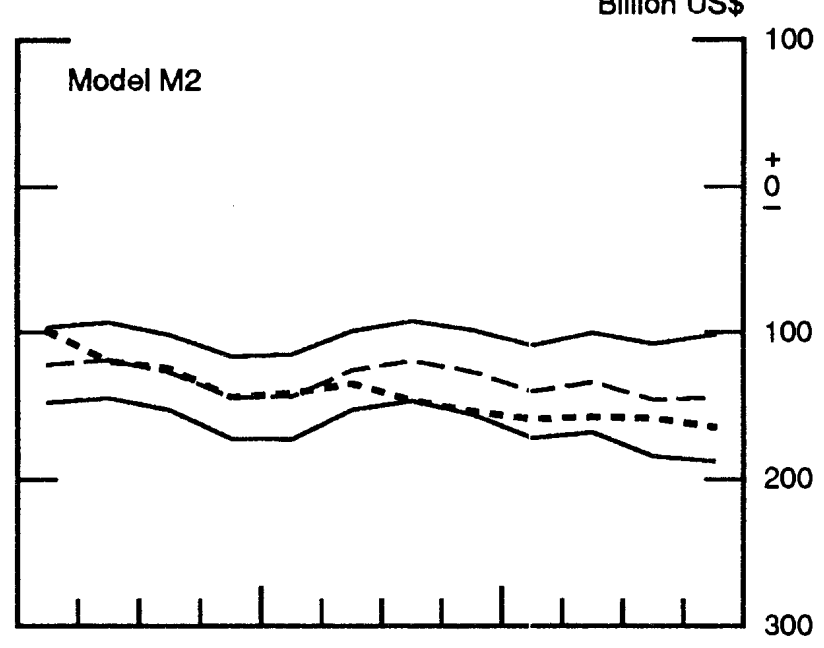

Figure 2d

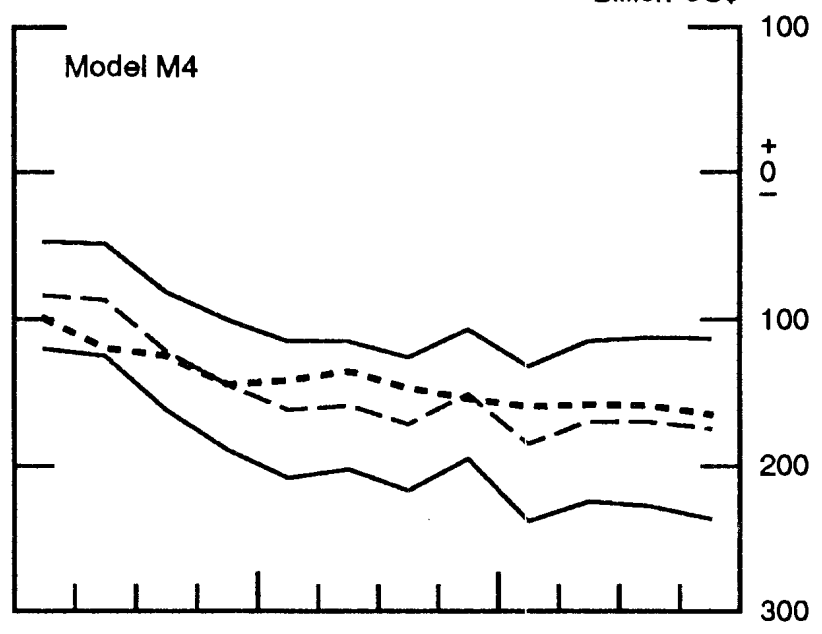

Figure $2 f$

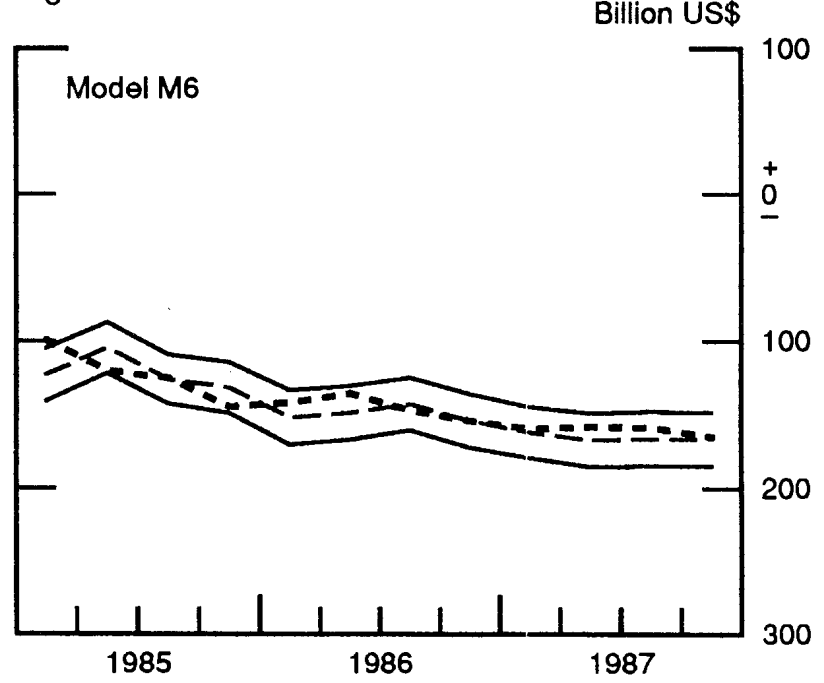


Figure 3: $95 \%$ Confidence Intervals For Trade-account Forecasts

s-step ahead, Approximate formula

Figure 3a

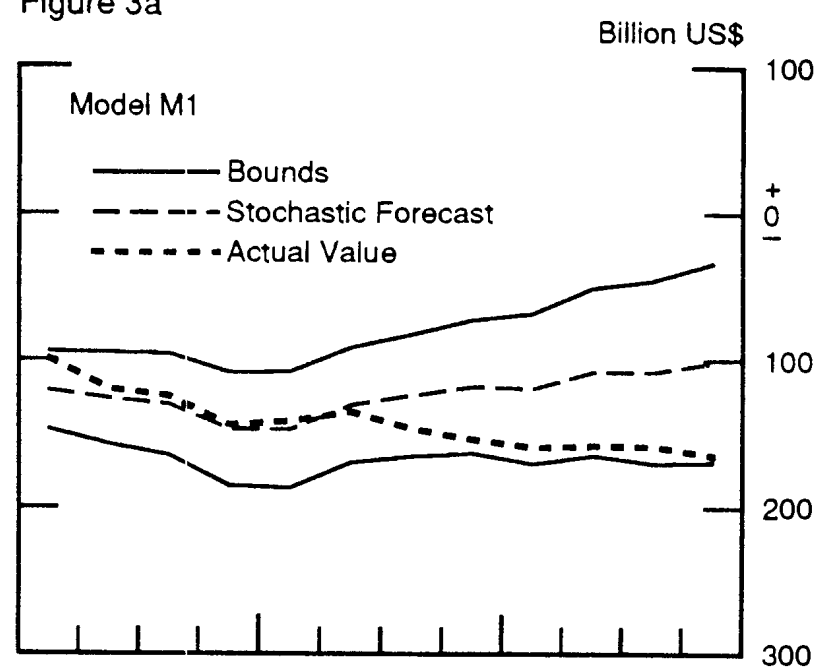

Figure 3c

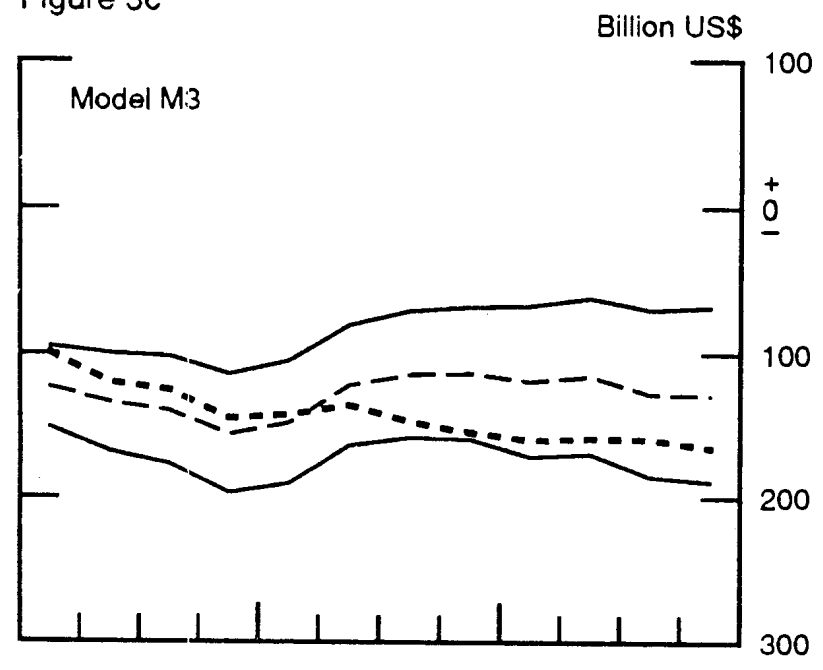

Figure $3 e$

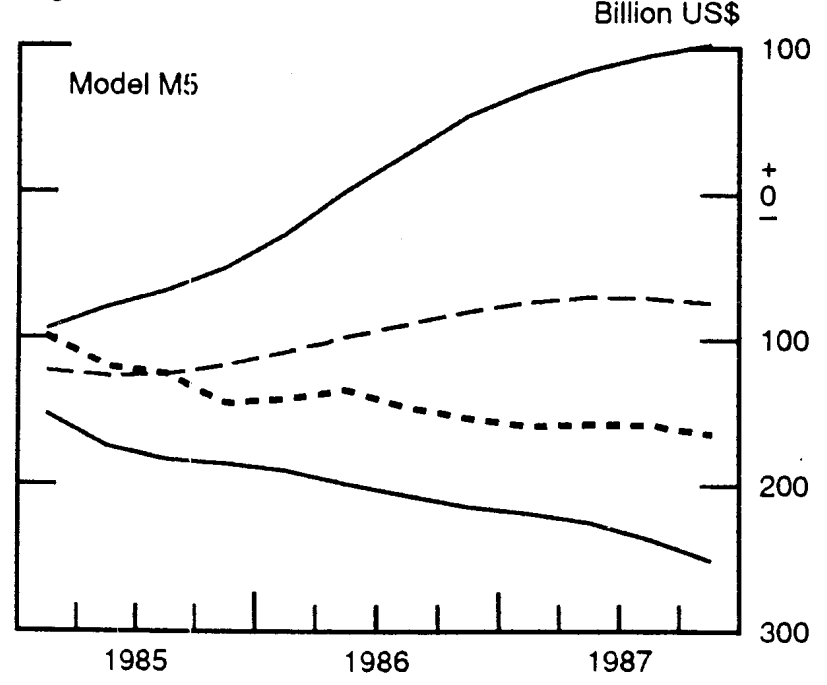

Figure 3b

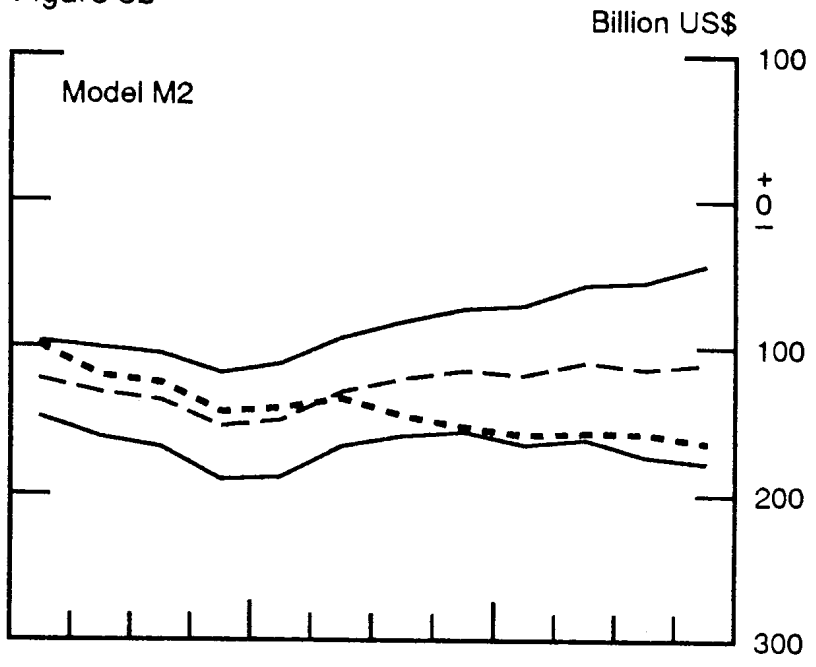

Figure 3d

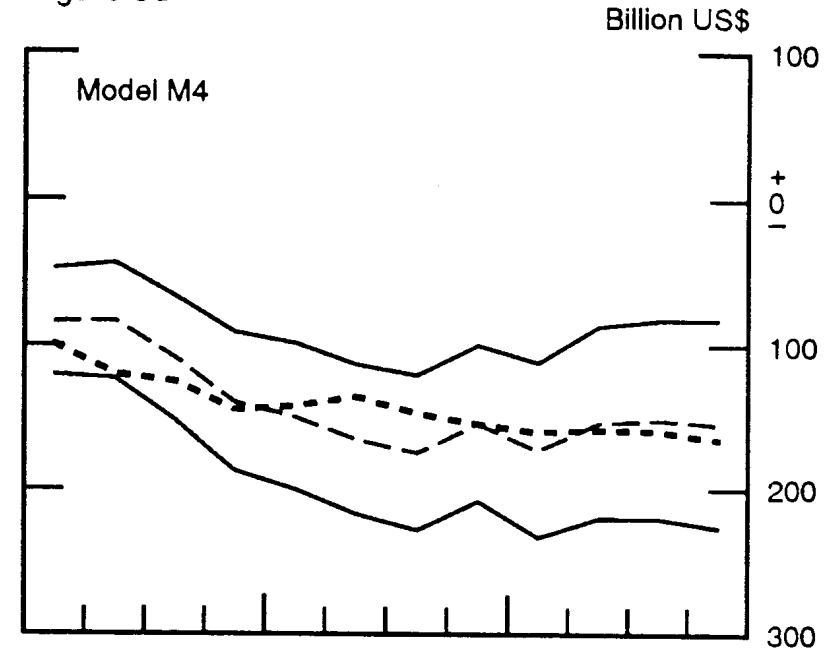

Figure $3 f$

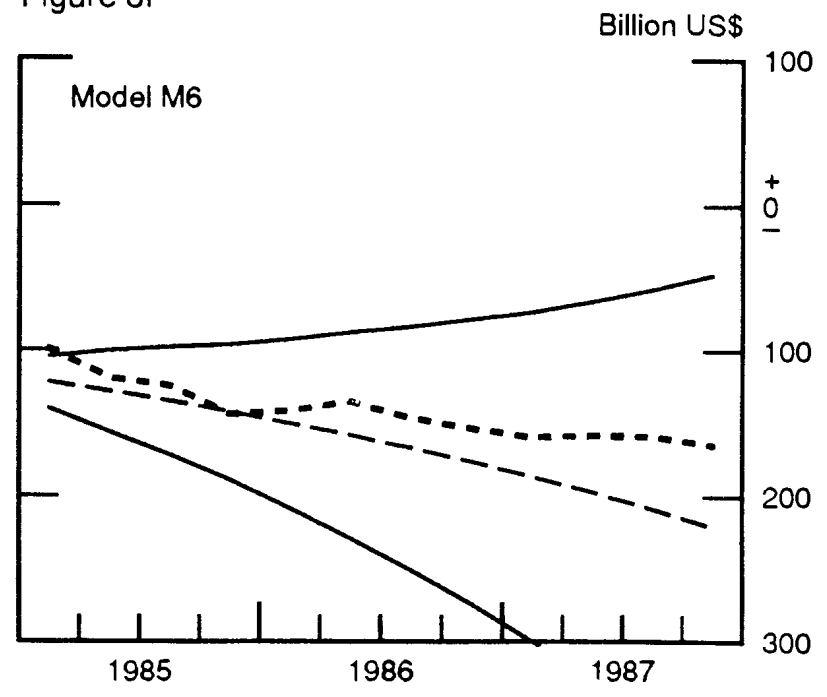


itself. Note that this problem need not appear in forecasting other functions of exports and imports, e.g., the export-import ratio.

For all models, the s-step ahead forecast standard error tends to increase as the forecast horizon lengthens. The sharpest increase is from $\$ 9$ billion in 1985Q1 to $\$ 87$ billion in $1987 \mathrm{Q} 4$ with model M6, and is due both to the omission of "exogenous" variables in the model and to the presence of an estimated dynamic root close to unity. The tendency of forecast uncertainty to increase is robust to model specification, albeit being less pronounced in the other models. However, the numerical size of the forecast standard error is sensitive to model specification: standard errors range from $\$ 8.9$ billion (M6) to $\$ 18.3$ billion (M4) in the first quarter and from $\$ 30$ billion (M3) to $\$ 88$ billion (M5) in the twelfth quarter (all figures in annual rates). FIML yields only small gains in precision, with the forecast standard errors for model M2 typically being $5-10 \%$ smaller than those for M1. Finally, the confidence intervals are not monotonically increasing in the forecast horizon, nor need they be; cf. Chong and Hendry (1986, p. 685) and Ericsson and Marquez (1989).

The 95\% s-step ahead confidence intervals displayed in Figure 3 often are larger than the realized trade balance itself. For models M1-M4, their confidence intervals are large in spite of taking "future" production costs, degree of rationing, trend factors, real incomes, GDP deflators, and nominal exchange rates as known. Standard errors for comparable ex ante forecasts of the trade account would almost invariably be larger, perhaps similar to those for the (ex ante) timeseries forecasts from models M5 and M6.

The numbers for the analysis above are all calculated using the approximate formula, i.e., accounting for uncertainty from future shocks and estimation. The component from estimation can be substantial, as indicated by Figures 4 and 5, which respectively plot one-step and s-step $\tilde{\sigma}_{\mathrm{T}+\mathrm{s}}$ from both the asymptotic and approximate formulae. In the extreme, the twelve-step ahead forecast standard errors of M1, M2, and M5 nearly double and that of M6 more than doubles by accounting for the uncertainty from estimation. 
Figure 4: Standard Errors for One-step Ahead Forecasts

Figure 4a

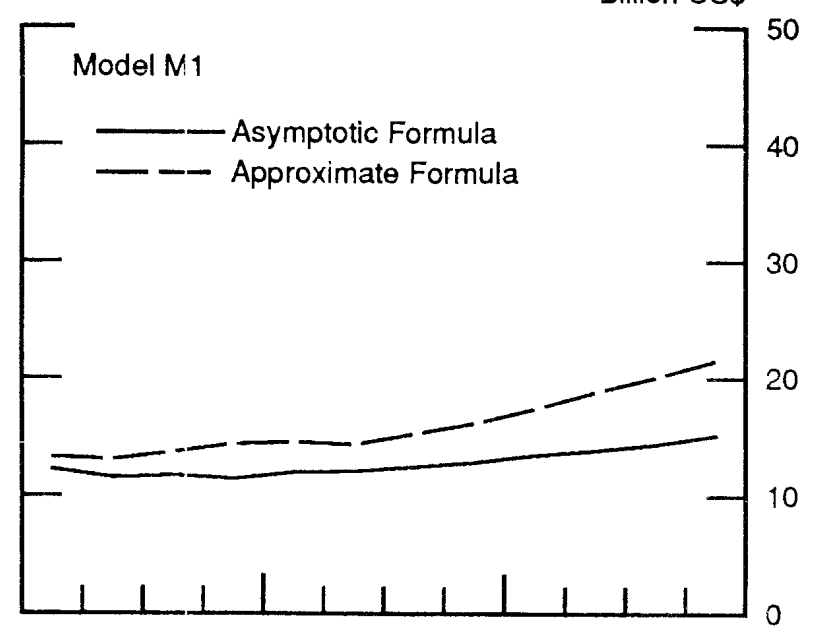

Figure 4c

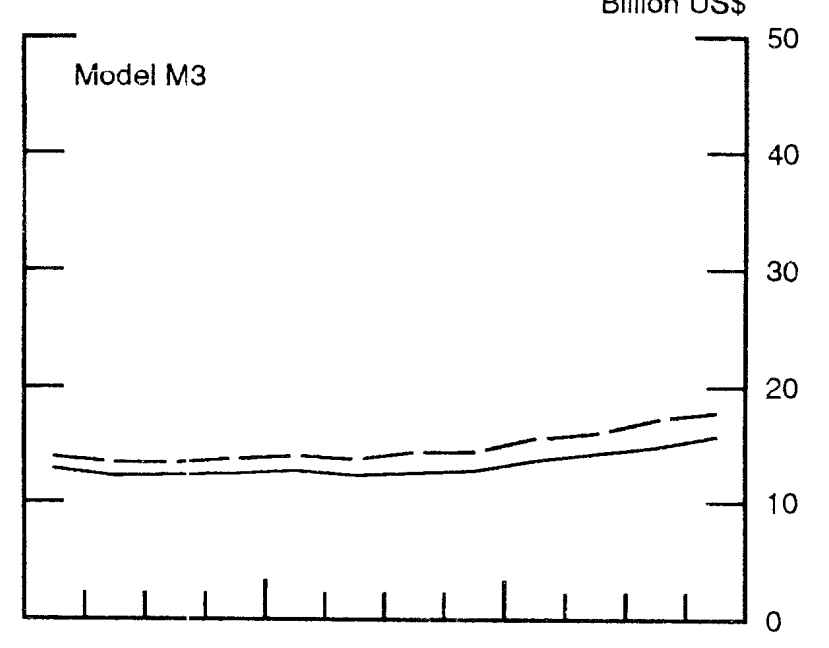

Figure $4 e$

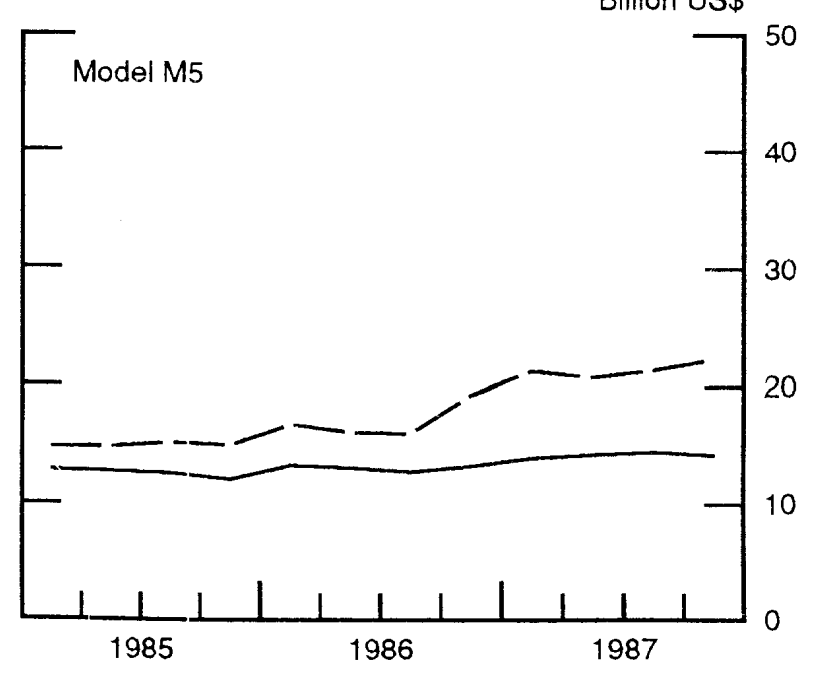

Figure 4b

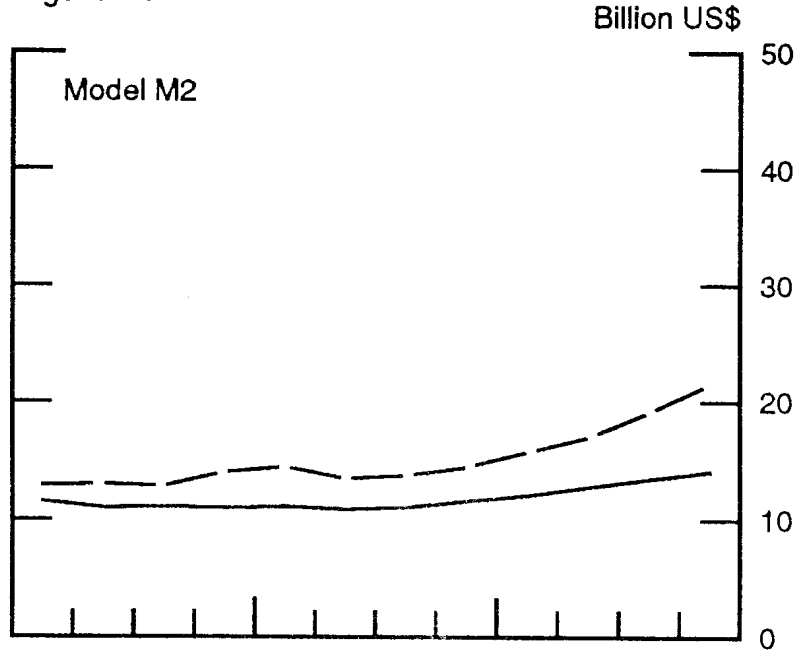

Figure $4 d$

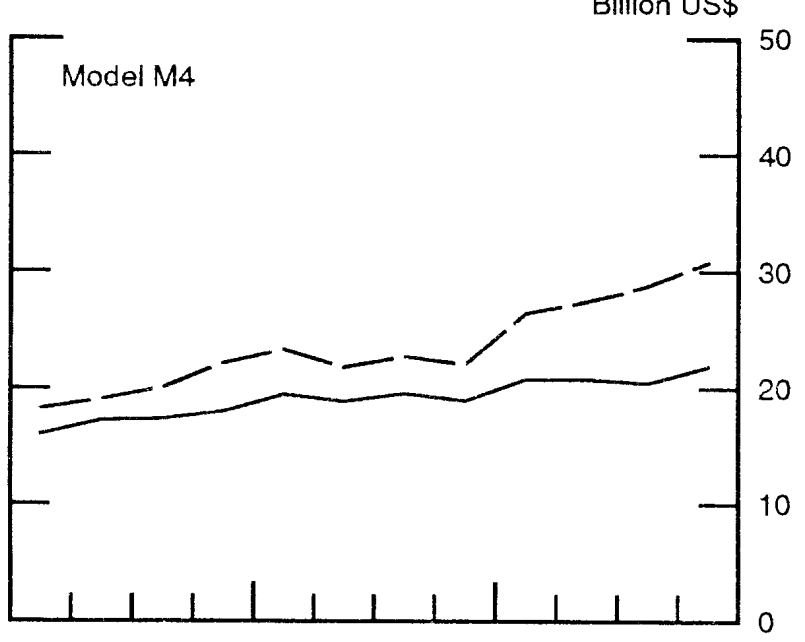

Figure $4 f$

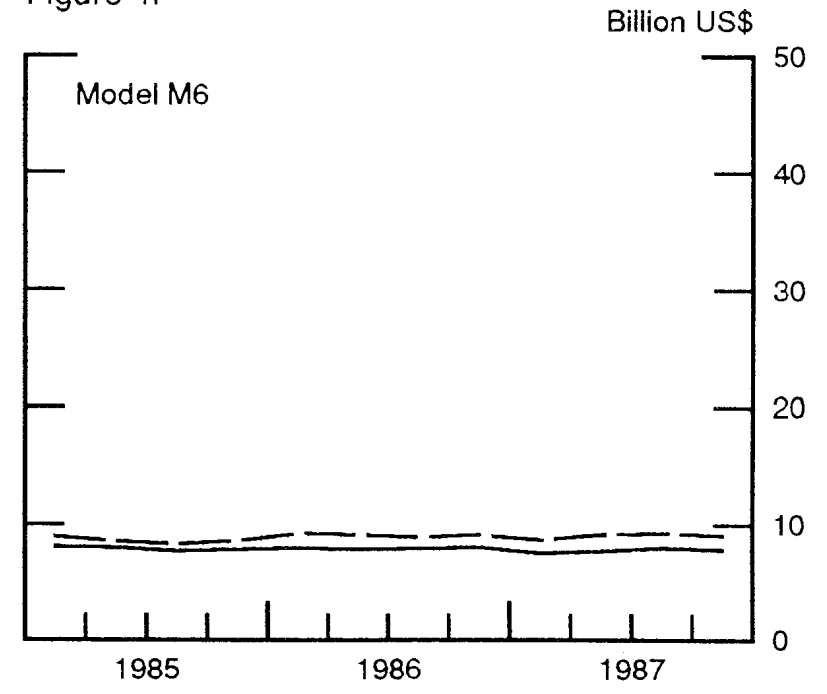


Figure 5: Standard Errors for s-step Ahead Forecasts

Figure 5a

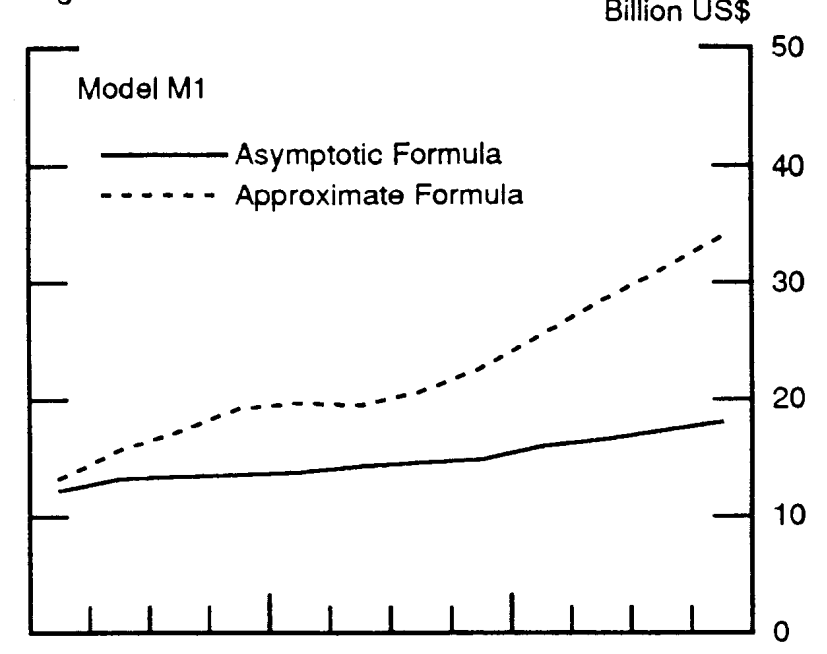

Figure 5c
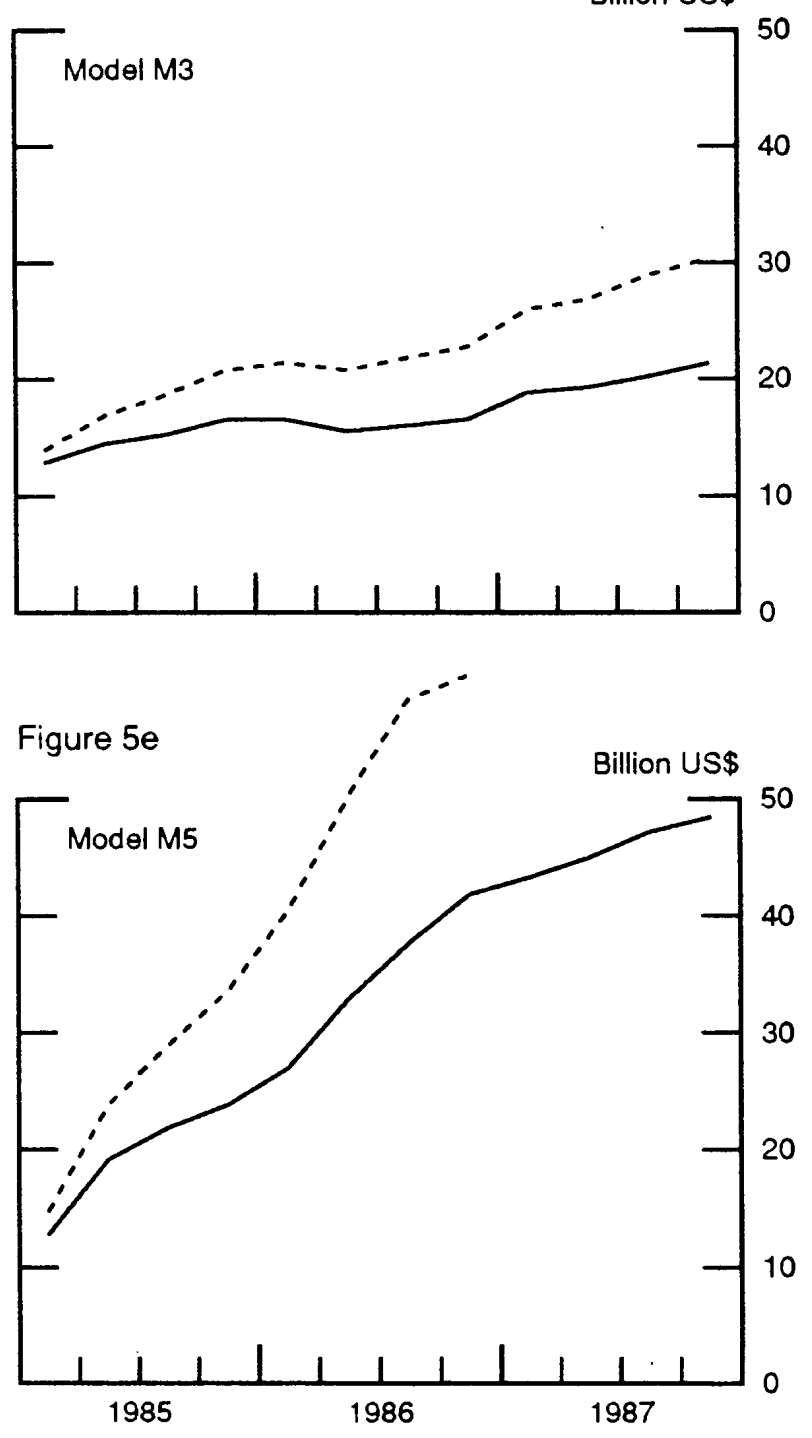

Figure 5b

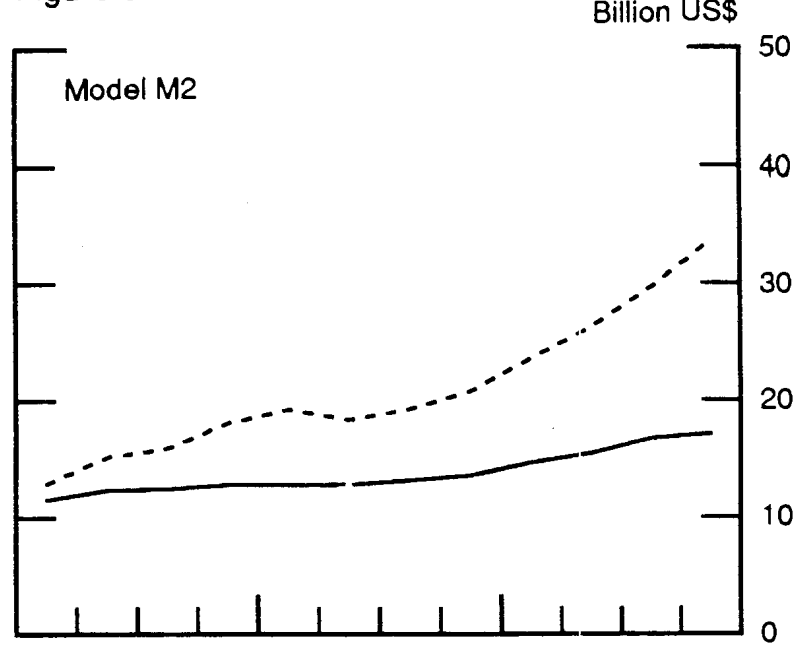

Figure 5d

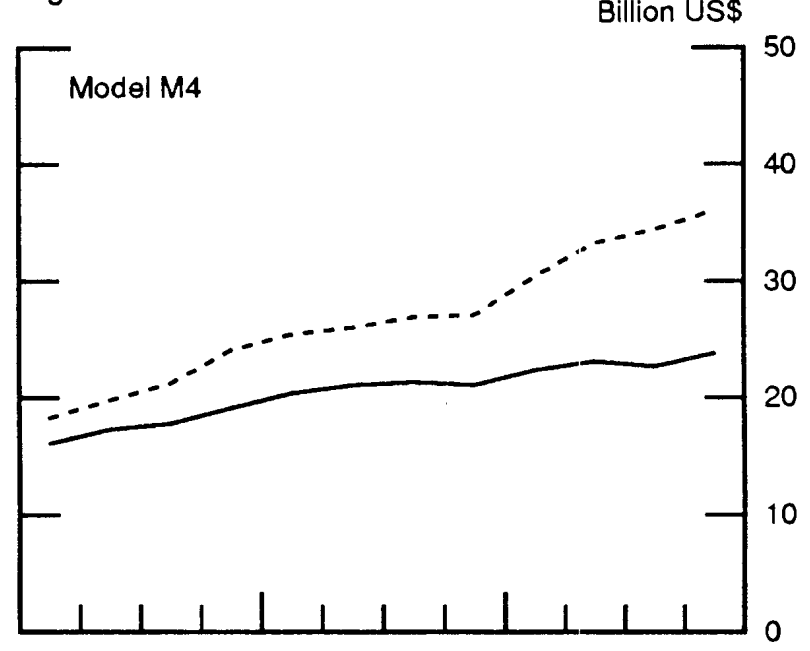

Figure $5 f$

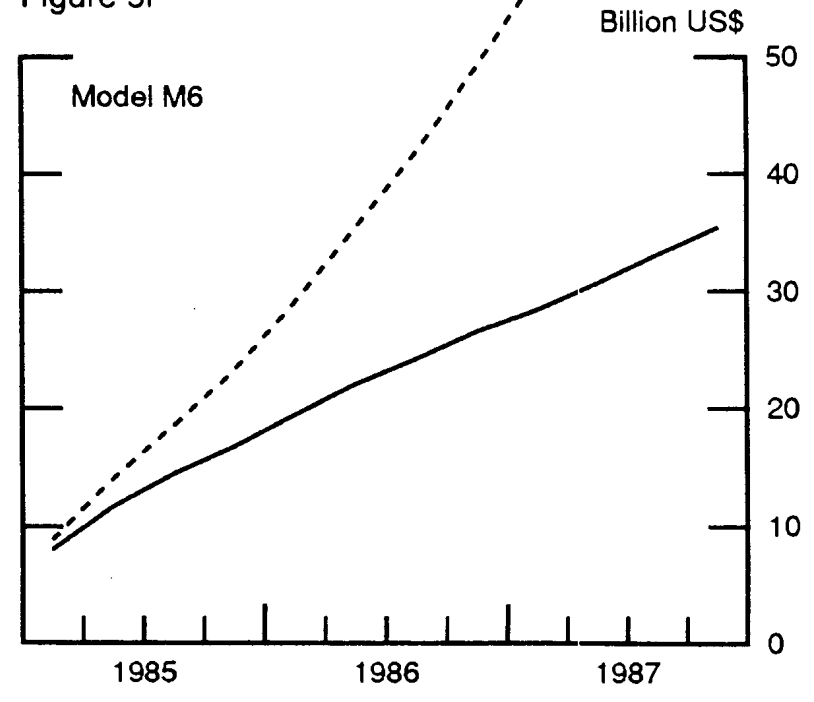


The statistics $\tau$ and $\tau *$ provide two measures of parameter constancy (i.e., predictive failure) for the six models over the twelve quarters forecast. From the values of $\tau$ in Tables 5 and 6, significant predictive failure is apparent in model M6 only. Even so, model M6 has a smaller one-step ahead MAE and RMSFE than do models M1-M5. That may reflect the inadequacy of the MAE as an evaluation criterion for nonlinear models, or the in-sample variance dominance by the time-series model, or both. Even for a given model, the estimated forecast standard error $\tilde{\sigma}_{\mathrm{T}+\mathrm{S}}$ can vary dramatically with the forecast period, invalidating the basis for comparison by MAE or RMSFE; cf. Tables 5 and 6 and Section 3.1. The statistic $\tau^{*}$ is statistically insignificant, except for model M5 with one-step ahead forecasts.

The validity of the $\chi^{2}$ and $t$ distributions for $\tau$ and $\tau *$ rests upon the forecast errors being normally distributed under the null hypothesis. The errors are asymptotically normal for linear models, but need not be for nonlinear ones. To examine the closeness to normality of the distribution of the forecast errors under the null, we have calculated Jarque and Bera's (1980) $\chi^{2}$ (2) statistic for the $\mathrm{K}$ simulated values of each forecast period of each model. The JarqueBera statistic tests whether or not skewness and excess kurtosis are zero, i.e., whether or not they are what they would be if the error distribution were normal. If the number of replications is large, the statistic will have unit power for trivially small non-zero values of skewness and excess kurtosis, so the values of the sample moments are of interest as well. Tables C.1-C.4 in Appendix C report values of the Jarque-Bera statistic and the corresponding measures of skewness and excess kurtosis. Very little skewness and excess kurtosis is apparent in the stochastic forecasts for models M1-M4, whether statistically or numerically assessed. By contrast, considerable non-normality is apparent in the s-step ahead forecast errors from models M5 and M6 using the approximate formula, especially at longer horizons. This is not so surprising, given that all coefficient variation (constant term aside) is in the dynamics for these two models, and the dynamic coefficients enter nonlinearly for forecast horizons of more than one period, all the more nonlinearly for longer horizons. Thus, the assumption of normality of 
the $\phi_{\mathrm{k}}$ appears reasonable for the most part, supporting the use of standard critical values for $\tau$ and $\tau^{*}$.

Two general conclusions are evident for the models examined. First, the trade-account forecasts are subject to a wide margin of error, even in the short run. Yet, in spite of the large confidence intervals implied, forecast errors from some models are detectably larger than anticipated, as indicated by rejection using $\tau$ and $\tau^{*}$. Second, forecast uncertainty is timedependent, with both dynamics and model nonlinearity as contributing factors. Although not monotonic, the forecast variance tends to increase (and considerably so) with the forecast horizon. This non-constancy of the forecast variance implies that the MAE and RMSFE are unreliable evaluation criteria, even when interpreted in what would be a sensible manner for static linear models. By contrast, the statistics $\tau$ and $\tau *$ are robust to time-dependent forecast uncertainty.

\section{Forecast Encompassing}

As seen in Section 3, model-based forecasts can help evaluate model performance by comparing characteristics of a given model across different subsamples, e.g., via the test statistics $\tau$ and $\tau^{*}$. With forecasts from more than one model, models may be evaluated with a different criterion, forecast encompassing, in which a model's forecasts over a given period are compared against another model's forecasts over the same period. Section 4.1 motivates this procedure, and Section 4.2 applies it to the six sets of model-dependent forecasts. In brief, all models fail the forecast encompassing tests, notably so with s-step ahead forecasts. That may reflect the different implicit alternatives being tested with the one-step and s-step ahead statistics. For general expositions on forecast encompassing, see Chong and Hendry (1986), who develop the concept of forecast encompassing and clarify its relationship to the pooling of forecasts; and Ericsson (1989), who establishes parallels between forecast encompassing and the testing of nonnested hypotheses. 


\subsection{The Analytics of Forecast Encompassing}

The question of interest is whether or not the forecast errors of a given model (model h, say) may be explained (at least in part) by the forecasts of another model (model $\ell$ ). Under the null hypothesis of model $\mathrm{h}$ being correctly specified, the forecast errors from model $\mathrm{h}$ are innovations, unpredictable by any information available at the time the forecasts were made, including the data of model $\ell$, and hence the forecasts of model $\ell$. If in fact model h's forecast errors are not predictable by model $\ell$ 's forecasts, then model h "forecast-encompasses" model $\ell$. That is, given model h's forecasts, model $\ell$ 's forecasts are redundant for predicting the variable of interest. However, if model $\ell$ 's forecasts are informative, model $\mathrm{h}$ is inadequate for forecasting, having predictable forecast errors. Model $\ell$ has useful information that model $\mathrm{h}$ does not have, or equivalently, relying on model $\mathrm{h}$ alone entails a loss of information. One useful property of forecast encompassing is that it establishes a partial ranking on models: if model $\mathrm{h}$ forecast-encompasses model $\ell$, then the converse cannot be true, at least asymptotically. However, it could be that neither model forecast-encompasses the other, indicating room for improvement in both models.

Tests of forecast encompassing are simple to calculate, being based on a regression involving only the forecasts and the actual outcomes:

$$
\tilde{v}_{\mathrm{T}+\mathrm{s}}^{(\mathrm{h})}=\kappa_{0}+\kappa_{\ell} \tilde{\mu}_{\mathrm{T}+\mathrm{s}}^{(\ell)}, \quad \mathrm{s}=1, \ldots, \mathrm{S},
$$

where $\tilde{v}_{\mathrm{T}+\mathrm{s}}^{(\mathrm{h})}\left(\equiv \mathrm{NX} \mathrm{T}+\mathrm{s}_{\mathrm{T}+\mathrm{s}} \tilde{\mu}_{\mathrm{T}}^{(\mathrm{h})}\right)$ is the mean forecast error of model $\mathrm{h}$ and $\tilde{\mu}_{\mathrm{T}+\mathrm{s}}^{(l)}$ is the mean forecast of model $\ell(\ell \neq h)$. In its simplest form, the forecast-encompassing statistic is the $t$-ratio on $\kappa_{\ell}$, with $\kappa_{0} \equiv 0$; cf. Chong and Hendry (1986, pp. 676-679).

Forecast encompassing may be generalized to include the constant term, as in (24), and to include forecasts from several models, rather than just one. By allowing for a non-zero constant term ( $\kappa_{0}$ not necessarily identically zero) and testing $\kappa_{\ell}=0$, a more powerful forecast encompassing test may result if the forecast errors of model $\mathrm{h}$ are systematically biased. However, such a systematic bias is predictable (i.e., by a constant term), so it is of interest to test 
$\kappa_{0}=0$ and $\kappa_{\ell}=0$ jointly, and also $\kappa_{0}=0$ given $\kappa_{\ell} \equiv 0 .{ }^{23}$ The initial "simple" forecast-encompassing test and each of its three variants generalize immediately to tests with forecasts from several models. ${ }^{24}$ The corresponding regression is:

(25) $\tilde{v}_{\mathrm{T}+\mathrm{s}}^{(\mathrm{h})}=\kappa_{0}+\Sigma_{\ell \neq \mathrm{h}} \kappa_{\ell} \tilde{\mu}_{\mathrm{T}+\mathrm{s}}^{(\ell)}$, $s=1, \ldots, S$.

Both "pairwise" and "multiple-model" forecast-encompassing test statistics are calculated below.

Forecast encompassing as a principle of model evaluation is agnostic on the type of forecast (whether one-step or s-step ahead) and on the type of model (linear or nonlinear). However, Chong and Hendry designed the original statistic with one-step ahead forecasts from linear models with normal independent disturbances, so some modifications are necessary for the general case. Under the null hypothesis of model $\mathrm{h}$ being correctly specified, Chong and Hendry's assumptions ensured that the forecast errors from model $\mathrm{h}$ were themselves normal and independent (ignoring coefficient uncertainty), and so the t-ratio from an OLS regression of (24) had the desired null distribution. However, model nonlinearity implies heteroscedastic forecast errors, and s-step (rather than one-step) ahead forecasts imply autocorrelation inherent in the forecast errors; cf. Chong and Hendry (1986, equation (26)) and Hendry (1990, Chapter 10[10]) on the latter. The most natural modification is feasible generalized least-squares (GLS) estimation of (24) and (25), using $\left[\widetilde{\Phi}^{(h)}\right]^{-1 / 2}$ as the correction factor. The matrix $\widetilde{\Phi}^{(h)}$ is approximately diagonal for one-step ahead forecasts, in which case the standard heteroscedasticity transformation using the diagonal elements of $\widetilde{\Phi}^{(h)}$ is suitable. A less efficient but still valid procedure for one-step ahead forecasts is to estimate (24) and (25) by OLS, and base the t-ratio (or F-ratio) on White's (1980) heteroscedasticity-consistent covariance matrix. However, here, and even with linear models, GLS has the advantage of correcting for the (asymptotically negligible) autocorrelation in the forecast errors arising from coefficient uncertainty.

\footnotetext{
${ }^{23}$ The $t$-ratio for the test of $\kappa_{0}=0$ given $\kappa_{\ell}=0$ is similar to $\tau^{*}$, but the latter (a) accounts for (rather than ignores) coefficient uncertainty and (b) may use either onc-step or s-step ahead (rather only one-step ahead) forecasts. The GLS procedure below addresses these issues. However, even with GLS, $\tau *$ conditions upon the estimation-sample and forecast-period disturbances having the same variance, whereas the t-ratio does not.

${ }^{24}$ However, the fourth test (of $\kappa_{0}=0$ given $\kappa_{f} \equiv 0$ ) is numerically invariant to the choice of the alternative model or models because only the constant erm appears in the regressions (24) and (25) for this test.
} 
Forecast-encompassing tests based on one-step and s-step ahead forecasts may have different power because the alternatives being tested are different. That is most easily seen in testing $\kappa_{0}=0$ given $\kappa_{\ell} \equiv 0$ with forecasts from a linear model for the asymptotic formula. Whether the regression uses one-step or s-step ahead forecasts, the dependent variable is the same, once rescaled by the appropriate $\left[\widetilde{\Phi}^{(h)}\right]^{-1 / 2}$. For one-step ahead forecasts, the regressor is a constant term (aside from a scale factor) because the one-step ahead $\widetilde{\Phi}^{(\mathrm{h})}$ matrix is diagonal with the same values on the diagonal. However, for s-step ahead forecasts, the regressor is $\left[\widetilde{\Phi}^{(h)}\right]^{-1 / 2} \cdot \mathrm{l}$ where $\mathrm{l}$ is a vector with unit elements, and the s-step ahead $\widetilde{\Phi}^{(\mathrm{h})}$ matrix is inherently non-diagonal if the model is dynamic. Thus, the dependent variables are the same but the regressors differ, so the alternatives are in general different. Likewise, in the more general regressions, the transformed forecasts of another model $\left[\widetilde{\Phi}^{(h)}\right]^{-1 / 2} \cdot \tilde{\mu}^{(\ell)}$ are not invariant to being one-step or s-step ahead.

\subsection{Empirical Results}

Based on the forecast data for 1985Q1-1987Q4, we apply feasible GLS to (24) and (25) and test for the significance of the associated coefficient estimates. Tables 7 and 8 report the results for one-step and s-step ahead forecasts respectively, both using the approximate formula.

Looking at the pairwise tests on Table 7 first, the mean predictions from the univariate timeseries model M6 help explain the mean forecast errors of the structural model M4. That suggests dynamic misspecification of M4 because dynamics are the only information in M6. However, M6 can not forecast-encompass the VAR, model M5. Further, models M1-M3 can not encompass M4, perhaps due to aggregation over countries. The multiple-model tests for one-step ahead forecasts reject models Ml-M4, and nearly rejects M5.

The s-step ahead tests in Table 8 roughly parallel those for one-step ahead forecasts, often with even larger numerical values of the test statistics. All models but M4 fail the pairwise tests, and all but M4 and M6 fail the multiple-model tests. The ability of the mean predictions from the structural models M1-M4 to help explain the mean forecast errors of each of the time-series 
Table 7

Forecast-encompassing Test Statistics for Alternative Trade-account Models One-step Ahead, Approximate Formula

Pairwise Forecast-encompassing Test Statistics (F valucs)

\begin{tabular}{|c|c|c|c|c|c|c|c|c|}
\hline \multirow{2}{*}{$\begin{array}{c}\text { Encompassing } \\
\text { Model (h) }\end{array}$} & \multirow[b]{2}{*}{ Null Hypothesis } & \multirow[b]{2}{*}{ d.f. } & \multicolumn{6}{|c|}{ Model To Be Encompassed ( $(\ell)$} \\
\hline & & & M1 & M2 & M3 & M4 & M5 & M6 \\
\hline \multirow[t]{3}{*}{ M1 } & $\mathrm{H}_{0}: \kappa_{\ell}=0 ; \kappa_{0}=0$ & 1,11 & 0.0 & 0.0 & 0.0 & 0.7 & 0.0 & 0.1 \\
\hline & $\mathrm{H}_{0}: \kappa_{\ell}=0$ & 1,10 & & 0.1 & 0.2 & 5.7 & 0.0 & 2.6 \\
\hline & $\mathrm{H}_{0}: \kappa_{\ell}=\kappa_{0}=0$ & 2,10 & & 0.0 & 0.1 & 2.8 & 0.0 & 1.3 \\
\hline \multirow[t]{3}{*}{ M2 } & $\mathrm{H}_{0}: \kappa_{\ell}=0 ; \kappa_{0} \equiv 0$ & 1,11 & 0.0 & 0.0 & 0.0 & 1.6 & 0.0 & 0.4 \\
\hline & $\mathrm{H}_{0}: \kappa_{\ell}=0$ & 1,10 & 0.0 & & 0.1 & 8.5 & 0.0 & 3.9 \\
\hline & $\mathrm{H}_{0}: \kappa_{\ell}=\kappa_{0}=0$ & 2,10 & 0.0 & & 0.1 & 4.2 & 0.0 & 2.0 \\
\hline \multirow[t]{3}{*}{ M3 } & $\mathrm{H}_{0}: \kappa_{\ell}=0 ; \kappa_{0}=0$ & 1,11 & 0.0 & 0.0 & 0.1 & 1.1 & 0.1 & 0.3 \\
\hline & $\mathrm{H}_{0}: \kappa_{\ell}=0$ & 1,10 & 0.1 & 0.4 & & 6.5 & 0.0 & 1.9 \\
\hline & $\mathrm{H}_{0}: \kappa_{\ell}=\kappa_{0}=0$ & 2,10 & 0.1 & 0.2 & & 3.3 & 0.0 & 1.0 \\
\hline \multirow[t]{3}{*}{ M4 } & $\mathrm{H}_{0}: \kappa_{\ell}=0 ; \kappa_{0}: 0$ & 1,11 & 0.0 & 0.1 & 0.1 & 0.2 & 0.0 & 0.0 \\
\hline & $\mathrm{H}_{0}: \kappa_{\ell}=0$ & 1,10 & 4.6 & 2.0 & 1.0 & & 3.5 & 14.3 \\
\hline & $\mathrm{H}_{0}: \kappa_{\ell}=\mathrm{x}_{0}=0$ & 2,10 & 2.4 & 1.1 & 0.6 & & 1.9 & 7.4 \\
\hline \multirow[t]{3}{*}{ M5 } & $\mathrm{H}_{0}: \kappa_{\ell}=0 ; \kappa_{0}=0$ & 1,11 & 0.3 & 0.3 & 0.5 & 1.4 & 0.2 & 0.4 \\
\hline & $\mathrm{H}_{0}: \kappa_{\ell}=0$ & 1,10 & 0.3 & 0.6 & 1.6 & 3.5 & & 0.6 \\
\hline & $\mathrm{H}_{0}: \kappa_{\ell}=\kappa_{0}=0$ & 2,10 & 0.3 & 0.4 & 0.9 & 1.9 & & 0.4 \\
\hline \multirow[t]{3}{*}{ M6 } & $\mathrm{H}_{0}: \kappa_{\ell}=0 ; \kappa_{0}=0$ & 1,11 & 0.0 & 0.0 & 0.0 & 0.0 & 0.1 & 0.0 \\
\hline & $\mathrm{H}_{0}: \kappa_{\ell}=0$ & 1,10 & 0.1 & 0.0 & 0.0 & 0.0 & 4.9 & \\
\hline & $\mathrm{H}_{0}: \kappa_{\ell}=\kappa_{0}=0$ & 2,10 & 0.0 & 0.0 & 0.0 & 0.0 & 2.5 & \\
\hline
\end{tabular}

Multiple-model $(\nabla \ell \neq h)$

Forecast-cncompassing Test Statistics

Null Hypothesis d.f. F valuc

\begin{tabular}{lll}
\hline $\mathrm{H}_{0}: \forall \kappa_{\ell}=0 ; \kappa_{0} 0$ & 5.7 & 2.8 \\
$\mathrm{H}_{0}: \forall \kappa_{\ell}=0$ & 5.6 & 5.3 \\
$\mathrm{H}_{0}: \forall \kappa_{\ell}=\kappa_{0}=0$ & 66 & 4.4 \\
$\mathrm{H}_{0}: \forall \kappa_{\ell}=0 ; \kappa_{0}=0$ & 5.7 & 3.1 \\
$\mathrm{H}_{0}: \forall \kappa_{\ell}=0$ & 5.6 & 5.3 \\
$\mathrm{H}_{0}: \forall \kappa_{\ell}=\kappa_{0}=0$ & 6.6 & 4.4 \\
$\mathrm{H}_{0}: \forall \kappa_{\ell}=0 ; \kappa_{0}=0$ & 5,7 & 3.1 \\
$\mathrm{H}_{0}: \forall \kappa_{\ell}=0$ & 5,6 & 5.5 \\
$\mathrm{H}_{0}: \forall \kappa_{\ell}=\kappa_{0}=0$ & 6,6 & 4.6 \\
$\mathrm{H}_{0}: \forall \kappa_{\ell}=0 ; \kappa_{0}=0$ & 5,7 & 2.0 \\
$\mathrm{H}_{0}: \forall \kappa_{\ell}=0$ & 5,6 & 5.0 \\
$\mathrm{H}_{0}: \forall \kappa_{\ell}=\kappa_{0}=0$ & 6,6 & 4.2 \\
$\mathrm{H}_{0}: \forall \kappa_{\ell}=0 ; \kappa_{0}=0$ & 5,7 & 2.7 \\
$\mathrm{H}_{0}: \forall \kappa_{\ell}=0$ & 5,6 & 3.4 \\
$\mathrm{H}_{0}: \forall \kappa_{\ell}=\kappa_{0}=0$ & 6,6 & 2.9 \\
$\mathrm{H}_{0}: \forall \kappa_{\ell}=0 ; \kappa_{0}=0$ & 5,7 & 0.7 \\
$\mathrm{H}_{0}: \forall \kappa_{\ell}=0$ & 5,6 & 0.9 \\
$\mathrm{H}_{0}: \forall \kappa_{\ell}=\kappa_{0}=0$ & 6,6 & 0.7 \\
\end{tabular}

Notes: $\quad$ a. The $5 \%$ critical values for the $F$ statistics are $F(1,11)=4.84, F(1,10)=4.96, F(2,10)=4.10, F(5,7)=3.97, F(5,6)=4.39, F(6,6)=4.28$.

b. The regressions for pairwise and multiple-model forecast encompassing are

$$
\text { and } \begin{aligned}
\tilde{v}_{T+s}^{(h)} & =\kappa_{0}+\kappa_{\ell} \tilde{\mu}_{T+s}^{(\ell)} \\
\tilde{v}_{T+s}^{(h)} & =\kappa_{0}+\Sigma_{\ell \neq h} \kappa_{\ell} \tilde{\mu}_{T+s}^{(\ell)},
\end{aligned}
$$

respectively, where the $\ell^{\text {th }}$ model(s) is (are) being encompassed by the $h^{\text {th }}$ model (the cncompassing model). Each regress on uses GLS, i.e., premultiplying each equation by $\left[\widetilde{\Phi}^{(h)}\right]^{-1 / 2}$ in order to account for the autocorrelation and heteroscedasticity of the dependent variable $\tilde{v}_{T+s}^{(h)}$.

c. The diagonal clements in the block of pairwise forecast-encompassing test statistics are statistics testing $\kappa_{0}=0$ with $\kappa_{\ell}=0$. 
Table 8

Forecast-encompassing Test Statistics for Alternative Trade-account Models s-step Ahead, Approximate Formula

Pairwise Forecast-encompassing Test Statistics (F values)

\begin{tabular}{|c|c|c|c|c|c|c|c|c|}
\hline \multirow{2}{*}{$\begin{array}{c}\text { Encompassing } \\
\text { Model (h) }\end{array}$} & \multirow[b]{2}{*}{ Null Hypothesis } & \multirow[b]{2}{*}{ d.f. } & \multicolumn{6}{|c|}{ Model To Be Encompassed ( $\ell$ ) } \\
\hline & & & M1 & M2 & M3 & M4 & M5 & M6 \\
\hline \multirow[t]{3}{*}{ MI } & $\mathrm{H}_{0}: \kappa_{\ell}=0 ; \kappa_{0}=0$ & 1,11 & 1.4 & 2.2 & 2.0 & 0.1 & 3.5 & 0.1 \\
\hline & $H_{0}: \kappa_{\ell}=0$ & 1,10 & & 2.1 & 1.0 & 1.7 & 14.5 & 33.8 \\
\hline & $\mathrm{H}_{0}: \kappa_{\ell}=\kappa_{0}=0$ & 2,10 & & 1.8 & 1.2 & 1.6 & 8.7 & 19.6 \\
\hline \multirow[t]{3}{*}{ M2 } & $\mathrm{H}_{0}: \kappa_{\ell}=0 ; \kappa_{0}=0$ & 1,11 & 2.6 & 1.5 & 2.6 & 0.1 & 4.3 & 0.1 \\
\hline & $\mathrm{H}_{0}: \kappa_{\ell}=0$ & 1,10 & 3.3 & & 2.5 & 2.6 & 27.1 & 32.1 \\
\hline & $\mathrm{H}_{0}: \kappa_{\ell}=\kappa_{0}=0$ & 2,10 & 2.6 & & 2.1 & 2.1 & 16.1 & 18.9 \\
\hline \multirow[t]{3}{*}{ M3 } & $\mathrm{H}_{0}: \kappa_{\ell}=0 ; \kappa_{0} \equiv 0$ & 1,11 & 1.4 & 1.6 & 0.8 & 0.1 & 3.0 & 0.0 \\
\hline & $\mathrm{H}_{0}: \kappa_{\ell}=0$ & 1,10 & 2.2 & 3.2 & & 5.4 & 31.5 & 14.7 \\
\hline & $\mathrm{H}_{0}: \kappa_{\ell}=\kappa_{0}=0$ & 2,10 & 1.5 & 2.1 & & 3.2 & 17.2 & 8.2 \\
\hline \multirow[t]{3}{*}{ M4 } & $\mathrm{H}_{0}: \kappa_{\ell}=0 ; \kappa_{0}=0$ & 1,11 & 0.6 & 0.8 & 1.2 & 1.0 & 1.8 & 0.6 \\
\hline & $\mathrm{H}_{0}: \mathrm{\kappa}_{\ell}=0$ & 1,10 & 0.8 & 0.1 & 0.4 & & 1.9 & 0.5 \\
\hline & $\mathrm{H}_{0}: \kappa_{\ell}=\kappa_{0}=0$ & 2,10 & 0.9 & 0.5 & 0.7 & & 1.5 & 0.7 \\
\hline \multirow[t]{3}{*}{ M5 } & $\mathrm{H}_{0}: \kappa_{\ell}=0 ; \kappa_{0}=0$ & 1,11 & 3.7 & 3.4 & 3.1 & 1.6 & 5.4 & 3.2 \\
\hline & $\mathrm{H}_{0}: \kappa_{\ell}=0$ & 1,10 & 3.7 & 5.2 & 6.0 & 4.6 & & 19.1 \\
\hline & $\mathrm{H}_{0}: \kappa_{\ell}=\kappa_{0}=0$ & 2,10 & 5.2 & 6.3 & 6.9 & 5.8 & & 16.7 \\
\hline \multirow[t]{3}{*}{ M6 } & $\mathrm{H}_{0}: \kappa_{\ell}=0 ; \kappa_{0}=0$ & 1,11 & 2.4 & 2.1 & 1.8 & 1.5 & 4.4 & 5.2 \\
\hline & $\mathrm{H}_{0}: \kappa_{\ell}=0$ & 1,10 & 8.7 & 8.8 & 6.8 & 0.6 & 0.4 & \\
\hline & $\mathrm{H}_{0}: \kappa_{\ell}=\kappa_{0}=0$ & 2,10 & 8.8 & 8.8 & 7.4 & 2.9 & 2.7 & \\
\hline
\end{tabular}

Multiple-model $(\forall \ell \neq h)$

Forecast-encompassing Test Statistics

Null Hypothesis d.f. F value

\begin{tabular}{lll}
\hline $\mathrm{H}_{0}: \forall \kappa_{\ell}=0 ; \kappa_{0}=0$ & 5,7 & 5.9 \\
$\mathrm{H}_{0}: \forall \kappa_{\ell}=0$ & 5,6 & 5.0 \\
$\mathrm{H}_{0}: \forall \kappa_{\ell}=\kappa_{0}=0$ & 6,6 & 4.8 \\
$\mathrm{H}_{0}: \forall \kappa_{\ell}=0 ; \kappa_{0}=0$ & 5,7 & 7.7 \\
$\mathrm{H}_{0}: \forall \kappa_{\ell}=0$ & 5,6 & 5.8 \\
$\mathrm{H}_{0}: \forall \kappa_{\ell}=\kappa_{0}=0$ & 6,6 & 5.6 \\
$\mathrm{H}_{0}: \forall \kappa_{\ell}=0 ; \kappa_{0}=0$ & 5,7 & 6.3 \\
$\mathrm{H}_{0}: \forall \kappa_{\ell}=0$ & 5,6 & 5.0 \\
$\mathrm{H}_{0}: \forall \kappa_{\ell}=\kappa_{0}=0$ & 6,6 & 4.5 \\
$\mathrm{H}_{0}: \forall \kappa_{\ell}=0 ; \kappa_{0}=0$ & 5,7 & 3.8 \\
$\mathrm{H}_{0}: \forall \kappa_{\ell}=0$ & 5,6 & 3.2 \\
$\mathrm{H}_{0}: \forall \kappa_{\ell}=\kappa_{0}=0$ & 6,6 & 3.0 \\
$\mathrm{H}_{0}: \forall \kappa_{\ell}=0 ; \kappa_{0}=0$ & 5,7 & 2.3 \\
$\mathrm{H}_{0}: \forall \kappa_{\ell}=0$ & 5,6 & 6.6 \\
$\mathrm{H}_{0}: \forall \kappa_{\ell}=\kappa_{0}=0$ & 6,6 & 8.7 \\
$\mathrm{H}_{0}: \forall \kappa_{\ell}=0 ; \kappa_{0}=0$ & 5,7 & 2.1 \\
$\mathrm{H}_{0}: \forall \kappa_{\ell}=0$ & 5,6 & 1.1 \\
$\mathrm{H}_{0}: \forall \kappa_{\ell}=\kappa_{0}=0$ & 6,6 & 1.8
\end{tabular}

Notes: a. The $5 \%$ critical values for the $F$ statistics are $F(1,11)=4.84, F(1,10)=4.96, F(2,10)=4.10, F(5,7)=3.97, F(5,6)=4.39, F(6,6)=4.28$.

b. The regressions for pairwise and multiple-model forecast encompassing are

$$
\text { and } \begin{aligned}
\tilde{v}_{\mathrm{T}+\mathrm{s}}^{(h)} & =\kappa_{0}+\kappa_{\ell} \tilde{\mu}_{\mathrm{T}+\mathrm{s}}^{(\ell)} \\
\tilde{v}_{\mathrm{T}+\mathrm{s}}^{(\mathrm{h})} & =\kappa_{0}+\Sigma_{\ell \neq h} \kappa_{\ell} \tilde{\mu}_{\mathrm{T}+\mathrm{s}}^{(\ell)},
\end{aligned}
$$

respectively, where the $\ell^{\text {th }}$ model(s) is (are) being encompassed by the $h^{\text {th }}$ model (the encompassing model). Each regression uses GLS, i.e., premultiplying each equation by $\left[\tilde{\Phi}^{(h)}\right]^{-1 / 2}$ in order to account for the autocorrelation and heteroscedasticity of the dependent variable $\tilde{v}_{T+s}^{(h)}$.

c. The diagonal elements in the block of pairwise forccast-encompassing test statistics arc statistics testing $\kappa_{0}=0$ with $\kappa_{\ell=0}$ 
models suggests that the latter lack important economic determinants. ${ }^{2}{ }^{5}$ In short, from Tables 7 and 8 , every model contains information that would be valuable in improving the other models, and every model could be improved.

Contrasts between pairwise and multiple-model tests could exist even asymptotically, with rejection by multiple-model tests being "correct" if that rejection occurs. That brings home the importance of modeling and testing from general to simple, rather than the reverse; $\mathrm{cf}$. Ericsson and Hendry (1989). Also, although the forecast-encompassing tests may suggest the misspecification present and hence ways in which to improve a model, such inferences are speculative rather than definitive. Rejection of the null does not imply the alternative.

Notwithstanding our analysis of forecasts in this section and Section 3 above, we agree with Pagan (1989) on the conceptual equivalence of analyzing one-step ahead residuals, s-step ahead residuals, and fitted residuals for linear models and provided that the implicit assumption of strong exogeneity is valid; see also Chong and Hendry (1986, p. 681). There are several caveats to this equivalence. First, from a practical standpoint, only one type of residual may be available, in which case it is useful to have equivalent procedures for analyzing all three types. Second, $\tau$ and $\tau *$ are not invariant to the type of residual for nonlinear models, and the forecastencompassing statistics are not invariant for even linear models. Third, if strong exogeneity is invalid, forecast test statistics calculated with the s-step ahead residuals assuming strong exogeneity are no longer the correct s-step ahead forecast test statistics, even though the former as (incorrectly) calculated are still numerically equivalent to the one-step ahead statistics. The proper s-step statistics would require modeling the feedback mechanism of the endogenous variables onto the right-hand side weakly exogenous variables.

\footnotetext{
${ }^{25}$ That is, the other models' data (as distinct from their forecasts) might be informative: "model forecast encompassing" is the corresponding, more general concept; cf. Ericsson (1989). This distinction may be responsible for the contrasting results from pairwise and multiple-model forecast-encompassing tests, although rejection by any of the tests is sufficient to indicate predictive inadequacy. Due to model nonlinearities and model size, the model forecast encompassing test statistics were not calculated.

The failure of the time-series models to forccast-cncompass models M1-M4 may also reflect the larger information set of the latter, notably including future values of assumedly exogenous variables.
} 


\section{Nonlinearity Bias}

In general, deterministic forecasts from nonlinear models are biased: the expectation of a nonlinear function is not usually equal to the function of the expectations. In the context of s-step ahead forecasts from the first four models of the trade account, that means:

$$
\begin{aligned}
\mu_{\mathrm{T}-\mathrm{s}} & \equiv \boldsymbol{E}\left(\mathrm{A} \cdot g\left(\hat{\mathrm{y}}_{\mathrm{T}+\mathrm{s}-1}, \mathrm{z}_{\mathrm{T}+\mathrm{s}}, \hat{\theta}^{\mathrm{u}_{\mathrm{T}+\mathrm{s}}}\right)\right) \\
& \neq \delta_{\mathrm{T}+\mathrm{s}} \equiv \mathrm{A} \cdot g\left(\delta_{\mathrm{T}+\mathrm{s}-1}, \mathrm{z}_{\mathrm{T}+\mathrm{s}}, \hat{\boldsymbol{E}}(\hat{\theta}), \boldsymbol{E}\left(\mathrm{u}_{\mathrm{T}+\mathrm{s}}\right)\right) \quad \mathrm{s}=1, \ldots, \mathrm{S},
\end{aligned}
$$

where $\hat{\mathrm{y}}_{\mathrm{T}}=\delta_{\mathrm{T}} \equiv \mathrm{y}_{\mathrm{T}}, \boldsymbol{E}(\cdot)$ is the expectation operator, and $\mathrm{A}$ is a selection matrix extracting the nominal trade-account forecast from the vector function $g(\cdot)$. Even if the coefficients are known, bias exists because the disturbances enter $g(\cdot)$ nonlinearly. ${ }^{26}$ The same analysis applies to one-step ahead forecasts, but noting that such forecasts from linear models are unbiased. However, deterministic multi-step forecasts from linear models are biased because the forecasts are nonlinear functions of the (unbiased) coefficient estimates. This section estimates the "nonlinearity biases" of the deterministic forecasts for the six models of the trade account: Section 5.1 describes the underlying Monte Carlo methodology and Section 5.2 reports the results. All models have statistically significant biases for most forecast periods, but only models M4-M6 have economically significant biases, and those are primarily s-step ahead at longer horizons.

See Nagar (1969), Howrey and Kelejian (1969), and Calzolari (1979) inter alia for early studies that recognize systematic biases in deterministic forecasts arising from model nonlinearities. More recent studies include Mariano and Brown (1983), Brown and Mariano (1989), Fair (1984, 1988), and Fisher and Salmon (1986).

\subsection{Monte Carlo Methodology}

The bias of the deterministic forecast is the difference between $\mu_{\mathrm{T}+\mathrm{s}}$ (the mean of the stochastic trade-account forecast) and $\delta_{\mathrm{T}+\mathrm{s}}$ (the deterministic forecast). Almost by assumption,

${ }^{26}$ To illustrate, suppose $\mathrm{y}$ is normally distributed $\mathrm{N}\left(\mu, \sigma^{2}\right)$ and consider the bias in the deterministic forecast of $\mathrm{Y}$, the exponential of $\mathrm{y}(\mathrm{Y} \equiv \exp (\mathrm{y}))$. The deterministic forecast is $\exp (E(\mathrm{y}))=\exp (\mu)$, but the actual expectation of $Y$ is $\boldsymbol{E}(Y)=\boldsymbol{E}(\exp (\mathrm{y}))=\exp \left(\mu+\sigma^{2} / 2\right)$. Thus, the nonlincarity bias is $\exp (\mu) \cdot\left[\exp \left(\sigma^{2} / 2\right)-1\right]$ and depends on both $\mu$ and $\sigma$. 
$\mu_{\mathrm{T}+\mathrm{s}}$ is not known analytically; and obtaining its value numerically is a complicated process involving multiple integration of the whole trade model:

$$
\mu_{\mathrm{T}+\mathrm{s}} \equiv \mathrm{A} \cdot \boldsymbol{E}\left(\hat{\mathrm{y}}_{\mathrm{T}+\mathrm{s}}\right)=\mathrm{A} \cdot \iint g\left(\hat{\mathrm{y}}_{\mathrm{T}+\mathrm{s}-1}, \mathrm{z}_{\mathrm{T}+\mathrm{s}}, \hat{\theta}, \mathrm{u}_{\mathrm{T}+\mathrm{s}}\right) \cdot v(\mathrm{u}, \hat{\theta}) \cdot \mathrm{du} \cdot \mathrm{d} \hat{\theta}
$$

where $v(\cdot)$ is the joint density of $\hat{\theta}$ and $u\left(\equiv\left(\mathrm{u}_{\mathrm{T}+1}, \ldots, \mathrm{u}_{\mathrm{T}+\mathrm{s}}\right)^{\prime}\right)$, and $\hat{\mathrm{y}}_{\mathrm{T}+\mathrm{s}-1}$ is implicitly a function of $\hat{\theta}$ and $u$. The difficulties in numerically evaluating (27) stem from both the number of random variables and the absence of a closed-form solution. ${ }^{2} 7$

As an alternative to numerical integration, we estimate $\mu_{\mathrm{T}+\mathrm{s}}$ by Monte Carlc, using the variance-reduction technique antithetic variates. By exploiting the symmetry of the distribution of $\left(\left\{\eta_{\mathrm{k}, \mathrm{s}}\right\}, \zeta_{\mathrm{k}}\right)$ (the random drawings in Section 3 above), this method provides a much more precise estimate of $\mu_{\mathrm{T}+\mathrm{s}}$ than that offered by the standard Monte Carlo estimator $\tilde{\mu}_{\mathrm{T}+\xi}$.

To start, note that the values $\left(\left\{\eta_{\mathrm{k}, \mathrm{s}}\right\}, \zeta_{\mathrm{k}}\right)$ and $\left(\left\{-\eta_{\mathrm{k}, \mathrm{s}}\right\},-\zeta_{\mathrm{k}}\right)$ are equally likely (by symmetry), and little additional computational expense is required to calculate a simulated trade account from each, rather than from just the first. For $\mathrm{K}$ sets of random numbers, we generate $2 \mathrm{~K}$ simulated values of the trade account which are averaged to produce a forecast of the trade account. Thus, calculating the antithetic-variate estimate of the bias involves three steps.

1. Generate a random sample of trade-account forecasts with the drawings from (12) and (14). The trade-account forecasts for the kth replication are:

(28) $\mathrm{NX}_{\mathrm{k}, \mathrm{T}+\mathrm{s}}=\mathrm{A} \cdot g\left(\mathrm{y}_{\mathrm{k}, \mathrm{T}+\mathrm{s}-1}, \mathrm{z}_{\mathrm{T}+\mathrm{s}}, \hat{\theta}+\hat{\Gamma} \zeta_{\mathrm{k}}, \hat{\Lambda} \eta_{\mathrm{k}, \mathrm{s}}\right), \quad \mathrm{s}=1, \ldots, \mathrm{S}$.

2. Generate a random sample of trade-account forecasts using the negative of the random numbers drawn for (12) and (14). These forecasts for the kth replication are:

$$
\mathrm{NX}_{\mathrm{k}, \mathrm{T}+\mathrm{s}}^{+}=\mathrm{A} \cdot g\left(\mathrm{y}_{\mathrm{k}, \mathrm{T}+\mathrm{s}-1}^{+}, \mathrm{z}_{\mathrm{T}+\mathrm{s}}, \hat{\theta}-\hat{\Gamma}_{\mathrm{K}_{\mathrm{k}}},-\hat{\Lambda} \eta_{\mathrm{k}, \mathrm{s}}\right), \quad \mathrm{s}=1, \ldots, \mathrm{S}
$$

where the dagger ${ }^{+}$indicates switching the signs of the random numbers.

3. Construct the "pooled" Monte Carlo estimates of the trade-account forecasts by averaging the antithetic variates in steps 1 and 2 :

\footnotetext{
${ }^{27}$ Note that $\hat{\theta}$ is independent of $u$, a feature that would simplify solving (27) directly by numerical integration. Even so, this task remains a difficult one computationally, given the number of integrals involved. For example, model M4 has 127 coefficients and 21 (limes 12 forecast periods) disturbances for a total of 379 ranclom variables to be integrated out; see Table 2.
} 
(30)

$$
\begin{aligned}
\bar{\mu}_{\mathrm{T}+\mathrm{s}} & =\Sigma_{\mathrm{k}}\left(\mathrm{NX} \mathrm{k}, \mathrm{T}+\mathrm{s}+\mathrm{NX} \mathrm{k}_{\mathrm{T}, \mathrm{T}+\mathrm{s}}^{+}\right) /(2 \mathrm{~K}) \\
& =\left(\tilde{\mu}_{\mathrm{T}+\mathrm{s}}+\tilde{\mu}_{\mathrm{T}+\mathrm{s}}^{+}\right) / 2,
\end{aligned}
$$$$
\mathrm{s}=1, \ldots, \mathrm{S} .
$$

To illustrate how gains from antithetic variates arise, consider the relationship between the variance of the antithetic-variate estimator $\bar{\mu}_{\mathrm{T}+\mathrm{s}}$ and the variance of the standard Monte Carlo estimator $\tilde{\mu}_{\mathrm{T}+\mathrm{s}}$.

$$
\begin{aligned}
\operatorname{var}\left(\bar{\mu}_{\mathrm{T}+\mathrm{s}}\right) & =\left[\operatorname{var}\left(\tilde{\mu}_{\mathrm{T}+\mathrm{s}}\right)+\operatorname{var}\left(\tilde{\mu}_{\mathrm{T}+\mathrm{s}}^{+}\right)+2 \operatorname{cov}\left(\tilde{\mu}_{\mathrm{T}+\mathrm{s}}, \tilde{\mu}_{\mathrm{T}+\mathrm{s}}^{+}\right)\right] / 4 \\
& =\left[\sigma_{\mathrm{T}+\mathrm{s}}^{2} / \mathrm{K}+\operatorname{cov}\left(\tilde{\mu}_{\mathrm{T}+\mathrm{s}} \tilde{\mu}_{\mathrm{T}+\mathrm{s}}^{+}\right)\right] / 2 \\
& =\left(1+\rho_{\mathrm{T}+\mathrm{s}}\right)\left[\sigma_{\mathrm{T}+\mathrm{s}}^{2} /(2 \mathrm{~K})\right] \\
& \leq \sigma_{\mathrm{T}+\mathrm{s}}^{2} / \mathrm{K}=\operatorname{var}\left(\tilde{\mu}_{\mathrm{T}+\mathrm{s}}\right) .
\end{aligned}
$$

The inequality is strict, provided that $\rho_{\mathrm{T}+\mathrm{s}}$ (the correlation coefficient between $\tilde{\mu}_{\mathrm{T}+\mathrm{s}}$ and $\tilde{\mu}_{\mathrm{T}+\mathrm{s}}^{+}$) is less than urity. This correlation is also the correlation between $\mathrm{NX}_{\mathrm{k}, \mathrm{T}+\mathrm{s}}$ and $\mathrm{NX} \mathrm{k}_{\mathrm{T}}^{+} \mathrm{T}+\mathrm{s}$. For the highly negative correlations which we obtain, the reduction in variance (i.e., increase in precision) is considerable, from four-fold to over 2000-fold; see Appendix D.

To test whether or not the deterministic forecast is biased, we compute the t-ratio for the hypothesis $\mu_{\mathrm{T}+\mathrm{s}}=\delta_{\mathrm{T}+\mathrm{s}}$ :

$$
\begin{aligned}
\psi_{\mathrm{T}+\mathrm{s}} & =\left(\bar{\mu}_{\mathrm{T}+\mathrm{s}}-\delta_{\mathrm{T}+\mathrm{s}}\right) / \sqrt{ } \operatorname{var}\left(\bar{\mu}_{\mathrm{T}+\mathrm{s}}\right) \\
& =\mathrm{K}^{1 / 2} \cdot\left(\bar{\mu}_{\mathrm{T}+\mathrm{s}}-\delta_{\mathrm{T}+\mathrm{s}}\right) / \sqrt{ } \operatorname{var}\left[\left(\mathrm{NX}_{\mathrm{k}, \mathrm{T}+\mathrm{s}}+\mathrm{NX}_{\mathrm{k}, \mathrm{T}+\mathrm{s}}^{+}\right) / 2\right],
\end{aligned}
$$

where the variance of $\left(\mathrm{NX}_{\mathrm{k}, \mathrm{T}+\mathrm{s}}+\mathrm{NX}_{\mathrm{k}, \mathrm{T}+\mathrm{s}}^{+}\right) / 2$ is estimated as was the variance of $\mathrm{NX} \mathrm{k}, \mathrm{T}+\mathrm{s}_{\text {from }}$ (18), but with $\left(\mathrm{NX}_{\mathrm{k}, \mathrm{T}+\mathrm{s}}+\mathrm{NX} \mathrm{k}_{\mathrm{k}, \mathrm{T}+\mathrm{s}}^{+}\right) / 2$ and $\bar{\mu}_{\mathrm{T}+\mathrm{s}}$ replacing $\mathrm{NX} \mathrm{k}, \mathrm{T}+\mathrm{s}$ and $\tilde{\mu}_{\mathrm{T}+\mathrm{s}}$ in that formula. Large values of $\psi_{\mathrm{T}+\mathrm{s}}$ indicate that the nonlinearity bias in the deterministic trade-account forecast is statistically significant, e.g., at approximately the 95\% confidence level if $\left.\right|_{\psi_{\mathrm{T}+\mathrm{s}}} \mid>1.96$. Selection of a large enough number of replications $\mathrm{K}$ will make any bias statistically significant, so it is also of interest to consider the numerical importance of the bias, as measured by $\bar{\mu}_{\mathrm{T}+\mathrm{s}}{ }^{-\delta_{\mathrm{T}+\mathrm{s}}}$.

For concise discussions of Monte Carlo analysis, including the use of antithetic variates, see Hammersley and Handscomb (1964) and Hendry (1984). For applications of antithetic 
variates to forecasts from econometric models, see Calzolari (1979), Fisher and Salmon (1986), and Mariano and Brown (1989), noting that they all treat the coefficient estimates as though they were known with certainty, whereas this section relaxes that assumption.

\subsection{Empirical Results}

Tables 9 and 10 respectively report for one-step and s-step ahead forecasts the estimated bias $\bar{\mu}_{\mathrm{T}+\mathrm{s}}-\delta_{\mathrm{T}+\mathrm{s}}$, the estimated standard error of the estimated bias $\sqrt{ } \operatorname{va} r\left(\bar{\mu}_{\mathrm{T}-\mathrm{s}}\right)$, and the corresponding t-ratio $\psi_{\mathrm{T}+\mathrm{s}}$. Some deterministic forecasts from all models have statistically significant nonlinearity biases, summarized as follows. First, the estimated biases from all models are usually highly statistically significant, although not as often or as much for M3 (one-step) or M1 (s-step). Second, the size of the bias changes with the forecast period, even switching sign in some cases. Third, for Helkie and Hooper's model, the choice of estimation method hardly affects either the magnitude or the profile of the bias.

Despite their statistical significance, the nonlinearity biases need not be economically significant. For models M1-M3, the deterministic and stochastic forecasts differ by only $\$ 2$ billion at most, although often statistically significantly so. By contrast, models M4-M6 have much larger and economically potentially important biases, e.g., of approximately $\$ 10$ billion at twelve periods ahead. The sometime difference between economically significant and statistically significant biases stems from the considerable accuracy with which antithetic variates estimate the mean of the trade-account forecast, making numerically slight departures from this mean statistically significant.

The numerically large biases for s-step ahead forecasts from models M4, M5, and M6 appear to arise for distinctly different reasons, e.g., dynamics for M5 and M6 and disaggregation for M4. Model M6 has (analytically) zero bias using the asymptotic formula (no uncertainty from estimation) but substantial bias with the approximate formula. Thus, that bias must be due to the nonlinear way in which dynamics affects multi-step forecasts. Specifically, the s-step ahead forecast error for the AR(1) model M6 is:

$$
\mathrm{NX} \mathrm{T}+\mathrm{s}-\hat{\mathrm{N} X} \mathrm{~T}_{\mathrm{T}+\mathrm{s}}=\sum_{\mathrm{i}=0}^{\mathrm{s}-1} \lambda_{1}^{\mathrm{i}} \mathrm{v}_{\mathrm{T}+\mathrm{s}-\mathrm{i}}+\left(\lambda_{\mathrm{i}-\hat{\lambda}}^{\mathrm{s}} \hat{\mathrm{s}}_{\mathrm{i}}^{\mathrm{s}}\right) \mathrm{N} \mathrm{X}_{\mathrm{T}}
$$


Table 9

Nonlinearity Biases in Deterministic Forecasts of the U.S. Trade Account One-step Ahead, Approximate Formula

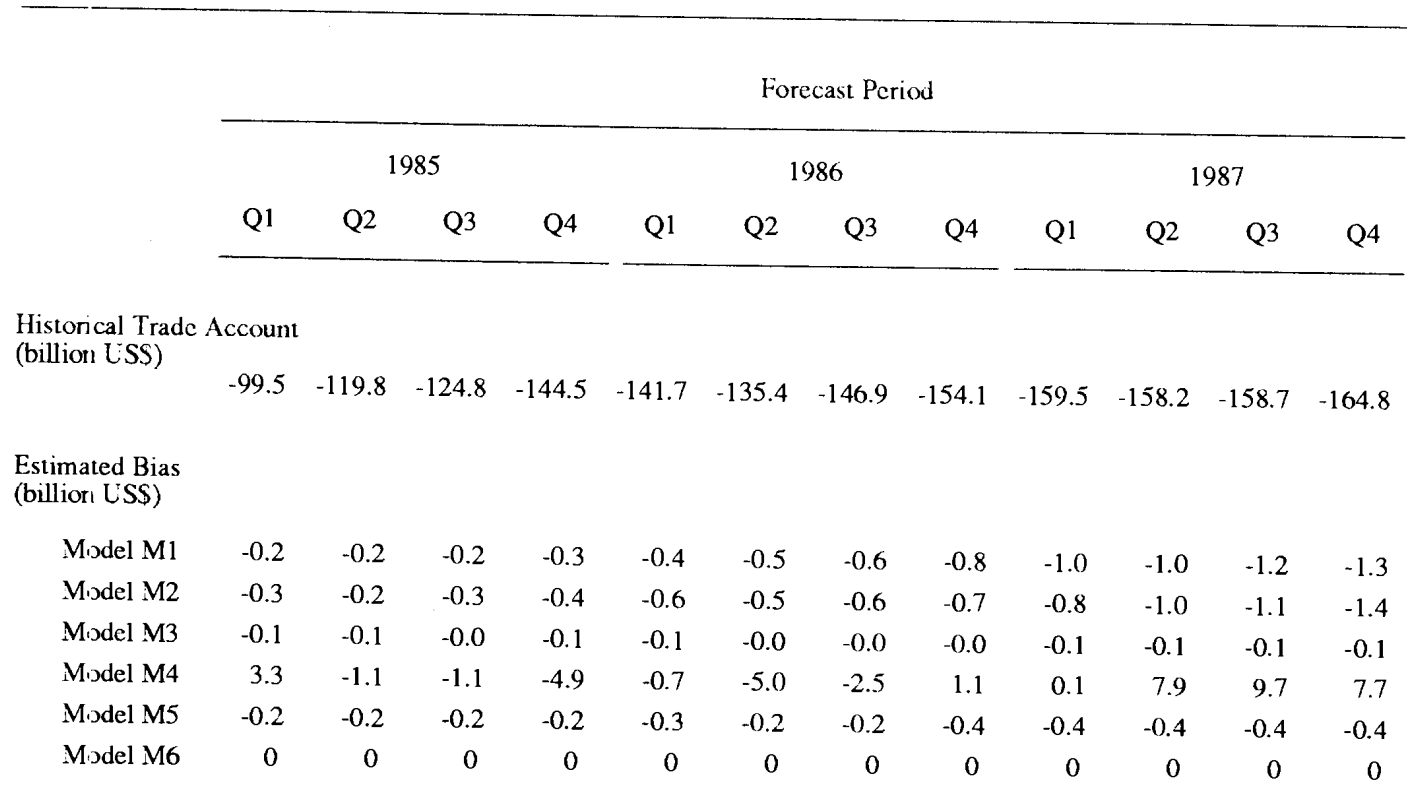

Estimated Standard Error of the Bias (billior, US\$)

$\begin{array}{lllllllllllll}\text { Midel M1 } & 0.04 & 0.043 & 0.047 & 0.053 & 0.057 & 0.062 & 0.066 & 0.072 & 0.076 & 0.081 & 0.09 & 0.1\end{array}$

$\begin{array}{lllllllllllll}\text { Model M2 } & 0.036 & 0.039 & 0.044 & 0.049 & 0.053 & 0.053 & 0.054 & 0.06 & 0.067 & 0.075 & 0.088 & 0.101\end{array}$

$\begin{array}{lllllllllllllll}\text { Model M3 } & 0.016 & 0.016 & 0.016 & 0.017 & 0.018 & 0.018 & 0.021 & 0.02 & 0.021 & 0.022 & 0.023 & 0.026\end{array}$

$\begin{array}{llllllllllllll}\text { Model M4 } & 0.039 & 0.045 & 0.047 & 0.05 & 0.057 & 0.062 & 0.062 & 0.061 & 0.069 & 0.078 & 0.082 & 0.094\end{array}$

$\begin{array}{lcccccccccccc}\text { Model M5 } & 0.019 & 0.019 & 0.02 & 0.021 & 0.023 & 0.022 & 0.022 & 0.03 & 0.037 & 0.032 & 0.034 & 0.038\end{array}$

$\begin{array}{lllllllllllll}\text { Model M6 } & 0 & 0 & 0 & 0 & 0 & 0 & 0 & 0 & 0 & 0 & 0 & 0\end{array}$

"t" ratio"

$\begin{array}{lrrrrrrrrrrrr}\text { Model M1 } & 4.3 & 3.9 & 3.6 & 5.0 & 7.4 & 7.5 & 8.9 & 10.6 & 13.2 & 12.2 & 13.2 & 13.5 \\ \text { Model M2 } & 7.6 & 6.2 & 7.2 & 9.1 & 10.7 & 9.3 & 10.9 & 11.5 & 12.6 & 12.8 & 13.0 & 13.5 \\ \text { Model M3 } & 6.7 & 4.1 & 2.2 & 4.7 & 5.9 & 2.3 & 1.7 & 1.1 & 3.0 & 3.5 & 3.1 & 2.7 \\ \text { Model M4 } & 83.7 & 25.8 & 22.3 & 98.8 & 12.9 & 80.8 & 39.5 & 17.8 & 1.1 & 101.2 & 118.4 & 82.0 \\ \text { Model M5 } & 11.9 & 11.9 & 10.6 & 9.6 & 12.6 & 9.9 & 9.4 & 12.0 & 12.1 & 12.8 & 12.3 & 11.4 \\ \text { Model M6 } & - & - & - & - & - & - & - & - & - & - & - & -\end{array}$

Notes: $\quad$ Model Ml: Helkie and Hooper (1988).

Model M2: Model M1 by FLML.

Model M3: Model M1 by FIML, with partial adjustment, without non-price rationing.

Model M4: Bilateral trade model by FIML.

Model M5: VAR(4) of impon and expon volumes and price indices.

Model M6: AR(1) of the nominal trade account.

a. The " $t$ " ratios are numerically accurate. However, they do not always match the ratios between the reported biases and standard crrors because the latter are rounded. 
Table 10

Nonlinearity Biases in Deterministic Forecasts of the U.S. Trade Account s-step Ahead, Approximate Formula

\begin{tabular}{|c|c|c|c|c|c|c|c|c|c|c|c|c|}
\hline & \multicolumn{12}{|c|}{ Forccast Period } \\
\hline & \multicolumn{4}{|c|}{1985} & \multicolumn{4}{|c|}{1986} & \multicolumn{4}{|c|}{1987} \\
\hline & Q1 & Q2 & Q3 & Q4 & Q1 & Q2 & Q3 & Q4 & Q1 & Q2 & Q3 & Q4 \\
\hline \multicolumn{13}{|c|}{$\begin{array}{l}\text { Historical Trade Account } \\
\text { (billion LSS) }\end{array}$} \\
\hline & -99.5 & $-119.8-$ & -124.8 & -144.5 & -141.7 & -135.4 & -146.9 & -154.1 & -159.5 & -158.2 & -158.7 & -164.8 \\
\hline \multicolumn{13}{|l|}{$\begin{array}{l}\text { Estimated Bias } \\
\text { (billion US\$) }\end{array}$} \\
\hline Model M1 & -0.2 & -0.0 & -0.1 & -0.0 & -0.1 & 0.0 & -0.1 & -0.1 & -0.4 & -0.7 & -0.8 & -1.0 \\
\hline Model M2 & -0.3 & -0.2 & -0.1 & -0.3 & -0.3 & -0.3 & -0.1 & -0.1 & -0.1 & -0.4 & -0.8 & -1.3 \\
\hline Model M3 & -0.1 & -0.2 & -0.2 & -0.3 & -0.4 & -0.6 & -0.7 & -0.8 & -0.7 & -0.8 & -0.7 & -0.7 \\
\hline Model M4 & 3.3 & -1.2 & -1.0 & -4.5 & -0.0 & -4.4 & -2.3 & 0.8 & -0.7 & 7.2 & 9.8 & 7.7 \\
\hline Model M5 & -0.2 & -0.7 & -0.6 & -0.8 & -1.6 & -2.5 & -3.1 & -3.7 & -4.5 & -5.0 & -5.6 & -6.8 \\
\hline Model M6 & 0 & -0.1 & -0.4 & -0.8 & -1.3 & -2.1 & -3.1 & -4.3 & -5.8 & -7.6 & -9.8 & -12.4 \\
\hline \multicolumn{13}{|c|}{$\begin{array}{l}\text { Estimated Standard Error of the Bias } \\
\text { (billion LSS) }\end{array}$} \\
\hline Model M1 & 0.04 & 0.064 & 0.084 & 0.099 & 0.104 & 0.111 & 0.118 & 0.123 & 0.129 & 0.137 & 0.148 & 0.15 \\
\hline Model M2 & 0.036 & 0.057 & 0.07 & 0.082 & 0.09 & 0.096 & 0.102 & 0.114 & 0.12 & 0.128 & 0.136 & 0.146 \\
\hline Model M3 & 0.016 & 0.041 & 0.058 & 0.076 & 0.089 & 0.096 & 0.106 & 0.118 & 0.135 & 0.149 & 0.164 & 0.178 \\
\hline Model M4 & 0.039 & 0.066 & 0.083 & 0.1 & 0.115 & 0.136 & 0.145 & 0.155 & 0.171 & 0.202 & 0.212 & 0.24 \\
\hline Model M5 & 0.019 & 0.12 & 0.235 & 0.341 & 0.446 & 0.546 & 0.67 & 0.812 & 0.952 & 1.078 & 1.218 & 1.349 \\
\hline Model M6 & 0 & 0.011 & 0.027 & 0.051 & 0.082 & 0.124 & 0.177 & 0.243 & 0.323 & 0.418 & 0.531 & 0.665 \\
\hline \multicolumn{13}{|l|}{ "t" ratio } \\
\hline Model M1 & 4.3 & 0.7 & 1.1 & 0.4 & 0.8 & 0.2 & 0.5 & 0.9 & 2.9 & 4.8 & 5.6 & 6.9 \\
\hline Model M2 & 7.6 & 3.2 & 2.1 & 3.1 & 3.6 & 3.0 & 1.3 & 1.0 & 0.8 & 3.2 & 6.0 & 9.0 \\
\hline Model M3 & 6.7 & 4.0 & 3.3 & 3.7 & 4.5 & 5.9 & 6.8 & 6.6 & 5.4 & 5.4 & 4.5 & 4.1 \\
\hline Model M4 & 83.7 & 17.8 & 11.6 & 45.4 & 0.3 & 32.6 & 15.5 & 5.2 & 4.2 & 35.5 & 46.0 & 32.3 \\
\hline Model M5 & 11.9 & 5.9 & 2.3 & 2.4 & 3.5 & 4.5 & 4.6 & 4.6 & 4.8 & 4.6 & 4.6 & 5.0 \\
\hline Model M6 & - & 11.5 & 14.0 & 15.4 & 16.3 & 16.9 & 17.4 & 17.7 & 18.0 & 18.3 & 18.5 & 18.6 \\
\hline
\end{tabular}

Notes: $\quad$ Model M1: Helkie and Hooper (1988).

Model M2: Model M1 by FIML.

Model M3: Model M1 by FIML, with partial adjustment, without non-price rationing.

Model M4: Bilateral trade model by FIML.

Model M5: VAR(4) of import and export volumes and price indices.

Model M6: AR(1) of the nominal trade account.

a. The " $\mathrm{t}$ " ratios are numerically accurate. However, they do not always match the ratios between the reported biases and standard errors because the latter are rounded. 
where $v_{t}$ is the error on the $\operatorname{AR}(1)$ process and the intercept is ignored for expositional simplicity. The errors are assumed normal, so the linear combination of them (the first term) is also normal. The asymptotic formula sets $\lambda_{1}=\hat{\lambda}_{1}$, ignoring the uncertainty from estimation (the second term) and making the corresponding forecast unbiased. In the approximate formula, $\hat{\lambda}_{1}$ is assumed normally distributed, unbiased for $\lambda_{1} ;$ but $\hat{\lambda}_{1}^{s}$ is biased for $\lambda_{1}^{s}(s>1)$. That nonlinearity in $\hat{\lambda}_{1}$ is what the results in Table 10 for M6 detect. Although dynamics may contribute to the nonlinearity biases for M4, other explanations could be more important. Model M4 is much more disaggregated (by country) than the other models, and if the relative fluctuations of the disaggregated variables are larger than of the aggregate, nonlinearity biases should be more pronounced for the disaggregated model (M4).

Overall, the sensitivity of the nonlinearity bias to the forecast period, estimation method, level of aggregation, and dynamic specification suggests that no simple correction exists for the bias, other than simulation. When a substantive nonlinearity bias is present, deterministic forecasts will be at an inherent disadvantage in terms of forecasting performance relative to (unbiased) stochastic forecasts. All of the models examined have statistically significant nonlinearity biases, of which three have numerically substantive biases. More generally, since nonlinearity is a feature common to most macro-econometric models, deterministic forecasts from them should be interpreted with caution, at least until the magnitude of the bias is assessed.

\section{Summary and Conclusions}

This paper generalizes existing methodology for evaluating forecasts and applies it to forecasts over 1985Q1-1987Q4 from six econometric models of the U.S. trade account. The predictive performance of these models has implications for econometric practice, trade modeling, and the role of these models in policy making.

Deterministic forecasts are shown to be an unreliable basis for assessing model performance, both because they typically lack a measure of forecast uncertainty and because they tend to be biased for nonlinear models. Forecasts generated by stochastic simulation are a simple, computationally feasible alternative without these problems, and can allow for 
uncertainty not only from the disturbances but also from coefficient estimation. Confidence intervals for the forecasts are immediately obtainable from stochastic simulation.

Measures of forecast uncertainty aid the interpretation of forecasts in mariy situations, including in ex ante prediction, counter-factual policy simulation, and the evaluation of the forecasting models themselves. For the last, intra-model and inter-model analyses based upon stochastic forecasts are easily conducted with parameter constancy (i.e., predictive failure) and forecast-encompassing test statistics, and each provides unique information about the models. To apply the latter statistic to the trade models examined, we generalize it to allow for s-step ahead forecasts from nonlinear models, accounting for coefficient uncertainty. Finally, stochastic simulation with antithetic variates offers an efficient, reliable technique for detecting and assessing nonlinearity biases.

Empirically, the confidence intervals of the trade-account forecasts are very wide, and are generally increasing with the forecast horizon. Both features are common across the models, even though the models differ in several basic attributes which might have influenced the results: model size, dynamic specification, choice of "exogenous" variables, estimation method, and level of country and commodity aggregation. The forecast errors are large and systematic, and the 95\% confidence interval of even a one-step ahead forecast is often an order of magnitude greater than the quarter-to-quarter (or month-to-month) trade-account fluctuations receiving attention by policy makers. The uncertainty of the model-based forecasts clearly tempers the role of these models in formulating policy.

In spite of this large uncertainty, the forecast-encompassing tests indicate that forecast errors from each of the six trade-account models examined are in part predictable by the forecasts (and so the data) of the other models. That is, each model involves a loss of information relative to the other models. Conversely, those tests imply that better forecasts are obtainable from the data currently used in modeling. However, to assess the magnitude of the implied reduction in forecast uncertainty feasible, we must await the development of an improved model. 
Finally, the deterministic forecasts of several models are subject to substantial biases from model non inearity. As a rule, ignoring such biases degrades forecast performance.

As currently implemented, the models in this analysis are subject to many limitations, two of the most important being the chosen dynamic specifications and the assumed weak exogeneity of income, GDP deflators, and the exchange rate. Testing these and other assumptions and redesigning the models in light of the outcomes almost certainly would modify the numerical results obtained above. Even so, the message of the paper remains the same: model-based forecasts are random variables, and accounting for their distributional properties is essential for interpreting, the forecasts properly, whether in policy analysis, model evaluation, or ex ante prediction exercises. 


\section{References}

Baillie, R.T. (1979) "Asymptotic Prediction Mean Squared Error for Vector Autoregressive Models", Biometrika, 66, 675-678.

Baldwin, R. (1988) "Hysteresis in Import Prices: The Beachhead Effect", American Economic Review, 78, 773-785.

Brown, B.W. and R.S. Mariano (1984) "Residual-based Procedures for Prediction and Estimation in a Nonlinear Simultaneous System", Econometrica, 52, 321-343.

Brown, B.W. and R.S. Mariano (1989) "Predictors in Dynamic Nonlinear Models: Large-sample Behavior", Econometric Theory, 5, 430-452.

Bryant, R.C. and G. Holtham (1988) "The U.S. External Deficit: Diagnosis, Prognosis, and Cure", Chapter 3 in R.C. Bryant, G. Holtham, and P. Hooper (eds.) External Deficits and the Dollar: The Pit and the Pendulum, Washington D.C., Brookings Institution, 57-81.

Calzolari, G. (1979) "Antithetic Variates to Estimate the Simulation Bias in Non-linear Models", Economics Letters, 4, 323-328.

Chong, Y.Y. and D.F. Hendry (1986) "Econometric Evaluation of Linear Macro-economic Models", Review of Economic Studies, 53, 671-690.

Chow, G.C. (1960) "Tests of Equality Between Sets of Coefficients in Two Linear Regressions", Econometrica, 28, 591-605.

Cline, W.R. (1989a) "Macroeconomic Influences on Trade Policy", American Economic Review, AEA Papers and Proceedings, 79, 123-127.

Cline, W.R. (1989b) United States External Adjustment and the World Economy, Washington, D.C., Institute for International Economics.

Edison, H.J., J.R. Marquez, and R.W. Tryon (1987) "The Structure and Properties of the Federal Reserve Board Multicountry Model", Economic Modelling, 4, 115-315.

Eichengreen, B.J. (1989) "Trade Deficits in the Long Run", Chapter 4 in A.E. Burger (ed.) U.S.Trade Deficit: Causes, Consequences, and Cures, Boston, Kluwer Academic Publishers, 239-278.

Engle, R.F., D.F. Hendry, and J.-F. Richard (1983) "Exogeneity", Econometrica, 51, 277-304.

Ericsson, N.R. (1989) "Parameter Constancy, Mean Squared Forecast Errors, and Measuring Forecast Performance: An Exposition and Extensions", mimeo, Federal Reserve Board, Washington, D.C.

Ericsson, N.R. and D.F. Hendry (1989) "Encompassing and Rational Expectations: How Sequential Corroboration Can Imply Refutation", International Finance Discussion Paper No. 354, Federal Reserve Board, Washington D.C.

Ericsson, N.R. and J.R. Marquez (1989) "Exact and Approximate Multi-period Mean-square Forecast Errors for Dynamic Econometric Models", International Finance Discussion Paper No. 348, Federal Reserve Board, Washington D.C. 
Fair, R.C. (1984) Specification, Estimation, and Analysis of Macroeconometric Models, Cambridge, Harvard University Press.

Fair, R.C. (1986) "Evaluating the Predictive Accuracy of Models", Chapter 33 in Z. Griliches and M.D. Intriligator (eds.) Handbook of Econometrics. Amsterdam, North-Holland, Volume III, 1979-1995.

Fair, R.C. (1988) "Sources of Economic Fluctuations in the United States", Quarterly Journal of Economics, 53, 313-332.

Feldstein, M. (1986) "Correcting the World Trade Inbalance", Harvard University, Cambridge, mimeo.

Fisher, P. and M. Salmon (1986) "On Evaluating the Importance of Nonlinearity in Large Macroeconometric Models", International Economic Review, 27, 625-646.

Goldstein, M. and M.S. Khan (1985) "Income and Price Effects in Foreign Trade", Chapter 20 in R.W. Jones and P.B. Kenen (eds.) Handbook of International Economics, Amsterdam, North-Holland, Volume II, 1041-1105.

Haavelmo, T. (1944) "The Probability Approach in Econometrics", Econometrica, 12, Supplement.

Hammersley, J.M. and D.C. Handscomb (1964) Monte Carlo Methods, London, Chapman and Hall.

Helkie, W.L. and P. Hooper (1987) "The U.S. External Deficit in the 1980s: An Empirical Analysis", International Finance Discussion Paper No. 304, Federal Reserve Board, Wasaington D.C.

Helkie, W.L. and P. Hooper (1988) "An Empirical Analysis of the External Deficit, 1980-86", Chapter 2 in R.C. Bryant, G. Holtham, and P. Hooper (eds.) External Deficits and the Dollar: The Pit and the Pendulum, Washington, D.C., Brookings Institution, 10-56.

Helliwell, J.F. (1989) "Reducing International Imbalances: Evidence from Multicountry Models", American Economic Review, AEA Papers and Proceedings, 79, 258-263.

Hendry, D.F. (1979) "Predictive Failure and Econometric Modelling in Macroeconomics: The Transactions Demand for Money", Chapter 9 in P. Ormerod (ed.) Economic Modelling, London, Heinemann Education Books, 217-242.

Hendry, D.F. (1984) "Monte Carlo Experimentation in Econometrics", Chapter 16 in Z. Griliches and M.D. Intriligator (eds.) Handbook of Econometrics, Amsterdam, North-Holland, Volume II, 937-976.

Hendry, D.F. (1989) PC-GIVE: An Interactive Econometric Modelling System, Version 6.0/6.01, Oxford, Institute of Economics and Statistics and Nuffield College, University of Oxford.

Hendry, D.F. (1990) Lectures on Econometric: Methodology, Oxford, Oxford University Press, forthcoming (with Duo Qin and Carlo Favero).

Hendry, D.F. and J.-F. Richard (1982) "On the Formulation of Empirical Models in Dynamic Econometrics", Journal of Econometrics, 20, 3-33. 
Hendry, D.F. and P.K. Trivedi (1972) "Maximum Likelihood Estimation of Difference Equations with Moving Average Errors: A Simulation Study", Review of Economic Studies, 39, 117-145.

Hooper, P. (1988) "The Dollar, External Imbalance, and the U.S. Economy", Journal of Economic and Monetary Affairs, 2, 30-53.

Hooper, P. (1989) "Exchange Rates and U.S. External Adjustment in the Short Run and the Long Run", International Finance Discussion Paper No. 346, Federal Reserve Board, Washington, D.C.

Hooper, P. and C.L. Mann (1989) "Exchange Rate Pass-through in the 1980s: The Case of U.S. Imports of Manufactures", Brookings Papers on Economic Activity, 297-337 (with discussion).

Hoque, A., J.R. Magnus, and B. Pesaran (1988) "The Exact Multi-period Mean-square Forecast Error for the First-order Autoregressive Model", Journal of Econometrics, 39, 327-346.

Houthakker, H.S. and S.P. Magee (1969) "Income and Price Elasticities in World Trade", Review of Economics and Statistics, 51, 111-125.

Howard, D.H. (1989a) "Implications of the U.S. Current Account Deficit", Journal of Economic Perspectives, 3, 153-165.

Howard, D.H. (1989b) "The United States as a Heavily Indebted Country", International Finance Discussion Paper No. 353, Federal Reserve Board, Washington, D.C.

Howrey, P. and H.H. Kelejian (1969) "Simulation Versus Analytical Solutions" in T.H. Naylor (ed.) The Design of Computer Simulation Experiments, Durham, North Carolina, Duke University Press, 207-231.

Intex Solutions (1989) TROLL Version 13, Reference Manuals, Volumes 1-6 and Updates, Needham, Massachusetts, Intex Solutions.

Jarque, C.M. and A.K. Bera (1980) "Efficient Tests for Normality, Homoscedasticity and Serial Independence of Regression Residuals", Economics Letters, 6, 255-259.

Klein, L.R. (1981) Econometric Models as Guides for Decision-making, The Charles C. Moskowitz Memorial Lectures, No. XXII, New York, The Free Press.

Krugman, P.R. (1988) "US External Adjustment", paper prepared for the meeting of academic advisers to the Board of Governors of the Federal Reserve System, November 3, 1988.

Krugman, P.R. (1989) Exchange-rate Instability, Cambridge, MIT Press.

Krugman, P.R. and R.E. Baldwin (1987) "The Persistence of the U.S. Trade Deficit", Brookings Papers on Economic Activity, 1-55 (with discussion).

Magnus, J.R. and B. Pesaran (1989) "The Exact Multi-period Mean-square Forecast Error for the First-order Autoregressive Model with an Intercept", Journal of Econometrics, 42, $157-179$.

Mariano, R.S. and B.W. Brown (1983) "Asymptotic Behavior of Predictors in a Nonlinear Simultaneous System", International Economic Review, 24, 523-536. 
Mariano, R.S. and B.W. Brown (1989) "Stochastic Simulation, Prediction and Validation of Nonlinear Models", Chapter 2 in L.R. Klein and J. Marquez (eds.) Economics in Theory and Practice: An Eclectic Approach, Dordrecht, The Netherlands, Kluwer Academic Publishers, 17-36.

Marquez, J. (1989) "Income and Price Elasticities of Foreign Trade Flows: Econometric Estimation and Analysis of the US Trade Deficit", Chapter 6 in L.R. Klein and J. Marquez (eds.) Economics in Theory and Practice: An Eclectic Approach, Dordrecht, The Netherlands, Kluwer Academic Publishers, 129-176.

Marris, S. (1987) Deficits and the Dollar: The World Economy at Risk, Policy Analyses in International Economics, No. 14, Washington, D.C., Institute for International Economics, Updated Edition.

Marsaglia, G. (1965) "Ratios of Normal Variables and Ratios of Sums of Uniform Variables", Journal of the American Statistical Association, 60, 193-204.

Meade, E.E. (1988) "Exchange Rates, Adjustment, and the J-curve", Federal Reserve Bulletin, $74,633-644$

Nagar, A.L. (1969) "Stochastic Simulation of the Brookings Econometric Model", Chapter 12 in J.S. Duesenberry, G. Fromm, L.R. Klein, and E. Kuh (eds.) The Brookings Model: Some Further Results, Amsterdam, North-Holland, 425-456.

Pagan, A. (1989) "On the Role of Simulation in the Statistical Evaluation of Econometric Models", Journal of Econometrics, 4(), 125-139.

Orcutt, G.H. and H.S. Winokur, Jr. (1969) "First Order Autoregression: Inference, Estimation, and Prediction", Econometrica, 37, 1-14.

Sargan, J.D. (1982) "On Monte Carlo Estimates of Moments That Are Infinite" in R.L. Basmann and G.F. Rhodes, Jr. (eds.) Advances in Econometrics: A Research Annual, Volume 1, Greenwich, Connecticut, JAI Press, 267-299.

Schmidt, P. (1974) "The Asymptotic Distribution of Forecasts in the Dynamic Simulation of an Econometric Model", Econometrica, 42, 303-309.

Silvey, S.D. (1975) Statistical Inference, London, Chapman and Hall.

U.S. Congressional Budget Office (1989) Policies for Reducing the Current-account Deficit, Washington, D.C., Congress of the United States, August.

U.S. Library of Congress (1988) "The Dollar and the Trade Deficit: What's To Be Done?", Congressional Research Service, June 7.

White, H. (1980) "A Heteroskedasticity-consistent Covariance Matrix Estimator and a Direct Test for Heteroskedasticity", Econometrica, 48, 817-838. 


\section{Appendix A: Description of the Data}

Sections A.1, A.2, A.3, and A.4 below respectively describe the data for the Helkie-Hooper model and its closest variants (M1-M3), the bilateral trade model (M4), the VAR (M5), and the univariate autoregressive model (M6). Data sources appear as italicized abbreviations and are described in Section A.5.

\section{A.1. Data for Models M1-M3}

All series for these models are maintained in the databank of the trade model developed in Helkie and Hooper (1988).

Exports, Imports, Their Deflators, and the Trade Account. The nominal values of agricultural exports and non-agricultural exports are in billions of U.S. dollars, quarterly at annual rates, and come from NIA Table 4.3. Real exports are in billions of (constant) 1982 U.S. dollars, quarterly at annual rates, and come from NIA Table 4.4. The price deflators for agricultural and non-agricultural exports are obtained as the ratios between the respective nominal and real exports.

Nominal and real values of non-oil imports are in billions of (current and 1982) U.S. dollars, quarterly at annual rates, and come from NIA Tables 4.3 and 4.4 , respectively. The nonoil import deflator is constructed as the ratio between nominal and real non-oil imports.

The nominal value of oil imports is in billions of U.S. dollars, quarterly at annual rates, and comes from NIA Table 4.3. The volume of oil imports, quarterly in billions of barrels per year, is constructed as the excess of domestic consumption over the sum of domestic production and inventory drawdowns:

$$
\mathrm{MQFL}=\mathrm{FLC}-\mathrm{FLQ}+\mathrm{FLSCN},
$$

where MQFL, FLC, FLQ, and FLSCN are respectively oil imports, oil consumption, oil production, and the change in oil inventories (all quarterly in billions of barrels per year, $D O E$ ). The unit value of oil imports is obtained as the ratio between the nominal value and the volume of oil imports. 
The nominal trade account (billions of U.S. dollars, quarterly at annual rates) is constructed as the difference between the nominal value of exports and the nominal value of imports.

GNP and CPI. Real U.S. GNP comes from NIA Table 1.2. The U.S. GNP and consumption deflators are constructed as ratios between nominal magnitudes (NIA Table 1.1) and real variables (NIA Table 1.2). U.S. capacity utilization comes from the $F R B$ Table 2.12 .

Foreign GNP is constructed as a geometric mean of the levels of foreign GNPs, using the weights in Table A.1 below. The sources for foreign GNPs are: CSR (Canada); BOJ (Japan); ET (United Kingdom); Statistical Supplement, DBB (Germany); Comptes Nationales, INSEE (France); INSTAT (Italy); Bulletin de Statistique, Institute National de Statistique (Belgium); Kwartaalrekeningen, Central Bureau of Statistics (Netherlands); Reflets de L'Economie, Office Fédéral de la Statistique (Switzerland); and National Accounts, National Central Bureau of Statistics (Sweden).

Table A.1. 1978-83 Average Trade Weights for the G-10 Countries

\begin{tabular}{lc} 
Country & Trade Weights \\
\cline { 2 - 2 } Canada & \\
Japan & $9.1 \%$ \\
United Kingdom & $13.6 \%$ \\
Germany & $11.9 \%$ \\
France & $20.8 \%$ \\
Italy & $13.1 \%$ \\
Belgium & $9.0 \%$ \\
Netherlands & $6.4 \%$ \\
Switzerland & $8.3 \%$ \\
Sweden & $3.6 \%$ \\
Total & $4.2 \%$ \\
& $100.0 \%$
\end{tabular}

The foreign consumer price index (CPI) is constructed as a geometric mean of the countryspecific consumer price indices, using the trade weights in Table A.1. The sources for the individual CPIs are: CSR (Canada); BOJ (Japan); Employment Gazette, Department of Employment (United Kingdom); DBB (Germany); Bulletin Mensuel de Statistique, INSEE (France); INSTAT (Italy); Bulletin de la Banque Nationale, National Bank of Belgium (Belgium); Maandstatistiek, van de Pryzen, Central Bureau of Statistics (Netherlands); La Vie Economique, 
Dept. Fed. Econ. Publ. (Switzerland); and Allman Manadsstatistik, Swedish Official Statistical Office (Sweden). Each trade weight is the average over 1978-83 of the given country's share in the group's total imports. The source of these nominal imports is the IFS, Line 77abd.

Commodity Price. The world non-fuel commodity price comes from the IFS Commodity Price Table (Line 001).

Capital Stock. Relative capital stocks are constructed as ratios between the U.S. capital stock and the respective foreign capital stocks. For every country, the (real) capital stock equals cumulated real gross fixed investment. Real investment equals nominal investment deflated by the GNP (GDP) deflator. Nominal investment comes from the IFS, Line 93e; and the GNP (GDP) deflator is obtained as the ratio between nominal and real GNP (GDP) where both nominal and real variables are from the IFS, typically Lines 99a (99b) and 99a.r (99b.r). Capital stocks for foreign industrialized countries (KDC) and for developing countries (KLDC) are constructed as geometric means of the capital stocks of selected countries, where the weights are 1978-83 multilateral trade weights. For KDC, the countries and weights are: Belgium (0.061), Canada (0.068), France (0.112), Germany (0.151), Italy (0.081), Japan (0.132), Netherlands (0.069), Sweden (0.029), Switzerland (0.030), United Kingdom (0.102), Australia (0.023), Austria (0.019), Denmark (0.017), Finland (0.014), Greece (0.007), Ireland (0.009), New Zealand (0.005), Norway (0.016), Portugal (0.006), Spain (0.025), Turkey (0.006), and South Africa (0.018). For KLDC, the countries and weights are: Brazil (0.142), India (0.076), Israel (0.051), S. Korea (0.149), Malaysia (0.079), Mexico (0.108), Philippines (0.044), Singapore (0.149), Taiwan (0.149), and Thailand (0.053). An overall foreign capital stock is constructed as the geometric mean of KDC and KLDC:

$$
\mathrm{KFOREIGN}=\mathrm{KDC}^{0.767} \mathrm{KLDC}^{0.233}
$$

The country-specific weights and the weights on KDC and KLDC are the country's (or countries') average shares in the corresponding group's total imports. The source of these imports is the IFS, Line 77abd. 
Exchange Rates and the U.S. PPI. The weighted average of the dollar relative to G-10 currencies is constructed as a geometric mean of the bilateral exchange rates, using the weights in Table A.1. The bilateral exchange rates are from the FRB Table 3.28.

The U.S. producer price index (with export weights) is constructed as a geometric mean of the producer price indices for durable manufacturing, non-durable manufacturing, and petroleum products. The weights are the 1982 shares of these products in their combined export value. The source of the individual PPIs is the PPI Press Release of the Bureau of Labor Statistics, U.S. Department of Labor. The source of the weights is Highlights of Exports and Imports Trade (FT990) from the Bureau of Economic Analysis, U.S. Department of Commerce.

\section{A.2. Data for Model M4}

Model M4 is described in Marquez (1989). All of the series for M4 are maintained in the databank of the Federal Reserve Board's Multicountry Model; cf. Edison, Marquez, and Tryon (1987). The countries modeled in M4 are: Canada, Germany, Japan, the United Kingdom, the rest of the OECD countries (ROECD), non-OPEC developing countries (LDCs), and OPEC.

Exports, Imports, Their Deflators, and the Trade Account. All (nominal) bilateral trade flows are in billions of U.S. dollars, F.O.B., quarterly at annual rates, and come from the DOT (1987).

To estimate the value of imports in 1972 U.S. dollars from each of Canada, Germany, Japan, and the United Kingdom, the nominal dollar value of U.S. (bilateral) imports from a given country $\mathrm{s}$ is deflated by $\mathrm{P}_{\mathrm{S}} \mathrm{E}_{\mathrm{s}}$, where $\mathrm{P}_{\mathrm{S}}$ is the multilateral export unit value of country $\mathrm{s}$ in local currency with $1972=1.00$ and $E_{S}$ is the U.S. dollar exchange rate index (\$U.S./local currency) with 1972=1.00. $\mathrm{P}_{\mathrm{S}} \mathrm{E}_{\mathrm{S}}$ estimates the associated dollar import price, and uses the multilateral export price rather than the bilateral trade price because long series of quarterly data on the latter are not publicly available. Thus, the deflator for imports from country s is $P_{S} E_{S}(1972=1.00)$. The sources for the multilateral export unit values of the four countries involved are: $C S R$, D50501*100/D40587 (Canada); DBB, XU0110 (Germany); IFS, Line 74 divided by its value in 1972 (Japan); and ET, CGTOQU8080 0- (United Kingdom). 
The export price for the rest of the OECD (ROECD) is measured as a geometric mean of the country-specific dollar export prices of the countries in this aggregate, where those prices come from the IFS. The weight on each export price is the sample mean of the same country's export share in total exports of the ROECD. The countries in the ROECD are as follows, with the corresponding weight and IFS line number in parentheses: Austria $(5 \%, 122)$, Belgyium $(15 \%$, 126), France $(26 \%, 132)$, Italy $(18 \%, 136)$, Netherlands (17\%, 138), Norway (4\%, 142), Sweden $(8 \%, 144)$, and Switzerland $(7 \%, 146)$. For these export prices and for the LDC export price below, the line numbers are from the IFS Table 74d of "Export Unit Values", whereas other IFS data are from the IFS country-specific tables.

The source for the LDC export price is the IFS, Line 201.

For OPEC, the export price is the oil market price, in U.S. dollars, as reported by the IEA.

The value of U.S. exports in 1972 U.S. dollars is estimated as the nominal value of total bilateral exports deflated by the U.S. multilateral export unit value $P_{U S}$. The source for $P_{U S}$ is the U.S. Department of Commerce, Bureau of the Census, U.S. Import/Export Unit Value Press Release (discontinued as of June 1989).

The procedures used for constructing real trade flows assume that the commodity mix of country s's exports to the U.S. is (and remains) the same as that to other countries, and likewise for U.S. exports to country s.

The nominal trade account (billions of U.S. dollars, quarterly at annual rates) is constructed as the difference between the sum of the nominal values of bilateral exports and the sum of the nominal values of bilateral imports.

Two caveats on the trade account for M4 must be noted for the forecast analysis in this paper. First, the numerical values of the trade account for M1-M3 are not the same as those for M4 because the sources are different (NIA versus DOT). To standardize the forecast analysis, we use the numbers from the NIA, which are those for the Helkie-Hooper model. The percentage discrepancies between the two trade-account series can be substantial, the maximun over the forecast period being $26.5 \%$ ( $\$ 31.8$ billion) in $1985 \mathrm{Q} 2$. Even so, estimation of M4 uses the DOT 
numbers. Siecond, trade with countries not modeled in M4 are aggregated into a "Rest of World" sector (ROW), whose imports and exports are treated as known in forecasting. By contrast, M1M3 treat al imports and exports as endogenous. This difference should not give M4 much of an inherent advantage in forecasting, noting that the maximum percentages over the forecast period of ROW imports, exports, and trade account (in absolute value) out of total figures are $6.8 \%$, $4.3 \%$, and $11.1 \%$, respectively.

Tariffs. Goods imported are often subject to tariffs, which in turn affect the price paid by the consumer. The imputed price $\left(\mathrm{P}_{\mathrm{ks}}\right)$ of country k's imports from country $\mathrm{s}$ is constructed as $\mathrm{P}_{\mathrm{ks}}=\mathrm{E}_{\mathrm{ks}}\left(1+\tau_{\mathrm{k}}\right) \mathrm{P}_{\mathrm{s}}$, where $\mathrm{E}_{\mathrm{ks}}$ is the bilateral exchange rate between countries $\mathrm{k}$ and $\mathrm{s}$ (see below), $\tau_{\mathrm{k}}$ is the average ad valorem tariff rate of country $\mathrm{k}$, and $\mathrm{P}_{\mathrm{S}}$ is the multilateral export unit value of country $s$ in local currency (described above). These imputed prices determine (in part) the demand for different bilateral imports in M4.

The tariff rate is available only for the United States, and is constructed as the share of total (i.e., multilateral) tariff receipts in total U.S. imports. (Hence, the tariff rates on goods imported by countries other than the United States are assumed to be zero.) The source for tariff receipts is the Monthly Bulletin, U.S. Department of the Treasury.

Third-country Import Prices. Imports from one country often face competition by imports from another country, e.g., U.S. imports of Japanese cars face competition by U.S. imports of German cars. Thus, the bilateral trade equations include third-country import prices. For instance, the equation for country k's imports from country s includes a geometrically weighted average of country k's import prices from country $q(q \neq s, k)$, constructed as:

$$
P_{k l s}=\prod_{q \neq s, k}\left[E_{k q} P_{q}\right]^{\omega} q
$$

where $\omega_{\mathrm{q}}$ is the share of the qth country in the group's total exports and $\mathrm{P}_{\mathrm{q}}$ is the multilateral export unit value of country $q$ in local currency (described above). The aggregation of export prices of various countries into a single index makes two important assumptions: first, country k's imports from country s are strongly separable from country k's imports from countries other than s; second, the elasticity of substitution among imports from countries other than $s$ is unity. 
Real Income, and GNP (GDP) Deflators. Real incomes for Canada, Germany, Japan, the United Kingdom, and the United States are defined as real GNP (or GDP) measured in domestic currency. The sources are: CSR, Series D40593 (Canada); DIW (Germany); BOJ (Japan); ET (United Kingdom); and NIA, Table 1.2 (United States). For the ROECD and the I.DCs, real income is measured as a geometric mean of industrial production, using the means of trade shares as weights. For ROECD, industrial production is from the IFS, Line 66; and the countries and weights are the same as for export prices, above. The countries included as LDCs are as follows, with weights and IFS line numbers in parentheses: South Korea $(32 \%, 66)$, Mexico $(36 \%, 66)$, and Taiwan $(32 \%)$. Taiwan's industrial production is reported in Financiai Statistics (Bank of China, Taiwan District), Line 66. In view of data difficulties, the model assumes that OPEC's income equals OPEC's real exports.

Each GNP (GDP) deflator is constructed as the nominal value of GNP (GDP) divided by the corresponding real value. The sources are: CSR, Table 1.2 (Canada); DIW (Germany); BOJ (Japan); ET, Table 2 (United Kingdom); and NIA, Table 7.1 (United States). In vi€w of data difficulties, the model assumes that the deflators for the ROECD, LDCs, and OPEC are their export prices. Thus, (e.g.) the equation for U.S exports to OPEC uses OPEC's export price as a proxy for OPEC's GNP price deflator.

Potential Output. Potential output for Canada, Germany, Japan, the United Kingdom, and the United States is generated using Cobb-Douglas production functions. These functions include labor, capital, oil, and imports as inputs, and the associated parameters are estimated econometrically. The estimated elasticities are $4 \%-14 \%$ for the share of capital, $60 \%-80 \%$ for the share of labor, $4 \%-7 \%$ for the share of oil, and $8 \%-18 \%$ for the share of imports. See Edison, Marquez, and Tryon (1987) for details. Potential output of the LDCs and of the ROECD are generated as fitted trends to actual output.

Exchange Rates. Only four bilateral exchange rates are used: the Canadian dollar, the West German DM, the Pound sterling, and the Japanese Yen, all as quarterly averages against the U.S. dollar. The source is FRB, Table 3.28. Export prices for the ROECD, LDCs, and OPEC 
are in U.S. dollars, as are the values of U.S. bilateral trade with them, so it is not necessary to calculate exchange rates for them.

\section{A.3. Data for Model M5}

Model M5 is a logarithmic VAR explaining real exports and imports by the United States, and the price deflators for these two trade flows. The nominal values of multilateral exports and imports are in billions of U.S. dollars, quarterly at annual rates, and come from NIA Table 4.3. Real exports and imports are in billions of (constant) 1982 U.S. dollars, quarterly at annual rates, and come from NIA Table 4.4. The associated price deflators for these trade flows are obtained as the ratios between the respective nominal and real exports. The nominal trade account (billions of U.S. dollars, quarterly at annual rates) is constructed as the difference between the nominal value of exports and the nominal value of imports.

\section{A.4. Data for Model M6}

Model M6 explains the nominal trade account by its lagged value alone. The only variable involved is the trade account itself, and it is constructed as the difference between the nominal values of exports and imports, both in billions of U.S. dollars, quarterly at annual rates. See Section A.1 in this appendix for details.

\section{A.5. Data Sources}

BOJ Economic Statistics Monthly, Bank of Japan, Tokyo, monthly.

CSR Canadian Statistical Review, Statistics Canada, Ottawa, quarterly.

DBB Monthly Report, Deutsche Bundesbank, Frankfurt am Main, monthly.

DIW Lange Reihen der vierteljahrlichen volkswirtschaftlichen Gesamtrechnung für die Bundesrepublik Deutschland, Deutsches Institute für Wirtschaftsforshung, Berlin, quarterly.

DOE Monthly Petroleum Statistics, U.S. Department of Energy, Washington, D.C., monthly.

DOT Direction of Trade Statistics, International Monetary Fund, Washington, D.C., monthly.

ET Economic Trends, U.K. Central Statistical Office, London, monthly.

FRB Federal Reserve Bulletin, Board of Governors of the Federal Reserve System, Washington, D.C., monthly. 
IEA "End of Month Oil Market Report", International Energy Agency, Paris, monthly.

IFS International Financial Statistics, International Monetary Fund, Washington, D.C., monthly.

INSEE Comptes Nationales and Bulletin Mensuel de Statistique, Institute National de la Statistique et des Etudes Economique, Paris, quarterly and monthly respectively.

INSTAT Indicatori Mensili, Instituto Centrale di Statistica, Rome, monthly.

NIA "National Income Accounts" in Survey of Current Business, U.S. Department of Commerce, Bureau of Economic Analysis, Washington, D.C., monthly. 


\section{Appendix B. Calculation of Standard Errors for Trade Elasticities}

Because of model design, the long-run elasticities for models M3 and M4 are nonlinear functions of the estimated coefficients. For example, the estimate of the long-run income elasticity for exports of model M4 is constructed as:

(B1) $\hat{a}_{2 j}^{\prime}=\hat{\alpha}_{2 j}^{\prime} /\left(1-\hat{\alpha}_{0 j}^{\prime}\right)$

where the notation follows that in Table 1. By being the ratio of two estimates, each of which is approximately normally distributed, the distribution of $\hat{a}_{2 j}$ is difficult to handle analytically; cf. Marsaglia (1965). So, to estimate the properties of $\hat{a}_{2 j}$, we assume that the coefficient estimates have an exact joint normal distribution with a mean and covariance matrix given by the estimated coefficients and their estimated covariance matrix. We generate a random sample of values for $\left(\hat{\alpha}_{2 \mathrm{j}}^{\prime}, \hat{\alpha}_{0 \mathrm{j}}^{\prime}\right)$ following that distribution, and, for each set of values, calculate the corresponding elasticity via substitution into (B1). From that sample of simulated elasticities, estimates of the mean and the standard deviation of the simulated $\hat{a}_{2 j}$ are calculated, and they appear on Table 3 in the text. This procedure generates standard errors for the estimated elasticities similar to those from the standard analytical formula for asymptotic standard errors of a nonlinear function of estimates which are themselves asymptotically normally distributed; cf. Silvey (1975, pp. 115-116). We use the 1000 replications of the coefficient estimates from the stochastic simulation as the random sample of values for $\left(\hat{\alpha}_{2 j}^{\prime}, \hat{\alpha}_{0 j}^{\prime}\right)$.

Strictly speaking, the moments of $\hat{a}_{2 j}$ as simulated in this Monte Carlo study do not exist because $\left(\hat{\alpha}_{2 \mathrm{j}}, \hat{\alpha}_{0 \mathrm{j}}^{\prime}\right)$ is assumed normally distributed. However, the lack of moments may be relatively unirnportant. First, provided $\left[1-\boldsymbol{E}\left(\hat{\alpha}_{0 \mathrm{j}}^{\prime}\right)\right] / \sqrt{ } \operatorname{var}\left(\hat{\alpha}_{0 \mathrm{j}}^{\prime}\right)$ is relatively large (e.g., 3 or 4$)$, the Monte Carlo is unlikely to generate "extreme" values of $\hat{a}_{2 j}$, so the finite-replication Monte Carlo estimates of the mean and variance of $\hat{a}_{2 j}$ may be well-behaved; cf. Sargan (1982). Second, the econometric (wather than Monte Carlo) finite-sample moments of $\hat{a}_{2 j}$ may or may not exist, regardless. Third, alternative measures are easily calculated from the Monte Carlo, e.g., the median simulated elasticities and their $95 \%$ confidence intervals. 
Tables B.1 and B.2 summarize the statistical properties of the Monte Carlo distributions for the elasticity estimates of models M3 and M4 respectively. The statistics reported are the mean, median, standard deviation, scaled median absolute deviation, minimum, maximum, and the critical values for the $95 \%$ confidence interval. Overall, the evidence reveals that the distributions are well behaved, that is, they are fairly symmetrical and have few extreme values. Exceptions to this pattern are oil consumption in model M3 and the U.K. export frice (and so U.K. passthrough) in model M4. For the former, the ratio $\left[1-\hat{\boldsymbol{E}}\left(\hat{\alpha}_{0 \mathrm{j}}^{\prime}\right)\right] / \sqrt{ } \operatorname{var}\left(\hat{\alpha}_{0 \mathrm{j}}^{\prime}\right)$ is 2.4 whereas for the latter this ratio is even smaller, 1.4. These relatively low values are consistent with a "high" probability of generating extreme values. 
Table B. 1

Empirical Distribution of Long-run Elasticities: Model $\mathrm{M}^{\mathrm{a}}$

\begin{tabular}{|c|c|c|c|c|c|c|c|c|}
\hline & \multirow[b]{2}{*}{ Mean } & \multirow[b]{2}{*}{ Median } & \multirow{2}{*}{$\begin{array}{l}\text { Standard } \\
\text { Deviation }\end{array}$} & \multirow{2}{*}{$\begin{array}{c}\text { Scaled }^{b} \\
\text { Deviation }\end{array}$} & \multirow[b]{2}{*}{ Minimum } & \multirow[b]{2}{*}{ Maximum } & \multicolumn{2}{|c|}{$\begin{array}{c}\text { Approximate } \\
95 \% \text { Confidence Interval }^{c}\end{array}$} \\
\hline & & & & & & & Lower Bound & Lpper Bound \\
\hline \multicolumn{9}{|l|}{ Oil Consumption $^{d}$} \\
\hline price & 0.104 & -0.223 & 12.185 & 0.153 & -33.502 & 382.451 & -0.979 & 0.022 \\
\hline income & 0.165 & 0.493 & 15.989 & 0.383 & -495.329 & 77.597 & -0.410 & 1.793 \\
\hline \multicolumn{9}{|l|}{ Non-Oil Imports } \\
\hline price & -0.974 & -0.970 & 0.089 & 0.082 & -1.351 & -0.672 & -1.170 & -0.819 \\
\hline income & 2.754 & 2.749 & 0.084 & 0.085 & 2.515 & 3.126 & 2.571 & 2.958 \\
\hline \multicolumn{9}{|l|}{ Export Volume } \\
\hline \multicolumn{9}{|l|}{ Agricultural } \\
\hline pricc & -0.657 & -0.658 & 0.171 & 0.161 & -1.385 & 0.006 & -1.037 & -0.319 \\
\hline income & 1.330 & 1.337 & 0.100 & 0.099 & 0.727 & 1.628 & 1.110 & 1.511 \\
\hline \multicolumn{9}{|l|}{ Non-Agricultural } \\
\hline price & -1.035 & -1.011 & 0.255 & 0.223 & -3.979 & -0.452 & -1.559 & -0.609 \\
\hline income & 1.271 & 1.281 & 0.113 & 0.104 & 0.578 & 1.566 & 1.003 & 1.480 \\
\hline \multicolumn{9}{|c|}{ Non-oil Import Price } \\
\hline Passthrougt & 0.938 & 0.940 & 0.093 & 0.085 & 0.544 & 1.241 & 0.749 & 1.139 \\
\hline
\end{tabular}

Notcs:

a. The empirical distribution is based on a sample of 1000 clasticity estimates.

b. The scaled median absolute deviation is constructed as median $(i x$ - median $(x) \mid) / 0.6745$ where $x$ is an observation of the empirically generated sample of long-run clasticities.

c. The 1000 sample points are grouped in 100 intervals of equal length, and the upper and lower bounds for the $95 \%$ confidence interval correspond to the mid-point of the intervals associated with $2.5 \%$ and $97.5 \%$ probability, respectively.

d. The cocfficient for the lagged dependent variable is 0.88 with a standard error of 0.05; sce Appendix E, Model M3, equation 21.

The clasticities for oil consumption differ from those for oil imports because of domestic production. 
Table B. 2

Empirical Distribution of Long-run Elasticities: Model $M 4^{\mathrm{a}}$

\begin{tabular}{|c|c|c|c|c|c|c|c|c|}
\hline & \multirow[b]{2}{*}{ Mean } & \multirow[b]{2}{*}{ Median } & \multirow{2}{*}{$\begin{array}{l}\text { Standard } \\
\text { Deviation }\end{array}$} & \multirow{2}{*}{$\begin{array}{c}\text { Scaled }^{b} \\
\text { Deviation }\end{array}$} & \multirow[b]{2}{*}{ Minimum } & \multirow[b]{2}{*}{ Maximum } & \multicolumn{2}{|c|}{$\begin{array}{c}\text { Approx imatc } \\
95 \% \text { Confider ce Interval }\end{array}$} \\
\hline & & & & & & & Lower Bound & Upper Bound \\
\hline \multicolumn{9}{|l|}{ Price Elasticities } \\
\hline \multicolumn{9}{|l|}{ Expont Volume } \\
\hline Canada & -0.440 & -0.429 & 0.335 & 0.323 & -1.526 & 0.949 & -1.140 & 0.216 \\
\hline Germany & -0.986 & -0.987 & 0.172 & 0.169 & -1.512 & -0.433 & -1.336 & -0.650 \\
\hline Japan & -0.405 & -0.395 & 0.283 & 0.247 & -1.815 & 1.049 & -1.020 & 0.100 \\
\hline U.K. & -0.868 & -0.860 & 0.361 & 0.342 & -1.917 & 0.704 & -1.602 & -0.118 \\
\hline ROECD & -0.834 & -0.831 & 0.218 & 0.199 & -1.809 & 0.003 & -1.311 & -0.383 \\
\hline LDCs & -1.621 & -1.620 & 0.615 & 0.589 & -5.518 & 0.372 & -2.814 & -0.403 \\
\hline OPEC & -0.857 & -0.846 & 0.173 & 0.136 & -1.992 & 0.999 & -1.235 & -0.596 \\
\hline \multicolumn{9}{|c|}{ Impon Volume $^{\mathrm{d}}$} \\
\hline Canada & -0.632 & -0.631 & 0.168 & 0.160 & -1.235 & -0.145 & -0.972 & -0.283 \\
\hline Germany & -1.410 & -1.407 & 0.328 & 0.307 & -2.454 & -0.401 & -2.084 & -0.741 \\
\hline Japan & -0.581 & -0.589 & 0.228 & 0.229 & -1.471 & 0.035 & -1.031 & -0.104 \\
\hline U.K. & -0.436 & -0.489 & 0.394 & 0.322 & -1.197 & 3.720 & -1.076 & 0.404 \\
\hline ROECD & -0.681 & -0.681 & 0.141 & 0.139 & -1.110 & -0.150 & -0.953 & -0.405 \\
\hline LDCs & -1.438 & -1.402 & 0.428 & 0.400 & -3.009 & -0.336 & -2.351 & -0.625 \\
\hline \multicolumn{9}{|c|}{ Income Elasticities } \\
\hline \multicolumn{9}{|c|}{ Expon Volume } \\
\hline Canada & 1.697 & 1.693 & 0.210 & 0.207 & 0.872 & 2.339 & 1.273 & 2.136 \\
\hline Germany & 1.523 & 1.515 & 0.173 & 0.169 & 1.024 & 2.080 & 1.172 & 1.871 \\
\hline Japan & 0.751 & 0.759 & 0.171 & 0.145 & -0.140 & 1.355 & 0.396 & 1.070 \\
\hline U.K. & 3.409 & 3.323 & 0.695 & 0.620 & 1.532 & 6.595 & 2.275 & 5.125 \\
\hline ROECD & 1.788 & 1.772 & 0.291 & 0.285 & 0.943 & 3.056 & 1.237 & 2.389 \\
\hline LDCs & 0.395 & 0.409 & 0.159 & 0.149 & -0.226 & 0.983 & 0.036 & 0.699 \\
\hline OPEC & 1.289 & 1.214 & 0.468 & 0.319 & 0.564 & 8.259 & 0.737 & 2.193 \\
\hline \multicolumn{9}{|l|}{ Impon Volume } \\
\hline Canada & 1.639 & 1.636 & 0.171 & 0.159 & 1.157 & 2.169 & 1.311 & 2.015 \\
\hline Germany & 2.918 & 2.925 & 0.309 & 0.292 & 1.964 & 3.907 & 2.322 & 3.598 \\
\hline Japan & 3.696 & 3.683 & 0.296 & 0.296 & 2.893 & 4.683 & 3.133 & 4.332 \\
\hline U.K. & 2.427 & 2.357 & 0.517 & 0.464 & -0.109 & 4.864 & 1.870 & 3.482 \\
\hline ROECD & 2.318 & 2.319 & 0.311 & 0.305 & 1.251 & 3.470 & 1.701 & 2.956 \\
\hline LDCs & 3.122 & 3.121 & 0.209 & 0.217 & 2.482 & 3.807 & 2.691 & 3.784 \\
\hline \multicolumn{9}{|l|}{ Import Prices $^{\mathrm{e}}$} \\
\hline \multicolumn{9}{|l|}{ Passthrough } \\
\hline Canada & 0.713 & 0.726 & 0.173 & 0.159 & 0.277 & 1.130 & 0.294 & 0.776 \\
\hline Germany & 0.827 & 0.826 & 0.026 & 0.025 & 0.713 & 0.914 & 0.772 & 0.880 \\
\hline Japan & 0.479 & 0.480 & 0.075 & 0.076 & 0.251 & 0.689 & 0.319 & 0.621 \\
\hline U.K. & 0.411 & 0.221 & 8.228 & 0.551 & -55.043 & 124.299 & -4.429 & 4.219 \\
\hline ROECD & 1.100 & 1.098 & 0.058 & 0.060 & 0.949 & 1.303 & 1.051 & 1.214 \\
\hline LDC & 0.839 & 0.842 & 0.163 & 0.143 & 0.138 & 1.307 & 0.437 & 1.233 \\
\hline
\end{tabular}

Notes: $\quad$ a-c. See Table B.1.

d. The equation for oil consumption does not include the normalized variable lagged one period as an explanatory variable.

e. The coefficient of the lagged dependent variable for the United Kingdom is 0.94 with a standard error of 0.04 ; sec Appendix E, Model M4, equation 29. 


\section{Appendix C: Additional Results}

In many instances, results exist for four distinct cases: one-step ahead and s-step ahead, each with either the approximate or the asymptotic formula. For ease of presentation, often results for only the approximate formula are reported in the text: e.g., Tables 5 and 6, Figures 2 and 3, Tables 7 and 8, and Tables 9 and 10. This appendix contains comparable tables and figures for the asymptotic formula, denoted Tables C.5 and C.6, Figures C.2 and C.3, Tables C.7 and C.8, and Tables C.9 and C.10, respectively. Further, Tables C.1-C.4 in this appendix include numerical results for all four cases on higher moments of the forecast errors. 
Table C. 1

Further Statistical Properties of the Stochastic Trade Account Forecasts

One-step Ahead, Approximate Formula

\begin{tabular}{|c|c|c|c|c|c|c|c|c|c|c|c|c|}
\hline & \multicolumn{12}{|c|}{ Forecast Period } \\
\hline & \multicolumn{4}{|c|}{1985} & \multicolumn{4}{|c|}{1986} & \multicolumn{4}{|c|}{1987} \\
\hline & Q1 & Q2 & Q3 & Q4 & Q1 & Q2 & Q3 & Q4 & Q1 & Q2 & Q3 & Q4 \\
\hline \multicolumn{13}{|c|}{$\begin{array}{l}\text { Historical Trade Account } \\
\text { (billion LS\$) }\end{array}$} \\
\hline & -99.5 & -119.8 & -124.8 & -144.5 & -141.7 & -135.4 & -146.9 & -154.1 & -159.5 & -158.2 & -158.7 & -164.8 \\
\hline \multicolumn{13}{|l|}{ Skewness } \\
\hline Model M1 & -0.28 & -0.01 & -0.11 & -0.17 & -0.16 & -0.15 & -0.03 & -0.07 & -0.09 & -0.13 & -0.06 & -0.05 \\
\hline Model M2 & -0.19 & 0.00 & -0.08 & -0.02 & -0.02 & -0.14 & -0.08 & -0.08 & 0.02 & -0.12 & -0.02 & -0.05 \\
\hline Model M3 & -0.11 & -0.00 & -0.08 & -0.01 & 0.09 & -0.07 & -0.08 & 0.01 & 0.11 & -0.16 & -0.08 & 0.08 \\
\hline Model M4 & -0.07 & -0.11 & -0.05 & -0.13 & -0.11 & -0.27 & -0.10 & -0.05 & -0.15 & -0.20 & -0.20 & -0.26 \\
\hline Model M5 & -0.21 & -0.10 & -0.13 & -0.14 & .0 .13 & -0.19 & 0.02 & -0.41 & -0.16 & -0.27 & -0.22 & -0.06 \\
\hline Model M6 & 0.08 & 0.07 & -0.03 & 0.09 & -0.01 & 0.04 & 0.01 & -0.01 & -0.02 & 0.08 & 0.00 & 0.14 \\
\hline Excess Kurtosis & & & & & & & & & . & & & \\
\hline Model M1 & 0.07 & 0.18 & -0.02 & 0.16 & 0.08 & -0.02 & -0.09 & -0.21 & -0.15 & 0.18 & -0.00 & 0.24 \\
\hline Model M2 & 0.01 & 0.03 & -0.03 & 0.23 & -0.33 & -0.05 & -0.04 & 0.24 & -0.29 & -0.19 & -0.26 & 0.20 \\
\hline Model M3 & 0.02 & 0.13 & -0.16 & 0.07 & 0.25 & -0.27 & -0.17 & -0.14 & -0.12 & 0.09 & -0.02 & -0.05 \\
\hline Model M4 & 0.10 & 0.01 & 0.04 & -0.01 & 0.00 & 0.09 & 0.14 & 0.33 & -0.00 & 0.29 & -0.04 & 0.13 \\
\hline Model M5 & 0.13 & -0.16 & 0.25 & 0.05 & -0.25 & 0.14 & 0.03 & 0.60 & 0.03 & 0.17 & 0.13 & 0.11 \\
\hline Model M6 & 0.17 & 0.15 & -0.09 & 0.01 & 0.00 & 0.14 & 0.04 & 0.03 & -0.03 & -0.22 & 0.12 & -0.18 \\
\hline \multicolumn{13}{|c|}{ Jarque-Bera $\chi^{2}(2)$ Statistic } \\
\hline Model M1 & 13.57 & 1.44 & 2.12 & 5.97 & 4.29 & 3.96 & 0.52 & 2.54 & 2.33 & 4.08 & 0.68 & 2.78 \\
\hline Modcl M2 & 6.16 & 0.05 & 1.18 & 2.19 & 4.68 & 3.58 & 1.05 & 3.42 & 3.62 & 3.96 & 2.78 & 2.10 \\
\hline Model M3 & 1.96 & 0.75 & 2.09 & 0.25 & 3.92 & 3.83 & 2.38 & 0.84 & 2.46 & 4.78 & 1.04 & 1.06 \\
\hline Model M4 & 1.22 & 1.92 & 0.44 & 3.00 & 1.96 & 12.33 & 2.62 & 4.90 & 3.78 & 10.26 & 6.45 & 11.67 \\
\hline Model M5 & 8.23 & 2.91 & 5.45 & 3.59 & 5.42 & 6.87 & 0.10 & 43.28 & 4.05 & 13.68 & 8.74 & 1.04 \\
\hline Model M6 & 2.29 & 1.81 & 0.53 & 1.25 & 0.03 & 1.08 & 0.06 & 0.06 & 0.12 & 2.99 & 0.62 & 4.73 \\
\hline
\end{tabular}

Notes: $\quad$ Model M1: Helkie and Hooper (1988).

Model M2: Model M1 by FIML.

Model M3: Model M1 by FIML, with partial adjustment, without non-price rationing.

Model M4: Bilateral trade model by FlML.

Model M5: VAR(4) of import and expon volumes and price indices.

Model M6: $\mathrm{AR}(1)$ of the nominal trade account. 
Table C.2

Further Statistical Properties of the Stochastic Trade Account Forecasts s-step Ahead, Approximate Formula

\begin{tabular}{|c|c|c|c|c|c|c|c|c|c|c|c|c|}
\hline & \multicolumn{12}{|c|}{ Forecast Period } \\
\hline & \multicolumn{4}{|c|}{1985} & \multicolumn{4}{|c|}{1986} & \multicolumn{4}{|c|}{1987} \\
\hline & Q1 & Q2 & Q3 & Q4 & Q1 & Q2 & Q3 & Q4 & Q1 & Q2 & Q3 & Q4 \\
\hline \multicolumn{13}{|c|}{$\begin{array}{l}\text { Historizal Trade Account } \\
\text { (billion US\$) }\end{array}$} \\
\hline & -99.5 & -119.8 & -124.8 & -144.5 & -141.7 & -135.4 & -146.9 & -154.1 & -159.5 & -158.2 & -158.7 & -164.8 \\
\hline \multicolumn{13}{|l|}{ Skewnesss } \\
\hline Model M1 & -0.28 & -0.08 & -0.08 & -0.14 & -0.18 & -0.17 & -0.12 & -0.13 & -0.10 & -0.22 & -0.16 & -0.03 \\
\hline Model M2 & -0.19 & 0.03 & 0.04 & 0.04 & 0.01 & -0.00 & 0.07 & -0.03 & 0.04 & -0.00 & 0.10 & 0.05 \\
\hline Model M3 & -0.11 & -0.06 & -0.03 & -0.10 & -0.03 & -0.16 & -0.07 & -0.19 & -0.16 & -0.21 & -0.12 & -0.01 \\
\hline Model M4 & -0.07 & -0.08 & -0.09 & -0.09 & -0.08 & -0.20 & -0.19 & -0.26 & -0.13 & 0.01 & -0.07 & -0.08 \\
\hline Model M5 & -0.21 & -0.21 & -0.26 & -0.20 & -0.15 & -0.20 & -0.23 & -0.39 & -0.32 & -0.23 & -0.31 & -0.41 \\
\hline Model M6 & 0.08 & -0.00 & -0.05 & -0.13 & -0.29 & -0.39 & -0.57 & -0.68 & -0.84 & -0.95 & -1.07 & -1.22 \\
\hline \multicolumn{13}{|l|}{ Excess Kurtosis } \\
\hline Model M1 & 0.07 & 0.38 & 0.29 & 0.10 & 0.09 & 0.22 & -0.06 & -0.09 & -0.17 & -0.10 & -0.02 & -0.12 \\
\hline Model M2 & 0.01 & -0.03 & -0.03 & 0.10 & -0.29 & -0.10 & 0.14 & 0.38 & -0.11 & -0.14 & -0.08 & 0.17 \\
\hline Model M3 & 0.02 & 0.01 & 0.13 & 0.00 & 0.17 & 0.08 & -0.09 & 0.22 & 0.76 & 0.62 & 0.74 & 0.36 \\
\hline Model M4 & 0.10 & 0.02 & -0.00 & -0.06 & -0.01 & -0.04 & 0.18 & 0.46 & 0.22 & 0.69 & 0.24 & 0.08 \\
\hline Model M5 & 0.13 & 0.18 & 0.77 & 0.34 & 0.33 & 0.68 & 0.99 & 1.74 & 2.01 & 2.35 & 2.96 & 3.25 \\
\hline Model M6 & 0.17 & -0.06 & -0.13 & 0.02 & 0.17 & 0.41 & 0.72 & 0.99 & 1.41 & 1.78 & 2.22 & 2.91 \\
\hline \multicolumn{13}{|c|}{ Jarque-Bera $\chi^{2}(2)$ Statistic } \\
\hline Mıdel M1 & 13.57 & 7.16 & 4.62 & 3.51 & 6.03 & 6.92 & 2.53 & 3.31 & 2.98 & 8.15 & 4.17 & 0.76 \\
\hline Misdel M2 & 6.16 & 0.20 & 0.35 & 0.72 & 3.48 & 0.39 & 1.57 & 6.16 & 0.72 & 0.86 & 1.79 & 1.66 \\
\hline Misdel M3 & 1.96 & 0.64 & 0.85 & 1.57 & 1.42 & 4.30 & 1.26 & 7.98 & 27.98 & 23.67 & 25.05 & 5.39 \\
\hline M $s$ del M4 & 1.22 & 1.17 & 1.31 & 1.63 & 0.95 & 6.95 & 7.19 & 19.54 & 5.05 & 19.71 & 3.31 & 1.37 \\
\hline Model M5 & 8.23 & 8.39 & 35.74 & 11.62 & 8.29 & 26.09 & 49.69 & 151.03 & 185.48 & 238.32 & 382.44 & 467.52 \\
\hline Model M6 & 2.29 & 0.14 & 1.21 & 2.84 & 15.21 & 32.84 & 75.96 & 117.23 & 200.04 & 282.77 & 397.03 & 600.06 \\
\hline
\end{tabular}

Notes: Model M1: Helkie and Hooper (1988).

Model M2: Model M1 by FLML.

Model M3: Model M1 by FIML, with panial adjustment, without non-price rationing.

Model M4: Bilateral trade model by FIML.

Model M5: VAR(4) of import and export volumes and price indices.

Model M6: $A R(1)$ of the nominal trade account. 
Table C. 3

Further Statistical Properties of the Stochastic Trade Account Forecasts One-step Ahead, Asymptotic Formula

\begin{tabular}{|c|c|c|c|c|c|c|c|c|c|c|c|c|}
\hline & \multicolumn{12}{|c|}{ Forecast Pcriod } \\
\hline & \multicolumn{4}{|c|}{1985} & \multicolumn{4}{|c|}{1986} & \multicolumn{4}{|c|}{1987} \\
\hline & Q1 & Q2 & Q3 & Q4 & Q1 & Q2 & Q3 & Q4 & Q1 & Q2 & Q3 & Q4 \\
\hline \multicolumn{13}{|c|}{$\begin{array}{l}\text { Historical Trade Account } \\
\text { (billion USS) }\end{array}$} \\
\hline & -99.5 & -119.8 & -124.8 & -144.5 & -141.7 & -135.4 & -146.9 & -154.1 & -159.5 & -158.2 & -158.7 & -164.8 \\
\hline \multicolumn{13}{|l|}{ Skewness } \\
\hline Model M1 & -0.28 & 0.04 & -0.01 & -0.05 & 0.01 & -0.05 & -0.09 & 0.04 & -0.05 & -0.06 & -0.05 & -0.05 \\
\hline Model M2 & -0.16 & 0.04 & -0.02 & -0.04 & -0.06 & -0.07 & -0.01 & 0.05 & 0.05 & -0.04 & -0.05 & 0.03 \\
\hline Model M3 & -0.23 & 0.00 & -0.06 & -0.08 & -0.07 & -0.08 & -0.06 & 0.00 & 0.05 & -0.11 & -0.05 & 0.02 \\
\hline Model M4 & -0.07 & -0.17 & 0.00 & -0.11 & -0.20 & -0.26 & -0.01 & -0.07 & -0.07 & -0.04 & -0.19 & -0.19 \\
\hline Model M5 & -0.13 & -0.09 & -0.10 & -0.22 & -0.05 & -0.12 & 0.09 & -0.14 & 0.04 & -0.20 & -0.32 & -0.14 \\
\hline Model M6 & 0.05 & 0.08 & -0.08 & 0.07 & 0.10 & 0.08 & 0.16 & -0.05 & -0.04 & 0.09 & 0.01 & 0.15 \\
\hline \multicolumn{13}{|l|}{ Excess Kurtosis } \\
\hline Model M1 & 0.19 & 0.00 & -0.21 & 0.19 & 0.08 & -0.03 & -0.32 & -0.13 & -0.22 & 0.21 & 0.14 & -0.08 \\
\hline Model M2 & 0.07 & 0.11 & -0.14 & 0.19 & 0.13 & 0.00 & -0.24 & -0.07 & -0.41 & 0.21 & -0.01 & -0.14 \\
\hline Model M3 & 0.03 & 0.07 & -0.21 & 0.15 & 0.03 & -0.05 & -0.18 & -0.10 & -0.38 & 0.19 & -0.09 & -0.14 \\
\hline Model M4 & 0.12 & 0.27 & 0.24 & -0.01 & 0.05 & 0.22 & -0.01 & 0.18 & -0.01 & -0.15 & 0.06 & -0.15 \\
\hline Model M5 & 0.01 & -0.16 & 0.18 & -0.03 & -0.16 & -0.12 & 0.16 & 0.16 & -0.20 & -0.05 & 0.09 & -0.13 \\
\hline Model M6 & 0.31 & -0.01 & -0.11 & 0.01 & -0.09 & -0.00 & -0.03 & -0.18 & -0.05 & -0.17 & 0.27 & -0.00 \\
\hline \multicolumn{13}{|c|}{ Jarque-Bera $\chi^{2}(2)$ Statistic } \\
\hline Model M1 & 14.50 & 0.21 & 1.80 & 1.94 & 0.30 & 0.45 & 5.38 & 0.93 & 2.40 & 2.32 & 1.30 & 0.72 \\
\hline Model M2 & 4.60 & 0.73 & 0.87 & 1.77 & 1.22 & 0.82 & 2.43 & 0.61 & 7.25 & 2.10 & 0.35 & 1.01 \\
\hline Model M3 & 8.84 & 0.20 & 2.40 & 2.11 & 0.78 & 1.16 & 1.91 & 0.44 & 6.33 & 3.38 & 0.76 & 0.91 \\
\hline Model M4 & 1.33 & 7.63 & 2.39 & 1.97 & 6.60 & 13.40 & 0.03 & 2.27 & 0.80 & 1.33 & 5.93 & 6.96 \\
\hline Model M5 & 2.80 & 2.53 & 3.02 & 8.45 & 1.47 & 3.12 & 2.36 & 4.16 & 1.97 & 6.65 & 17.36 & 3.86 \\
\hline Model M6 & 4.26 & 0.99 & 1.50 & 0.88 & 2.01 & 1.10 & 4.34 & 1.81 & 0.37 & 2.65 & 2.96 & 3.74 \\
\hline
\end{tabular}

Notes: $\quad$ Model MI: Helkie and Hooper (1988).

Model M2: Model M1 by FLML.

Model M3: Model M1 by FLML, with parial adjustment, without non-price rationing.

Model M4: Bilateral trade model by FIML.

Model M5: VAR(4) of import and export volumes and price indices.

Model M6: AR(1) of the nominal trade account. 
Table C. 4

Further Statistical Properties of the Stochastic Trade Account Forecasts s-step Ahead, Asymptotic Formula

\begin{tabular}{|c|c|c|c|c|c|c|c|c|c|c|c|c|}
\hline & \multicolumn{12}{|c|}{ Forecast Period } \\
\hline & \multicolumn{4}{|c|}{1985} & \multicolumn{4}{|c|}{1986} & \multicolumn{4}{|c|}{1987} \\
\hline & Q1 & Q2 & Q3 & Q4 & Q1 & Q2 & Q3 & Q4 & Q1 & Q2 & Q3 & Q4 \\
\hline \multicolumn{13}{|c|}{$\begin{array}{l}\text { Historical Trade Account } \\
\text { (billion JSS) }\end{array}$} \\
\hline & -99.5 & -119.8 & -124.8 & -144.5 & -141.7 & -135.4 & -146.9 & -154.1 & -159.5 & -158.2 & -158.7 & -164.8 \\
\hline \multicolumn{13}{|l|}{ Skewne:s } \\
\hline Morlel M1 & -0.28 & 0.02 & 0.02 & -0.04 & 0.03 & -0.05 & -0.07 & -0.04 & -0.01 & -0.22 & 0.00 & -0.05 \\
\hline Morlel M2 & -0.16 & 0.04 & 0.08 & -0.03 & -0.06 & -0.05 & 0.04 & -0.06 & 0.08 & -0.13 & 0.07 & 0.09 \\
\hline Model M3 & -0.23 & -0.03 & 0.06 & -0.13 & -0.08 & -0.03 & 0.03 & 0.02 & 0.01 & -0.15 & 0.02 & 0.11 \\
\hline Morlel M4 & -0.07 & -0.12 & -0.04 & -0.17 & -0.20 & -0.16 & -0.01 & -0.08 & -0.01 & -0.01 & -0.17 & -0.17 \\
\hline Morlel M5 & -0.13 & -0.03 & -0.04 & -0.22 & -0.10 & -0.16 & -0.13 & -0.22 & -0.20 & -0.27 & -0.27 & -0.21 \\
\hline Morlel M6 & 0.05 & 0.09 & 0.04 & 0.02 & -0.04 & 0.05 & -0.01 & 0.02 & -0.01 & 0.05 & 0.07 & 0.08 \\
\hline \multicolumn{13}{|l|}{ Excess Furtosis } \\
\hline Morlel M1 & 0.19 & 0.04 & 0.10 & 0.16 & 0.17 & 0.01 & -0.21 & 0.32 & -0.11 & 0.06 & 0.39 & -0.17 \\
\hline Moclel M2 & 0.07 & 0.04 & 0.09 & 0.11 & 0.08 & -0.10 & -0.31 & 0.25 & -0.13 & 0.05 & 0.31 & -0.12 \\
\hline Mocel M3 & 0.03 & -0.08 & -0.02 & 0.05 & 0.02 & 0.07 & -0.16 & 0.16 & -0.15 & -0.03 & 0.11 & -0.13 \\
\hline Mocel M4 & 0.12 & 0.27 & 0.22 & 0.18 & 0.09 & -0.04 & -0.14 & 0.11 & -0.10 & -0.04 & -0.02 & -0.13 \\
\hline Mocel M5 & 0.01 & 0.06 & -0.02 & 0.05 & -0.12 & -0.12 & 0.12 & 0.15 & 0.10 & 0.15 & 0.39 & 0.10 \\
\hline Model M6 & 0.31 & -0.10 & -0.20 & -0.04 & 0.07 & 0.01 & -0.08 & -0.10 & -0.00 & -0.10 & -0.13 & -0.30 \\
\hline \multicolumn{13}{|c|}{ Jarque-Bera $\chi^{2}(2)$ Statistic } \\
\hline Model M1 & 14.50 & 0.12 & 0.50 & 1.33 & 1.39 & 0.47 & 2.53 & 4.64 & 0.47 & 8.12 & 6.49 & 1.63 \\
\hline Model M2 & 4.60 & 0.29 & 1.39 & 0.72 & 0.89 & 0.90 & 4.22 & 3.20 & 1.71 & 2.89 & 4.81 & 1.88 \\
\hline Modsl M3 & 8.84 & 0.46 & 0.54 & 2.80 & 1.17 & 0.31 & 1.25 & 1.22 & 1.01 & 3.96 & 0.51 & 2.66 \\
\hline Mod:1 M4 & 1.33 & 5.28 & 2.39 & 6.17 & 6.97 & 4.44 & 0.82 & 1.48 & 0.42 & 0.07 & 4.95 & 5.48 \\
\hline Mod:I M5 & 2.80 & 0.25 & 0.26 & 8.27 & 2.25 & 5.14 & 3.30 & 8.77 & 6.98 & 13.23 & 18.49 & 8.03 \\
\hline Mod:l M6 & 4.26 & 1.73 & 1.85 & 0.13 & 0.55 & 0.44 & 0.27 & 0.47 & 0.03 & 0.77 & 1.55 & 4.69 \\
\hline
\end{tabular}

Nites: Model M1: Helkie and Hooper (1988).

Model M2: Model M1 by FIML.

Model M3: Model M1 by HML, with partial adjustment, without non-price rationing.

Model M4: Bilatcral trade model by FIML.

Model M5: VAR(4) of import and expon volumes and price indices.

Model M6: $A R(1)$ of the nominal trade account. 
Table C.5

Forecast Performance: The U.S. Trade Account

One-step Ahead, Asymptotic Formula

\begin{tabular}{|c|c|c|c|c|c|c|c|c|c|c|c|c|c|c|c|c|}
\hline & \multicolumn{12}{|c|}{ Forecast Period } & \multicolumn{4}{|c|}{$\begin{array}{l}\text { Summary Measures of } \\
\text { Forecast Performance }\end{array}$} \\
\hline & \multicolumn{4}{|c|}{1985} & \multicolumn{4}{|c|}{1986} & \multicolumn{4}{|c|}{1987} & \multirow[b]{2}{*}{ MAE } & \multirow[b]{2}{*}{ RMSFE } & \multirow[b]{2}{*}{$\tau$} & \multirow[b]{2}{*}{$\tau *$} \\
\hline & Q1 & Q2 & Q3 & Q4 & Q1 & Q2 & Q3 & Q4 & Q1 & Q2 & Q3 & Q4 & & & & \\
\hline \multicolumn{17}{|c|}{$\begin{array}{l}\text { Mean Forecast Error } \\
\text { (billion USS) }\end{array}$} \\
\hline Model M1 & 21.1 & -4.4 & -0.8 & -3.6 & 1.8 & -9.8 & -26.0 & -27.0 & -21.1 & -26.9 & -19.7 & -29.2 & 15.9 & 19.1 & 25.6 & -3.2 \\
\hline Model M2 & 22.4 & -1.0 & 2.2 & -0.4 & 1.7 & -9.9 & -27.8 & -27.5 & -19.7 & -24.8 & -13.5 & -21.6 & 144 & 17.8 & 28.5 & -2.9 \\
\hline Model M6 & 23.0 & -15.3 & 0.9 & -12.9 & 10.1 & 13.0 & -4.4 & -0.1 & 2.5 & 8.9 & 7.5 & 1.7 & 8.4 & 10.7 & 21.3 & 1.2 \\
\hline \multicolumn{17}{|c|}{$\begin{array}{l}\text { Estimated Standard Error of the Mean Forecast Error } \\
\text { (billion LSS) }\end{array}$} \\
\hline Model M1 & 12.2 & 11.5 & 11.7 & 11.4 & 12.0 & 12.0 & 12.4 & 12.8 & 13.4 & 13.8 & 14.4 & 15.1 & & & & \\
\hline Model M2 & 11.5 & 11.0 & 11.1 & 10.9 & 11.1 & 10.9 & 11.0 & 11.6 & 12.1 & 12.8 & 13.4 & 14.1 & & & & \\
\hline Model M3 & 12.9 & 12.2 & 12.3 & 12.4 & 12.7 & 12.3 & 12.5 & 12.7 & 13.7 & 14.3 & 14.9 & 15.8 & & & & \\
\hline Model M4 & 16.1 & 17.3 & 17.4 & 18.0 & 19.5 & 18.9 & 19.6 & 18.9 & 20.8 & 20.8 & 20.5 & 21.9 & & & & \\
\hline Model M5 & 12.8 & 12.7 & 12.6 & 12.1 & 13.3 & 13.1 & 12.7 & 13.2 & 13.9 & 14.2 & 14.5 & 14.2 & & & & \\
\hline Model M6 & 8.1 & 8.0 & 7.7 & 7.9 & 8.0 & 7.9 & 8.0 & 8.0 & 7.5 & 7.7 & 8.0 & 7.9 & & & & \\
\hline Model M5 & 1.8 & -1.4 & 0.1 & -2.5 & -0.2 & -0.9 & -2.6 & -1.9 & -1.5 & -1.1 & -2.3 & -3.5 & & & & \\
\hline Model M6 & 2.8 & -1.9 & 0.1 & -1.6 & 1.3 & 1.7 & -0.5 & -0.0 & 0.3 & 1.2 & 0.9 & 0.2 & & & & \\
\hline
\end{tabular}

Notes: $\quad$ Model M1: Helkie and Hooper (1988).

Model M2: Model M1 by FIML.

Model M3: Model M1 by FLML, with partial adjustment, without non-price rationing.

Model M4: Bilateral trade model by FIML.

Model M5: VAR(4) of import and export volumes and price indices.

Model M6: AR(1) of the nominal trade account.

MAE: Mean absolute error.

RMSFE: Root mean-square forecast error.

$\tau$ : $\quad$ The $\chi^{2}(12)$ statistic testing against predictive failure. Its $5 \%$ and $10 \%$ levels are 21.0 and 18.5 .

$\tau *$ : The $t$-statistic testing against non-zero mean forecast error. 
Table C.6

Forecast Performance: The U.S. Trade Account s-step Ahead, Asymptotic Formula

\begin{tabular}{lllllllllllll}
\multicolumn{10}{c}{ Forecast Period } \\
\hline
\end{tabular}

Summary Measures of Forecast Performance

MAF RMSFE $\tau \quad \tau *$

Historical Trade Accoult (billion LSS)

Mean Forecast Error (billion USS)

\begin{tabular}{|c|c|c|c|c|c|c|c|c|c|c|c|c|c|c|c|c|}
\hline Model M1 & 21. & 6.3 & 5.0 & 1.9 & 5.0 & -5.3 & -23.7 & -36.9 & -41.2 & -51.8 & -52.4 & -65.2 & 26.3 & 34.0 & 26.4 & -3.0 \\
\hline Model M2 & 22.4 & 11.1 & 11.4 & 9.1 & 7.6 & -5.4 & -25.7 & -38.8 & -41.0 & -48.8 & -44.7 & -55.1 & 26.8 & 31.9 & 27.4 & -2.6 \\
\hline Model M3 & 23. & 13.2 & 13.5 & 10.2 & 5.0 & -14.8 & -34.0 & -41.9 & -41.6 & -44.1 & -32.2 & -37.4 & 25.9 & 29.2 & 15.8 & -1.8 \\
\hline Model M4 & $-16 . ?$ & -37.2 & -16.5 & -5.6 & 7.4 & 29.5 & 27.5 & 0.0 & 12.7 & -4.8 & -7.1 & -10.3 & 14.6 & 18.2 & 9.0 & -0.5 \\
\hline Model M5 & 23.5 & 6.5 & 0.4 & -25.8 & -32.8 & -37.1 & -57.4 & -74.3 & -86.9 & -90.1 & -90.6 & -94.0 & 51.6 & 61.4 & 13.5 & -2.0 \\
\hline Yodel M6 & $23.1)$ & 8.7 & 10.0 & -2.5 & 7.6 & 20.9 & 17.5 & 18.1 & 21.4 & 31.2 & 40.1 & 43.6 & 20.4 & 23.8 & 21.3 & 1.2 \\
\hline
\end{tabular}

Estimated Standard Error of the Mean Forecast Error (billion LSS)

$\begin{array}{lrrrrrrrrrrrr}\text { Model M1 } & 12.2 & 13.2 & 13.4 & 13.6 & 13.8 & 14.3 & 14.6 & 14.9 & 16.0 & 16.6 & 17.3 & 18.0 \\ \text { Model M2 } & 11.5 & 12.3 & 12.4 & 12.8 & 12.7 & 12.8 & 13.2 & 13.6 & 14.7 & 15.5 & 16.7 & 17.1 \\ \text { Model M3 } & 12.9 & 14.5 & 15.2 & 16.5 & 16.5 & 15.5 & 16.0 & 16.6 & 18.8 & 19.3 & 20.2 & 21.3 \\ \text { Model M4 } & 16.1 & 17.3 & 17.8 & 19.1 & 20.4 & 21.1 & 21.3 & 21.1 & 22.4 & 23.1 & 22.7 & 23.8 \\ \text { Model M5 } & 12.3 & 19.2 & 21.8 & 23.8 & 27.0 & 32.9 & 37.8 & 41.9 & 43.3 & 45.0 & 47.2 & 48.4 \\ \text { Model M6 } & 8.1 & 11.7 & 14.5 & 16.7 & 19.4 & 22.1 & 24.2 & 26.6 & 28.4 & 30.7 & 33.1 & 35.4\end{array}$

Forecast Error "i" ratio

$\begin{array}{lrrrrrrrrrrrr}\text { Model M1 } & 1.7 & 0.5 & 0.4 & 0.1 & 0.4 & -0.4 & -1.6 & -2.5 & -2.6 & -3.1 & -3.0 & -3.6 \\ \text { Model M2 } & 1.9 & 0.9 & 0.9 & 0.7 & 0.6 & -0.4 & -2.0 & -2.8 & -2.8 & -3.2 & -2.7 & -3.2 \\ \text { Model M3 } & 1.3 & 0.9 & 0.9 & 0.6 & 0.3 & -1.0 & -2.1 & -2.5 & -2.2 & -2.3 & -1.6 & -1.8 \\ \text { Model M4 } & -1.1 & -2.2 & -0.9 & -0.3 & 0.4 & 1.4 & 1.3 & 0.0 & 0.6 & -0.2 & -0.3 & -0.4 \\ \text { Model M5 } & 1.3 & 0.3 & 0.0 & -1.1 & -1.2 & -1.1 & -1.5 & -1.8 & -2.0 & -2.0 & -1.9 & -1.9 \\ \text { Model M6 } & 2.3 & 0.7 & 0.7 & -0.1 & 0.4 & 0.9 & 0.7 & 0.7 & 0.8 & 1.0 & 1.2 & 1.2\end{array}$

Notes: $\quad$ Model M1: Helkie and Hooper (1988)

Model M2: Model M1 by FLL.

Model M3: Model M1 by FLML, with panial adjustment, without non-price rationing.

Model M4: Bilateral trade model by FLM.

Model M5: VAR(4) of impon and expon volumes and price indices.

Model M6: AR(1) of the nominal trade account.

MAE: Mean absolute error.

RMSFE: Root mean-square forecast error.

t: $\quad$ The $\chi^{2}(12)$ statistic testing against predictive failure. Its $5 \%$ and $10 \%$ levels are 21.0 and 18.5.

$\imath^{*}$ : The t-statistic testing against non-zero mean forecast error. 
Figure C.2: $95 \%$ Confidence Intervals For Trade-account Forecasts

One-step ahead, Asymptotic formula

Figure C.2a

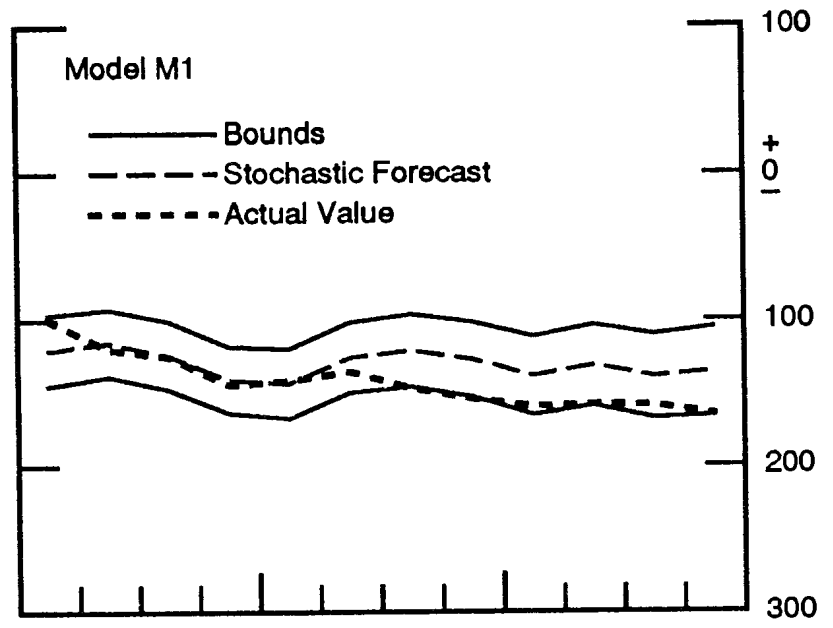

Figure C.2c

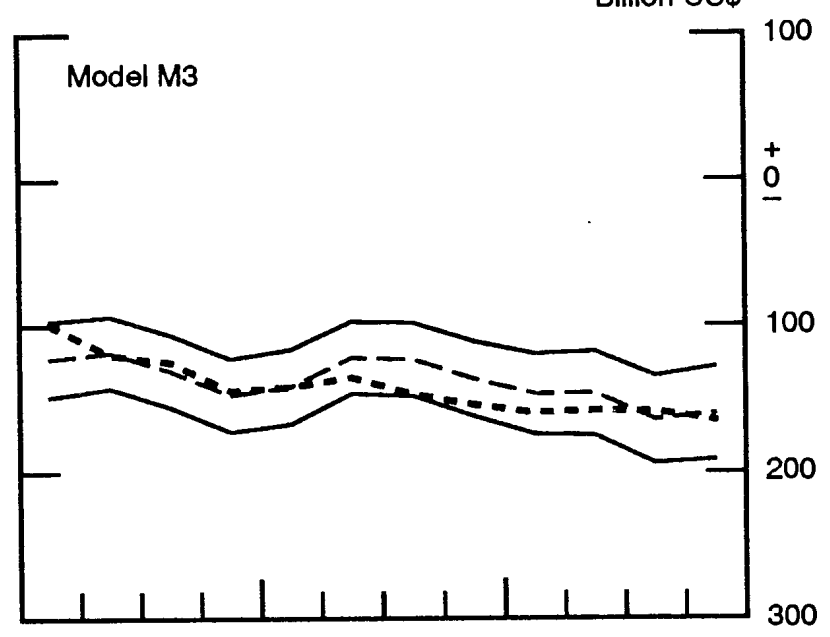

Figure C.2e

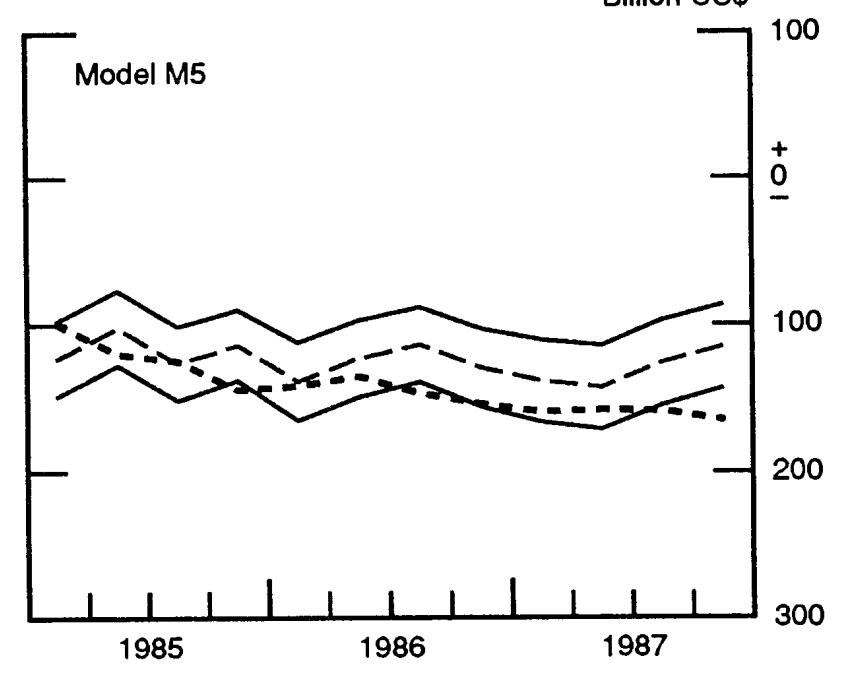

Figure C.2b

Billion US\$

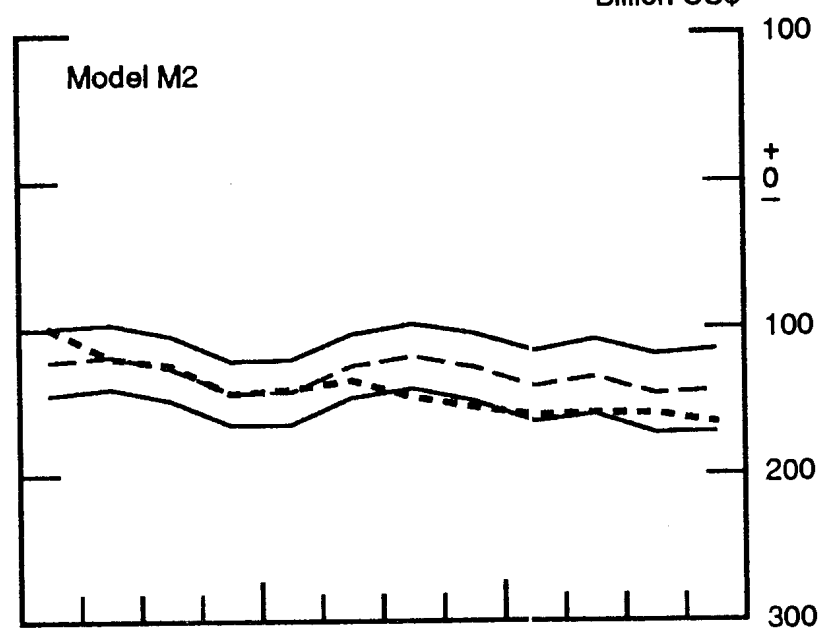

Figure C.2d

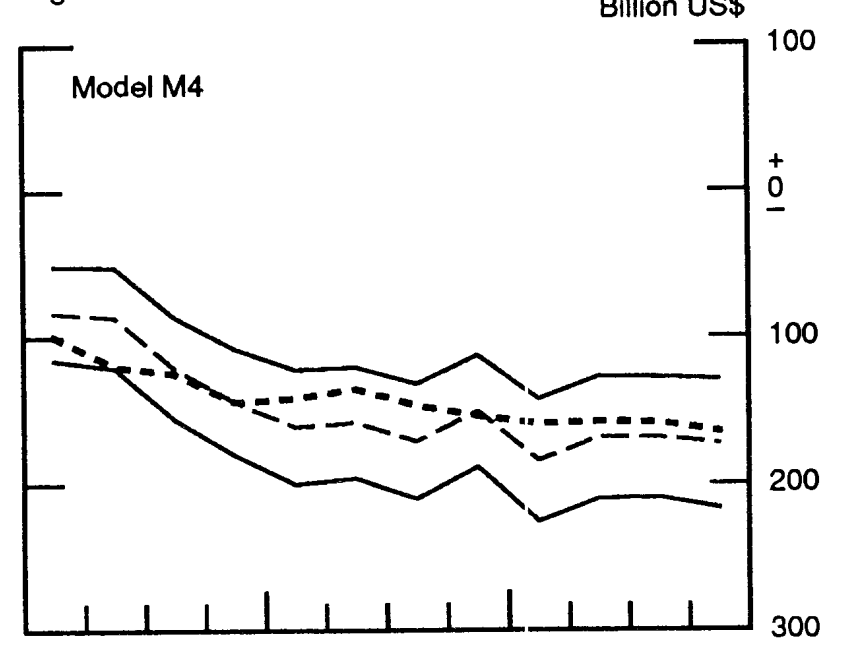

Figure C.2f

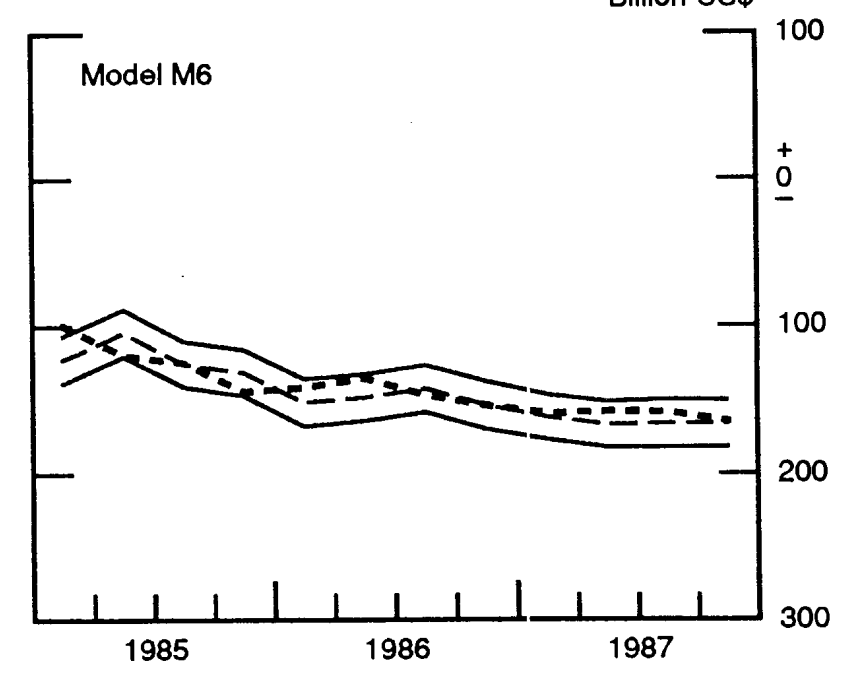


Figure C.3: 95 \% Confidence Intervals For Trade-account Forecasts s-step ahead, Asymptotic formula

Figure C.3a

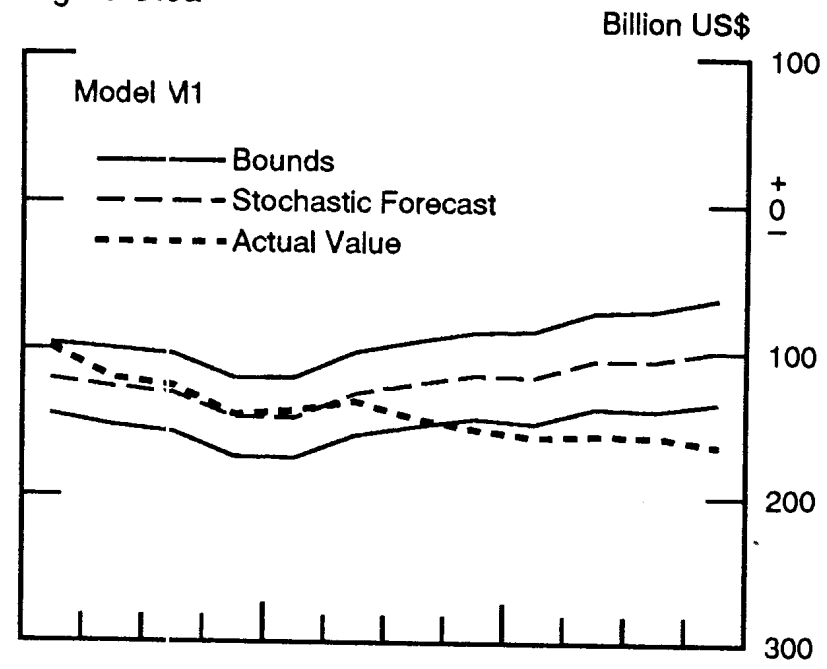

Figure C.3b

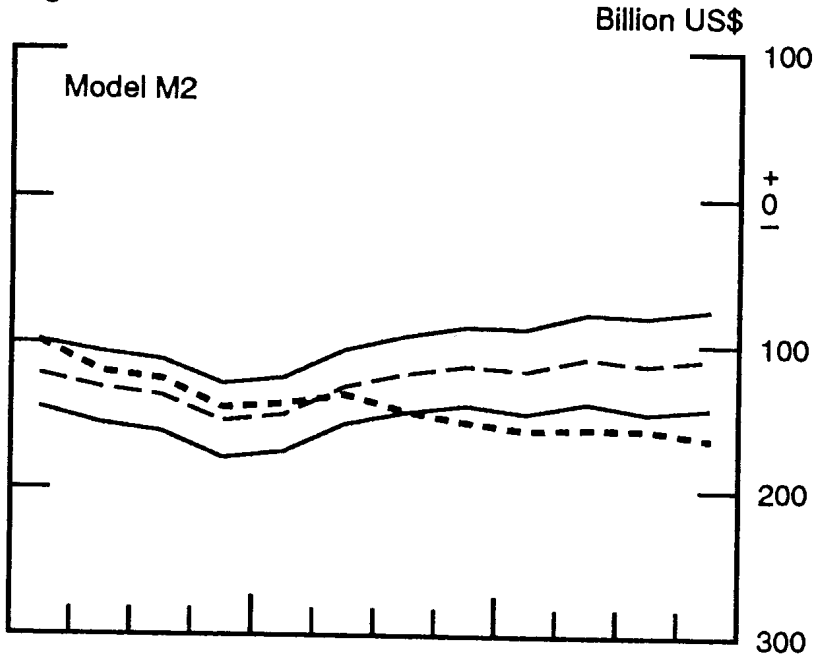

Figure C.3d

Billion US\$

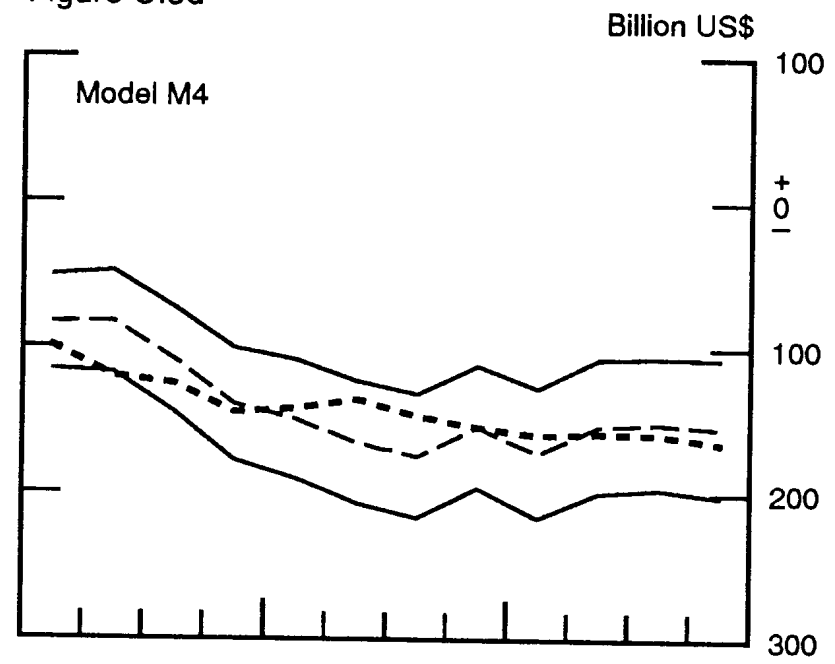

Figure C.3e

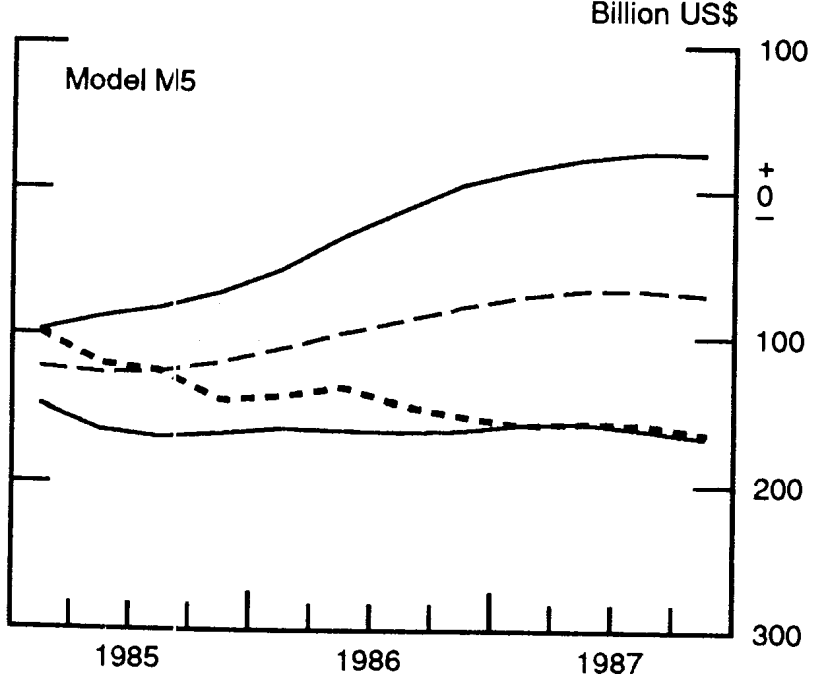

Figure C.3f

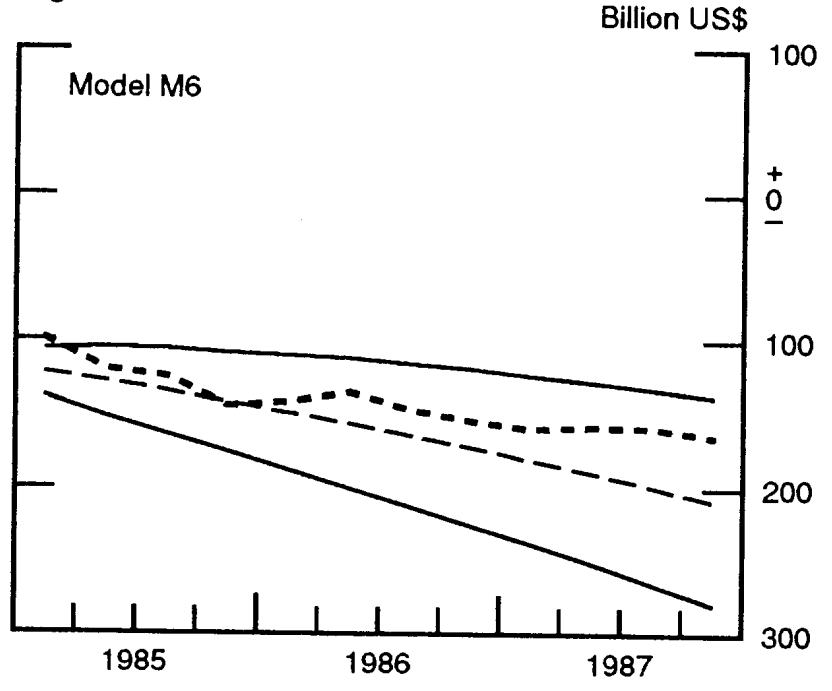


Table C.7

Forecast-encompassing Test Statistics for Alternative Trade-account Models One-step Ahead, Asymptotic Formula

Pairwise Forecast-encompassing Test Statistics (F values)

\begin{tabular}{|c|c|c|c|c|c|c|c|c|}
\hline \multirow{2}{*}{$\begin{array}{c}\text { Encompassing } \\
\text { Model (h) }\end{array}$} & \multirow[b]{2}{*}{ Null Hypothesis } & \multirow[b]{2}{*}{ d.f. } & \multicolumn{6}{|c|}{ Model To Be Encompassed $(\ell)$} \\
\hline & & & M1 & M2 & M3 & M4 & M5 & M6 \\
\hline \multirow[t]{3}{*}{ M1 } & $\mathrm{H}_{0}: \kappa_{\ell}=0 ; \kappa_{0}=0$ & 1,11 & 5.9 & 6.1 & 6.9 & 11.0 & 6.2 & 8.4 \\
\hline & $H_{0}: \kappa_{\ell}=0$ & 1,10 & & 0.2 & 1.9 & 11.8 & 0.2 & 7.7 \\
\hline & $\mathrm{H}_{0}: \kappa_{\ell}=\kappa_{0}=0$ & 2,10 & & 2.8 & 4.1 & 11.7 & 2.9 & 8.6 \\
\hline \multirow[t]{3}{*}{ M2 } & $\mathrm{H}_{0}: \kappa_{\ell}=0 ; \kappa_{0}=0$ & 1,11 & 4.5 & 4.4 & 4.9 & 8.4 & 4.6 & 6.2 \\
\hline & $\mathrm{H}_{0}: \kappa_{\ell}=0$ & 1,10 & 0.1 & & 0.9 & 13.0 & 0.3 & 7.2 \\
\hline & $H_{0}: \kappa_{\ell}=\kappa_{0}=0$ & 2,10 & 2.0 & & 2.6 & 11.1 & 2.2 & 7.0 \\
\hline \multirow[t]{3}{*}{ M3 } & $\mathrm{H}_{0}: \kappa_{\ell}=0 ; \kappa_{0} \equiv 0$ & 1,11 & 1.2 & 1.1 & 1.2 & 2.7 & 1.3 & 1.7 \\
\hline & $\mathrm{H}_{0}: \kappa_{\ell}=0$ & 1,10 & 0.0 & 0.3 & & 7.4 & 0.1 & 2.4 \\
\hline & $\mathrm{H}_{0}: \kappa_{\ell}=\kappa_{0}=0$ & 2,10 & 0.6 & 0.7 & & 4.6 & 0.6 & 1.9 \\
\hline \multirow[t]{3}{*}{ M4 } & $\mathrm{H}_{0}: \kappa_{\ell}=0 ; \kappa_{0}=0$ & 1,11 & 0.6 & 0.6 & 0.6 & 0.4 & 0.7 & 1.0 \\
\hline & $\mathrm{H}_{0}: \kappa_{\ell}=0$ & 1,10 & 5.3 & 2.6 & 1.7 & & 4.0 & 14.4 \\
\hline & $\mathrm{H}_{0}: \kappa_{\ell}=\kappa_{0}=0$ & 2,10 & 2.9 & 1.6 & 1.1 & & 2.3 & 7.6 \\
\hline \multirow[t]{3}{*}{ M5 } & $\mathrm{H}_{0}: \kappa_{\ell}=0 ; \kappa_{0}=0$ & 1,11 & 9.2 & 9.5 & 10.5 & 14.1 & 8.6 & 10.7 \\
\hline & $\mathrm{H}_{0}: \kappa_{\ell}=0$ & 1,10 & 1.0 & 1.5 & 3.9 & 6.5 & & 2.7 \\
\hline & $\mathrm{H}_{0}: \kappa_{\ell}=\kappa_{0}=0$ & 2,10 & 4.8 & 5.2 & 7.4 & 9.7 & & 6.3 \\
\hline \multirow[t]{3}{*}{ M6 } & $\mathrm{H}_{0}: \mathrm{\kappa}_{\ell}=0 ; \kappa_{0} \equiv 0$ & 1,11 & 0.7 & 0.7 & 0.7 & 0.7 & 1.0 & 0.7 \\
\hline & $\mathrm{H}_{0}: \kappa_{\ell}=0$ & 1,10 & 0.1 & 0.0 & 0.0 & 0.1 & 5.3 & \\
\hline & $\mathrm{H}_{0}: \kappa_{\ell}=\kappa_{0}=0$ & 2,10 & 0.4 & 0.3 & 0.3 & 0.3 & 3.1 & \\
\hline
\end{tabular}

Multiple-model $(\forall \ell \neq h)$

Forecast-encompassing Test Statistics

Null Hypothesis d.f. F valuc

Notes: a. The $5 \%$ critical values for the $F$ statistics are $F(1,11)=4.84, F(1,10)=4.96, F(2,10)=4.10, F(5,7)=3.97, F(5,6)=4.39, F(6,6)=4.28$.

b. The regressions for pairwise and multiple-model forecast encompassing are

$$
\text { and } \begin{aligned}
\tilde{v}_{\mathrm{T}+\mathrm{s}}^{(h)} & =\kappa_{0}+\kappa_{\ell} \tilde{\mu}_{\mathrm{T}+\mathrm{s}}^{(\ell)} \\
\tilde{v}_{\mathrm{T}+\mathrm{s}}^{(h)} & =\kappa_{0}+\Sigma_{\ell \neq h} \kappa_{\ell} \tilde{\mu}_{\mathrm{T}+\mathrm{s}}^{(\ell)},
\end{aligned}
$$

respectively, where the $\ell^{\text {th }}$ model(s) is (are) being encompassed by the $h^{\text {th }}$ model (the encompassing model). Each regression uses GLS, i.e., premultiplying each equation by $\left[\tilde{\Phi}^{(\mathrm{h})}\right]^{-1 / 2}$ in order to account for the autocorrelation and heteroscedasticity of the: dependent variable $\tilde{v}_{\mathrm{T}+\mathrm{s}}^{(\mathrm{h})}$.

c. The diagonal elements in the block of pairwise forecast-encompassing test statistics are statistics testing $\kappa_{0}=0$ with $\kappa_{\ell}=0$. 
Table C. 8

Forecast-encompassing Test Statistics for Alternative Trade-account Models s-step Ahead, Asymptotic Formula

Pa rwise Forecast-encompassing Test Statistics (F values)

\begin{tabular}{|c|c|c|c|c|c|c|c|c|}
\hline \multirow{2}{*}{$\begin{array}{c}\text { Encompassing } \\
\text { Model (h) }\end{array}$} & \multirow[b]{2}{*}{ Null Hypothesis } & \multirow[b]{2}{*}{ d.f. } & \multicolumn{6}{|c|}{ Model To Be Encompassed ( $\ell$ ) } \\
\hline & & & M1 & M2 & M3 & M4 & M5 & M6 \\
\hline \multirow[t]{3}{*}{ M1 } & $\mathrm{H}_{0}: \kappa_{l}=0 ; \kappa_{0} \equiv 0$ & 1,11 & 1.7 & 1.1 & 1.3 & 3.8 & 0.3 & 4.2 \\
\hline & $\mathrm{H}_{0}: \mathrm{\kappa}_{\mathrm{l}}=0$ & 1,10 & & 2.9 & 0.7 & 5.0 & 39.2 & 90.6 \\
\hline & $H_{0}: \kappa_{\ell}=\kappa_{0}=0$ & 2,10 & & 2.5 & 1.2 & 3.7 & 23.5 & 53.2 \\
\hline \multirow[t]{3}{*}{ M2 } & $\mathrm{H}_{0}: \kappa_{\ell}=0 ; \kappa_{0}=0$ & 1,11 & 0.6 & 1.1 & 0.7 & 2.9 & 0.1 & 2.9 \\
\hline & $\mathrm{H}_{0}: \kappa_{\ell}=0$ & 1,10 & 5.5 & & 1.8 & 6.2 & 60.6 & 70.3 \\
\hline & $\mathrm{H}_{0}: \kappa_{\ell}=\kappa_{0}=0$ & 2,10 & 3.5 & & 1.5 & 3.9 & 33.9 & 39.3 \\
\hline \multirow[t]{3}{*}{ M3 } & $\mathrm{H}_{0}: \kappa_{\ell}=0 ; \kappa_{0}=0$ & 1,11 & 0.0 & 0.0 & 0.2 & 1.8 & 0.1 & 1.2 \\
\hline & $\mathrm{H}_{0}: \kappa_{\ell}=0$ & 1,10 & 2.7 & 3.2 & & 9.4 & 42.9 & 25.9 \\
\hline & $\mathrm{H}_{0}: \kappa_{\mathrm{l}}=\kappa_{0}=0$ & 2,10 & 1.5 & 1.7 & & 4.9 & 22.0 & 13.3 \\
\hline \multirow[t]{3}{*}{ M4 } & $\mathrm{H}_{0}: \kappa_{l}=0 ; \kappa_{0}=0$ & 1,11 & 0.6 & 0.7 & 0.9 & 0.8 & 1.4 & 0.5 \\
\hline & $\mathrm{H}_{0}: \mathrm{K}_{l}=0$ & 1,10 & 0.4 & 0.0 & 0.6 & & 2.1 & 1.1 \\
\hline & $\mathrm{H}_{0}: \mathrm{\kappa}_{l}=\mathrm{\kappa}_{0}=0$ & 2,10 & 0.5 & 0.4 & 0.7 & & 1.5 & 0.9 \\
\hline \multirow[t]{3}{*}{ M5 } & $\mathrm{H}_{0}: \kappa_{l}=0 ; \kappa_{0}=0$ & 1,11 & 0.4 & 0.3 & 0.2 & 0.0 & 0.6 & 0.1 \\
\hline & $\mathrm{H}_{0}: \kappa_{.}=0$ & 1,10 & 1.1 & 2.0 & 2.9 & 9.4 & & 49.2 \\
\hline & $\mathrm{H}_{0}: \mathrm{\kappa}_{!}=\mathrm{\kappa}_{0}=0$ & 2,10 & 0.8 & 1.3 & 1.8 & 5.2 & & 26.1 \\
\hline \multirow[t]{3}{*}{ M6 } & $\mathrm{H}_{0}: \kappa_{2,}=0 ; \kappa_{0}=0$ & 1,11 & 2.3 & 2.0 & 1.9 & 1.9 & 4.0 & 5.3 \\
\hline & $\mathrm{H}_{0}: \kappa_{: !}=0$ & 1,10 & 10.4 & 10.2 & 6.1 & 0.4 & 1.3 & \\
\hline & $\mathrm{H}_{0}: \kappa_{\| !}=\kappa_{0}=0$ & 2,10 & 10.1 & 9.9 & 6.9 & 2.7 & 3.3 & \\
\hline
\end{tabular}

Multiple-model $(\forall \ell \neq h)$

Forecast-encompassing Test Statistics

Null Hypothesis d.f. F value

Notes: $\quad$ a. The $5 \%$ critical values for the $F$ statistics are $F(1,11)=4.84, F(1,10)=4.96, F(2,10)=4.10, F(5,7)=3.97, F(5,6)=4.39, F(6,6)=4.28$.

b. The regressions for pairwise and multiple-model forecast encompassing are

$$
\text { and } \begin{aligned}
\tilde{v}_{\mathrm{T}+\mathrm{s}}^{(\mathrm{h})} & =\kappa_{0}+\kappa_{\ell} \tilde{\mu}_{\mathrm{T}+\mathrm{s}}^{(\ell)} \\
\tilde{v}_{\mathrm{T}+\mathrm{s}}^{(\mathrm{h})} & =\kappa_{0}+\Sigma_{\ell \neq h} \kappa_{\ell} \tilde{\mu}_{\mathrm{T}+\mathrm{s}}^{(\ell)},
\end{aligned}
$$

respectively, where the $\ell^{\text {th }}$ model(s) is (are) being encompassed by the $h^{\text {th }}$ model (the encompassing model). Each regression uses GLS, i.e., prer ultiplying each equation by $\left[\tilde{\Phi}^{(h)}\right]^{-1 / 2}$ in order to account for the autocorrelation and heteroscedasticity of the dependent variable $\tilde{v}_{\mathrm{T}+\mathrm{s}}^{(\mathrm{h})}$.

c. The diagonal eiements in the block of pairwise forecast-encompassing test statistics are statistics testing $\kappa_{0}=0$ with $\kappa_{\ell} \equiv 0$. 
$50 \mathrm{k}$

Table C.9

Nonlinearity Biases in Deterministic Forecasts of the U.S. Trade Account

One-step Ahead, Asymptotic Formula

\begin{tabular}{|c|c|c|c|c|c|c|c|c|c|c|c|c|}
\hline & \multicolumn{12}{|c|}{ Forecast Period } \\
\hline & \multicolumn{4}{|c|}{1985} & \multicolumn{4}{|c|}{1986} & \multicolumn{4}{|c|}{1987} \\
\hline & Q1 & Q2 & Q3 & Q4 & Q1 & Q2 & Q3 & Q4 & Q1 & Q2 & Q3 & Q4 \\
\hline \multicolumn{13}{|c|}{$\begin{array}{l}\text { Historical Trade Account } \\
\text { (billion US\$) }\end{array}$} \\
\hline & $-99.5-$ & -119.8 & -124.8 & -144.5 & -141.7 & -135.4 & -146.9 & -154.1 & $-159.5-$ & $-158.2-$ & $-158.7-$ & -164.8 \\
\hline \multicolumn{13}{|l|}{$\begin{array}{l}\text { Estimated Bias } \\
\text { (billion LSS) }\end{array}$} \\
\hline Model M1 & -0.1 & -0.0 & -0.0 & -0.1 & -0.1 & -0.0 & -0.0 & -0.0 & -0.1 & -0.0 & -0.1 & -0.0 \\
\hline Model M2 & -0.0 & -0.0 & -0.0 & -0.0 & -0.0 & 0.0 & 0.0 & 0.0 & -0.0 & -0.0 & -0.0 & -0.0 \\
\hline Model M3 & -0.1 & -0.1 & -0.1 & -0.1 & -0.1 & -0.0 & -0.0 & -0.0 & -0.1 & -0.1 & -0.1 & -0.1 \\
\hline Model M4 & 3.5 & -0.9 & -0.8 & -4.7 & -0.4 & -4.8 & -2.1 & 1.6 & 0.9 & 8.7 & 11.0 & 9.2 \\
\hline Model M5 & -0.2 & -0.2 & -0.1 & -0.1 & -0.2 & -0.2 & -0.2 & -0.2 & -0.2 & -0.2 & -0.2 & -0.2 \\
\hline Model M6 & 0 & 0 & 0 & 0 & 0 & 0 & 0 & 0 & 0 & 0 & 0 & 0 \\
\hline \multicolumn{13}{|c|}{$\begin{array}{l}\text { Estimated Standard Error of the Bias } \\
\text { (billion LSS) }\end{array}$} \\
\hline Model M1 & 0.009 & 0.009 & 0.008 & 0.008 & 0.009 & 0.009 & 0.009 & 0.009 & 0.01 & 0.01 & 0.011 & 0.012 \\
\hline Model M2 & 0.009 & 0.008 & 0.008 & 0.008 & 0.009 & 0.008 & 0.009 & 0.009 & 0.009 & 0.01 & 0.01 & 0.011 \\
\hline Model M3 & 0.01 & 0.01 & 0.01 & 0.01 & 0.011 & 0.01 & 0.011 & 0.011 & 0.011 & 0.012 & 0.012 & 0.014 \\
\hline Model M4 & 0.02 & 0.024 & 0.023 & 0.024 & 0.028 & 0.027 & 0.027 & 0.028 & 0.027 & 0.027 & 0.029 & 0.029 \\
\hline Model M5 & 0.014 & 0.015 & 0.013 & 0.013 & 0.014 & 0.013 & 0.014 & 0.014 & 0.015 & 0.015 & 0.015 & 0.016 \\
\hline Model M6 & 0 & 0 & 0 & 0 & 0 & 0 & 0 & 0 & 0 & 0 & 0 & 0 \\
\hline \multicolumn{13}{|l|}{ "t" ratio ${ }^{a}$} \\
\hline Model M1 & 6.9 & 5.4 & 4.5 & 6.6 & 6.6 & 3.5 & 3.4 & 4.2 & 5.7 & 4.4 & 5.2 & 4.2 \\
\hline Model M2 & 4.3 & 3.1 & 1.1 & 4.4 & 3.7 & 0.7 & 1.1 & 0.3 & 1.6 & 0.7 & 2.1 & 0.7 \\
\hline Model M3 & 8.6 & 7.1 & 5.3 & 8.2 & 6.9 & 3.4 & 3.1 & 3.9 & 5.8 & 5.7 & 7.6 & 5.6 \\
\hline Model M4 & 173.2 & 38.0 & 33.6 & 196.0 & 13.7 & 176.3 & 77.2 & 58.4 & 32.6 & 318.1 & 381.3 & 314.6 \\
\hline Modcl M5 & 11.6 & 12.3 & 11.0 & 10.7 & 12.7 & 11.5 & 11.3 & 13.1 & 12.8 & 13.4 & 12.5 & 11.3 \\
\hline Model M6 & - & - & - & - & - & - & - & - & - & - & - & - \\
\hline
\end{tabular}

Notes: $\quad$ Model M1: Helkie and Hooper (1988).

Model M2: Model M1 by FIML.

Model M3: Model M1 by FLML, with partial adjustment, without non-price rationing.

Model M4: Bilateral trade model by FIML.

Model M5: VAR(4) of import and export volumes and price indices.

Model M6: AR(1) of the nominal trade account.

a. The " $\mathrm{t}$ " ratios are numerically accurate. However, they do not always match the ratios betwe en the reported biases and standard crrors because the latter are rounded. 
Table C.10

Nonlinearity Biases in Deterministic Forecasts of the U.S. Trade Account s-step Ahead, Asymptotic Formula

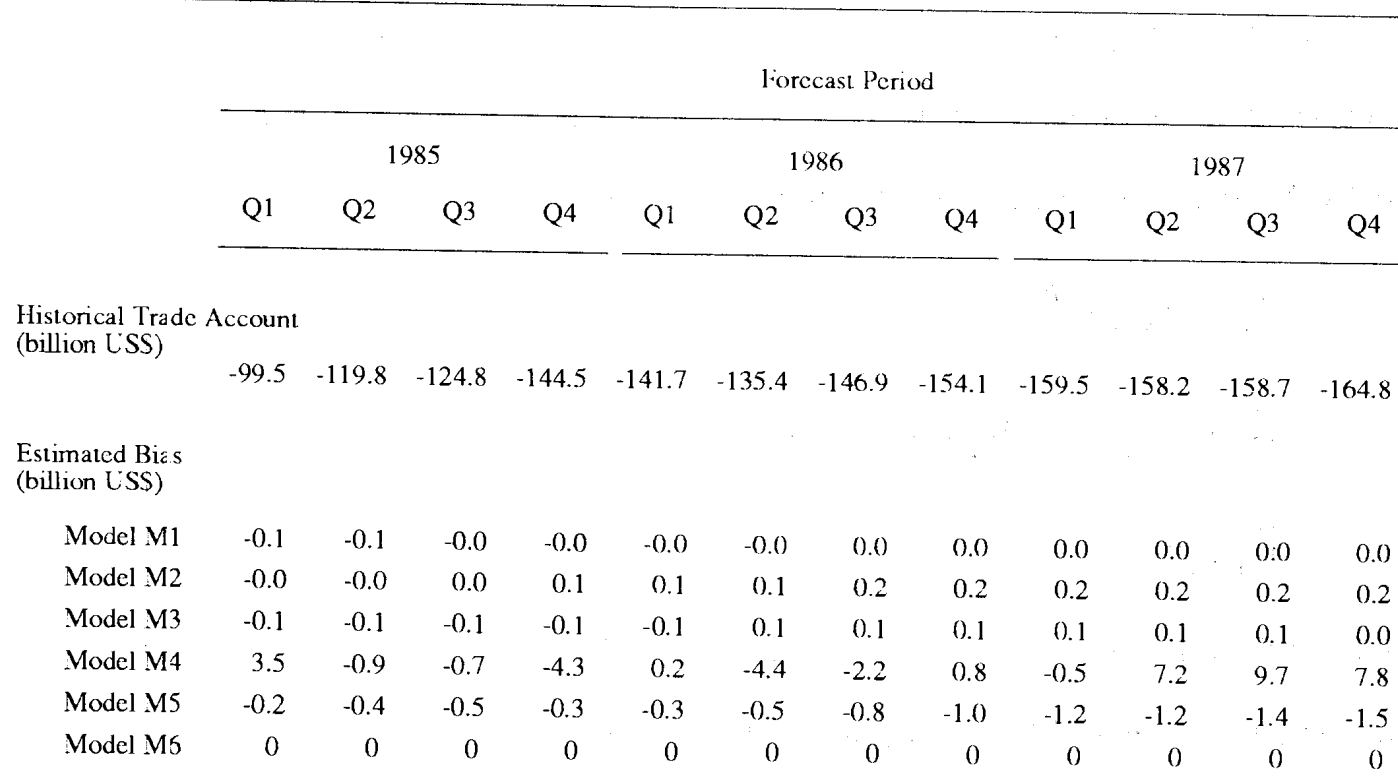

Estimated Standard Error of the Bias (billion LSS)

$\begin{array}{lllllllllllll}\text { Model M1 } & 0.009 & 0.011 & 0.011 & 0.012 & 0.011 & 0.013 & 0.013 & 0.013 & 0.014 & 0.015 & 0.015 & 0.016 \\ \text { Model M: } & 0.009 & 0.01 & 0.011 & 0.012 & 0.012 & 0.013 & 0.015 & 0.015 & 0.017 & 0.017 & 0.018 & 0.019 \\ \text { Model M:3 } & 0.01 & 0.013 & 0.016 & 0.018 & 0.018 & 0.018 & 0.02 & 0.02 & 0.023 & 0.023 & 0.025 & 0.026 \\ \text { Model M.1 } & 0.02 & 0.025 & 0.027 & 0.031 & 0.032 & 0.035 & 0.036 & 0.035 & 0.035 & 0.037 & 0.038 & 0.041 \\ \text { Model M:5 } & 0.014 & 0.033 & 0.044 & 0.052 & 0.073 & 0.097 & 0.123 & 0.15 & 0.167 & 0.187 & 0.208 & 0.22 \\ \text { Model Mí } & 0 & 0 & 0 & 0 & 0 & 0 & 0 & 0 & 0 & 0 & 0 & 0\end{array}$

$" i{ }^{\prime \prime}$ ratio ${ }^{a}$

$\begin{array}{lrrrrrrrrrrrr}\text { Model M: } & 6.9 & 5.1 & 2.0 & 1.4 & 2.2 & 0.2 & 1.4 & 1.4 & 1.8 & 0.9 & 1.7 & 1.6 \\ \text { Model M: } & 4.3 & 0.6 & 3.6 & 4.3 & 4.7 & 8.9 & 10.7 & 11.8 & 12.3 & 10.7 & 9.6 & 9.6 \\ \text { Model M3 } & 8.6 & 7.0 & 4.5 & 4.6 & 3.0 & 3.8 & 6.1 & 5.6 & 4.2 & 2.9 & 2.3 & 1.6 \\ \text { Model M4 } & 173.2 & 36.6 & 27.3 & 141.5 & 6.4 & 124.6 & 60.1 & 22.7 & 12.9 & 191.3 & 254.9 & 188.4 \\ \text { Model Ms; } & 11.6 & 13.2 & 10.3 & 6.5 & 3.8 & 5.1 & 6.6 & 6.8 & 7.0 & 6.3 & 6.5 & 6.6 \\ \text { Model M6; } & - & - & - & - & - & - & - & - & - & - & - & -\end{array}$

Notes: $\quad$ Model M1: Helkic and Hooper (1988).

Model M2: Model M1 by IIML.

Model M3: Model M1 by HML, with partial adjustment, without non-price rationing.

Model M4: Bilateral trade model by FIML.

Model M5: VAR(4) of import and export volumes and price indices.

Model M6: AR(1) of the nominal trade account.

a. The " $\mathrm{t}$ " ratios are numerically accurate. However, they do nol always match the ratios between the reported biases and standard crrors because the latter are rounded. 


\section{Appendix D: Efficiency Gains from the Use of Antithetic Variates}

The efficiency gain from the use of antithetic variates in estimating the nonlinearity bias of the deterministic forecasts is easily measured as the ratio of the estimated variance of $\tilde{\mu}_{\mathrm{T}+\mathrm{s}}$ (the "naive" mean forecast) to the estimated variance of $\mu_{\mathrm{T}+\mathrm{s}}$ (the mean forecast using antithetic variates). From (16)-(18), the naive mean forecast and its estimated variance are:

$$
\begin{aligned}
& \text { (D1) } \tilde{\mu}_{\mathrm{T}+\mathrm{s}} \quad=\Sigma_{\mathrm{k}} \mathrm{NX} \mathrm{k}, \mathrm{T}+\mathrm{s}_{\mathrm{K}} \text {, } \\
& \text { (D2) } \operatorname{vãr}\left(\tilde{\mu}_{\mathrm{T}+\mathrm{s}}\right)=\left[\Sigma_{\mathrm{k}}\left(\mathrm{NX} \mathrm{k}, \mathrm{T}+\mathrm{s}-\tilde{\mu}_{\mathrm{T}+\mathrm{s}}\right)^{2} / \mathrm{K}\right] / \mathrm{K} \\
& =\tilde{\sigma}_{\mathrm{T}+\mathrm{S}}^{2} / \mathrm{K},
\end{aligned}
$$

where $\mathrm{NX}_{\mathrm{k}, \mathrm{T}+\mathrm{S}}$ is the $\mathrm{kth}$ replication of the forecast of the trade account in period $\mathrm{T}+\mathrm{s}$. From Section 5 , the mean forecast using antithetic variates and its estimated variance are:

$$
\begin{aligned}
& \text { (D3) } \bar{\mu}_{\mathrm{T}+\mathrm{s}} \quad=\Sigma_{\mathrm{k}}\left(\mathrm{NX}_{\mathrm{k}, \mathrm{T}+\mathrm{s}}+\mathrm{NX}_{\mathrm{k}, \mathrm{T}+\mathrm{s}}^{+}\right) /(2 \mathrm{~K}) \\
& =\left(\tilde{\mu}_{\mathrm{T}+\mathrm{s}}+\tilde{\mu}_{\mathrm{T}+\mathrm{s}}^{+}\right) / 2 \text {, } \\
& \text { (D4) } \operatorname{varr}\left(\bar{\mu}_{\mathrm{T}+\mathrm{s}}\right)=\left[\Sigma_{\mathrm{k}}\left(\left\{\mathrm{NX}_{\mathrm{k}, \mathrm{T}+\mathrm{s}}+\mathrm{NX}_{\mathrm{k}, \mathrm{T}+\mathrm{s}}^{+}\right\} / 2-\bar{\mu}_{\mathrm{T}+\mathrm{s}}\right)^{2} / \mathrm{K}\right] / \mathrm{K} \text {, }
\end{aligned}
$$

where $\mathrm{NX}_{\mathrm{k}, \mathrm{T}+\mathrm{s}}^{+}$is the kth replication of the forecast of the trade account in period $\mathrm{T}+\mathrm{s}$, using the negative of the random numbers drawn to construct $\mathrm{NX}_{\mathrm{k}, \mathrm{T}+\mathrm{s}}$. The efficiency gain is the ratio of (D2) to (D4), i.e., the reduction in variance obtained by antithetic variates. Conversely, the efficiency gain represents the " $x$-fold" number of replications $\mathrm{K}$ that would be required to obtain a naive mean forecast with the same variance as that of the mean forecast using antithetic variates.

Table D.I presents the estimated efficiency gains for both one-step and s-step ahead forecasts. For models M1-M4, the efficiency gains range from around 20 to over 2000 . In those instances with very high efficiency gains, a single replication with antithetic variates would have produced a mean forecast with a smaller variance than that of the "naive" mean forecast obtained 
Table D.1

Efficiency Gains from Antithetic Variates

In Estimating the Nonlinearity Bias of Deterministic Forecasts

\begin{tabular}{|c|c|c|c|c|c|c|c|c|c|c|c|c|}
\hline & \multicolumn{12}{|c|}{ Forecast Period } \\
\hline & \multicolumn{4}{|c|}{1985} & \multicolumn{4}{|c|}{1986} & \multicolumn{4}{|c|}{1987} \\
\hline & Q1 & Q2 & Q3 & Q4 & Q1 & Q2 & Q3 & Q4 & Q1 & Q2 & Q3 & Q4 \\
\hline \multicolumn{13}{|l|}{ Model $\mathbf{M}:$} \\
\hline 1-period: Asymptotic & 1783 & 1821 & 2049 & 1890 & 1905 & 1886 & 1771 & 1875 & 1819 & 1827 & 1828 & 1716 \\
\hline Approximate & 109 & 92 & 83 & 72 & 64 & 53 & 53 & 50 & 52 & 54 & 50 & 46 \\
\hline s-period: Asymptotic & 1783 & 1526 & 1379 & 1268 & 1469 & 1286 & 1234 & 1392 & 1340 & 1235 & 1290 & 1319 \\
\hline Approximate & 109 & 59 & 42 & 38 & 36 & 31 & 31 & 34 & 39 & 43 & 44 & 51 \\
\hline \multicolumn{13}{|l|}{ Model M: } \\
\hline 1-period: Asymptotic & 1833 & 1938 & 2002 & 1880 & 1627 & 1672 & 1561 & 1835 & 1801 & 1769 & 1791 & 1606 \\
\hline Alproximate & 127 & 112 & 86 & 81 & 74 & 64 & 64 & 58 & 55 & 52 & 47 & 46 \\
\hline s-period: fisymptotic & 1833 & 1538 & 1225 & 1076 & 1078 & 914 & 770 & 790 & 759 & 818 & 842 & 772 \\
\hline Approximate & 127 & 70 & 51 & 49 & 45 & 36 & 36 & 33 & 39 & 42 & 48 & 53 \\
\hline \multicolumn{13}{|l|}{ Model M3 } \\
\hline 1-period: Asymptotic & 1546 & 1564 & 1603 & 1547 & 1417 & 1398 & 1298 & 1447 & 1508 & 1477 & 1549 & 1353 \\
\hline Approximate & 724 & 689 & 697 & 660 & 589 & 565 & 490 & 545 & 551 & 527 & 544 & 465 \\
\hline s-period: fssymptotic & 1546 & 1238 & 930 & 815 & 807 & 722 & 640 & 702 & 677 & 686 & 676 & 658 \\
\hline Approximate & 724 & 169 & 103 & 75 & 58 & 47 & 42 & 37 & 37 & 32 & 31 & 29 \\
\hline \multicolumn{13}{|l|}{ Model M4 } \\
\hline 1-period: Asymptotic & 651 & 515 & 555 & 574 & 501 & 485 & 531 & 473 & 577 & 580 & 505 & 555 \\
\hline Approximate & 217 & 183 & 179 & 196 & 166 & 125 & 133 & 129 & 145 & 125 & 124 & 108 \\
\hline s-period: Asymptotic & 651 & 484 & 444 & 391 & 402 & 360 & 350 & 361 & 403 & 382 & 356 & 331 \\
\hline Approximate & 217 & 91 & 66 & 58 & 49 & 37 & 34 & 30 & 32 & 27 & 26 & 23 \\
\hline \multicolumn{13}{|l|}{ Model M:; } \\
\hline 1-period: Asymptotic & 880 & 715 & 870 & 802 & 889 & 939 & 774 & 906 & 889 & 860 & 893 & 830 \\
\hline Approximate & 631 & 592 & 557 & 513 & 549 & 519 & 539 & 413 & 332 & 414 & 395 & 347 \\
\hline s-period: Assymptotic & 880 & 341 & 251 & 208 & 138 & 115 & 95 & 78 & 67 & 58 & 51 & 48 \\
\hline Approximate & 631 & 39 & 15 & 10 & 8 & 8 & 8 & 7 & 6 & 5 & 5 & 4 \\
\hline \multicolumn{13}{|l|}{ Model Mi } \\
\hline 1-period: Asymptotic & $\infty$ & $\infty$ & $\infty$ & $\infty$ & $\infty$ & $\infty$ & $\infty$ & $\infty$ & $\infty$ & $\infty$ & $\infty$ & $\infty$ \\
\hline Approximate & $\infty$ & $\infty$ & $\infty$ & $\infty$ & $\infty$ & $\infty$ & $\infty$ & $\infty$ & $\infty$ & $\infty$ & $\infty$ & $\infty$ \\
\hline s-period: Asymptotic & $\infty$ & $\infty$ & $\infty$ & $\infty$ & $\infty$ & $\infty$ & $\infty$ & $\infty$ & $\infty$ & $\infty$ & $\infty$ & $\infty$ \\
\hline Approximate & $\infty$ & 1750 & 460 & 210 & 125 & 82 & 56 & 41 & 31 & 25 & 20 & 17 \\
\hline
\end{tabular}

Notes:

Model M1: Helkie and Hooper (1988).

Model M2: Model M1 by FTML.

Model M3: Model M1 by FLML, with partial adjustment, without non-price rationing.

Model M4: Bilateral trade model by FLML.

Model M5: VAR(4) of import and export volumes and price indices.

Model M6: AR(1) of the nominal trade account. 
from the 1000 replications in our simulation study. Conversely, some of the mean forecasts in Section 5 obtained with antithetic variates have a smaller variance than that of a naive mean forecast using two million replications.

The efficiency gains for the VAR (M5) typically are between 100 and 1000, but drop to as low as 4 for s-step ahead forecast with the approximate formula.

For model M6, the estimated gains for s-period ahead forecasts ( $s>1$ ) with the: approximate formula range from 17 to almost 2000. For this model, efficiency gains are infinite' for all s-step ahead forecasts with the asymptotic formula and for all one-step ahead forecasts with either formula because these forecasts are linear in the terms simulated. This has the following explanation.

In linear models, the one-step ahead forecast is linear in the parameters (and so in $\zeta_{\mathrm{k}}$ ) and not a function of the disturbances, so a single replication provides a completely acciurate estimate of the expected outcome, i.e., of the expectation $\mu_{\mathrm{T}+\mathrm{s}}$ in (27). Specifically, suppose that the model is $y_{t}=x_{t}^{\prime} \theta+u_{t}$ with a symmetrically distributed estimator of $\theta$ denoted $\hat{\theta}$ and that the one-step forecast of $\mathrm{y}_{\mathrm{T}+1}$ is $\mathrm{x}_{\mathrm{T}+1}^{\prime} \hat{\theta}$. Then $\hat{\theta}+\hat{\Gamma} \zeta_{\mathrm{k}}$ and $\hat{\theta}-\hat{\Gamma} \zeta_{\mathrm{k}}$ are equally likely to occur. The two resulting forecasts are $\mathrm{x}_{\mathrm{T}+1}^{\prime}\left(\hat{\theta}+\hat{\Gamma}_{\mathrm{K}_{\mathrm{k}}}\right)$ and $\mathrm{x}_{\mathrm{T}+1}^{\prime}\left(\hat{\theta}-\hat{\Gamma}_{\zeta_{\mathrm{k}}}\right)$, whose average is $\mathrm{x}_{\mathrm{T}+1}^{\prime} \hat{\theta}$. This is the average for any and all $\zeta_{\mathrm{k}}$ drawn, so the expectation in (27) is $\mathrm{x}_{\mathrm{T}+1}^{\prime} \hat{\theta}$. Here, the gains from antithetic variates are infinite, since no replications were actually necessary to find the exact forecast. See Hendry and Trivedi (1972, p. 120, footnote 4) on the similar situation of the bias of OLS with fixed regressors.

With s-step ahead forecasts from (possibly nonlinear) dynamic models, antithetic variates reduce or eliminate the Monte Carlo variation from the weighted sum of future disturbances, and reduce the variation from coefficient uncertainty (which is nonlinear in the estimated coefficients). Equation (33) in the text partitions these two components clearly. Because (33) arises from a linear model, antithetic variates would eliminate the variation from the weighted sum of future shocks. 
Mean forecasts using antithetic variates often result in markedly improved estimates of the nonlinearity bias from deterministic forecasts, requiring virtually no additional programming and (at most) twice the computational time. Indeed, little justification remains for using naive Monte Carlo rather than antithetic variates, in so far as estimating that bias is concerned. Antithetic variates as a technique is applicable to calculating the deterministic bias arising either from nonzero future disturbances only ("asymptotic") or from non-zero future disturbances and coefficient uncertainty ("approximate"). This paper appears to be the first analyzing the bias from both sources by means of antithetic variates.

The precise gain from antithetic variates depends upon the forecast period, the nonlinearity of the process, and whether the asymptotic or approximate formula is used. However, the large gains in Table D.1 are in line with other authors' results; cf. Calzolari (1979) and Fisher and Salmon (1986). Interestingly, efficiency gains for the nonlinearity bias of deterministic forecasts can be substantial for purely dynamic processes: that contrasts with the zero incremental gains from antithetic variates when measuring biases in the estimation of parameters from linear autoregressive processes.

Antithetic variates probably would obtain only small gains for estimates of forecast variances (Section 3.2) because those variances are nearly invariant to the sign of the random numbers drawn for (12) and (14). For one-step ahead forecasts from a linear model, the forecast variance $i$ is invariant to the sign, in which case the correlation $\rho_{\mathrm{T}+\mathrm{s}}$ is unity and no gains accrue. 


\section{Appendix E: Model Listings}

This appendix provides a complete, ordered listing of models M1-M6. We use the format of Edison, Marquez, and Tryon (1987, pp. 152ff). For each model, there are three parts: a list of identities and stochastic equations, a cross-reference table, and a list of variable definitions. Each stochastic equation appears with its estimated coefficient values and estimated stanclard errors (the latter in parentheses). The equation comment line gives the equation number, the name of the associated left-hand-side variable, a short description of the variable, and its units. The crossreference table lists the numbers of all equations in which each variable of the model appears. The variable definitions are alphabetical with short descriptions; and exogenous variables have the keyword "EXOG", while endogenous variables are shown with the number of the corresponding equation.

With minor exceptions, variable names follow certain conventions. The first letter indicates the country:

$\begin{array}{ll}\text { C } & \text { Canada } \\ \text { E } & \text { United Kingdom } \\ \text { G } & \text { West Germany } \\ \text { J } & \text { Japan } \\ \text { U } & \text { United States } \\ \text { I } & \text { Rest of OECD countries } \\ \text { L } & \text { LDCs } \\ \text { O } & \text { OPEC } \\ \text { Z } & \text { Rest-of-World ("ROW"). }\end{array}$

The middle portion of the name describes the variable, with the meaning of the letters usually proceeding from the general to the specific. For example, JGNPPOT is Japanese potential output. The last letter(s) of a variable name sometimes indicates the units or basis of measurement. Two common codes are: 
V nominal value
D measured in U.S. dollars.

Bilateral trade flows are an exception to the initial letter rule and follow these formats instead:

$\mathrm{XijV}$ exports from country $\mathrm{i}$ to country $\mathrm{j}$, in current U.S. dollars

MijV imports by country i from country $\mathrm{j}$, in current U.S. dollars.

As indicated in note $b$ of Table 3, the starting date of the estimation sample for model M1 is not uniform across equations. The exact starting dates are $1962 \mathrm{Q} 4$ for the volume of nonagricultural exports, 1970Q2 for the volume of agricultural exports, 1975Q2 for the price of nonagricultural exports, 1973Q2 for the price of agricultural exports, 1969Q2 for the volume of nonoil imports, 1965Q2 for the volume of oil consumption, 1970Q2 for the price of non-oil imports, and 1973Q2 for the IFS world commodity price index.

Some of the lag distributions in the structural models are estimated as Almon polynomials. To facilitate writing the computer routine that perturbs the Almon coefficient estimates, the models are coded with the transformed variables of the Almon polynomials. Thus, if the equation of interest is

$$
\begin{aligned}
& Y_{t}=\Sigma_{j} \alpha_{j} X_{t-j}+u_{t} \\
& \alpha_{j}=\lambda_{0}+j \lambda_{1}+j^{2} \lambda_{2}
\end{aligned}
$$

with $\lambda_{0}, \lambda_{1}$, and $\lambda_{2}$ unrestricted, then the model is coded as

$$
Y_{t}=\lambda_{0}\left(\Sigma_{j} X_{t-j}\right)+\lambda_{1}\left(\Sigma_{j} j X_{t-j}\right)+\lambda_{2}\left(\Sigma_{j} j^{2} X_{t-j}\right)+u_{t} .
$$

The term $\Sigma_{j} X_{t-j}$ in the above equation is coded in TROLL syntax as

SUM(I = lower bound TO upper bound: variable of interest $)$.

Finally, note that the models are coded with a coefficient BETA multiplying each error term. When interpreting the model listings below, all BETA coefficients should be treated as equalling unity, both in estimation and in stochastic simulation. TROLL's internal conventions for BETA are slightly different but do not affect this interpretation. 


\section{Model M1}

1. UFCUFW10: (UFCUFW10) G-10 FOREIGN COUNTRY CAPACITY UTILIZATION

UFCUFW10 $=100$ * UFGNPG10/UFGNPP

2. UXGNAV: (UXGNAV) NON-AGRICULTURAL EXPORTS (BIL $\$$ - AR)

UXGNAV = UXGNA * UPXNAG/100

3. UXGAV: (UXGAV) AGRICULTURAL EXPORT (BIL $\$$ - AR)

UXGAV $=$ UXGA $\star$ UPXGAUV $/ 100$

4. UXG: (UXG) TOTAL EXPORT VOLUME (BIL $82 \$-A R$ )

UXG $=$ UXGA + UXGNA

5. UXGV: (UXGV) TOTAL EXPORT VALUE (BIL $\$$ - AR)

UXGV $=U X G A V+$ UXGNAV

6. UMQFLNSD: (UMQFLNSD) OIL IMPORTS (MB/D - NSA - DOE)

UMQFLNSD = UFLCNS - UFLQLUNS - UFLUCQNS + UXQFLNS + UFLSCNS

7. UMQFLNSI: (UMQFLNSI) OIL IMPORTS (MB/D - NSA - IA)

UMQFLNSI = UMQFLNSD + UDICONV

8. UMQGFL: (UMQGFL) OIL IMPORTS (MB/D - SA - IA)

UMQGFL = UMQFLNSI/UMQFLSF

9. UMGFLV: (UMGFLV) OIL IMPORTS (BIL \$ - AR)

UMGFLV $=$ UMQGFL $\star 0.365 *$ UPMGFLUV + UMGFLV_ERR

10. UMGFL: (UMGFL) VOLUME OF OIL IMPORTS (BIL $82 \$$ - AR)

UMGFL $=100 \star$ UMGFLV/UPMGFL

11. UMG: (UMG) TOTAL IMPORTS (BIL 82\$ - AR)

UMG = UMGFL + UMGNFL 
17. UPXNAG: (UPXNAG) NON-AG EXPORT PRICE DEFLATOR $(1982=100)$

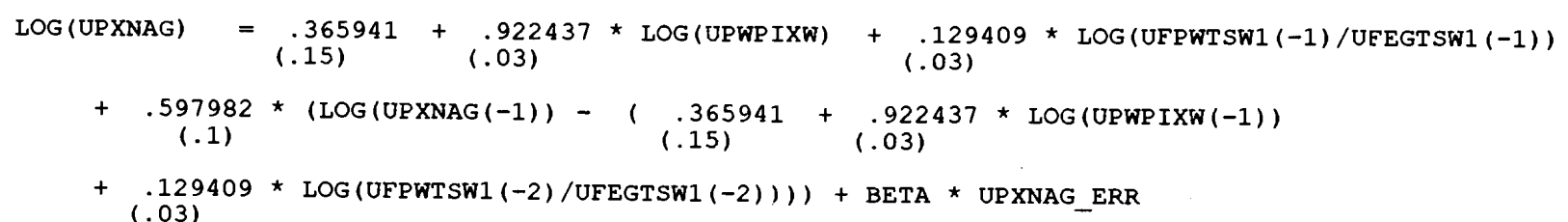

18. UPXGAUV: (UPXGAUV) AGRICULTURAL EXPORT PRICE DEFLATOR (REDUCED FORM EQUATION - $1982=100$ )

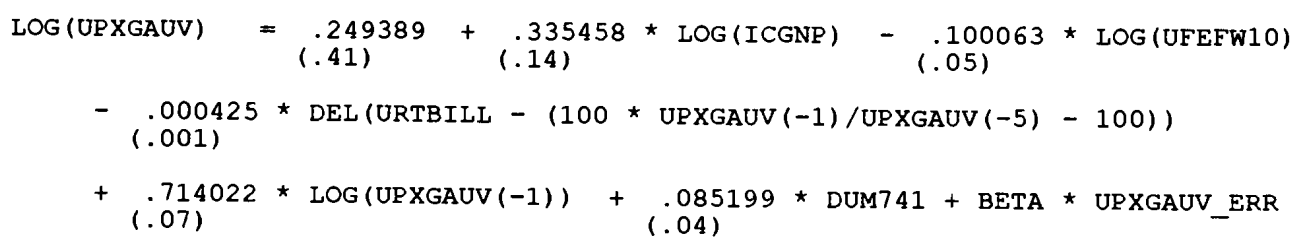

19. UMGNFL: (UMGNFL) NON-OIL IMPORTS (BIL $82 \$-A R$ )

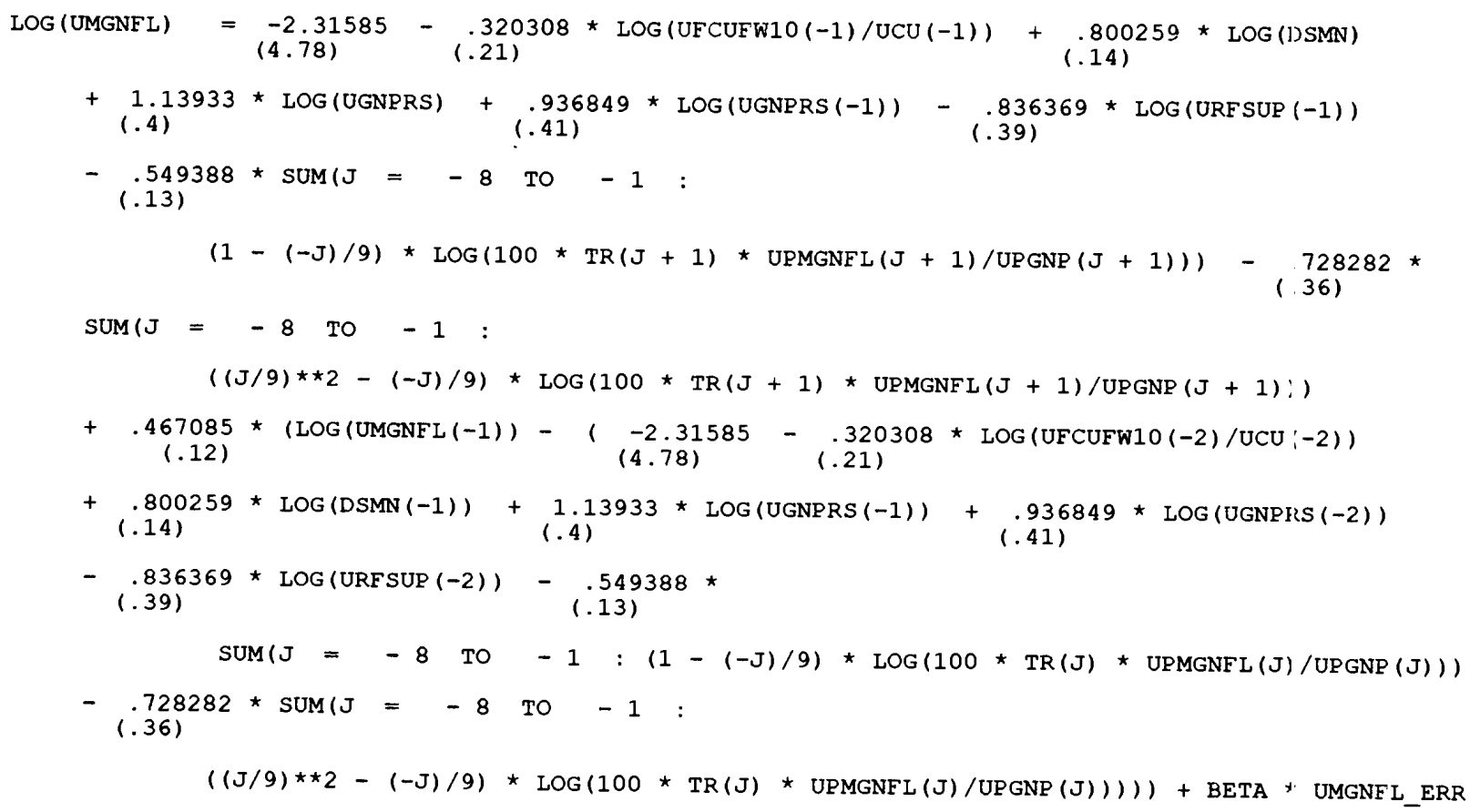


20. UFLCNS: (UFLCNS) DOMESTIC PETROLEUM CONSUMPTION (MB/D)

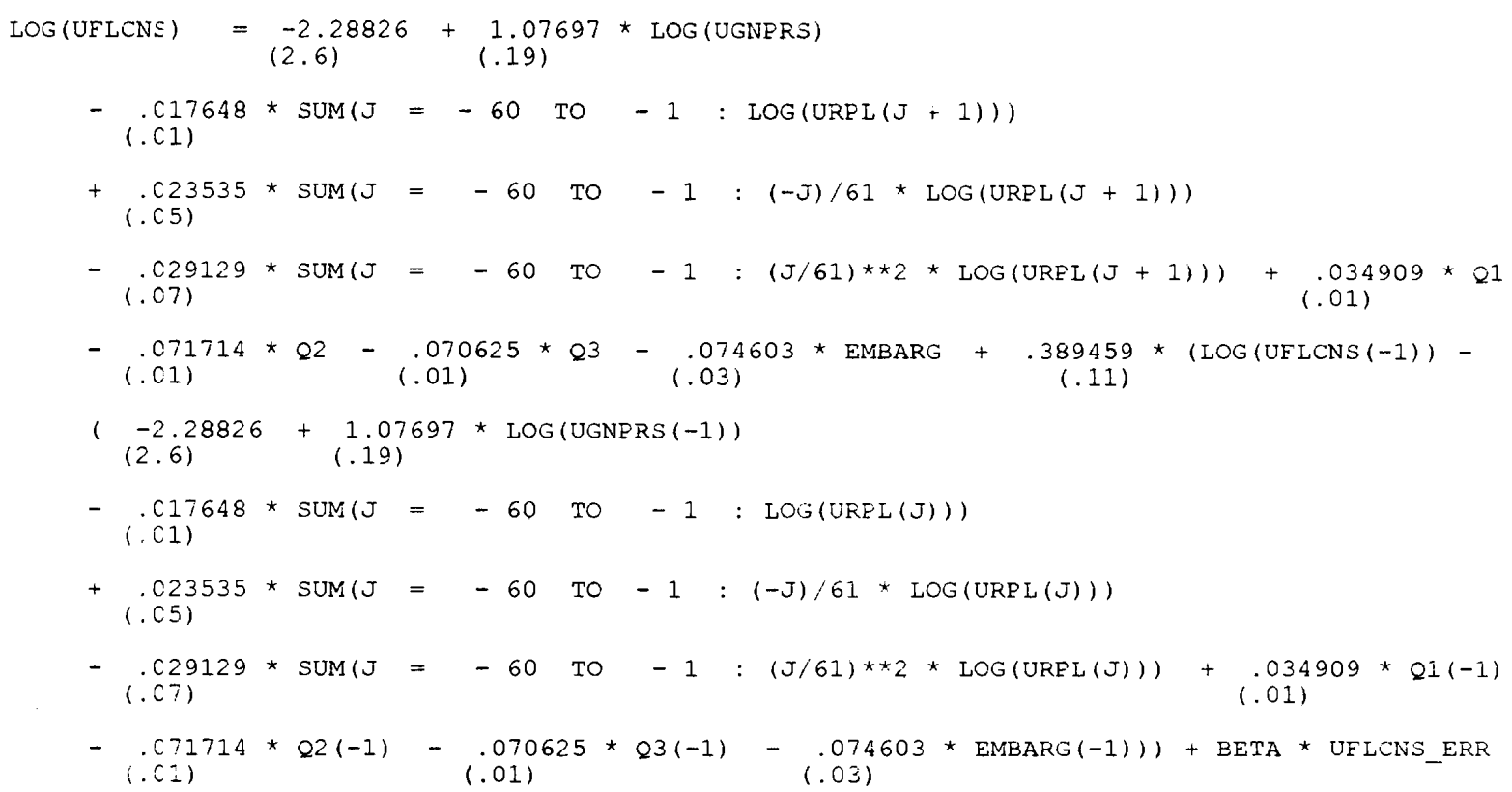


21. PIFSCOM: (PIFSCOM) IFS COMMODITY PRICE INDEX SOLUTION $(1980=100)$

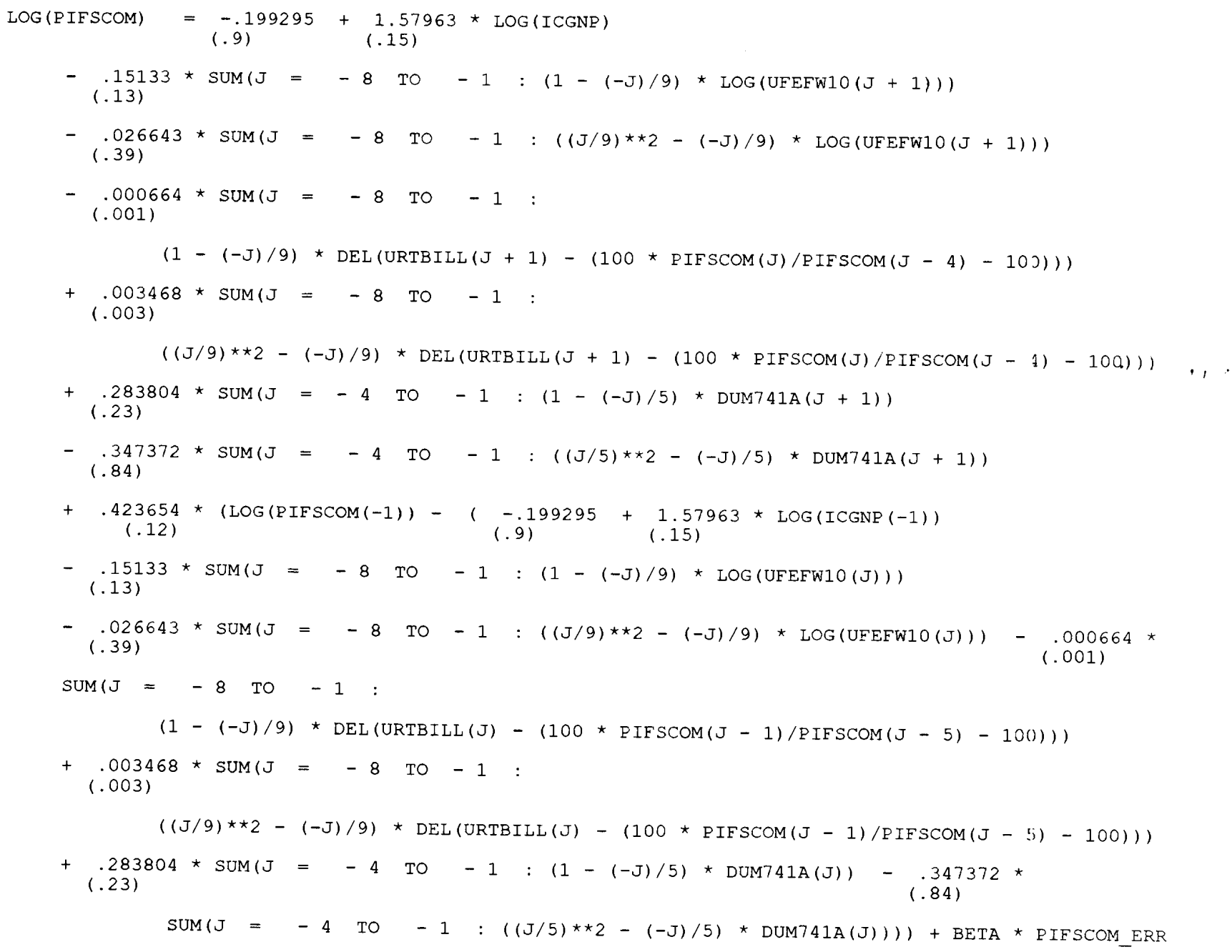


22. UPMGNFL: (UFMGNFL) NON-OIL IMPORT PRICE DEFLATOR $(1982=100)$

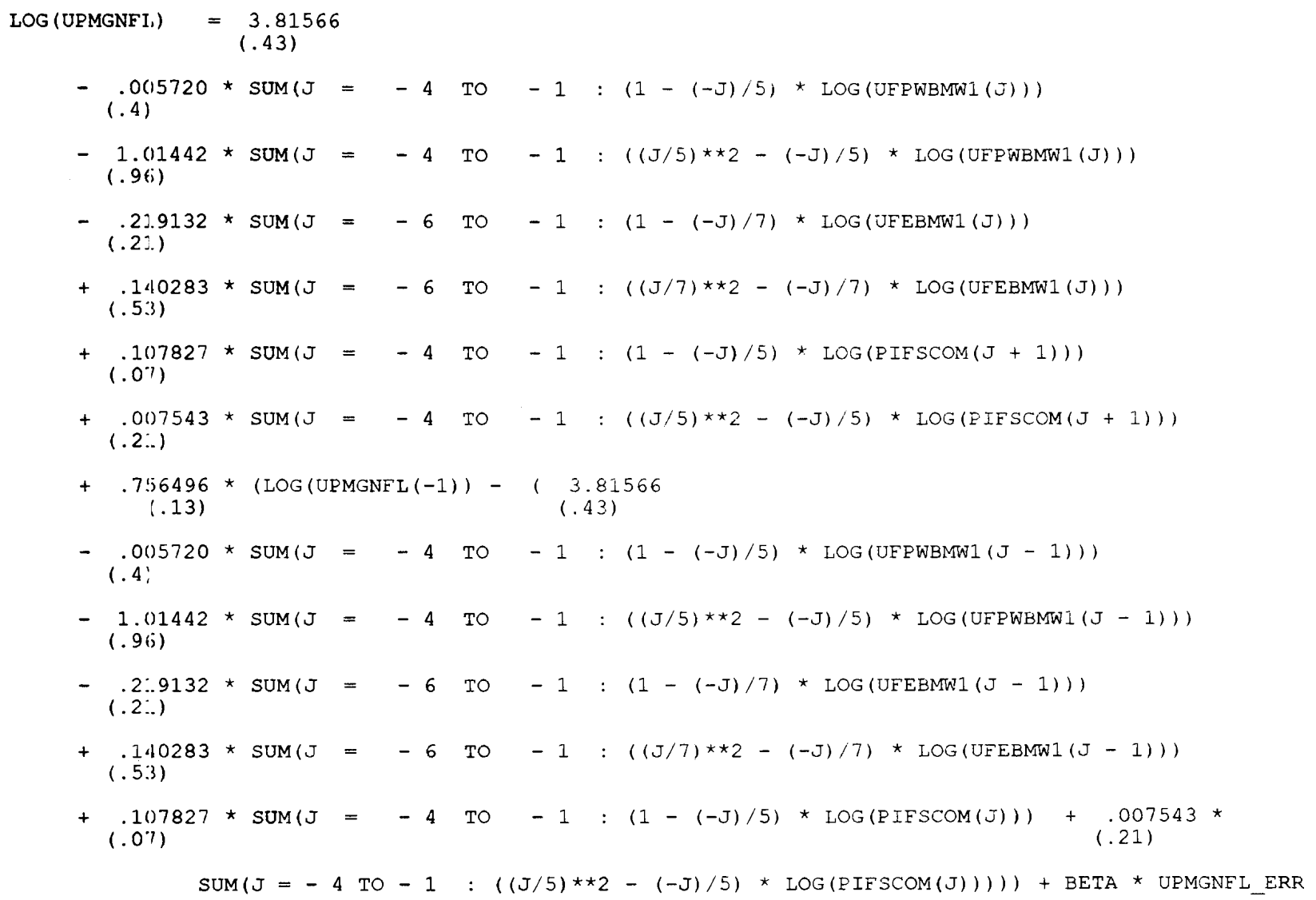


CROSS REFERENCE LIST OF VARIABLES AND EQUATIONS

VARIABLE | EQUATION NUMBER

\begin{tabular}{|c|c|c|c|c|c|c|c|}
\hline BETA & 15 & 16 & 17 & 18 & 19 & 20 & 21 \\
\hline DSMN & 19 & & & & & & \\
\hline DSXN & 15 & 16 & & & & & \\
\hline DUM7 41 & 18 & & & & & & \\
\hline DUM741A & 21 & & & & & & \\
\hline EMBARG & 20 & & & & & & \\
\hline ICGNP & 18 & 21 & & & & & \\
\hline PIFSCOM & 21 & 22 & & & & & \\
\hline PIFSCOM ERR & 21 & & & & & & \\
\hline & 20 & & & & & & \\
\hline 22 & 20 & & & & & & \\
\hline 23 & 20 & & & & & & \\
\hline $\mathrm{TR}$ & 19 & & & & & & \\
\hline $\mathrm{UCU}$ & 19 & & & & & & \\
\hline UDICONV & 7 & & & & & & \\
\hline UFCUFW10 & 1 & 19 & & & & & \\
\hline UFEBMW1 & 22 & & & & & & \\
\hline UFEFW10 & 16 & 18 & 21 & & & & \\
\hline UFEGTSW1 & 15 & 17 & & & & & \\
\hline UFGNPG10 & 1 & & & & & & \\
\hline UFGNPP & 1 & & & & & & \\
\hline UFGNPXWA & 16 & & & & & & \\
\hline UFGNPXWN & 15 & & & & & & \\
\hline UFLCNS & 6 & 20 & & & & & \\
\hline UFLCNS ERR & 20 & & & & & & \\
\hline UFLQLUN̄S & 6 & & & & & & \\
\hline UFLSCNS & 6 & & & & & & \\
\hline UFLUCQNS & 6 & & & & & & \\
\hline UFPCFW10 & 16 & & & & & & \\
\hline UFPGTSWI & 15 & & & & & & \\
\hline UFPWBMW1 & 22 & & & & & & \\
\hline UFPWTSW1 & 17 & & & & & & \\
\hline UGBAL & 14 & & & & & & \\
\hline UGNPRS & 19 & 20 & & & & & \\
\hline UMG & 11 & & & & & & \\
\hline UMGFL & 10 & 11 & & & & & \\
\hline UMGFLV & 9 & 10 & 13 & & & & \\
\hline UMGFLV_ERR & 9 & & & & & & \\
\hline UMGNFL $^{-}$ & 11 & 12 & 19 & & & & \\
\hline UMGNFL_ERR & 19 & & & & & & \\
\hline UMGNFL $\bar{V}$ & 12 & 13 & & & & & \\
\hline UMGV & 13 & 14 & & & & & \\
\hline UMQFLNSD & 6 & 7 & & & & & \\
\hline UMQFLNSI & 7 & 8 & & & & & \\
\hline UMQFLSF & 8 & & & & & & \\
\hline UMQGFL & 8 & 9 & & & & & \\
\hline UPCP I & 16 & & & & & & \\
\hline UP GNP & 19 & & & & & & \\
\hline UPMGFL & 10 & & & & & & \\
\hline UPMGFLUV & 9 & & & & & & \\
\hline UPMGNFL & 12 & 19 & 22 & & & & \\
\hline UPMGNFL_ERR & 22 & & & & & & \\
\hline UPWP IXW & 17 & & & & & & \\
\hline UPXGAUV & 3 & 16 & 18 & & & & \\
\hline UPXGAUV ERR & 18 & & & & & & \\
\hline UPXNAG $\overrightarrow{-}$ & 2 & 15 & 17 & & & & \\
\hline UPXNAG_ERR & 17 & & & & & & \\
\hline URFSUP $^{-}$ & 15 & 19 & & & & & \\
\hline URPL & 20 & & & & & & \\
\hline URTBILL & 18 & 21 & & & & & \\
\hline UXG & 4 & & & & & & \\
\hline UXGA & 3 & 4 & 16 & & & & \\
\hline UXGA ERR & 16 & & & & & & \\
\hline $\mathrm{UXGA \overline {V }}$ & 3 & 5 & & & & & \\
\hline UXGNA & 2 & 4 & 15 & & & & \\
\hline UXGNA ERR & 15 & & & & & & \\
\hline 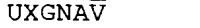 & 2 & 5 & & & & & \\
\hline UXGV & 5 & 14 & & & & & \\
\hline UXQFLNS & 6 & & & & & & \\
\hline
\end{tabular}


ALPHABETICAL LIST OF VARIABLES FOR MODEL

MNEMONIC | EQUATION |
DEFINITION

\section{PARAMETER}

DUMMY VARIABLE--DOCK STRIKE ON IMPORTS

DUMMY VARIABLE--DOCK STRIKE ON EXPORTS

DUMMY VARIABLE $=1$ IN $74.1-=0$ OTHERWISE

DUMMY VARIABLE $=$ LOG PERCENT CHANGE IN OIL PRICE DURING PERIODS OF RAPID CHANGE

DUMMY VARIABLE FOR ARAB OIL EMBARGO OF 19734

G-10 (INCLUDING US) GNP $(1982=100)$

IFS COMMODITY PRICE INDEX $(1980=100)$

IFS COMMODITY PRICE INDEX RESIDUAL

QUARTERLY DUMMY--1ST QUARTER

QUARTERLY DUMMY--2ND QUARTER

QUARTERLY DUMMY--3RD QUARTER

TARIFF RATES

US CAPACITY UTILIZATION (号)

DOE-BASED IMPORTS TO IA-BASED IMPORTS CONVERSION FACTOR (MB/D)

G-10 FOREIGN COUNTRY CAPACITY UTILIZATION

G18 EXCHANGE RATE INDEX BILATERAL NON-OIL IMPORT WEIGHTS $(1973 \quad 21=100)$

G-10 FOREIGN CURRENCY/US CENTS EXCHANGE RATE INDEX--

TRADE WEIGHTS (MAR $1973=1$ CO)

G18 EXCHANGE RATE INDEX MULTILATERAL TRADE WEIGHTS $(1973$ Q1 $=100)$

G-10 FOREIGN GNP--GNP WEIGHTS $(1982=100)$

FOREIGN POTENTIAL OUTPUT $(1982=100)$

WORLD FOREIGN GNP-- BILATERAL US AGRICULT. EXPORT WEIGHTS $(1982=100)$

WORLD GNP--BILATERAL US NON-AGRICULTURAL EXPORT WEIGHTS $(1982=100)$

OIL CONSUMPTION (MB/D - NSA)

OIL CONSUMPTION RESIDUAL (MB/D - NSA)

DOMESTIC PETROLEUM PRODUCTION LESS UNACCOUNTED FOR CRUDE (MB/D)

OIL STOCKBUILDING (MB/D - NSA)

DOMESTIC PETROLEUM UNACCOUNTED FOR CRUDE (MB/D)

G-10 FOREIGN CONSUMER PRICE INDEX--TRADE WEIGHTS $(1982=100)$

G18 CONSUMER PRICE INDEX MULTILATERAL TRADE WEIGHTS $(1982=100)$

G18 WHOLESALE PRICE INDEX BILATERAL NON-CIL IMPORT WEIGHTS $(1982=100)$

G18 WHOLESALE PRICE INDEX MULTILATERAL TRADE WEIGHTS $(1982=100)$

TRADE BALANCE (BIL $\$-A R$ )

CURRENT ASSUMPTION ON REAL GNP BY R AND $S$ (BIL $82 \$-A R$ )

TOTAL IMPORTS (BIL $82 \$$ - AR)

VOLUME OF OIL IMPORTS (BIL $82 \$$ - AR)

OIL IMPORTS (BIL $\$-A R$ )

OIL IMPORT RESIDUAL

NON-OIL IMPORT VOLUME (BIL $82 \$$ - AR)

NON-OIL IMPORT VOLUME RESIDUAL

NON-OIL IMPORTS (BIL $\$$ - AR)

TOTAL MERCHANDISE IMPORTS (BIL $\$-A R$ )

OIL IMPORTS (MB/D - NSA - DOE)

OIL IMEORTS (MB/D - NSA - IA)

OIL IMPORTS (IA) SEASONAL FACTOR

OIL IMPORTS (MB/D - SA - IA)

US CONSUMER PRICE INDEX $(1967=100)$

US GNP DEFLATOR $(1982=100)$

NIA PETROLEUM IMPORT PRICE DEFLATOR $(1982=100)$

OIL IMPORT UNIT VALUE (DOLLARS PER BARREL)

NON-OIL IMPORT PRICE DEFLATOR $(1982=100)$

NON-OIL IMPORT PRICE DEFLATOR RESIDUAL

US PRODUCER PRICE INDEX--EXPORT WEIGHTS $(1982=100)$

AGRICULTURAL EXPORT PRICE DEFLATOR $(1982=100)$

AGRICULTURAL EXPORT PRICE DEFLATOR RESIDUAL

NON-AGRICULTURAL EXPORT PRICE DEELATOR $(1982=100)$

NON-AGRICULTURAL EXPORT PRICE DEELATOR RESIDUAL

RELATIVE FOREIGN SUPPLY $(1982=100)$ (BIL $82 \$-A R$ )

RELATIVE PRICE OF OIL TO GNP DEFLATCR $(1982=100)$

RATE ON US 3-MONTH TREASURY BILLS

TOTAL EXPORT VOLUME (BIL $82 \$$ - AR)

AGRICULTURAL EXPORTS (BIL $82 \$$ - AR)

AGRICULTURAL EXPORTS RESIDUAL

AGRICULTURAL EXPORT VALUE (BIL $\$$ - AR)

NON-AGRICULTURAL EXPORTS (BIL $82 \$$ - AR)

NON-AGRICULTURAL EXPORTS RESIDUAL

NON-AGRICULTURAL EXPORTS (BIL $\$$ - AR)

TOTAL EXPORT VALUE (BIL $\$$ - AR)

UXGV 5

VOLUME OF OIL EXPORTS (MB/D) (NSA) 
Model M2

1. UFCUFW10: (UFCUFW10) G-10 FOREIGN COUNTRY CARACITY UTILIZATION

UFCUFW10 $=100 \star$ UFGNPG10/UFGNPP

2. UXGNAV: (UXGNAV) NON-AGRICULTURAL EXPORTS (BIL $\$$ - AR)

UXGNAV = UXGNA $\star$ UPXNAG/100

3. UXGAV: (UXGAV) AGRICULTURAL EXPORT (BIL $\$-A R$ )

$\mathrm{UXGAV}=\mathrm{UXGA} * \mathrm{UPXGAUV} / 100$

4. UXG: (UXG) TOTAL EXPORT VOLUME (BIL $82 \$-A R$ )

$\mathrm{UXG}=\mathrm{UXGA}+\mathrm{UXGNA}$

5. UXGV: (UXGV) TOTAL EXPORT VALUE (BIL $\$-A R$ )

$\mathrm{UXGV}=\mathrm{UXGAV}+\mathrm{UXGNAV}$

6. UMQFLNSD: (UMQFLNSD) OIL IMPORTS (MB/D - NSA - DOE)

UMQFLNSD = UFLCNS - UFLQLUNS - UFLUCQNS + UXQFLNS + UFLSCNS

7. UMQFLNSI: (UMQFLNSI) OIL IMPORTS (MB/D - NSA - IA)

UMQFLNSI $=$ UMQFLNSD + UDICONV

8. UMQGFL: (UMQGFL) OIL IMPORTS (MB/D - SA - IA)

UMQGFL = UMQFLNSI/UMQFLSF

9. UMGFLV: (UMGFLV) OIL IMPORTS (BIL $\$-A R$ )

UMGFLV $=$ UMQGFL $* 0.365 *$ UPMGFLUV + UMGFLV_ERR

10. UMGFL: (UMGFL) VOLUME OF OIL IMPORTS (BIL $82 \$$ - AR)

UMGFL $=100 \star$ UMGFLV/UPMGFL

11. UMG: (UMG) TOTAL IMPORTS (BIL $82 \$$ - AR)

UMG $=$ UMGFL + UMGNFL 
12. UMGNFLV: (UMGNFLV) NON-OIL IMPORTS (BIL \$)

UMGNFLV $=$ UMGNFL $*$ UPMGNFL $/ 100$

13. UMGV: (UNGV) TOTAL MERCHANDISE IMPORTS (BIL $\$-A R$ )

$\mathrm{UMGV}=\mathrm{UMGFLV}+\mathrm{UMGNFLV}$

14. UGBAL: (UGBAL) TRADE BALANCE (BIL $\$-$ AR)

UGBAL $=: \quad$ UXGV - UMGV

15. UXGNA: ([XGNA) NON-AGRICULTURAL EXFORTS (BIL $82 \$$ - AR)

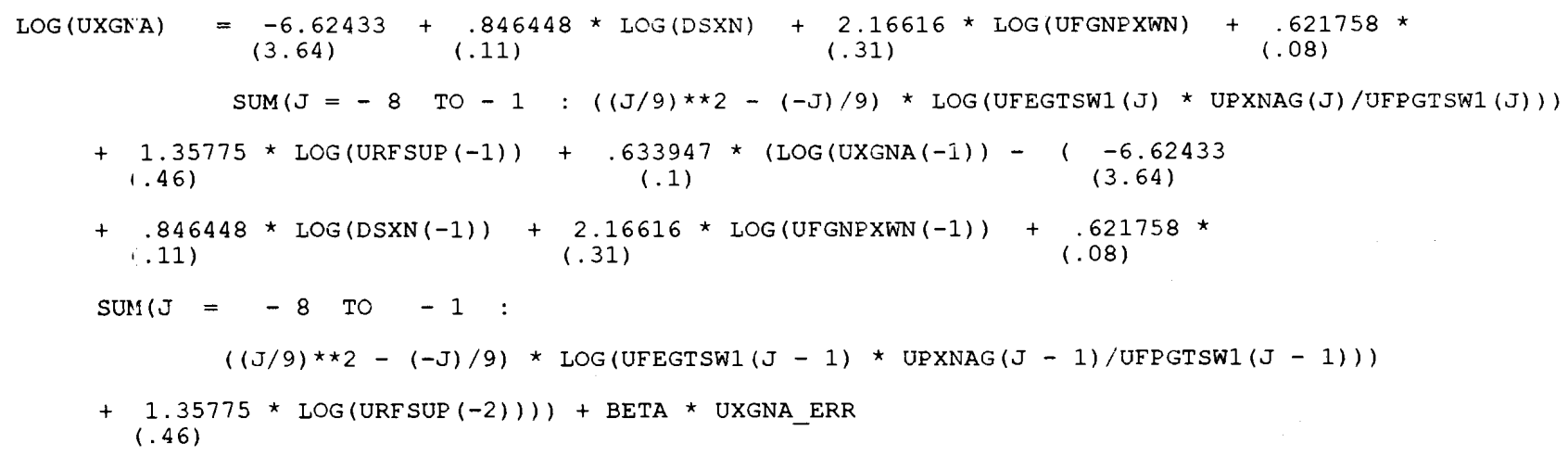

16. UXGA: (UXGA) AGRICULTURAL EXPORTS (STOCHASTIC EQN. - EIL $82 \$$ - AR)

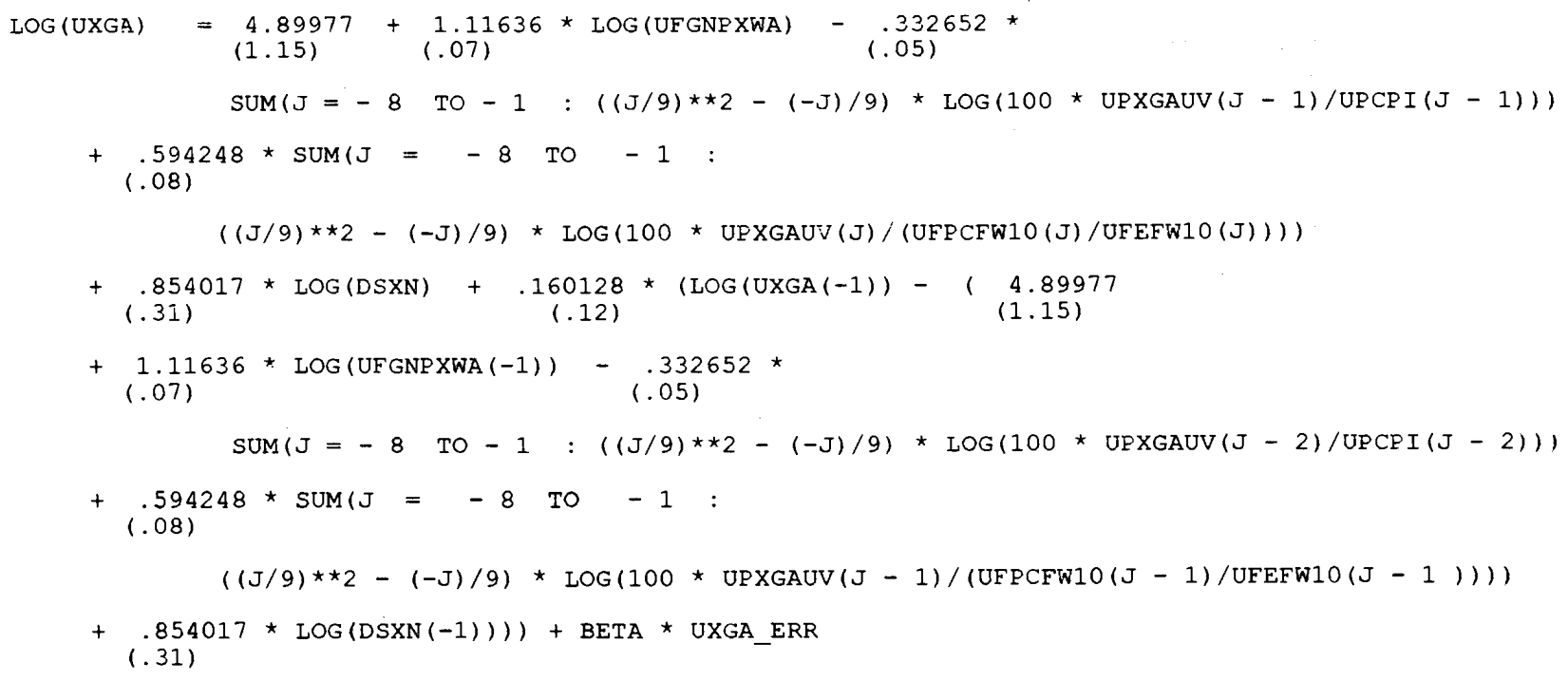


17. UPXNAG: (UPXNAG) NON-AG EXPORT PRICE DEFLATOR $(1982=100)$

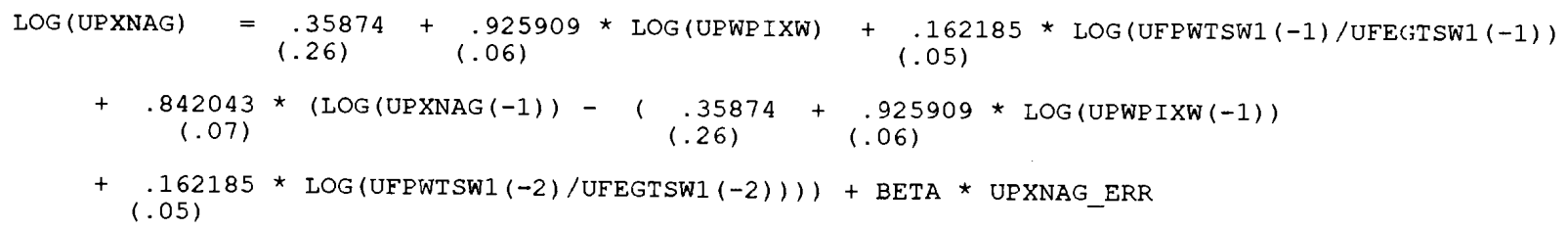

18. UPXGAUV: (UPXGAUV) AGRICULTURAL EXPORT PRICE DEFLATOR (REDUCED FORM EQUATION $-1982=1.00$ )

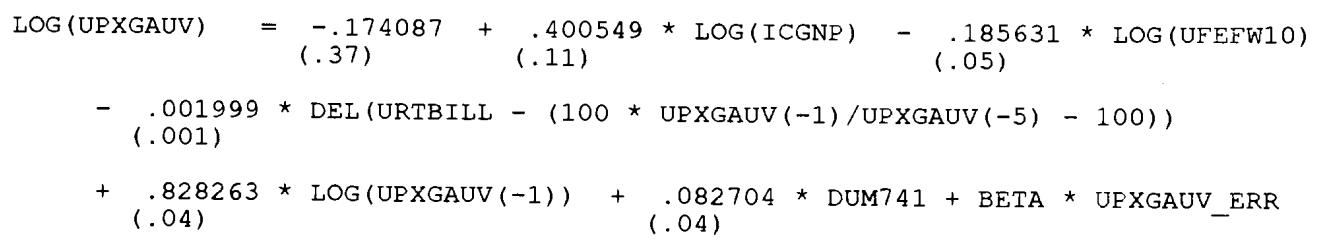

19. UMGNFL: (UMGNFL) NON-OIL IMPORTS (BIL $82 \$-A R$ )

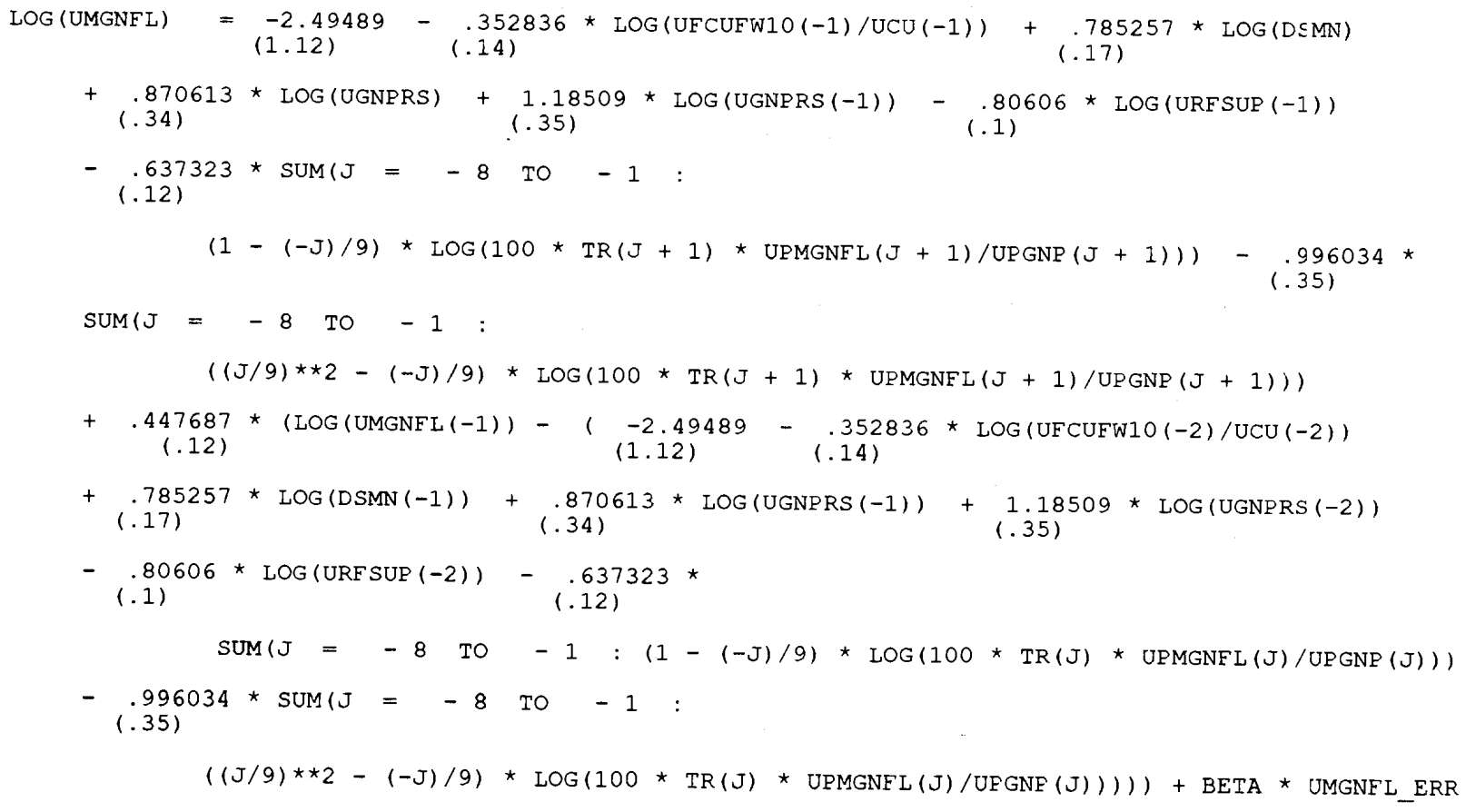


20. UFLCNS: (UFLCNS) DOMESTIC PETROLEUM CONSUMPTION (MB/D )

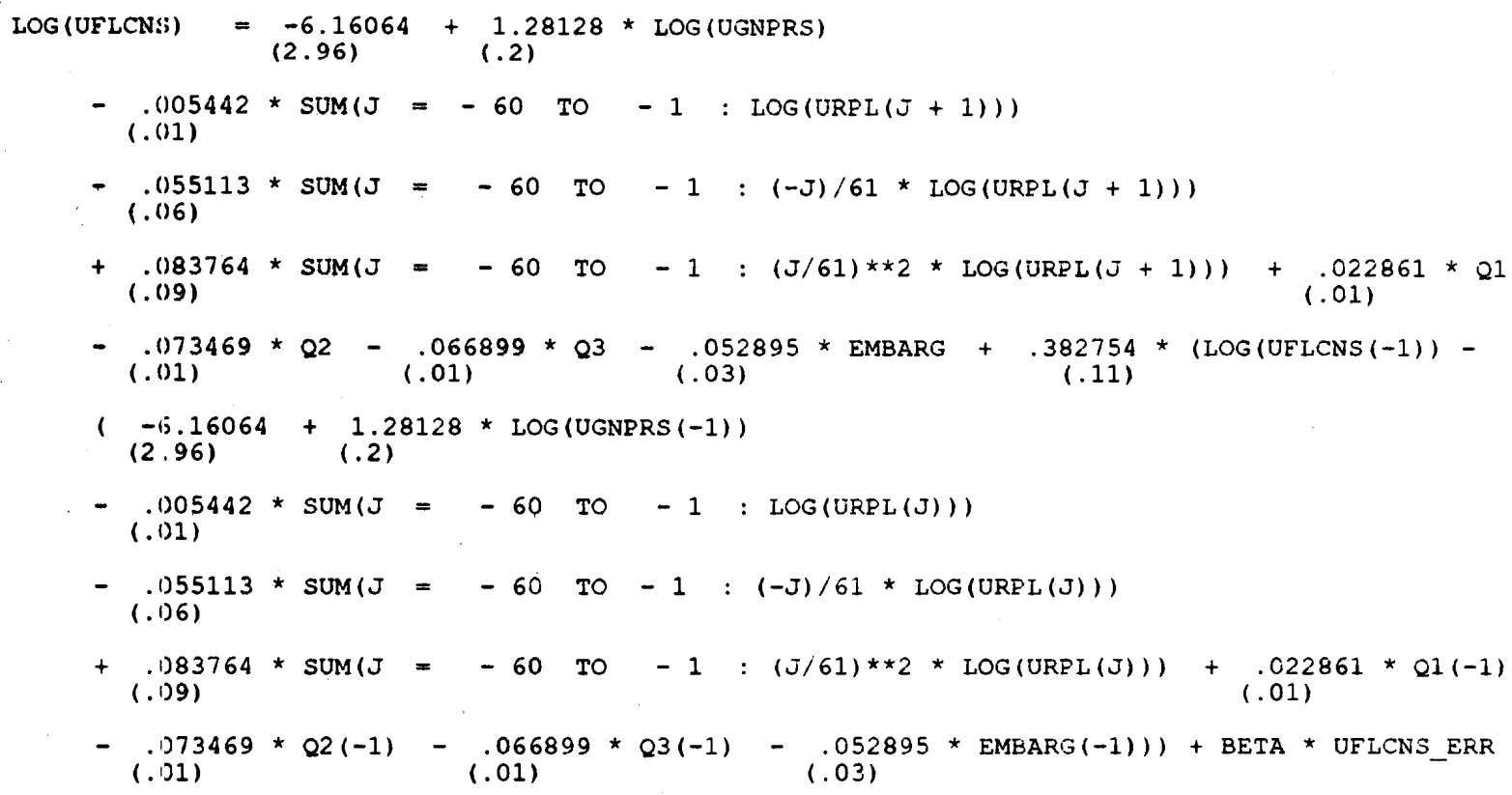


21. PIFSCOM: (PIFSCOM) IFS COMMODITY PRICE INDEX SOLUTION $(1980=100)$

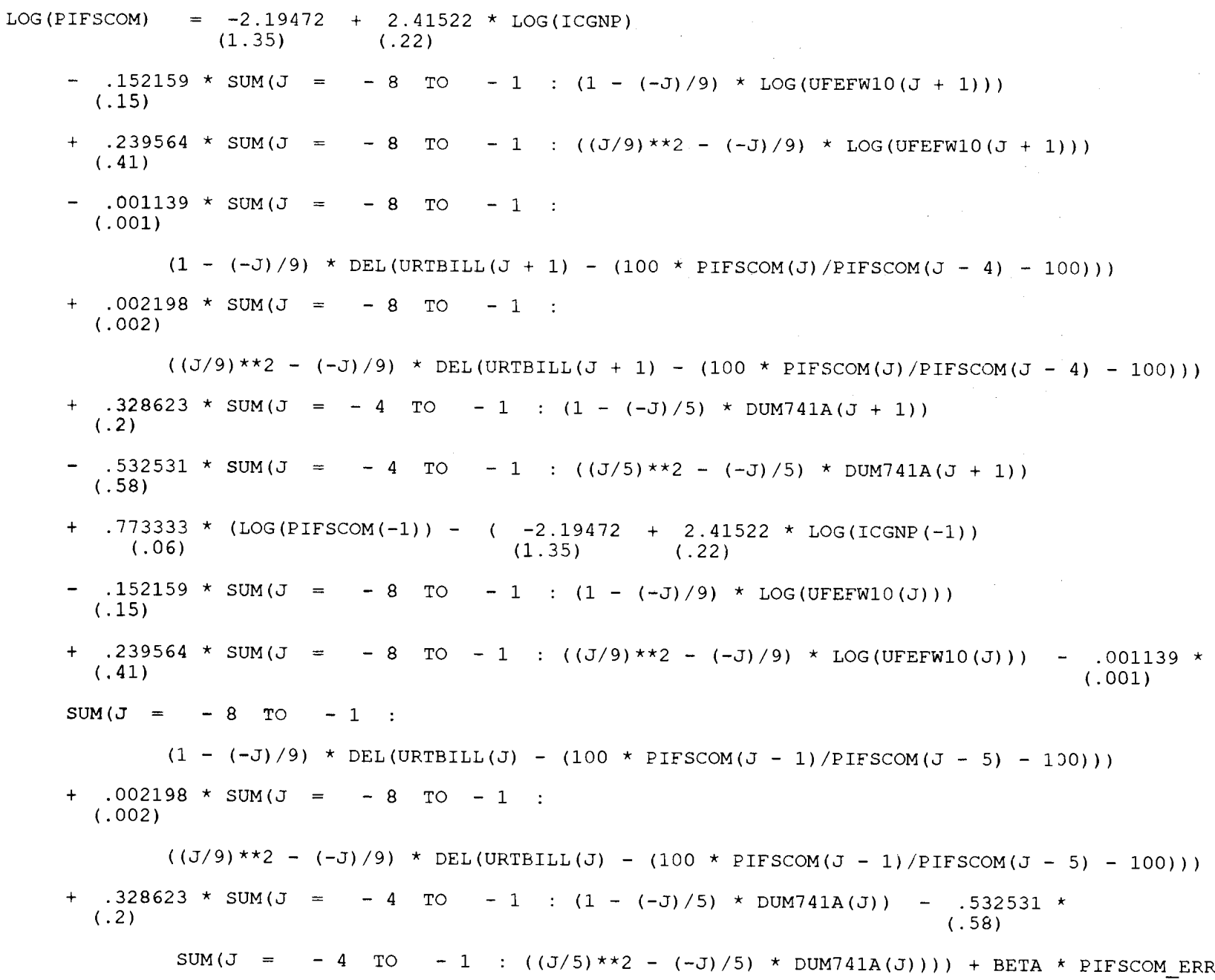


22. UPMGNFL: (UPMGNFL) NON-OIL IMPORT PRICE DEFLATOR $(1982=100)$

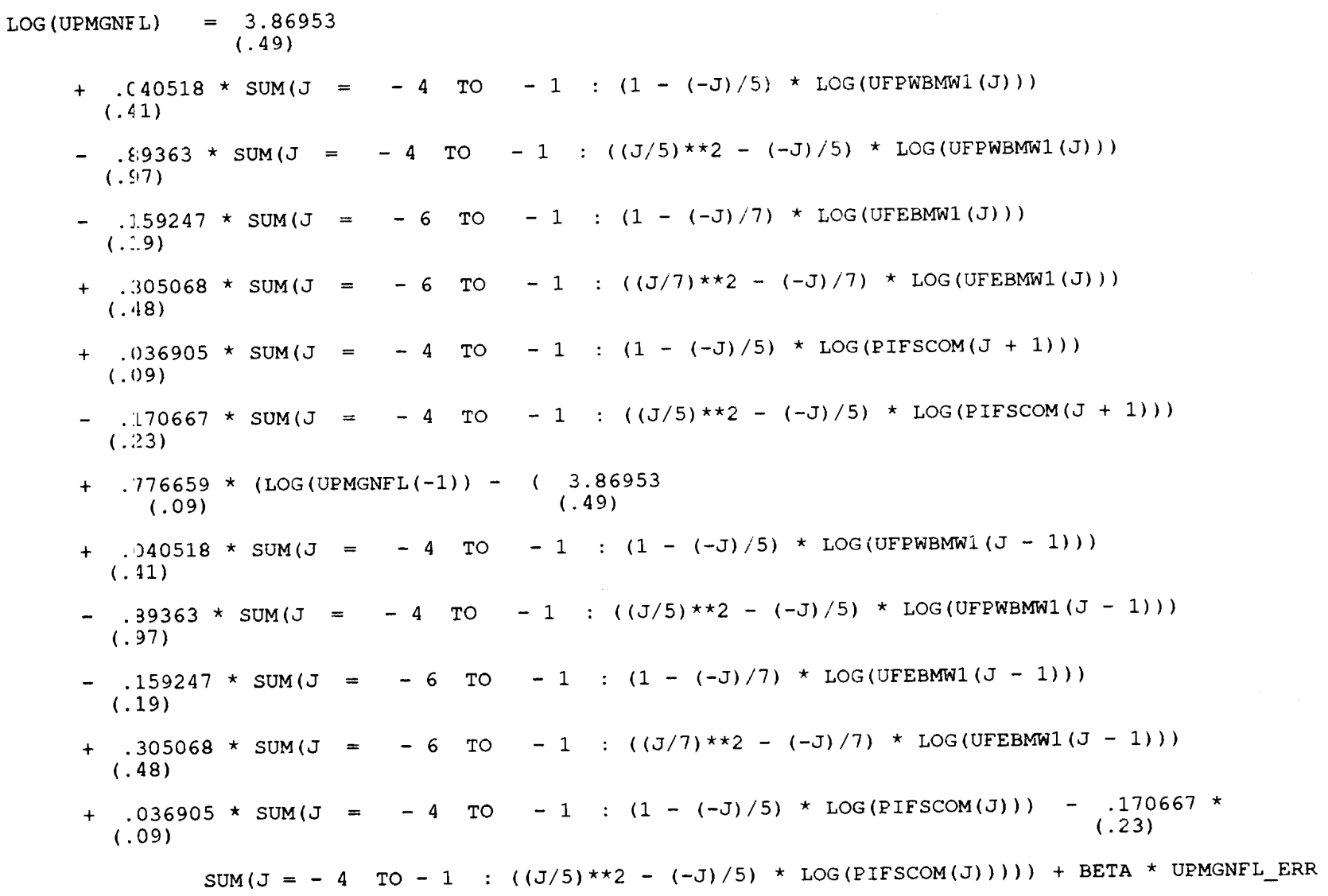


CROSS REFERENCE LIST OF VARIABLES AND EOUATIONS

VARIABLE | EQUATION NUMBER

\begin{tabular}{|c|c|c|c|c|c|c|c|c|}
\hline BETA & 15 & 16 & 17 & 18 & 19 & 20 & 21 & 22 \\
\hline DSMN & 19 & & & & & & & \\
\hline DSXN & 15 & 16 & & & & & & \\
\hline $\begin{array}{l}\text { DUM741 } \\
\text { DUM741A }\end{array}$ & $\begin{array}{l}18 \\
21\end{array}$ & & & & & & & \\
\hline EMBARG & 20 & & & & & & & \\
\hline ICGNP & 18 & 21 & & & & & & \\
\hline PIFSCOM & 21 & 22 & & & & & & \\
\hline PIFSCOM_ERR & 21 & & & & & & & \\
\hline Q1 - & 20 & & & & & & & \\
\hline$Q 2$ & 20 & & & & & & & \\
\hline 23 & 20 & & & & & & & \\
\hline TR & 19 & & & & & & & \\
\hline UCU & 19 & & & & & & & \\
\hline UDICONV & 7 & & & & & & & \\
\hline UFCUFW10 & 1 & 19 & & & $\cdots$ & 1 & & \\
\hline UFEBMW1 & 22 & & & & & & & \\
\hline UFEFW10 & 16 & 18 & 21 & & & & & \\
\hline UFEGTSW1 & 15 & 17 & & & & & & \\
\hline UFGNPG10 & 1 & & & & & & & \\
\hline UFGNPP & 1 & & & & & & & \\
\hline UF GNPXWA & 16 & & & & & & & \\
\hline UFGNPXWN & 15 & & & & & & & \\
\hline UFLCNS & 6 & 20 & & & & & & \\
\hline UFLCNS ERR & 20 & & & & & & & \\
\hline UF LQLUN̄S & 6 & & & & & & & \\
\hline UFLSCNS & 6 & & & & & & & \\
\hline UF LUCQNS & 6 & & & & & & & \\
\hline UFPCFW10 & 16 & & & & & & & \\
\hline UFPGTSW1 & 15 & & & & & & & \\
\hline UFPWBMW1 & 22 & & & & & & & \\
\hline UFPWTSW1 & 17 & & & & & & & \\
\hline UGBAL & 14 & & & & & & & \\
\hline UGNPRS & 19 & 20 & & & & & & \\
\hline UMG & 11 & & & & & & & \\
\hline UMGFL & 10 & 11 & & & & & & \\
\hline UMGF LV & 9 & 10 & 13 & & & & & \\
\hline UMGFLV_ERR & 9 & & & & & & & \\
\hline $\mathrm{UMGNFL}^{-}$ & 11 & 12 & 19 & & & & & \\
\hline UMGNFI_ERR & 19 & & & & & & & \\
\hline UMGNF L $\overline{\mathrm{V}}$ & 12 & 13 & & & & & & \\
\hline UMGV & 13 & 14 & & & & & & \\
\hline UMQF LNSD & 6 & 7 & & & & & & \\
\hline UMQF LNSI & 7 & 8 & & & & & & \\
\hline UMQFLSF & 8 & & & & & & & \\
\hline UMQ̈GFL & 8 & 9 & & & & & & \\
\hline $\mathrm{UPCPI}$ & 16 & & & & & & & \\
\hline UP GNP & 19 & & & & & & & \\
\hline UPMGF I & 10 & & & & & & & \\
\hline UPMGFIUV & 9 & & & & & & & \\
\hline UPMGNFL & 12 & 19 & 22 & & & & & \\
\hline UPMGNFL_ERR & 22 & & & & & & & \\
\hline UPWP IXW' & 17 & & & & & & & \\
\hline UPXGAUV & 3 & 16 & 18 & & & & & \\
\hline UPXGAUV_ERR & 18 & & & & & & & \\
\hline UPXNAG & 2 & 15 & 17 & & & & & \\
\hline UPXNAG_ERR & 17 & & & & & & & \\
\hline URFSUP $^{-}$ & 15 & 19 & & & & & & \\
\hline URPL & 20 & & & & & & & \\
\hline URTBILL & 18 & 21 & & & & & & \\
\hline UXG & 4 & & & & & & & \\
\hline UXGA & 3 & 4 & 16 & & & & & \\
\hline UXGA_ERR & 16 & & & & & & & \\
\hline UXGA $\bar{V}$ & 3 & 5 & & & & & & \\
\hline UXGNA & 2 & 4 & 15 & & & & & \\
\hline UXGNA ERR & 15 & & & & & & & \\
\hline UXGNA $\vec{V}$ & 2 & 5 & & & & & & \\
\hline UXGV & 5 & 14 & & & & & & \\
\hline UXQFLNS & 6 & & & & & & & \\
\hline
\end{tabular}


ALPHABETICAL LIST OF VARIABLES FOR MODEL

MNEMONIC: | EQUATION |
DEFINITION

\begin{tabular}{|c|c|}
\hline BITA & (EXOG) \\
\hline DSSMN & (EXOG) \\
\hline D $\$ X N$ & (EXOG) \\
\hline $\mathrm{DUM}^{-1} 41$ & (EXOG) \\
\hline DUM $7 \llbracket 1 \mathrm{~A}$ & (EXOG) \\
\hline EMB $\ R$ RG & (EXOG) \\
\hline ICCiNP & (EXOG) \\
\hline PIFSC:OM & 21 \\
\hline PIFSCOM_ERR & (EXOG) \\
\hline$-Q 1$ & (EXOG) \\
\hline $\mathrm{Q} 2$ & (EXOG) \\
\hline 83 & ( $E X O G)$ \\
\hline $\mathrm{TR}$ & (EXOG) \\
\hline UCU & (EXOG) \\
\hline UDICONV & (EXOG) \\
\hline UFCUFW110 & 1 \\
\hline UFEBNW1 & (EXOG) \\
\hline UFEFWIO & (EXOG) \\
\hline UFEGTSiW1 & (EXOG) \\
\hline UFGNP $(; 10$ & (EXOG) \\
\hline UFGIPP & (EXOG) \\
\hline UFGNP XWA & (EXOG) \\
\hline UFGNPY:WN & (EXOG) \\
\hline UFLC:NS & 20 \\
\hline UFLCNS_F'RR & (EXOG) \\
\hline 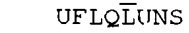 & (EXOG) \\
\hline UFLSC:NS & (EXOG) \\
\hline 'TELUCSNS & (EXOG) \\
\hline$\because F P C F W 10$ & (EXOG) \\
\hline$\because$ FPGTSW1 & (EXOG) \\
\hline UEPWBMW1 & (EXOG) \\
\hline UFPWT\$W1 & (EXOG) \\
\hline UGHAL & 14 \\
\hline UGNI'RS & (EXOG) \\
\hline IIMG & 11 \\
\hline UMC;F L & 10 \\
\hline UMGI'LV & 9 \\
\hline UMGFLV ISRR & (EXOG) \\
\hline UMGIJF L & 19 \\
\hline UMGNFL_I:RR & (EXOG) \\
\hline UMGN̄FI $L V$ & 12 \\
\hline UMGV & 13 \\
\hline UMQFLNSD & 6 \\
\hline UMQFLIISI & 7 \\
\hline UMQF J,SF & $(E X O G)$ \\
\hline UMQGFL & 8 \\
\hline UPC:PI & (EXOG) \\
\hline UPCINP & (EXOG) \\
\hline UPMC;FL & (EXOG) \\
\hline UPMGF $1, U V$ & (EXOG) \\
\hline UPMGIJFL & 22 \\
\hline UPMGNFL_ISRR & (EXOG) \\
\hline UPWP $: . X W$ & (EXOG) \\
\hline UPXGMUV & 18 \\
\hline UPXGAUV_ISRR & (EXOG) \\
\hline UP X̄IJAG & 17 \\
\hline UPXNAG_IRR & (EXOG) \\
\hline URE $\bar{F}$ SUP & (EXOG) \\
\hline UIRPL & (EXOG) \\
\hline URTB:..LL & (EXOG) \\
\hline IJXG & 4 \\
\hline UXGA & 16 \\
\hline UXGA_ URR & (EXOG) \\
\hline $\mathrm{U} \overline{\mathrm{X}}(\mathrm{A} \mathrm{AV}$ & 3 \\
\hline UXGNA & 15 \\
\hline UXGNA IJRR & (EXOG) \\
\hline UXĞIAV & 2 \\
\hline UXGV & 5 \\
\hline UXQF'JNS & (EXOG) \\
\hline
\end{tabular}

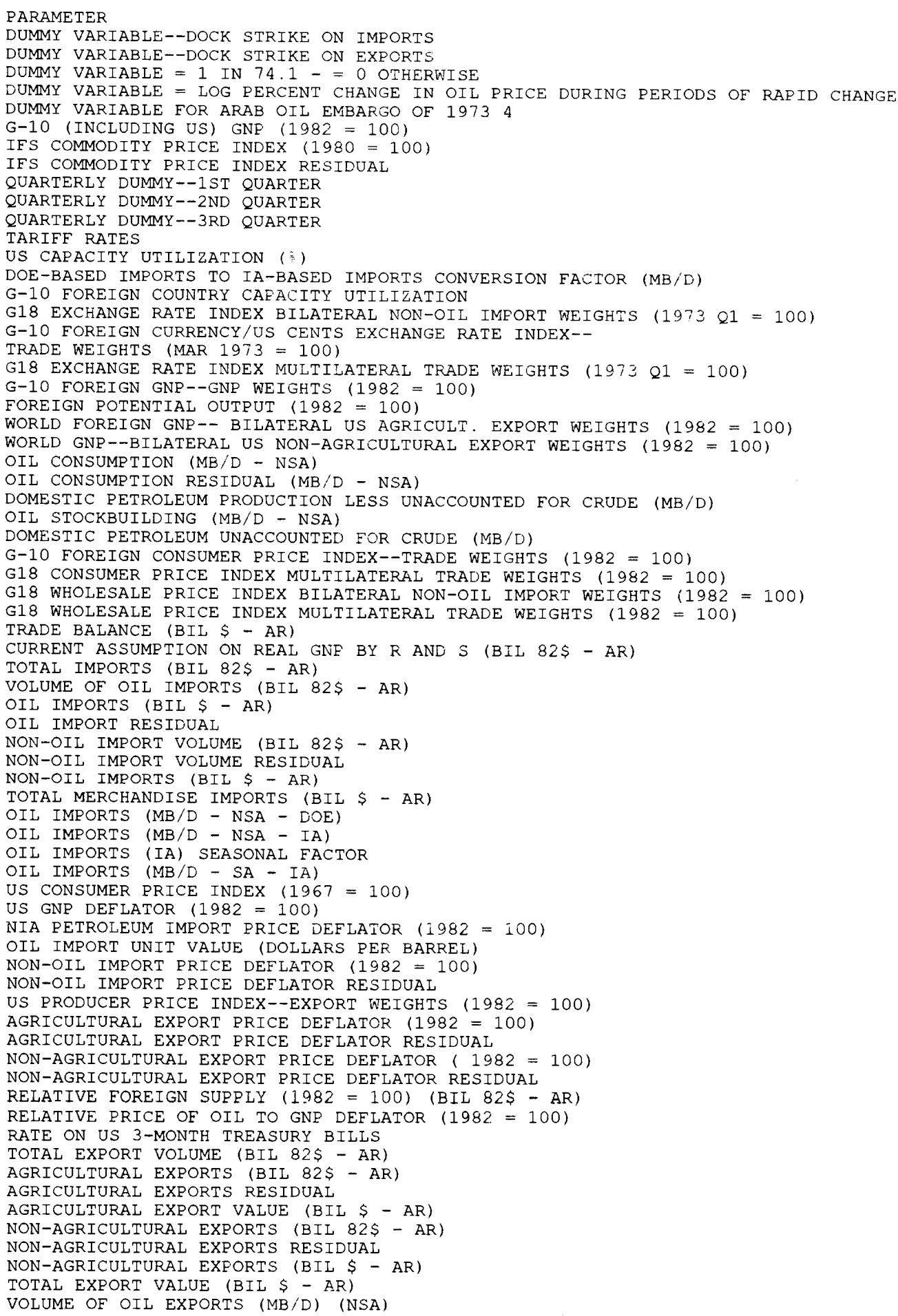




\section{Model M3}

1. UXGNAV: (UXGNAV) NON-AGRICULTURAL EXPORTS (BIL $\$-$ AR)

UXGNAV $=$ UXGNA $\star$ UPXNAG/100

2. UXGAV: (UXGAV) AGRICULTURAL EXPORT (BIL $\$-A R$ )

$\mathrm{UXGAV}=\mathrm{UXGA}$ *UPXGAUV $/ 100$

3. UXG: (UXG) TOTAL EXPORT VOLUME (BIL $82 \$-A R$ )

UXG = UXGA + UXGNA

4. UXGV: (UXGV) TOTAL EXPORT VALUE (BIL \$ - AR)

UXGV = UXGAV + UXGNAV

5. UMOFLNSD: (UMQFLNSD) OIL IMPORTS (MB/D - NSA - DOE)

UMQFLNSD = UFLCNS - UFLQLUNS - UFLUCQNS + UXQFLNS + UFLSCNS

6. UMOFLNSI: (UMQFLNSI) OIL IMPORTS (MB/D - NSA - IA)

UMQFLNSI = UMQFLNSD + UDICONV

7. UMQGFL: (UMQGFL) OIL IMPORTS (MB/D - SA - IA)

UMQGFL $=$ UMQFLNSI/UMQFLSF

8. UMGFLV: (UMGFLV) OIL IMPORTS (BIL $\$-A R$ )

UMGFLV $=$ UMQGFL $\star 0.365 *$ UPMGFLUV + UMGFLV_ERR

9. UMGFL: (UMGFL) VOLUME OF OIL IMPORTS (BIL $82 \$-A R$ )

UMGFL $=100 \star \mathrm{UMGFLV} /$ UPMGFL

10. UMG: (UMG) TOTAL IMPORTS (BIL $82 \$-A R$ )

$\mathrm{UMG}=\mathrm{UMGFL}+\mathrm{UMGNFL}$

11. UMGNFLV: (UMGNFLV) NON-OIL IMPORTS (BIL \$)

UMGNFLV $=$ UMGNFL * UPMGNFL $/ 100$ 
12. UMGV: (UMGV) TOTAL MERCHANDISE IMPORTS (BIL $\$$ - AR)

UMGV = UMGFLV + UMGNFLV

13. UGBAL: (UGBAL) TRADE BALANCE (BIL $\$-A R$ )

- - - - - - - - - -

$\mathrm{UGBAL}=\mathrm{UXGV}-\mathrm{UMGV}$

14. URPXNA: (URPXNA) RELATIVE PRICE OF US NON-AGRICULTURAL EXPORTS

URPXNA = UFEGTSW1 * UPXNAG/UFPGTSW1

15. URPMNFL: (URPMNFL) RELATIVE PRICE OF US NON-OIL IMPORTS $(1982=100)$

URPMNFL $=100 \star \mathrm{TR}$ * UPMGNFL/UPGNP

16. UXGNA: (UIXGNA) NON-AGRICULTURAL EXPORTS (BIL $82 \$-A R$ )

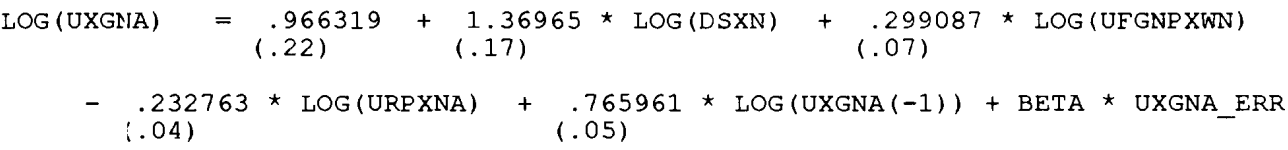

17. UXGA: (U:IGA) AGRICULTURAL EXPORTS (STOCHASTIC EQN. - BIL 82\$ - AR)

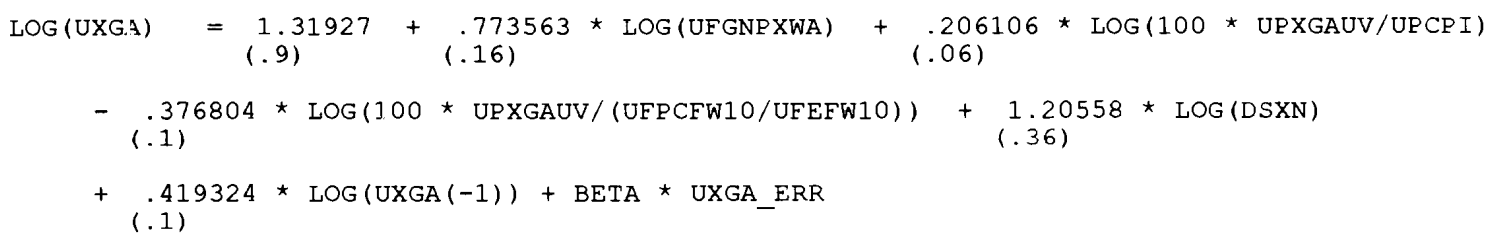

18. UPXNAG: (UPXNAG) NON-AG EXPORT PRICE DEFLATOR $(1982=100)$

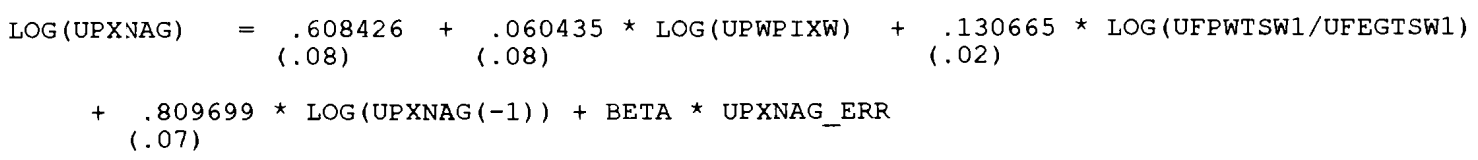

19. UPXGAUV: (UPXGAUV) AGRICULTURAL EXPORT PRICE DEFLATOR (REDUCED FORM EQUATION - 1982 = 1O0)

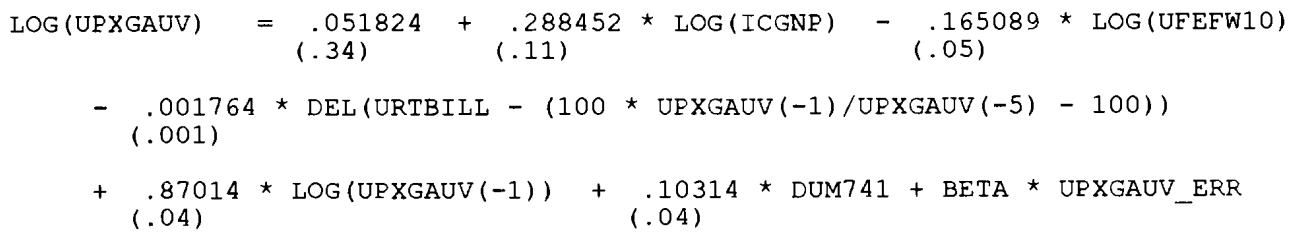


20. UMGNFL: (UMGNFL) NON-OIL IMPORTS (BIL $82 \$-A R$ )

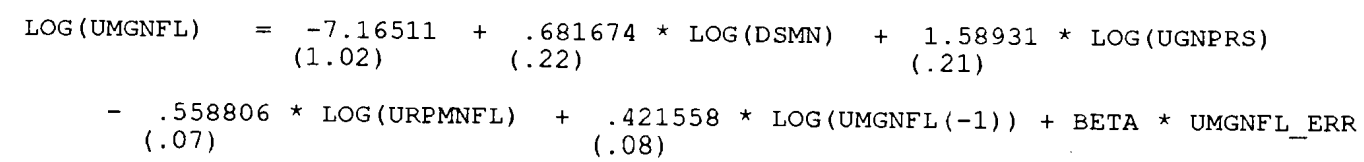


CROSS REFERENCE LIST OF VARIABLES AND EQUATIONS

VARIABLE | EQUATION NUMBER

\begin{tabular}{|c|c|c|c|c|c|c|c|}
\hline BETA & 16 & 17 & 18 & 19 & 20 & 21 & 22 \\
\hline DSMN & 20 & & & & & & \\
\hline DSXN & 16 & 17 & & & & & \\
\hline DUM741 & 19 & & & & & & \\
\hline DUM741A & 22 & & & & & & \\
\hline EMBARG & 21 & & & & & & \\
\hline ICGNP & 19 & 22 & & & & & \\
\hline PIFSCOM & 22 & 23 & & & & & \\
\hline PIFSCOM_ERR & 22 & & & & & & \\
\hline 01 & 21 & & & & & & \\
\hline$Q 2$ & 21 & & & & & & \\
\hline 2.3 & 21 & & & & & & \\
\hline TR & 15 & & & & & & \\
\hline UDICONV & 6 & & & & & & \\
\hline UFEBMW1 & 23 & & & & & & \\
\hline UFEFW10 & 17 & 19 & 22 & & & & \\
\hline UFEGTSW1 & 14 & 18 & & & & & \\
\hline UFGNPXWA & 17 & & & & & & \\
\hline UFGNPXWN & 16 & & & & & & \\
\hline UFLCNS & 5 & 21 & & & & & \\
\hline UFLCNS ERF! & 21 & & & & & & \\
\hline UFLQLUÑS & 5 & & & & & & \\
\hline UFLSCNS & 5 & & & & & & \\
\hline UFLUCQNS & 5 & & & & & & \\
\hline UFPCFW10 & 17 & & & & & & \\
\hline UFPGTSW1 & 14 & & & & & & \\
\hline UFPWBMW1 & 23 & & & & & & \\
\hline UFPWTSWI & 18 & & & & & & \\
\hline UGBAL & 13 & & & & & & \\
\hline UGNPRS & 20 & 21 & & & & & \\
\hline UMG & 10 & & & & & & \\
\hline UMGFL & 9 & 10 & & & & & \\
\hline UMGFLV & 8 & 9 & 12 & & & & \\
\hline UMGFLV_ERIR & 8 & & & & & & \\
\hline $\mathrm{UMGNFI}^{-}$ & 10 & 11 & 20 & & & & \\
\hline UMGNFL_ER:Z & 20 & & & & & & \\
\hline UMGNFL $\bar{V}$ & 11 & 12 & & & & & \\
\hline UMGV & 12 & 13 & & & & & \\
\hline UMQFLNSD & 5 & 6 & & & & & \\
\hline UMQFLNSI & 6 & 7 & & & & & \\
\hline UMQFLSF & 7 & & & & & & \\
\hline UMQGFL & 7 & 8 & & & & & \\
\hline UPCPI & 17 & & & & & & \\
\hline UPGNP & 15 & & & & & & \\
\hline UPMGFL & 9 & & & & & & \\
\hline UPMGF LUV & 8 & & & & & & \\
\hline UPMGNFL & 11 & 15 & 23 & & & & \\
\hline UPMGNFL_ERR & 23 & & & & & & \\
\hline UPWP IXW'- & 18 & & & & & & \\
\hline UPXGAUV & 2 & 17 & 19 & & & & \\
\hline UPXGAUV ERR & 19 & & & & & & \\
\hline UPXNAG & 1 & 14 & 18 & & & & \\
\hline UPXNAG_ERR & 18 & & & & & & \\
\hline URPL & 21 & & & & & & \\
\hline URPMNFL & 15 & 20 & & & & & \\
\hline URPXNA & 14 & 16 & & & & & \\
\hline URTBILL & 19 & 22 & & & & & \\
\hline UXG & 3 & & & & & & \\
\hline UXGA & 2 & 3 & 17 & & & & \\
\hline UXGA_ERR & 17 & & & & & & \\
\hline UXGĀ & 2 & 4 & & & & & \\
\hline UXGNA & 1 & 3 & 16 & & & & \\
\hline UXGNA_ERR & 16 & & & & & & \\
\hline UXGNA $\bar{V}$ & 1 & 4 & & & & & \\
\hline UXGV & 4 & 13 & & & & & \\
\hline UXQF LNS & 5 & & & & & & \\
\hline
\end{tabular}


ALPHABETICAL LIST OF VARIABLES FOR MODEL

MNEMONIC | EQUATION |
DEFINITION

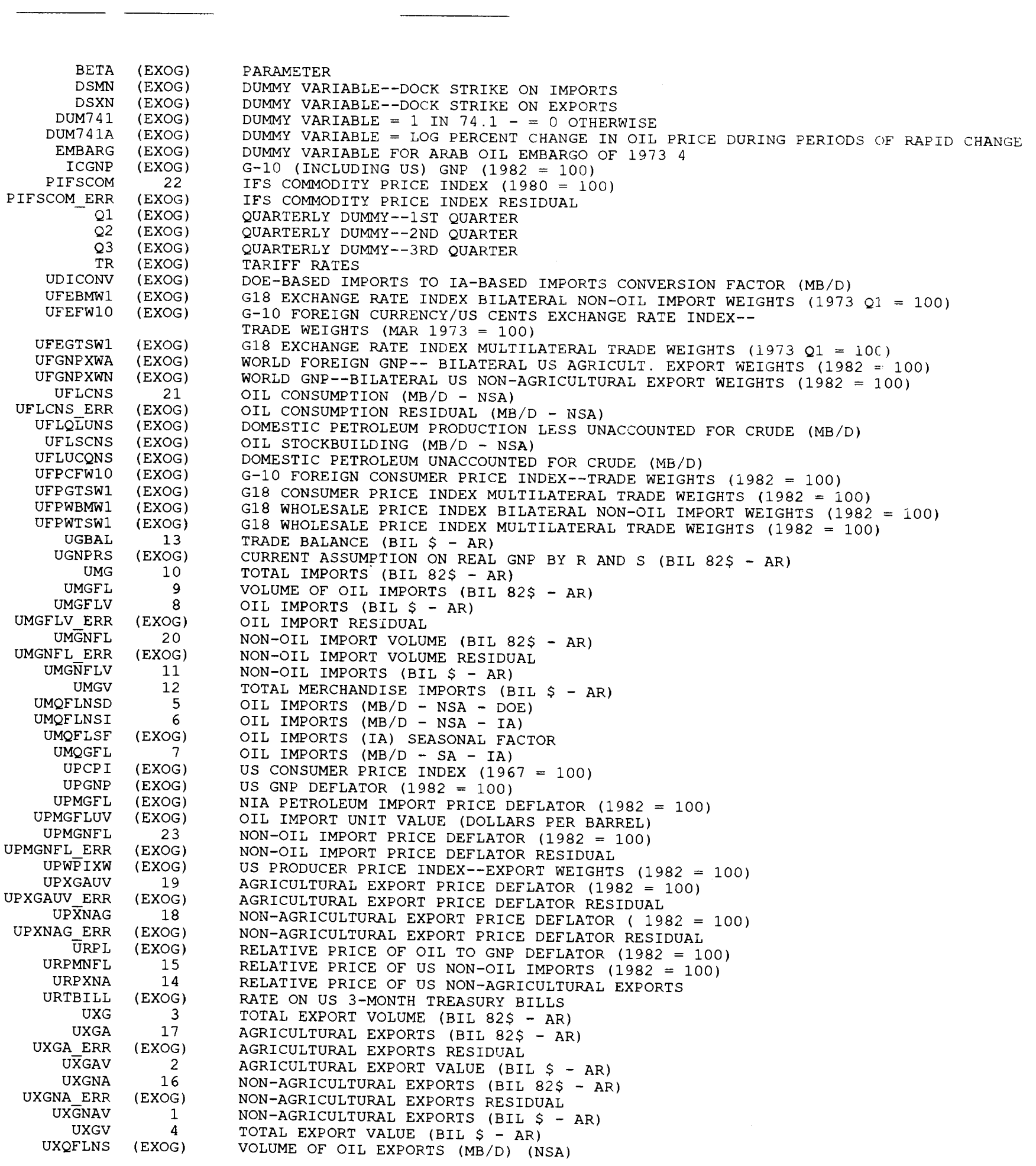




\section{Model M4}

1. UGPCOMP: (UGPCOMP) THIRD COUNTRY PRICE FOR US-GERMAN TRADE -

$\mathrm{UGPCOMP}=((\mathrm{CPXGUV} * \mathrm{CEI}) \star 0.165 *(\mathrm{EPXGUV} \star \mathrm{EEI}) \star 0.215 *(\mathrm{JPXGUV}$ * JEI) $\star \star 0.245) \star \star(1 /(1-0.375))$

2. GUPCOMP: GUPCOMP) THIRD COUNTRY PRICE FOR GERMAN-US TRADE -

GUPCOMP $=((\mathrm{CPXGUV} * \mathrm{CEI}) \star \star 0.155172$ * (EPXGUV * EEI) $\star * 0.206897$ * (JPXGUV * $J E I) \star \star 0.241379) \star \star(1 /(1-0.3965))$

3. UJPCOMP: (UJPCOMP) THIRD COUNTRY PRICE FOR US-JAFAN TRADE

UJPCOMP $=((\mathrm{CPXGUV} \star \mathrm{CEI}) \star \star 0.165 *(\mathrm{EPXGUV} \star \mathrm{EEI}) \star \star 0.215 *(\mathrm{GPXGUV} * \mathrm{GEI})$ $\star \star 0.375) \star \star(1 /(1-0.245))$

4. UPPXFTW: (UFPXFTW) U.S. IMPORT FRICES FROM MCM COUNTRIES

JFPXFTW $=($ CPXGUV * CEI $) \star \star 0.165 *(E P X G U V *$ EEI $) \star 0.215 \star(G P X G U V \star G E I)$ $\star \star 0.375 \star(\mathrm{JPXGUV} \star \mathrm{JEI}) \star \star 0.245$

5. XUCV: (XUCV) EXPORTS OF THE US TO CANADA --NOMINAL \$

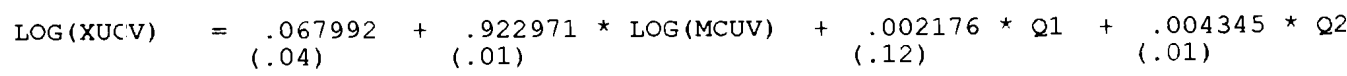
$-.001608 * 03+\mathrm{XUC}$ ERR * BETA

6. XUEV: (XUEV) EXPORTS OF THE US TO THE UK --NOMINAL \$

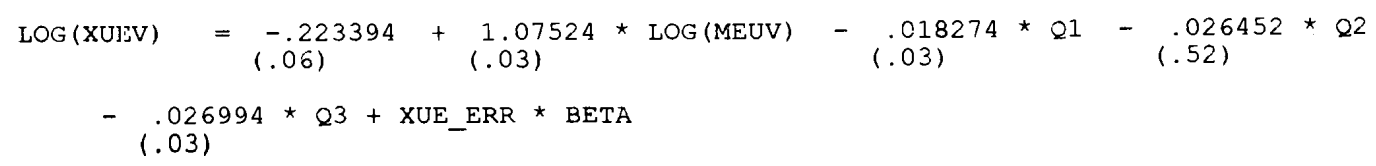

7. XUGV: (XJGV) EXPORTS OF THE US TO GERMANY --NOMINAL \$ (X) -

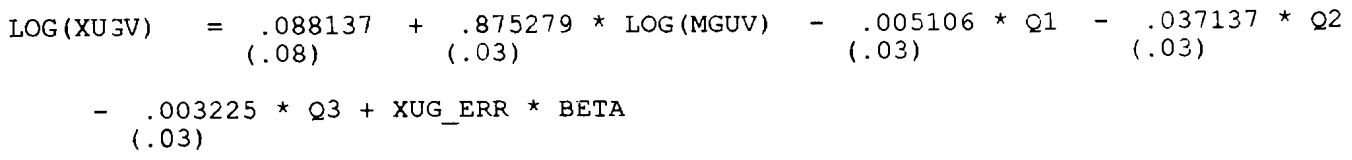


8. XUJV: (XUJV) EXPORTS OF THE US TO JAPAN --NOMINAL $\$$

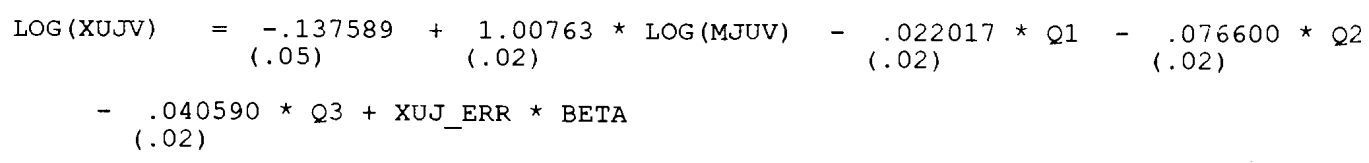

9. MCUV: (MCUV) CANADIAN IMPORTS FROM US (\$)

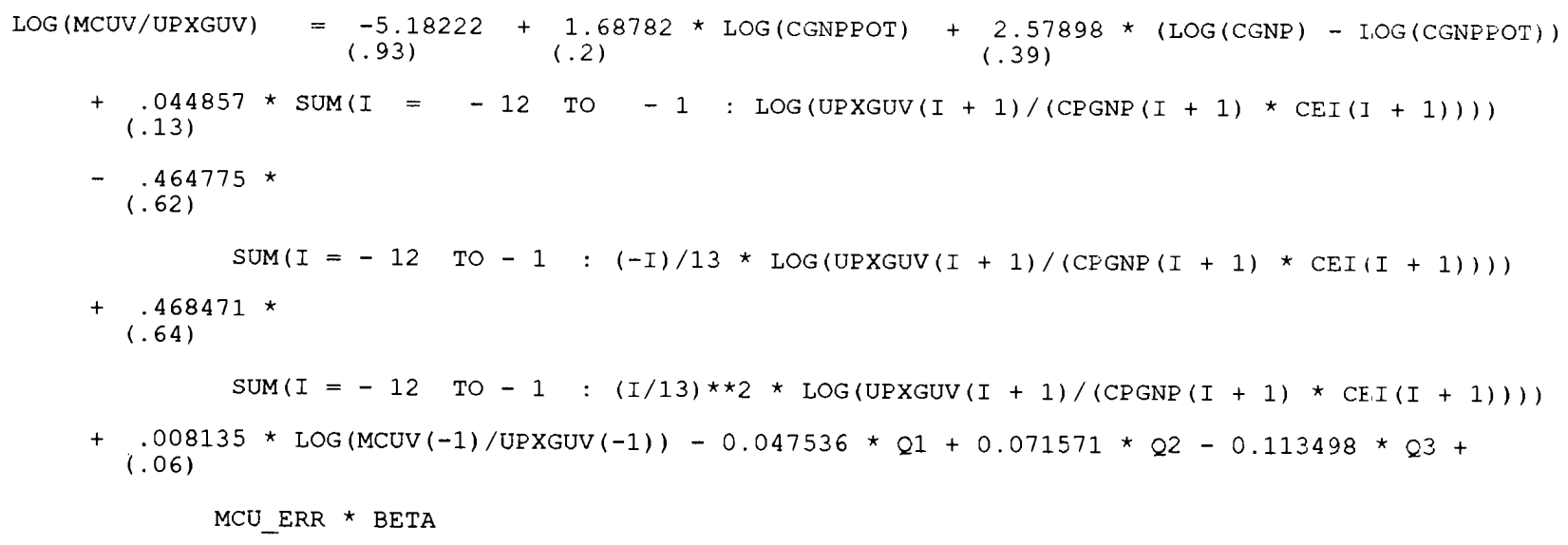

10. MEUV: (MEUV) UK IMPORTS FROM US--NOMINAL \$

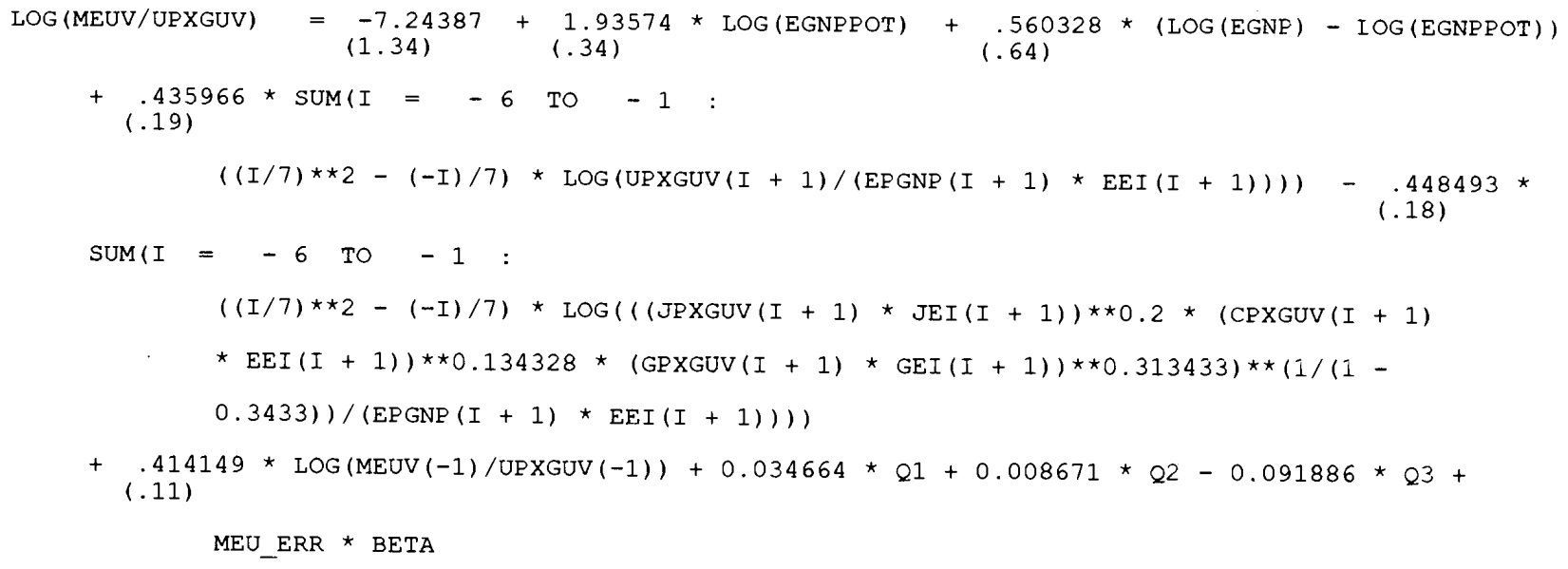

11. MGUV: (MGUV) GERMAN IMPORTS FROM THE US --NOMINAL \$

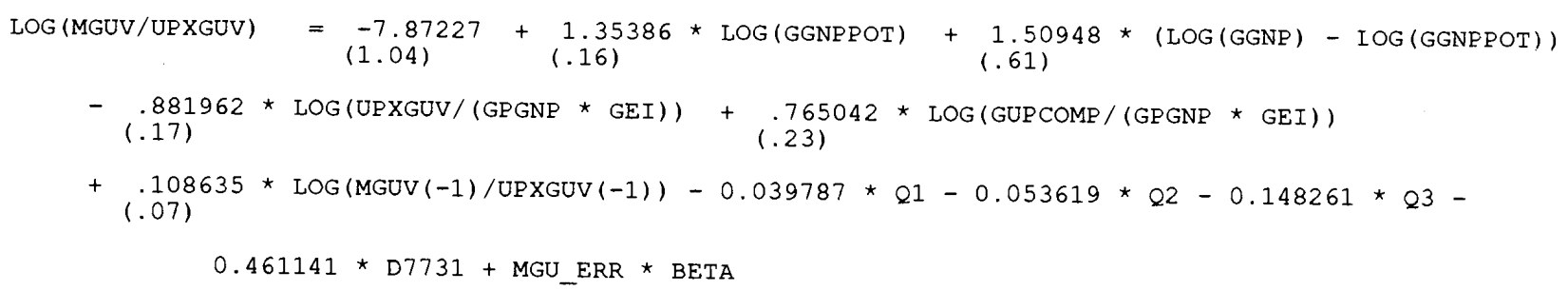


14. MUGV: (MJGV) IMPORTS OF THE US FROM GERMANY --NOMINAL \$

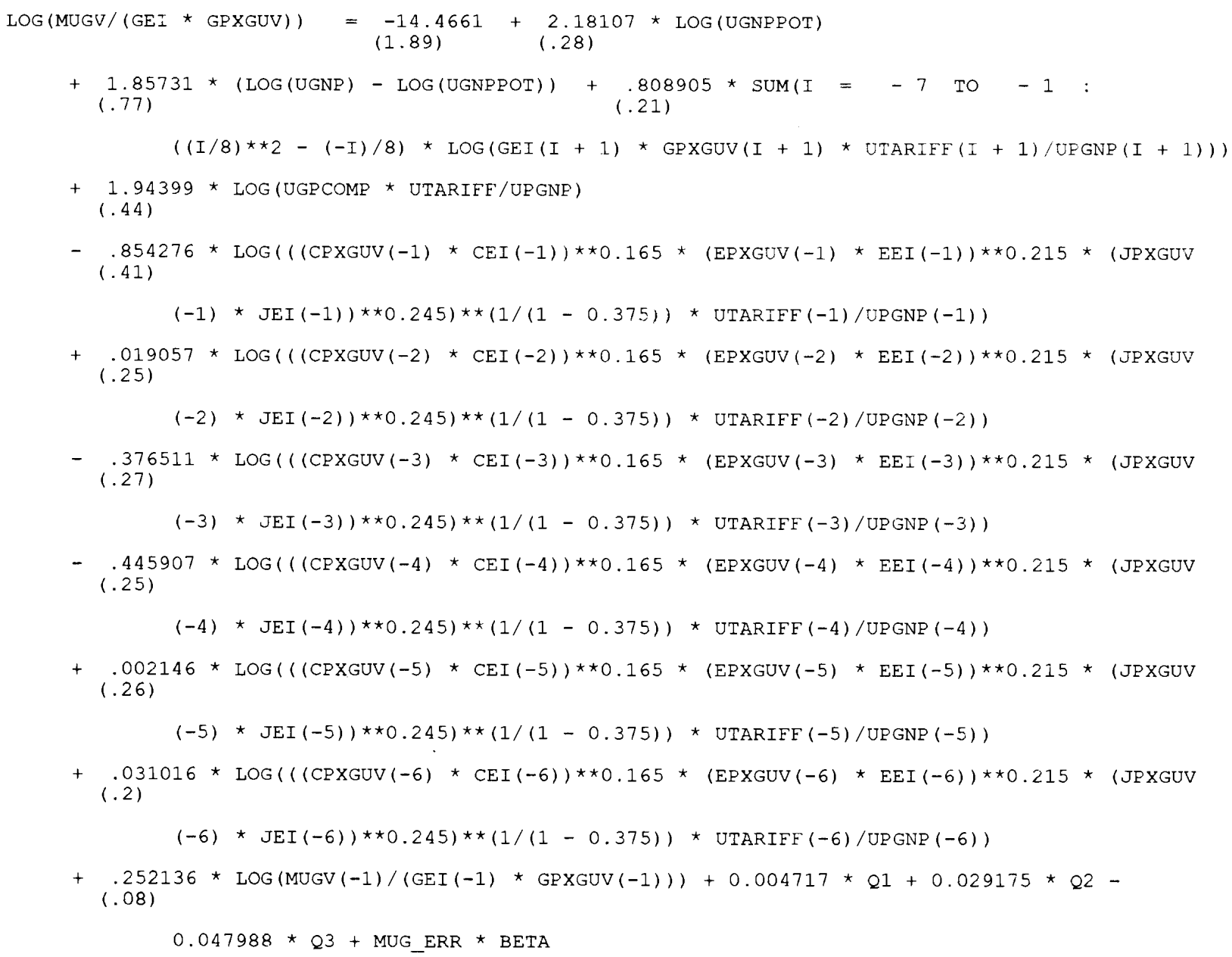


12. MUUV: (MJUV) IMPORTS OF JAPAN FROM THE US --NOMINAL \$

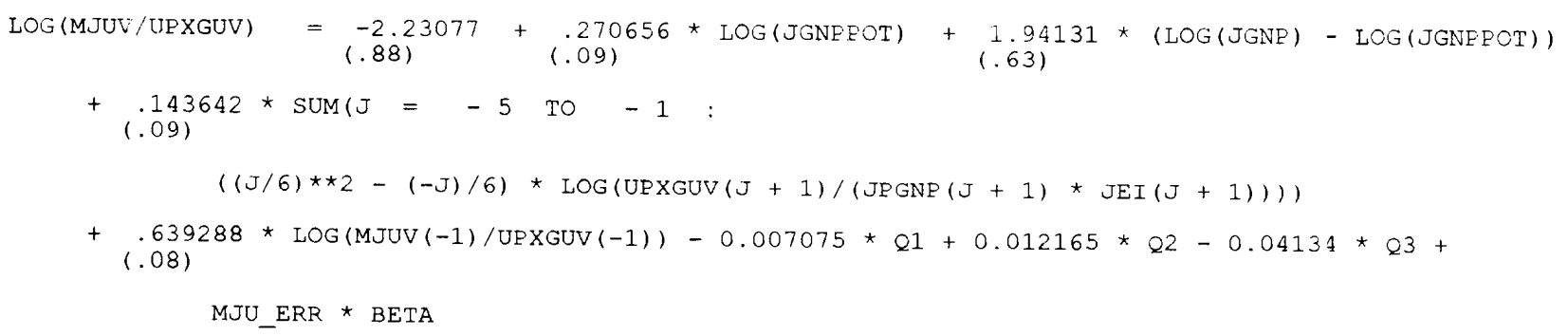

13. MUEV: (MUEV) IMPORTS OF THE US FROM THE UK --NOMINAI \$

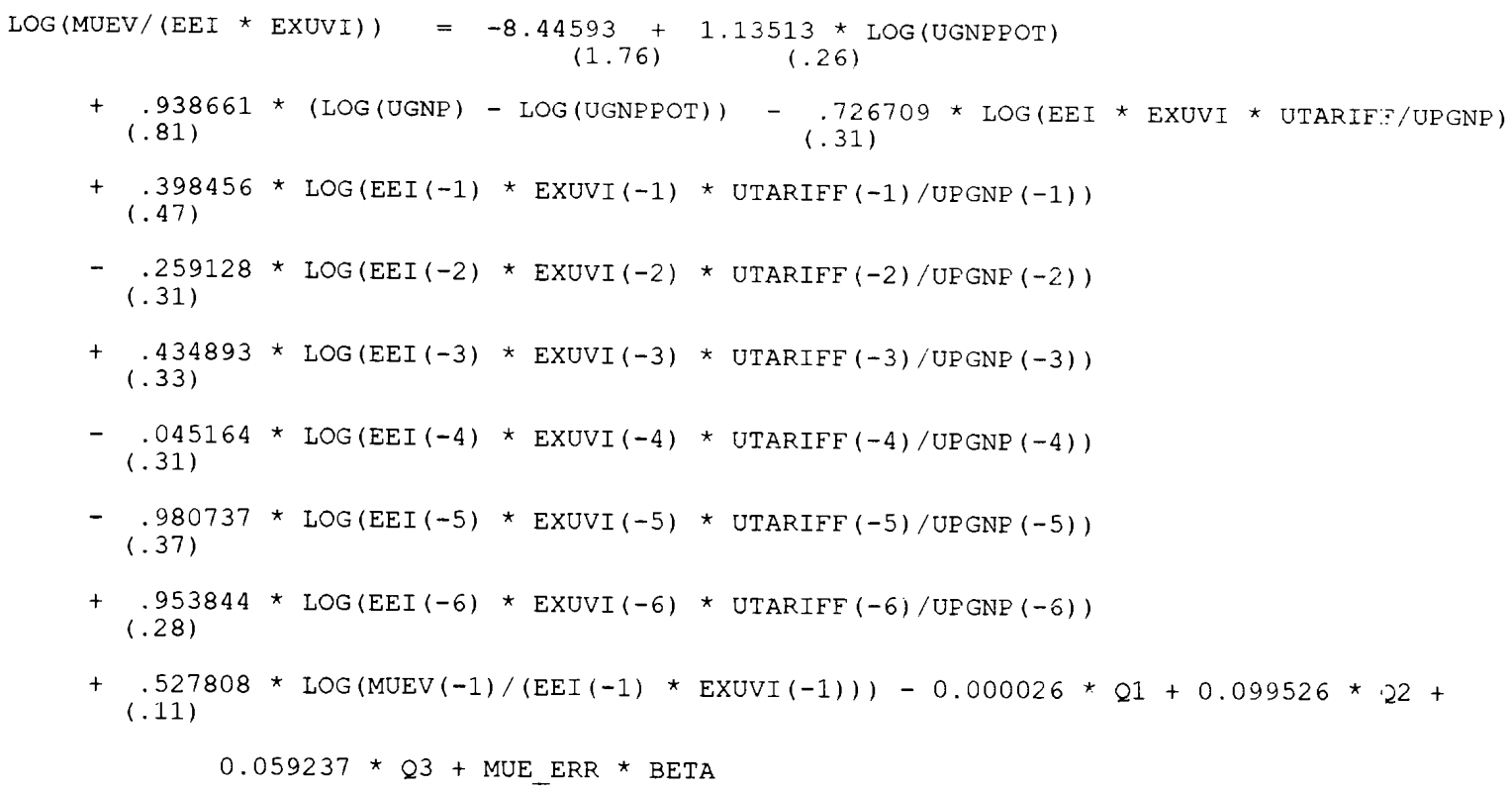


19. XULV: (XULV) EXPORTS OF THE US TO LDCS -- NOMINAL $\$$

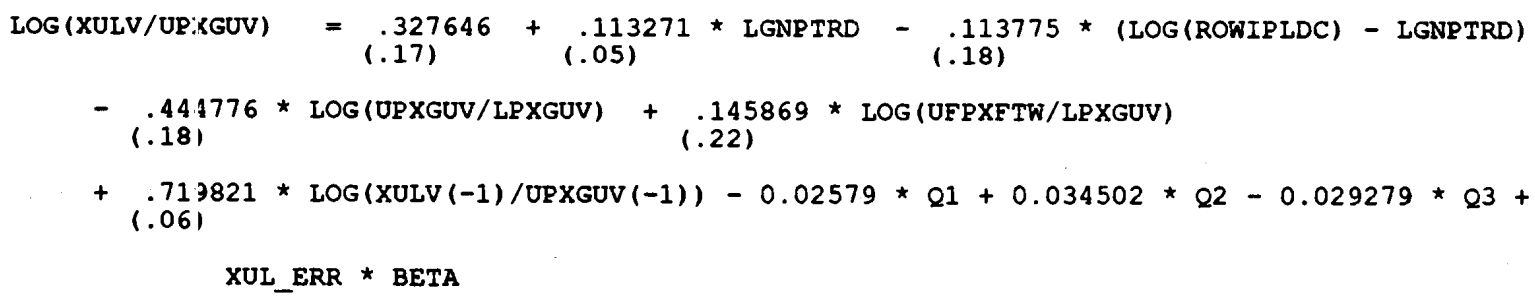

20. XUOV: (XUOV) EXPORTS OF THE US TO OPEC -- NOMINAL \$

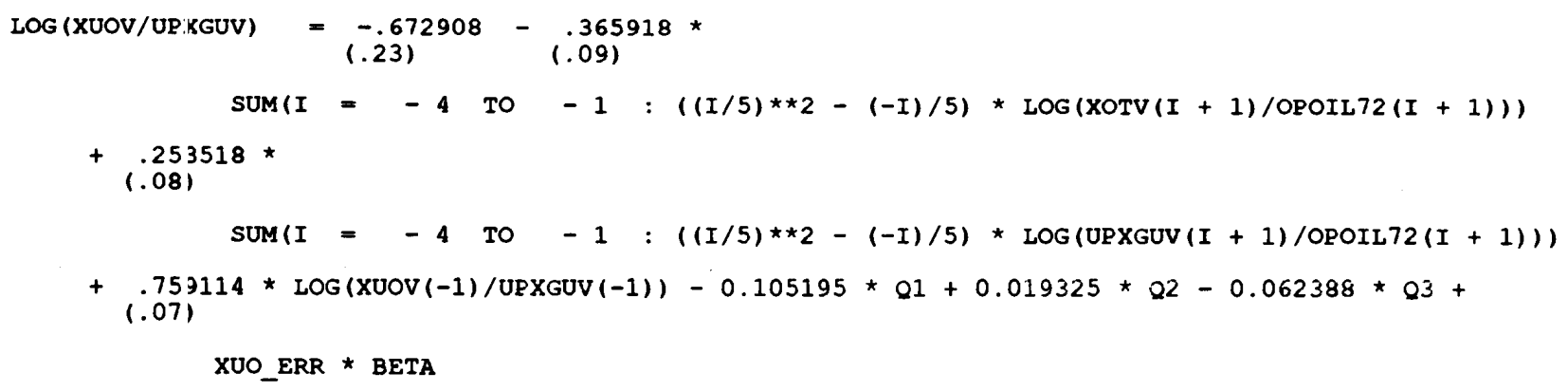

21. XUIV: (XUIV) EXPORTS OF THE UNITED STATES TO OTHER OECD --NOMINAL \$

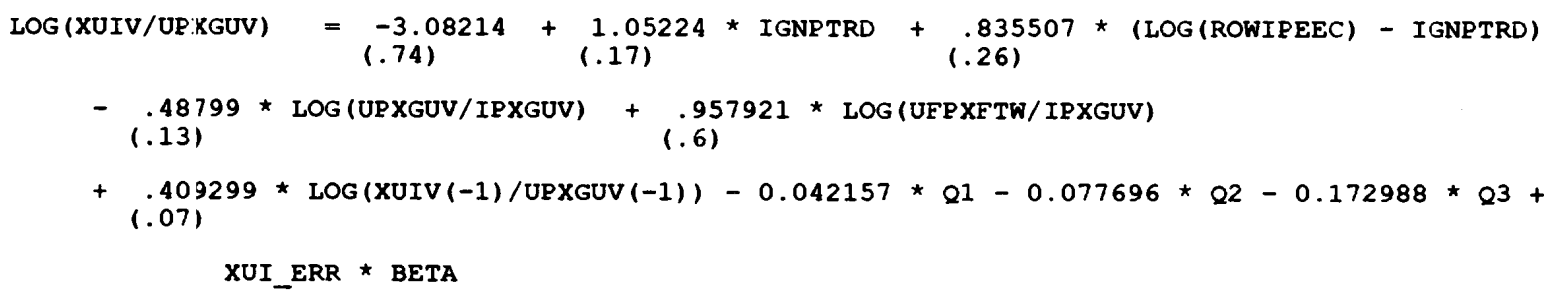

22. UFLCNS: (UFLZNS) U.S. OIL CONSUMPTION (MB/D - NSA)

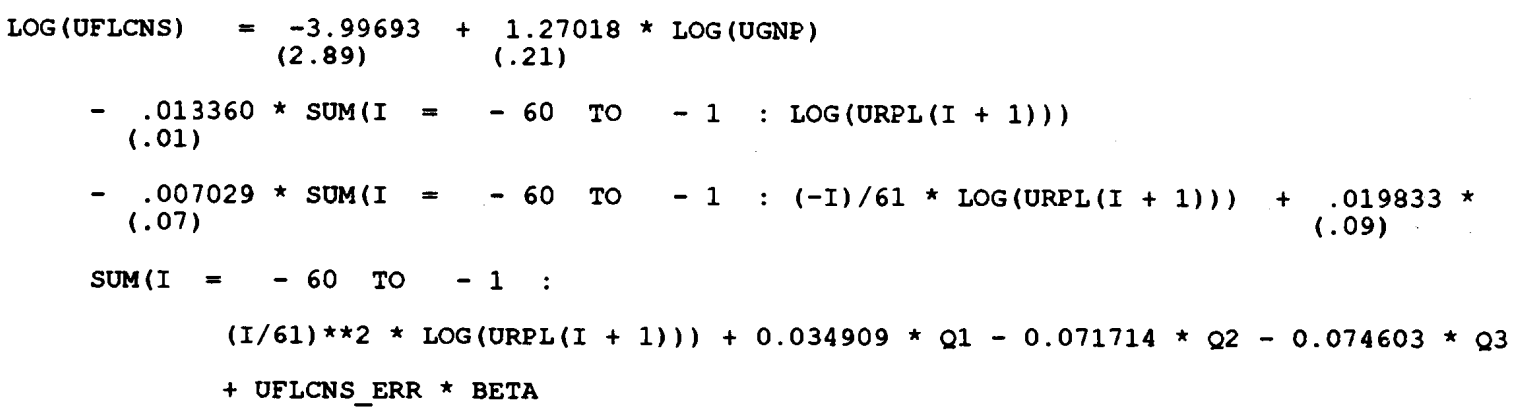

23. UMQFLNSD: (UMOFLNSD) U.S. OIL IMPORTS (MB/D - NSA - DOE)

UMQFLNSD = UFLCNS - UFLQLUNS - UFLUCQNS + UXQFLNS + UFLSCNS 
16. MUCV: (MUCV) IMPORTS OF THE US FROM CANADA --NOMINAL \$

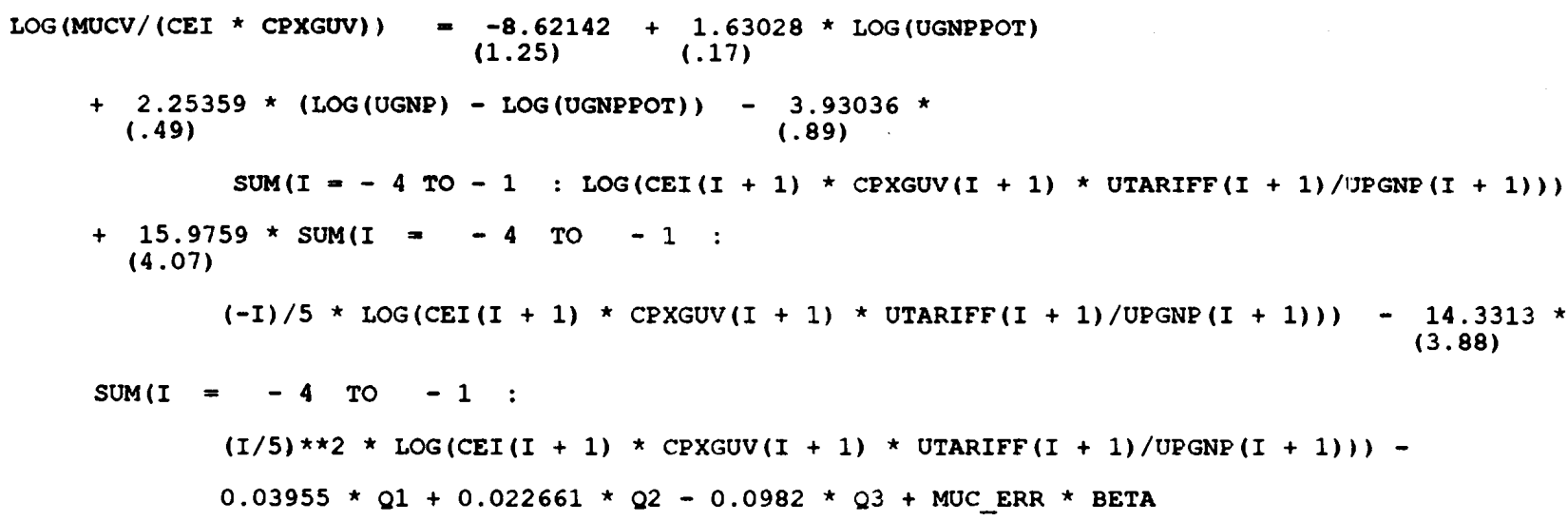

17. MULV: (MULV) IMPORTS OF THE US FROM LDCS --NOMINAL \$

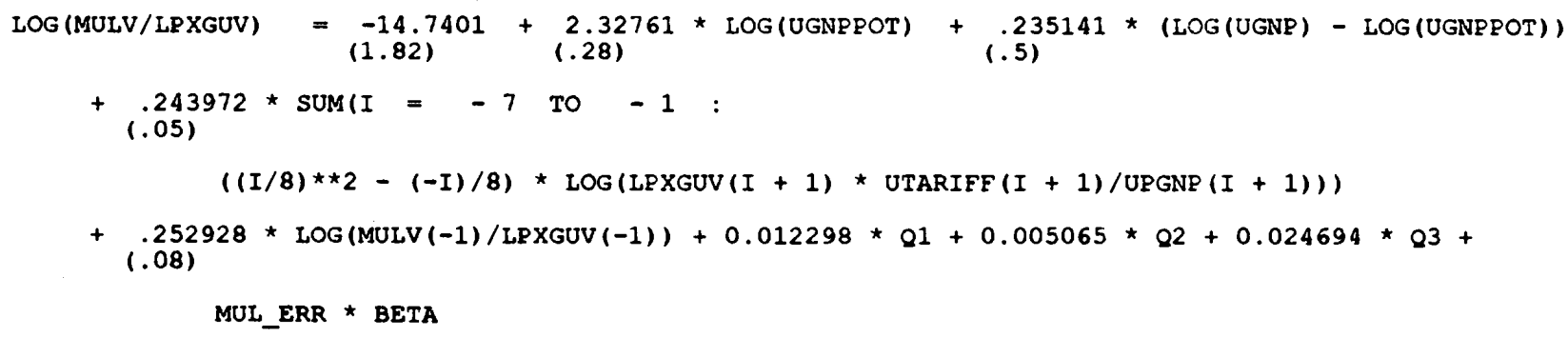

18. MUIV: (MUIV) IMPORTS OF THE US FROM OTHER OECD--NOMINAL \$

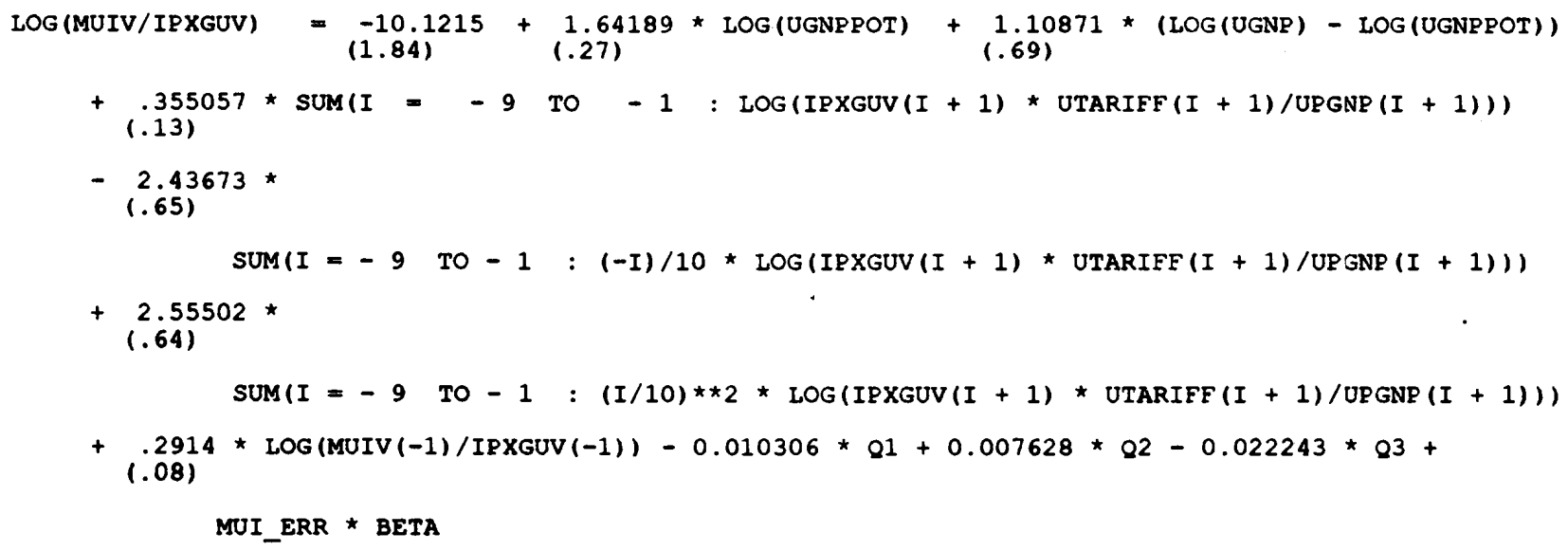


24. UMOFLNSI: (JMOFLNSI) U.S. OIL IMPORTS (MB/D - NSA - IA)

UMQFLNSI = UMQFLNSD + UDICONV

25. UMQGFL: (UMQGFL) U.S. OIL IMPORTS (MB/D - SA - IA)

UMQGFL = UMQFLNSI/UMQFLSF

26. UMGFLV: (UMGFLV) U.S. OIL IMPORTS (BIL \$ - AR)

UMGFLV = UMQGFL * 0.365 * UPMGFLUV + UMGFLV ERR

27. MUOV: (MUOV) IMPORTS OF THE US FROM OPEC --NOMINAL \$

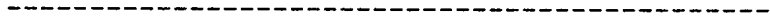

MUOV = UMGELV - UMOILNO

28. CPXGUV: (CPXGUV) CANADIAN EXPORT UNIT VALUE - DOM. CUR. -1972

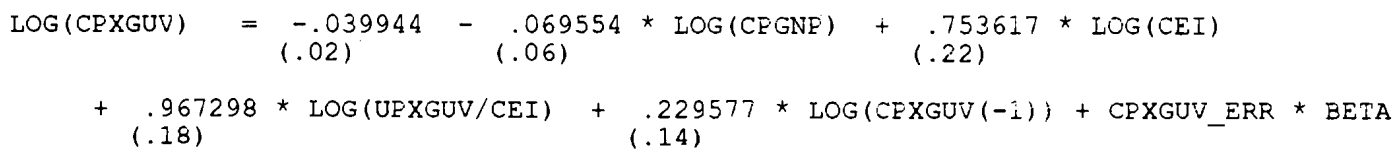

29. EXUVI: (EXUVI) UK NON-OIL EXPORT UNIT VALUE - DOM. CUR. - 1972

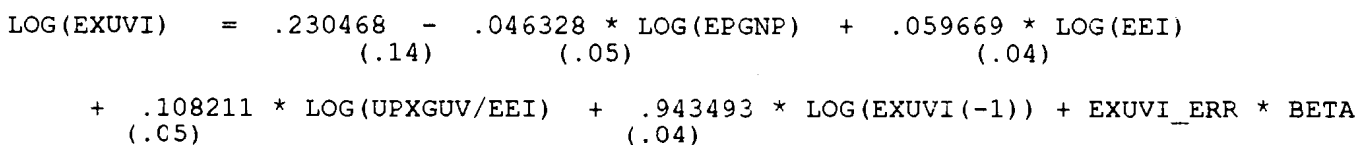

31. GPXGUV: (GEXGUV) GERMAN EXPORT UNIT VALUE - DOM. CUR. - 1972

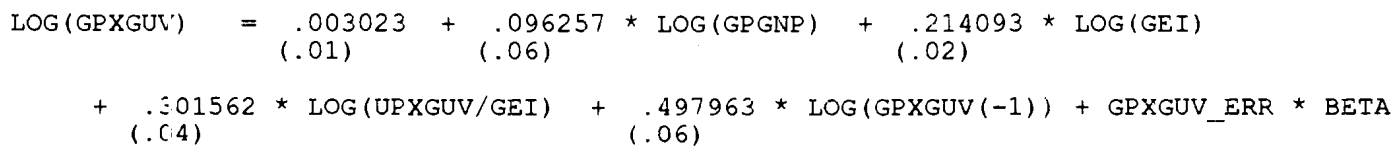


32. JPXGUV: (JPXGUV) JAPAN EXPORT UNIT VALUE - DOM. CUR. - 1972

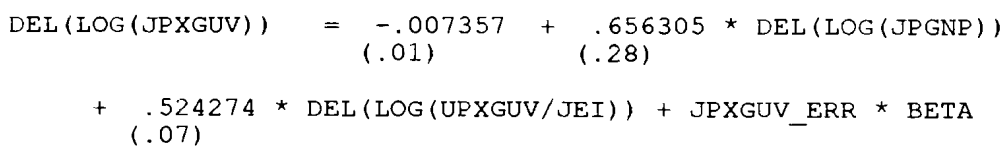

33. IPXGUV: (IPXGUV) NIC EXPORT UNIT VALUE - DOM. CUR. - 1972

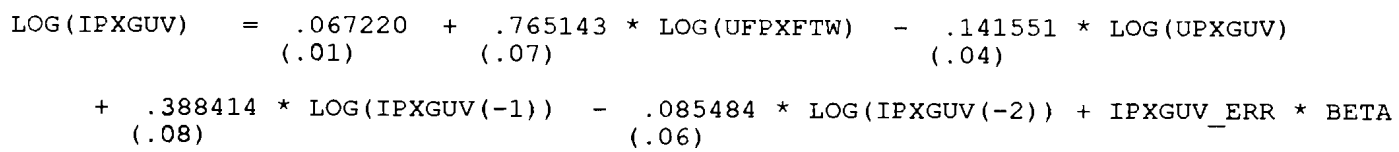

36. MUTV: (MUTV) TOTAL IMPORTS OF THE US --NOMINAL \$

$\mathrm{MUTV}=\mathrm{MUCV}+\mathrm{MUEV}+\mathrm{MUGV}+\mathrm{MUJV}+\mathrm{MUIV}+\mathrm{MULV}+\mathrm{MUOV}+\mathrm{MUZV}$

37. XUTV: (XUTV) TOTAL EXPORTS OF THE US --NOMINAL \$

$\mathrm{XUTV}=\mathrm{XUCV}+\mathrm{XUEV}+\mathrm{XUGV}+\mathrm{XUJV}+\mathrm{XUIV}+\mathrm{XULV}+\mathrm{XUOV}+\mathrm{XUZV}$

38. UTRADE: (UTRADE) U.S. TRADE BALANCE -- NOMINAL \$

UTRADE $=$ XUTV - MUTV 
CROSS REFERENCE LIST OF VARIABLES AND EQUATIONS

VARIABLE | ESUATION NUMBER

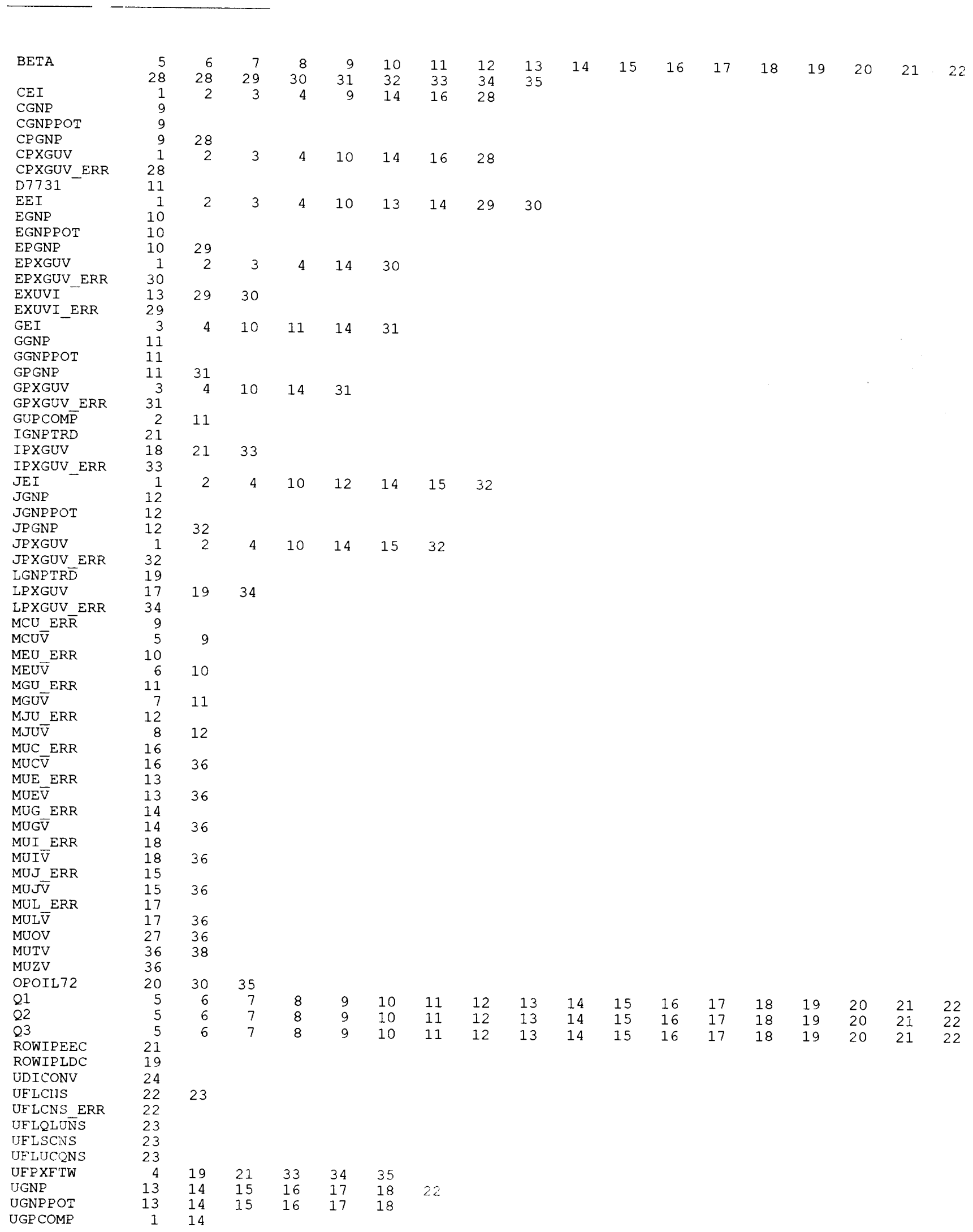


VARIABLE | EQUATION NUMBER

\begin{tabular}{|c|c|c|c|c|c|c|c|c|c|c|c|c|c|c|}
\hline UJPCOMP & 3 & 15 & & & & & & & & & & & & \\
\hline UMGFLV & 26 & 27 & & & & & & & & & & & & \\
\hline UMGFLV_ERR & 26 & & & & & & & & & & & & & \\
\hline $\begin{array}{l}\text { UMOILND } \\
\text { UMOFLNSD }\end{array}$ & 27 & 24 & & & & & & & & & & & & \\
\hline UMQF LNSI & 24 & 25 & & & & & & & & & & & & \\
\hline UMOF LSF & 25 & & & & & & & & & & & & & \\
\hline UMQGFL & 25 & 26 & & & & & & & & & & & & \\
\hline UPGNP & 13 & 14 & 15 & 16 & 17 & 18 & 35 & & & & & & & \\
\hline $\begin{array}{l}\text { UPMGFLUV } \\
\text { UPXGUV }\end{array}$ & $\begin{array}{r}26 \\
9\end{array}$ & 10 & 11 & 12 & 19 & 20 & 21 & 28 & & & & & & 35 \\
\hline UPXGUV ERR & 35 & & & & & & & & 29 & 31 & 32 & 33 & 34 & 35 \\
\hline URPL & 22 & & & & & & & & & & & & & \\
\hline UTARIFF & 13 & 14 & 15 & 16 & 17 & 18 & & & & & & & & \\
\hline UTRADE & 38 & & & & & & & & & & & & & \\
\hline UXQFLNS & 23 & & & & & & & & & & & & & \\
\hline XOTV & 20 & & & & & & & & & & & & & \\
\hline XUC_ERR & 5 & & & & & & & & & & & & & \\
\hline $\mathrm{XUC \overline {V }}$ & 5 & 37 & & & & & & & & & & & & \\
\hline XUE_ERR & 6 & & & & & & & & & & & & & \\
\hline XUEV $\bar{V}$ & 6 & 37 & & & & & & & & & & & & \\
\hline XUG_ERR & 7 & & & & & & & & & & & & & \\
\hline XUGV̄ & 7 & 37 & & & & & & & & & & & & \\
\hline XUI_ERR & 21 & & & & & & & & & & & & & \\
\hline $\mathrm{XUIV} \overline{\mathrm{V}}$ & 21 & 37 & & & & & & & & & & & & \\
\hline XUJ_ERR & 8 & & & & & & & & & & & & & \\
\hline $\mathrm{XUV \overline {V }}$ & 8 & 37 & & & & & & & & & & & & \\
\hline XUL_ERR & 19 & & & & & & & & & & & & & \\
\hline XULV̄ & 19 & 37 & & & & & & & & & & & & \\
\hline XUO_ERR & 20 & & & & & & & & & & & & & \\
\hline $\mathrm{xUOV}$ & 20 & 37 & & & & & & & & & & & & \\
\hline XUTV & 37 & 38 & & & & & & & & & & & & \\
\hline XUZV & 37 & & & & & & & & & & & & & \\
\hline
\end{tabular}


ALPHABETICAL LIST OF VARIABLES FOR MODEL

MNEMONIC | EQUHTION |
DEFINITION
PARAMETER

US-CANADA EXCHANGE RATE (US\$/C\$)--INDEX 1972

CANADIAN REAL GNP--DOMESTIC CURRENCY--1972

CANADIAN POTENTIAL OUTPUT--DOMESTIC CURRENCY--1972

CANADIAN GNP DEFLATOR--DOMESTIC CURRENCY--1972

CANADIAN EXPORT UNIT VALUE--DOMESTIC CURRENCY--1972

RESIDUAL IN CPXGUV EQUATION

DUMMY VARIABLE $=1$ IN 77 Q4

US-UK EXCHANGE RATE (US\$/POUND)--INDEX 1972

BRITISH REAL GNP--DOMESTIC CURRENCY--1972

BRITISH POTENTIAL OUTPUT--DOMESTIC CURRENCY--1972

BRITISH GNP DEFLATOR--DOMESTIC CURRENCY--1972

BRITISH EXPORT UNIT VALUE--DOMESTIC CURRENCY--1972

RESIDUAL IN EPXGUV EQUATION

NON-OIL UNIT VALUE FOR THE UK--1972=1

RESIDUAL IN EXUVI EQUATION

US-GERMANY EXCHANGE RATE (US\$/DM)--INDEX 1972

GERMAN REAL GNP--DOMESTIC CURRENCY--1972

GERMAN POTENTIAL OUTPUT--DOMESTIC CURRENCY--1972

GERMAN GNP DEFLATOR--DOMESTIC CURRENCY--1972

GERMAN EXPORT UNIT VALUE-DONESTIC CURRENCY--1972

RESIDUAL IN GPXGUV EQUATION

THIRD COUNTRY PRICE FOR GERMAN-US TRADE

LOG OF OTHER OECD TREND OUTPUT--DOMESTIC CURRENCY--1972

OTHER OECD EXPORT UNIT VALUE--DOMESTIC CURRENCY--1972

RESIDUAI, IN IPXGUV EQUATION

US-JAPAN EXCHANGE RATE (US\$/YEN) --INDEX 1972

JAPANESE REAL GNP--DOMESTIC CURRENCY--1972

JAPANESE POTENTIAL OUTPUT--DOMESTIC CURRENCY--1972

JAPANESE GNP DEFLATOR--DOMESTIC CURRENCY--1972

JAPANESE EXPORT UNIT VALUE--DOMESTIC CURRENCY--1972

RESIDUAL IN JPXGUV EQUATION

LOG OF LDCS TREND OUTPUT--DOMESTIC CURRENCY--1972

LDCS EXPORT UNIT VALUE--DOMESTIC CURRENCY--1972

RESIDUAL IN LPXGUV EQUATION

RESIDUAL IN MCUV EQUATION

CANADIAN IMPORTS FROM US (\$)

RESIDUAL IN MEUV EQUATION

UK IMPORTS FROM US--NOMINAL \$

RESIDUAL IN MGUV EQUATION

GERMAN IMPORTS FROM THE US --NOMINAL \$

RESIDUAL IN MJUV EQUATION

IMPORTS OF JAPAN FROM THE US --NOMINAL \$

RESIDUAL IN MUCV EQUATION

IMPORTS OF THE US FROM CANADA - NOMINAL \$

RESIDUAL IN MUEV EQUATION

IMPORTS OF THE US FROM THE UK --NOMINAL \$

RESIDUAL IN MUGV EQUATION

IMPORTS OF THE US FROM GERMANY - NOMINAL \$

RESIDUAL IN MUIV EQUATION

IMPORTS OF THE US FROM OTHER OECD--NOMINAL \$

RESIDUAL IN MUJV EOUATION

IMPORTS OF THE US FROM JAPAN --NOMINAL \$

RESIDUAL IN MULV EQUATION

IMPORTS OF THE US FROM LDCS --NOMINAL $\$$

IMPORTS OF THE US FROM OPEC --NOMINAL \$

TOTAL IMPORTS OF THE US --NOMINAL \$

US IMPORTS FROM THE RESIDUAL REGION--NOMINAL \$

NOMINAL OIL PRICE INDEX FOR OPEC--1972=1

DUMMY VARIABLE $=1$ IN FIRST QUARTER - ZERO OTHERWISE

DUMMY VARIABLE $=1$ IN SECOND QUARTER - ZERO OTHERWISE

DUMMY VARIABLE $=1$ IN THIRD QUARTER - ZERO OTHERWISE

OTHER OECD REAL GNP

LDCS REAL GNP

DOE-BASED IMPORTS TO IA-BASED IMPORTS COVERSION FACTOR (MB/D)

OIL CONSUMPTION (MB/D - NSA)

RESIDUAL IN UFLCNS EQUATION

DOMESTIC PETOLEUM PRODUCTION LESS UNACCOUNTED FOR CRUDE (MB/D)

OIL STOCKBUILDING (MB/D - NSA)

DOMESTIC PETROLEUM UNACCOUNTED FOR CRUDE (MB/D)

US FOREIGN IMPORT PRICES

US REAL GNP--DOMESTIC CURRENCY--1972

US POTENTIAL OUTPUT--DOMESTIC CURRENCY--1972

THIRD COUNTRY PRICE FOR US-GERMAN TRADE

THIRD COUNTRY PRICE FOR US-JAFAN TRADE 


\begin{tabular}{|c|c|}
\hline UMGFLV & 26 \\
\hline UMGFLV_ERR & (EXOG) \\
\hline UMOĪLNO & (EXOG) \\
\hline UMQF LNSD & 23 \\
\hline UMQFLNSI & 24 \\
\hline UMQFLSF & (EXOG) \\
\hline UMOGFL & 25 \\
\hline UPGNP & $(E X O G)$ \\
\hline UPMGFLUV & (EXOG) \\
\hline UPXGUV & 35 \\
\hline UPXGUV_ERR & $(E X O G)$ \\
\hline$\overline{\mathrm{U} R P L}$ & (EXOG) \\
\hline UTARIFF & (EXOG) \\
\hline UTRADE & 38 \\
\hline UXQFLNS & $(\mathrm{EXOG})$ \\
\hline XOTV & (EXOG) \\
\hline XUC_ERR & (EXOG) \\
\hline $\bar{X} U C V$ & 5 \\
\hline XUE_ERR & (EXOG) \\
\hline $\bar{X} U E V$ & 6 \\
\hline XUG_ERR & (EXOG) \\
\hline $\bar{X}$ UGV & 7 \\
\hline XUI_ERR & (EXOG) \\
\hline$\overline{\mathrm{X}} U I V$ & 21 \\
\hline XUJ_ERR & (EXOG) \\
\hline$\overline{\mathrm{X}} \cup J V$ & 8 \\
\hline XUL_ERR & (EXOG) \\
\hline$\overline{\mathrm{X}} U L V$ & 19 \\
\hline XUO_ERR & (EXOG) \\
\hline$\overline{\mathrm{X}} \mathrm{U} O V$ & 20 \\
\hline XUTV & 37 \\
\hline & \\
\hline
\end{tabular}

OIL IMPORTS (BIL $\$-A R$ )

RESIDUAL IN UMGFLV EQUATION

NON-OPEC OIL IMPORTS (BIL $\$$ - AR)

OIL IMPORTS (MB/D - NSA - DOE)

OIL IMPORTS (MB/D - NSA - IA)

OIL IMPORTS (IA) SEASONAL FACTORS

OIL IMPORTS (MB/D - SA - AI)

US GNP DEFLATOR--DOMESTIC CURRENCY--1972

AVERAGE IMPORT PRICE OF CRUDE OIL (\$/BARREL)

US EXPORT UNIT VALUE--DOMESTIC CURRENCY--1972

RESIDUAL IN UPXGUV EQUATION

RELATIVE PRICE OF OIL TO US GNP DEFLATOR $(' 82=100)$

MULTILATERAL US TARIFF--INDEX 1972=1

US TRADE BALANCE

OIL EXPORTS (MB/D - NSA)

TOTAL EXPORTS OF THE US --NOMINAL \$

RESIDUAL IN XUCV EQUATION

EXPORTS OF THE US TO CANADA --NOMINAL \$

RESIDUAL IN XUEV EQUATION

EXPORTS OF THE US TO THE UK --NOMINAL \$

RESIDUAL IN XUGV EOUATION

EXPORTS OF THE US TO GERMANY --NOMINAL \$

RESIDUAL IN XUIV EQUATION

EXPORTS OF THE UNITED STATES TO OTHER OECD --NOMINAL \$

RESIDUAL IN XUJV EQUATION

EXPORTS OF THE US TO JAPAN --NOMINAL \$

RESIDUAL IN XULV EQUATION

EXPORTS OF THE US TO LDCS -- NOMINAL \$

RESIDUAL IN XUOV EOUATION

EXPORTS OF THE US TO OPEC -- NOMINAL \$

TOTAL EXPORTS OF THE US --NOMINAL $\$$

US EXPORTS TO THE RESIDUAL REGION--NOMINAL \$ 


\section{Model M5}

1. UGBAL: (UGBAL) TRADE BALANCE (BIL \$ - AR)

$\mathrm{UGBAL}=\mathrm{UP}$ $\mathrm{UGUV}$ *UXG/100 - UPMGUV *UMG/100 + UGBAL ERR

2. UPXGUV: (UPXGUV) NIA EXPORT PRICE DEFLATOR $(1982=100)$

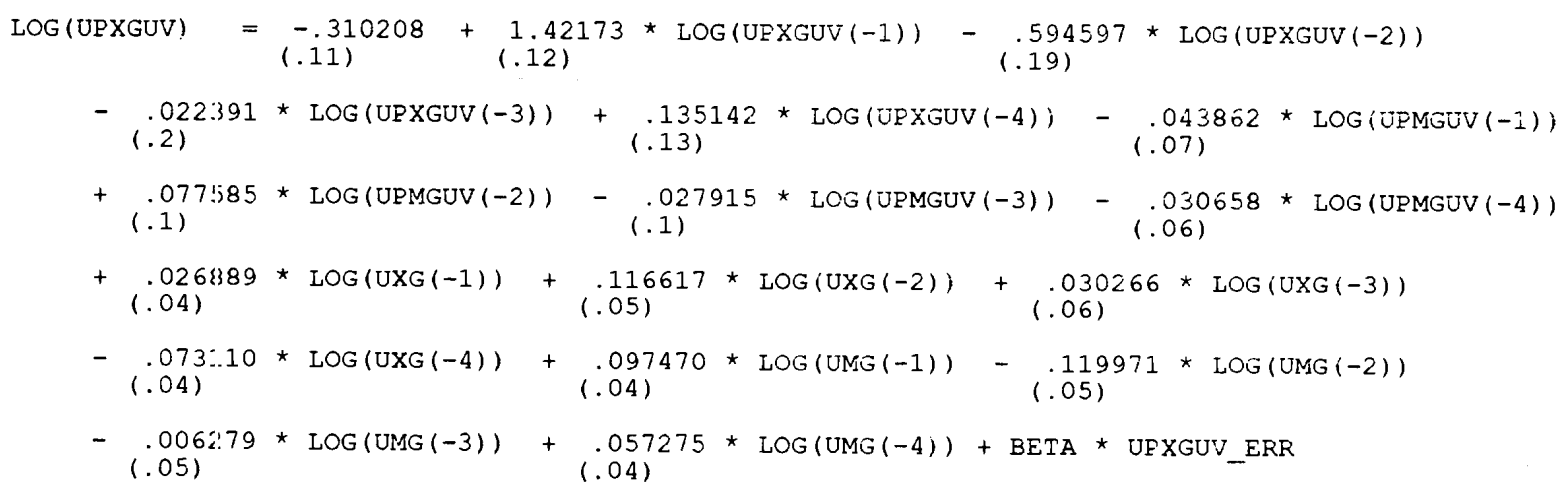

3. UFVGUV: (UPMGUV) NIA IMPORT PRICE DEFLATOR $(1982=100)$

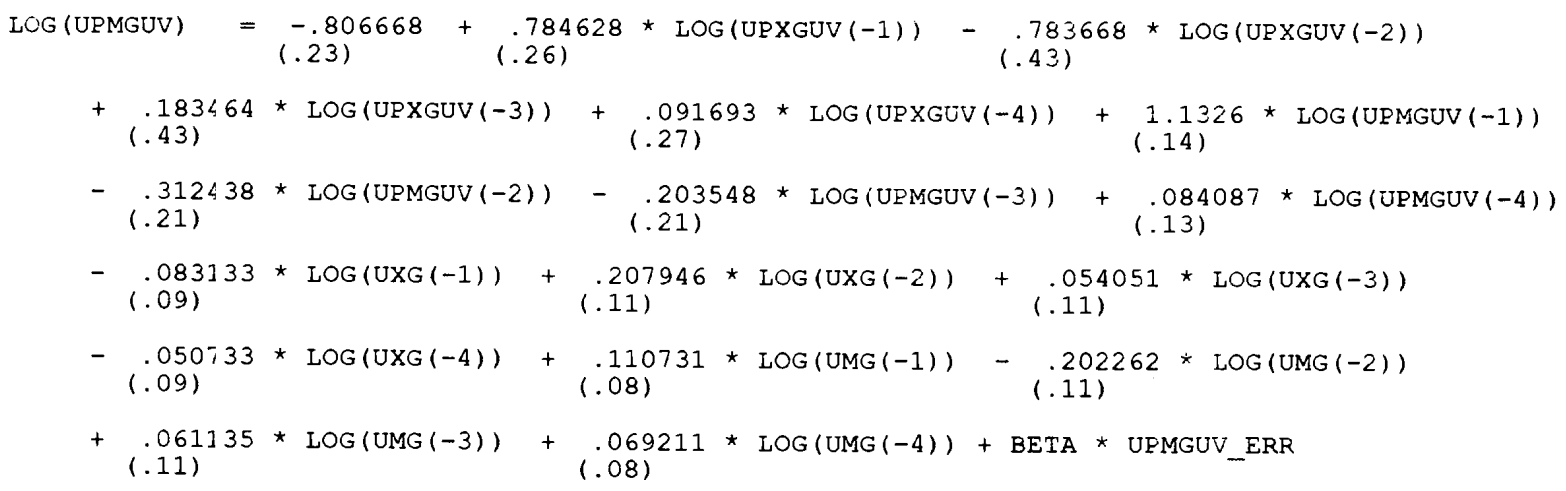

4. UXG: (UXG) TOTAL EXPORTS (BIL $82 \$-A R$ )

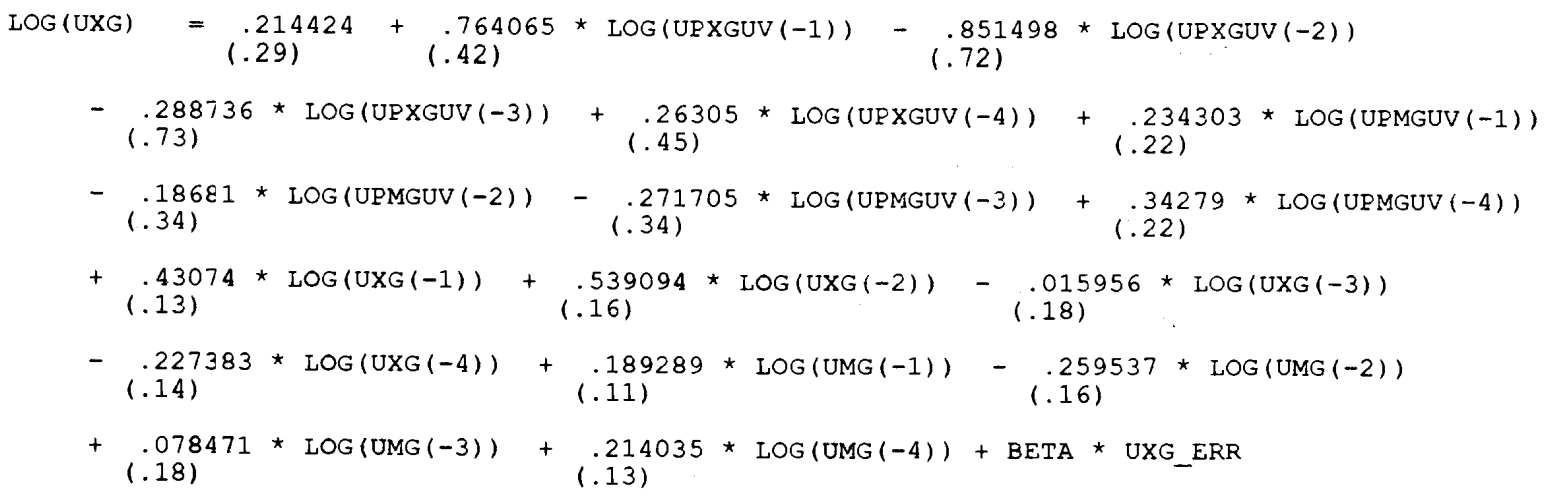


5. UMG: (UMG) TOTAL IMPORTS (BIL $82 \$-A R$ )

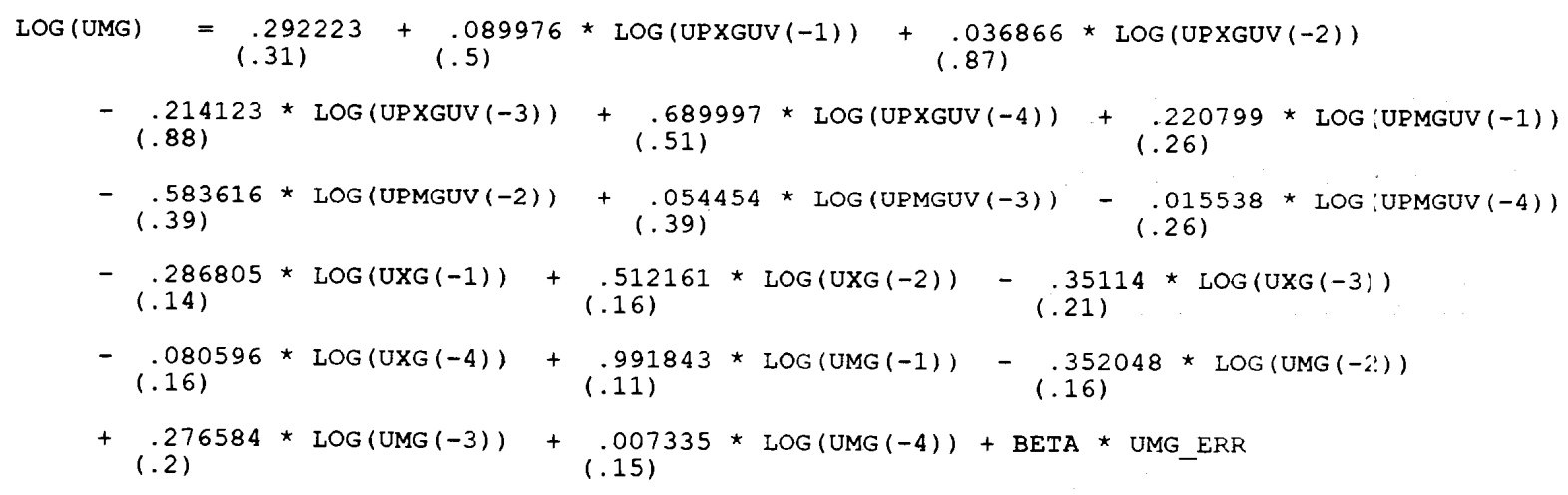

VARIABLE | EQUATION NUMBER

$\begin{array}{llllll}\text { BETA } & 2 & 3 & 4 & 5 & \\ \text { UGBAL } & 1 & & & & \\ \text { UGBAL_ERR } & 1 & & & & 5 \\ \text { UMG_ER } & 1 & 2 & 3 & 4 & 5 \\ \text { UMG_ERR } & 5 & & 3 & 4 & 5 \\ \text { UPMGUV } & 1 & 2 & 3 & & \\ \text { UPMGUV_ERR } & 3 & & 3 & 4 & 5 \\ \text { UPXGUV } & 1 & 2 & 3 & & \\ \text { UPXGUV_ERR } & 2 & & 3 & 4 & 5 \\ \text { UXG_ER } & 1 & 2 & 3 & & \end{array}$

ALPHABETICAL LIST OF VARIABLES FOR MODEL

MNEMONIC | EQUATION ।

DEFINITION

PARAMETER

TRADE BALANCE (BIL $\$$ - AR)

STATISTICAL DISCREPANCY

TOTAL IMPORTS (BIL $82 \$$ - AR)

IMPORT VOLUME RESIDUAL

NIA IMPORT PRICE DEFLATOR $(1982=100)$

IMPORT PRICE DEFLATOR RESIDUAL

NIA EXPORT PRICE DEFLATOR $(1982=100)$

EXPORT PRICE DFLATOR RESIDUAL

TOTAL EXPORT VOLUME (BIL $82 \$$ - AR)

EXPORT VOLUME RESIDUAL 


\section{Model M6}

1. UGBAL: (UGBAL) U.S. TRADE ACCOUNT

(

UGBAL $=\frac{-.914117}{(1.252224)}+\frac{1.04369}{(0.03451)}$ * UGBAL $(-1)+$ BETA * UGBAL_ERR

CROSS REFERENCE LIST OF VARIABLES AND EQUATIONS

VARIABLE | ESUATION NUMBER

$\begin{array}{ll} & \\ \text { BETA } & 1 \\ \text { UGBAL__ } & 1 \\ \text { UGBAL_ERR } & 1\end{array}$

ALPHABETICAL LIST OF VARIABLES FOR MODEL

MNEMONIC | ESIUATION |

DEFINITION

$\begin{array}{rcl} & & \\ \text { BETA } & \text { (EXOG) } & \text { PARAMETER } \\ \text { UGBAL } & 1 & \text { U.S. TRADE ACCOUNT } \\ \text { UGBAL_ERR } & \text { (EXOG) } & \text { RESIDUAL OF ARI EQUATION }\end{array}$


IFDP

NUMBER

377

376

375

374

373

372

371

370

369

368

367

366

365

364

363
International Finance Discussion Papers

\section{TITLES}

1990

Evaluating the Predictive Performance of Trade-Account Models

Towards the Next Generation of Newly Industrializing Economies: The Roles for Macroeconomic Policy and the Manufacturing Sector

The Dynamics of Interest Rate and Tax Rules in a Stochastic Model

Stock Markets, Growth, and Policy

Prospects for Sustained Improvement in U.S. External Balance: Structural Change versus Policy Change

International Financial Markets and the U.S. External Imbalance

Why Hasn't Trade Grown Faster Than Income? Inter-Industry Trade Over the Past Century

Contractionary Devaluation with Black Markets for Foreign Exchange

$\underline{1989}$

Exchange Rate Variability and the Level of International Trade

A Substitute for the Capital Stock Variable in Investment Functions

An Empirical Assessment of Non-Linearities In Models of Exchange Rate Determination

Equilibrium in a Production Economy with an Income Tax

Tariffs and the Macroeconomy: Evidence from the USA

European Integration, Exchange Rate Management, and Monetary Reform: A Review of the Major Issues

Savings Rates and Output Variability in Industrial Countries

\section{$\underline{\operatorname{AUTHOR}(\mathbf{s})}$}

Jaime Marquez

Neil R. Ericsson

Catherine L. Mann

Eric M. Leeper

Ross Levine

Catherine L. Mann

Deborah Lanker

Peter Hooper

Joseph E. Gagnon

Andrew K. Rose

Steven B. Kamin

Joseph E. Gagnon

Guy V.G. Stevens

Richard A. Meese Andrew K. Rose

Wilbur John Coleman II

Andrew K. Rose

Jonathan D. Ostry

Garry J. Schinasi

Garry J. Schinasi Joseph E. Gagnon

Please address requests for copies to International Finance Discussion Papers, Division of International Finance, Stop 24, Board of Governors of the Federal Reserve System, Washington, D.C. 20551. 
IFDP

NUMBER

362

361

360

359

358 Implications for Future U.S. Net

Investment Payments of Growing U.S

Net International Indebtedness

357

356 International Economic Policy: The Role

355 An Econometric Analysis of UK Money

354

353

352

351

350 of Exchange Rates Demand in Monetary Trends in the United States and the United Kingdom by Milton Friedman and Anna J. Schwartz

U.S. Policy on the Problems of International Debt

Encompassing and Rational Expectations: How Sequential Corroboration Can Imply Refutation

The United States as a Heavily Indebted Country

External Debt and Developing Country Growth

An Algorithm to Solve Dynamic Models

Implications of the U.S. Current Account Deficit

Financial Integration in the European Community

Exact and Approximate Multi-Period Mean-Square Forecast Errors for Dynamic Econometric Models

Macroeconomic Policies, Competitiveness, and U.S. External Adjustment

Exchange Rates and U.S. External Adjustment in the Short Run and the Long Run

\section{$\underline{\operatorname{AUTHOR}(s)}$}

Catherine L. Mann

Henry S. Terre11

Robert S. Dohner

Barbara R. Lowrey

Eric M. Leeper

Joseph E. Gagnon

Lois E. Stekler

William L. Helkie

Edwin M. Truman

Edwin M. Truman

David F. Hendry

Neil R. Ericsson

Neil R. Ericsson

David F. Hendry

David H. Howard

Steven B. Kamin

Robert B. Kahn

Ross Levine

Wilbur John Coleman II

David H. Howard

Sydney J . Key

Neil R. Ericsson

Jaime R. Marquez

Peter Hooper

Peter Hooper 